\title{
Child's Play: \\ Devising Intergenerational Collaborative Theatre With and For Young People in Aotearoa New Zealand
}

BY

Kerryn Lisa Palmer

A thesis submitted to the Victoria University of Wellington in fulfilment of the requirements for the degree of Doctor of Philosophy

Te Herenga Waka Victoria University of Wellington

2021 


\section{Abstract}

This thesis investigates intergenerational collaborative theatre with and for young people in Aotearoa/New Zealand. It researches current practices in theatre for, by, and with young people (henceforth referred to as TYA ${ }^{1}$ ), in New Zealand, and standards by which quality TYA can be recognised. Utilising an arts research methodology, this thesis identifies practical strategies for engaging a young audience and explores an intergenerational, collaborative devising theatre model for and with young people. It examines how theatre practitioners can work with young people to increase their sense of agency and empowerment in the work.

The purpose of this research is to contribute to an under-researched body of knowledge within New Zealand theatre, and enhance the current practice and status of TYA in Aotearoa and beyond. It critically analyses the way TYA is created, raising awareness of the body of work in Aotearoa/New Zealand, and contributes to academic and practitioner-based publications about TYA. This investigation aspires to create a pathway for directors and teachers, and to empower practitioners to create great TYA and view it as a valid and valuable career option, not just as a stepping stone to making adult theatre.

1 TYA (Theatre for, by, with Young Audiences) is the term is consistent with New Zealand's arts funding body -Creative New Zealand's- definitions. These and the acronym TYA are explained further on page 22. 


\section{Acknowledgments}

Like any good devising project this thesis has been filled with ups and downs. I have been incredibly fortunate to be surrounded by many wonderful people on what has been an epic voyage of research and learning and I have many people to thank: Nicola and Megan, my wonderful supervisors. I can't imagine having gone on this journey without you. You have supported, guided, cajoled and encouraged me over the past 4 1/2 years. As supervisors, colleagues and friends I have asked a lot of you and you have always been there. Thank you for teaching me the joys of academic writing, for picking me up when I felt discouraged and for always believing that I could do it.

A million thank yous to my amazing collaborators on the creative project: Samantha Tippet, Joel Rudolph, Peter Bolsover Rogers, Terri Cochrane, Cassidy Cruz, Daniel Gagau, Janaye Henry, Georgia May, Gemma Revell, Saffron Troughton, Corey Wills, Natalie Wilson, Georgia Ball, Dara Flaws, Yasmin Golding, Emma Maguire, Pelle Himmelmoe, Kevin Orlando, Alexander Robertson, Nicole Topp-Annan and Finnian Nacey. You were a dream to work with and have been incredibly generous in class and in the ways you have responded to my various emails over the past three years.

Thank you to our wonderful children and teachers at Te Aro and Tawa schools, for being such great collaborators.

Huge thanks to the PaperBoats team, in particular the amazing Dave Brown for his patience and wisdom; also, thanks to Stephen Blackburn and Brant Pope.

Thank you for the ongoing support, love and kindness shown by my colleagues in the Victoria University Theatre programme: David, James, Paul, Sam, James, Sarah, Sean, Lori, Cathy, Liz, Angelina, Adèl, Christina and David. Also, Koichi and Deborah for answering my endless questions, and to the Wellington Faculty of Graduate Research for the very helpful Doctoral Scholarship. 
To Anna Pastor-Bouwmeester, you were absolutely amazing to work with, generous, kind and tenacious, I miss you terribly.

To my proofreading and editing team: Andy, Mum, Rosey, Corey and Jean- you rock!! To my fabulous women doctor friends especially Sally and Hannah - thank you so much for sharing your knowledge and letting me pour through your theses, for reading my work and answering endless questions about writing. To all my other fabulous women friends - thank you for the coffee, wine, laughs and love and for putting up with and encouraging me.

Thank you to all the incredibly patient TYA practitioners who have been $\mathrm{SO}$ generous with their time and responded time and time again to my requests for information. Especially: Jenny, Tānemahuta, Tim, Briar, Marianne, Lynne, Ralph, Hannah, Mel, Peter, Sam.

Thank-you to my fabulous family; Dan, Nathan, Lynda, Rosey, Phil, John, Geoff, and all my gorgeous nieces and nephews in particular the small ones: Betsy, Teddy, Eli, Sam, Rosie, Sophia, Luca and Maddox who surround me with their gorgeousness.

To my own wonderful boys Isaac and Lochie - you inspire and teach me every day, I adore and love you so much and am very proud of you.

Mum and Dad- you are the greatest, you never flinched when I said I wanted a career in theatre and have always supported me in everything. Thank you for believing in me. Dad, I can't believe you aren't here to see me finish, I know how proud of me you both are and love you deeply. And finally, to my long-suffering, patient and generous husband Andy. Thank you for always being my rock, for picking me up, for knowing what I need, for loving me even when I am grumpy, you are awesome, I love you. 
This thesis is dedicated to my wonderful, generous, playful, outrageous and theatre-loving Dad; Colin Palmer. I love and miss you every day

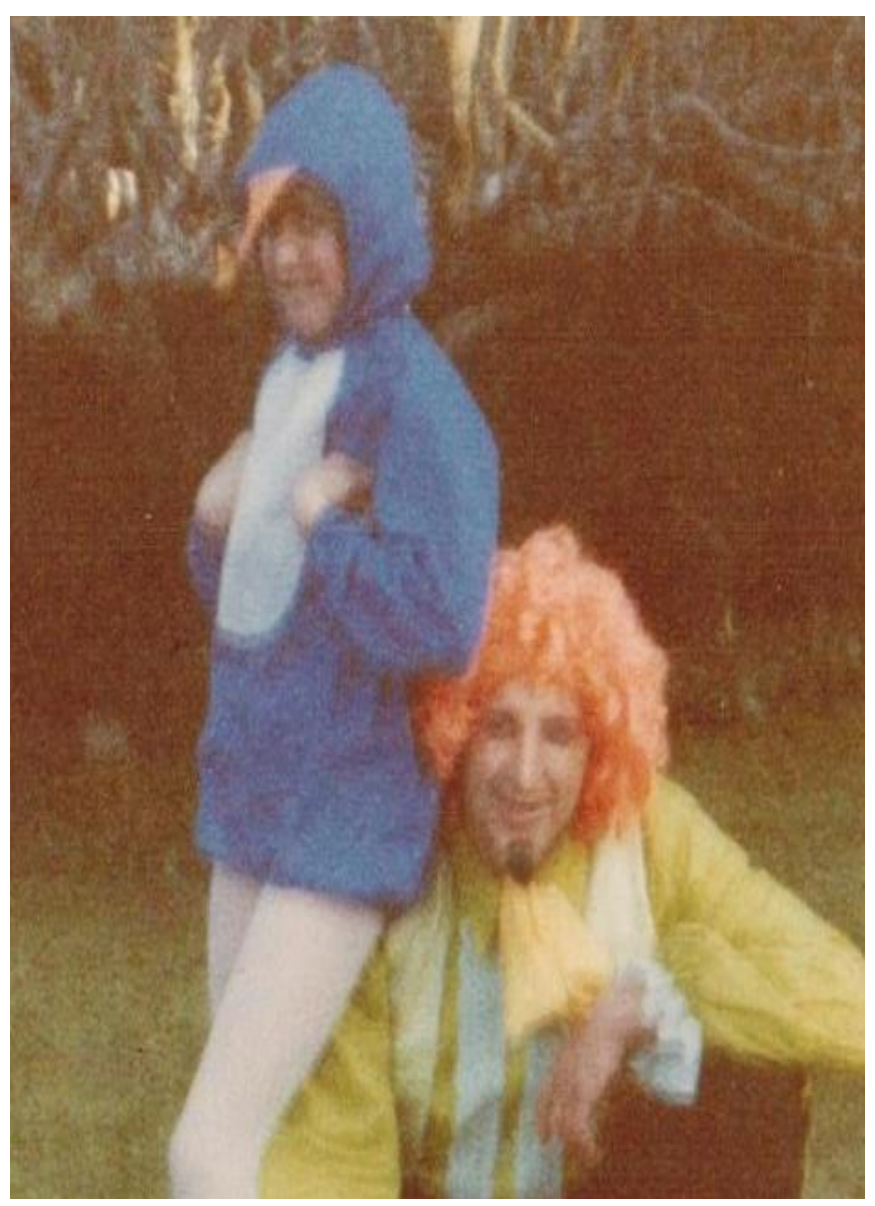




\section{Table of Contents}

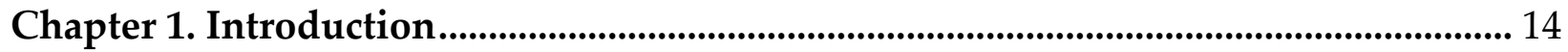

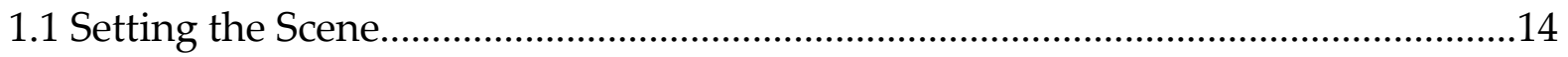

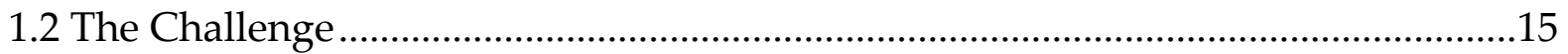

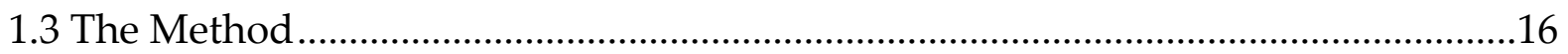

1.4 Outline of Thesis and Key Research Enquiries.......................................................19

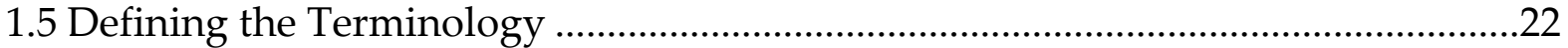

1.5.1 Theatre By, With or For, Young People ................................................23

Chapter 2. Defining the Whakapapa-Literature Review.......................................................31

The Broader Perspective: Key ideas, debates and challenges within the field of TYA...................32

2.1 Drama vs. Theatre ............................................................................................... 32

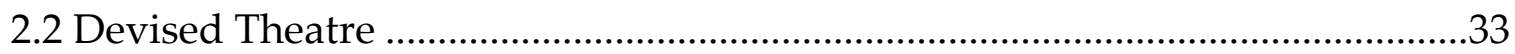

2.3 The Relevance and Benefit of Theatre By/With/For Young People....................37

2.4 Theatre By/With/For Young Audiences Within the Wider Field of Theatre....40

2.5 The Challenges of Making Theatre By/With/For Young People.........................47

2.5.1 The Conviction That All TYA Needs to Be Educative...........................48

2.5.2 Adults Assessing What is Best for Children ...........................................51

Theatre By/With/For Young People in Aotearoa /New Zealand................................................55

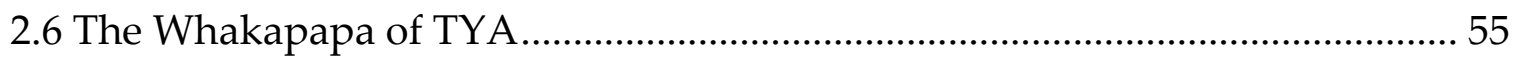

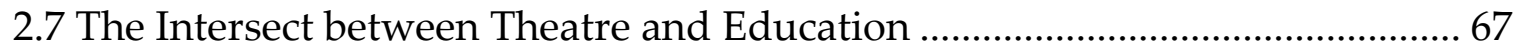

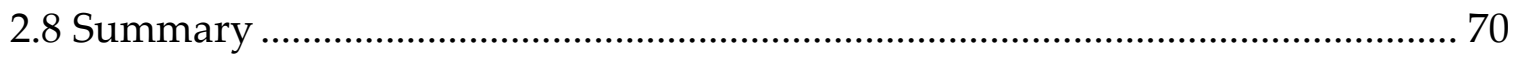

Chapter 3. Research Methods and Theoretical Frameworks...............................................72

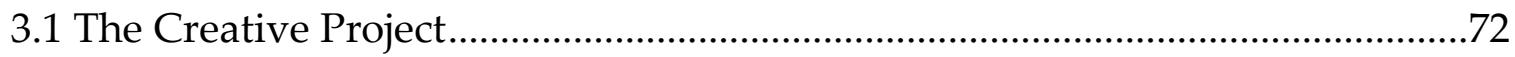

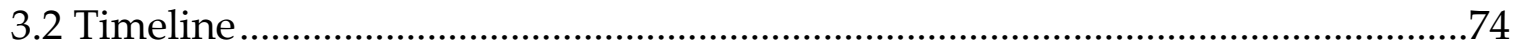

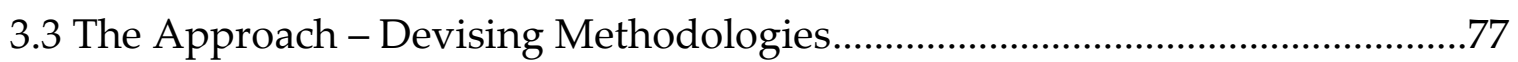

3.3.1 Jessica Swale's Five Stages of Devising …….................................. 78

3.3.2 The PaperBoats Seven Creative Principles.............................................79

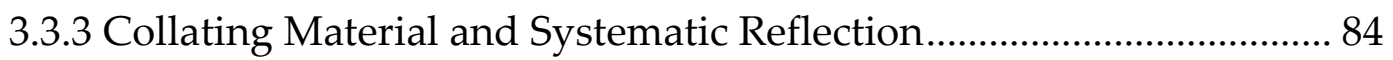

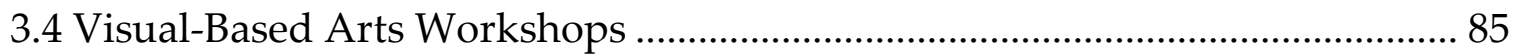

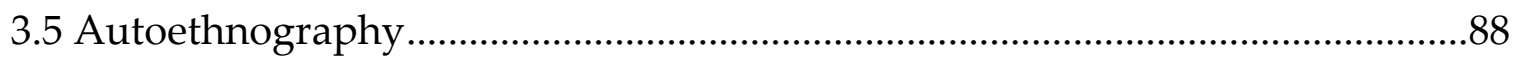

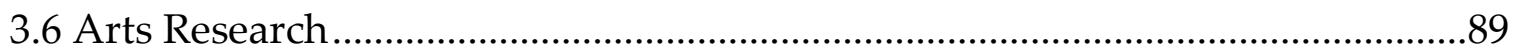

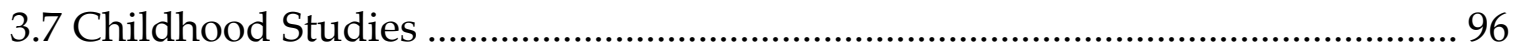

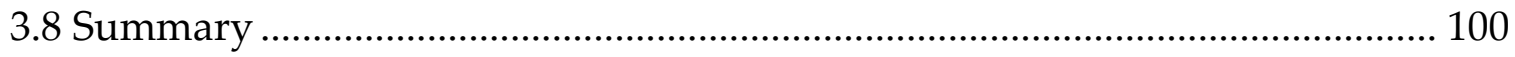

Chapter 4. Mapping the Field-Exploring the Form of Theatre By/With/For Young

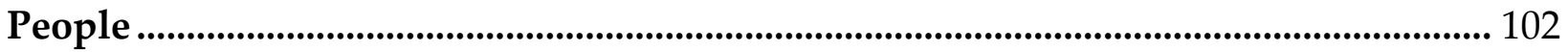


4.1 Defining Quality in Theatre By/With/For Young Audiences .......................... 104

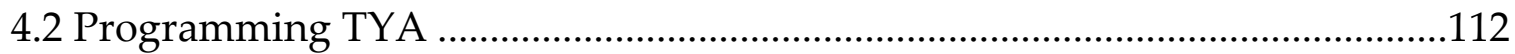

4.2.1 Fairy Tales and Pantomimes ...........................................................112

4.2.2 Adapting Children's Picture Books...................................................116

4.2.3 Challenging Subject Matter ...............................................................119

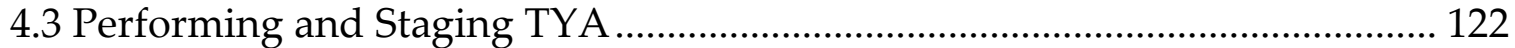

4.3.1 Audience Interaction/Participation in TYA ................................... 123

4.3.2 Children have 'Short Attention Spans' ........................................... 126

4.3.3 Adults Playing Children and Acting for a Young Audience ........ 128

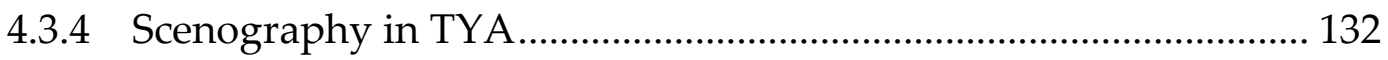

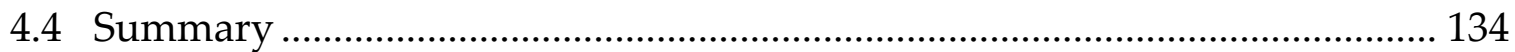

Chapter 5. Whakaari Mō Ngā Tamariki² An Analysis of TYA in Aotearoa/New

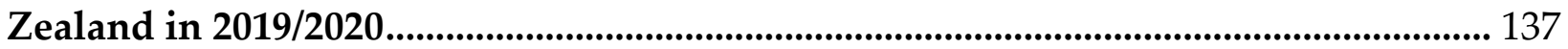

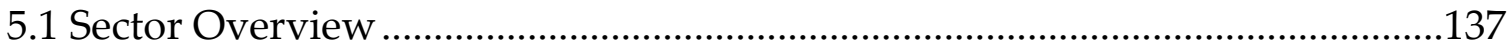

5.2 Funding TYA in Aotearoa/New Zealand .........................................................143

5.2.1 Tōtara, Kahikatea and Project Grant Funding ................................................145

5.2.2 Current Funding Streams for TYA …………....................................147

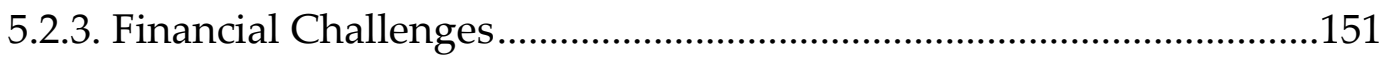

5.2.4 The Impact of Funding Restrictions ...................................................153

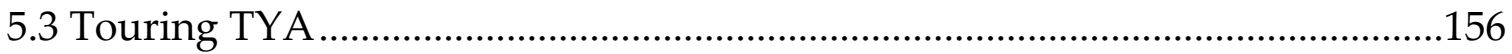

5.4 Value in The Theatre Community …………................................................158

5.5 Training TYA Actors ……………...................................................................... 159

5.6 Talking with The Audience/ The Audience Voice...............................................161

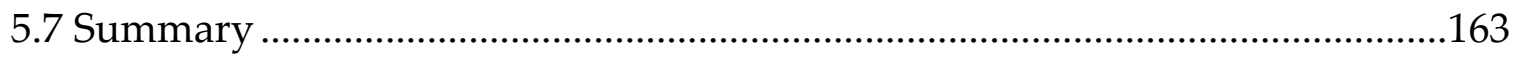

Chapter 6. He Whānau Kotahi ${ }^{3}$ - Directing the Youth Ensemble .....................................165

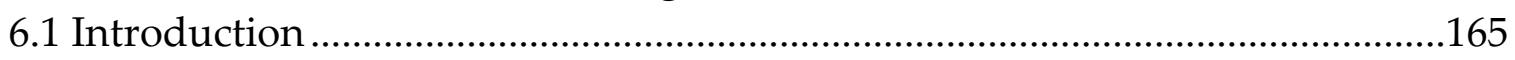

6.2 Preparation - Building The Ensemble ………....................................................169

6.2.1 A United Vision.........................................................................................

6.2.2 Looking to Childhood for Inspiration..................................................173

6.2.3 A Collective Contract- Check-Ins and Check-Out's ........................ 178

6.3 Generation and Exploration - Creating Material .............................................180

6.4 Encouraging Constructive Feedback ............................................................. 187

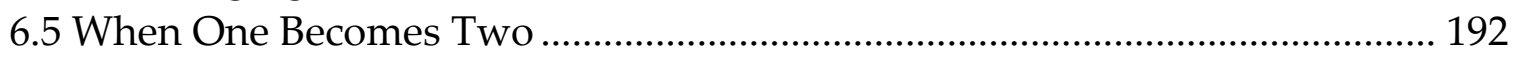

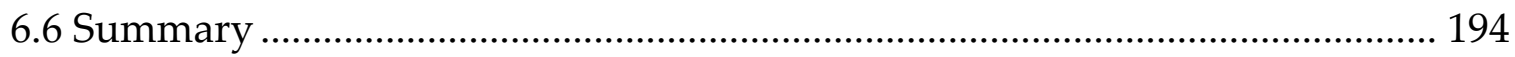

${ }^{2}$ (Theatre for Children)

3 (We are one family) 
Chapter 7. Working with Children for Inspiration and Agency ................................... 197

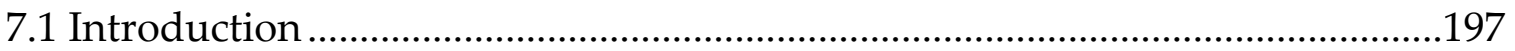

7.2 Intergenerational Play/Learning ...................................................................199

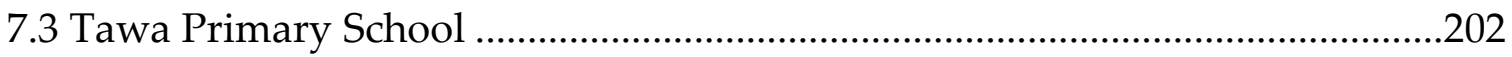

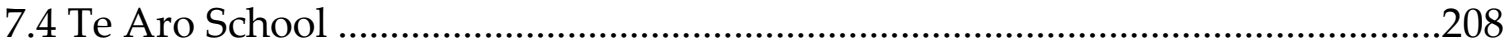

7.5 Trialling with an Audience .......................................................................... 216

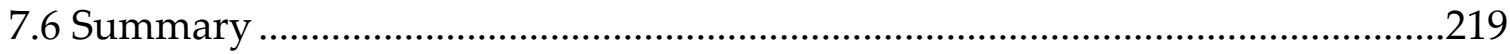

Chapter 8. Let Your Imagination Lead the Way-The Creation and Presentation of

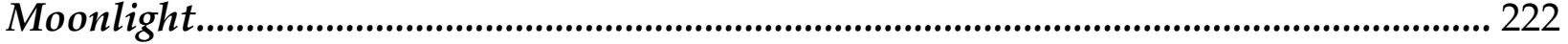

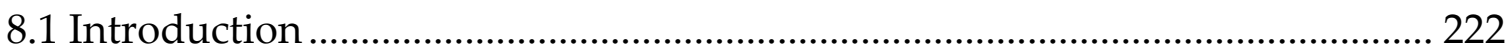

8.2 Character-Based Text Driven Narrative vs. Image -Based Narrative ........... 223

8.3 Paper Bag Productions ................................................................................. 227

8.4 Generating Scenes from Golden Moments …………...................................... 229

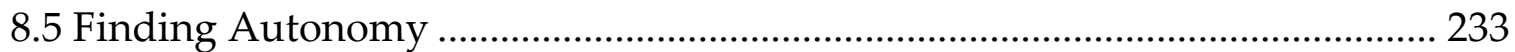

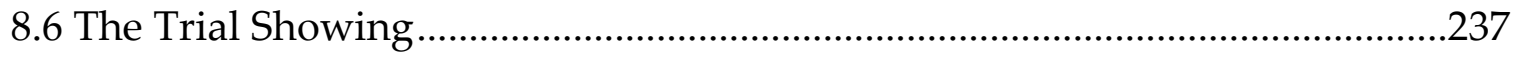

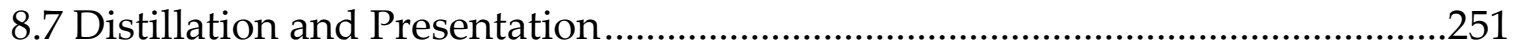

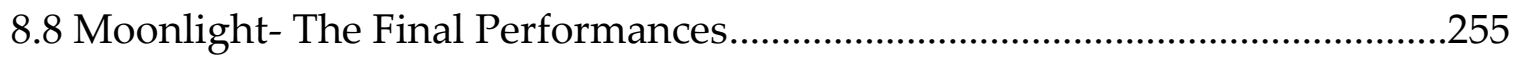

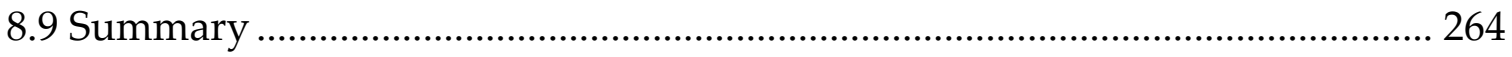

Chapter 9. Exploring the World of OWT-The Creation and Presentation of In The

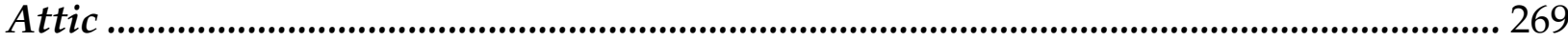

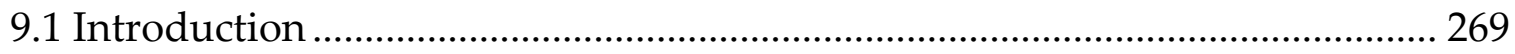

9.2 Youth, Young People and the Preadolescent Theatre Experience ....................270

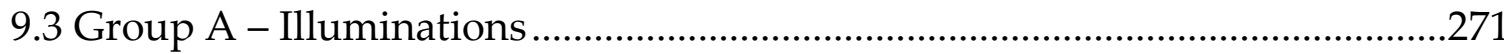

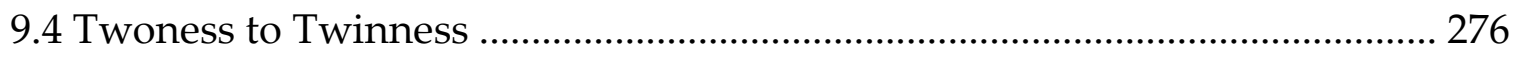

9.5 Creating the Narrative and the World of the Play ……....................................283

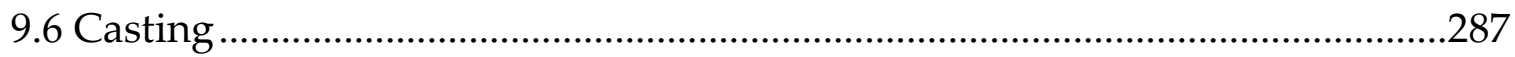

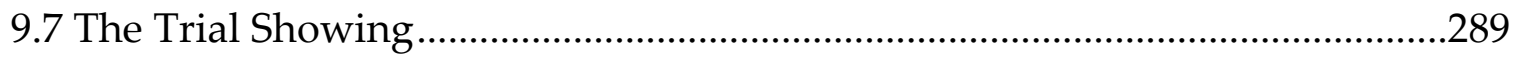

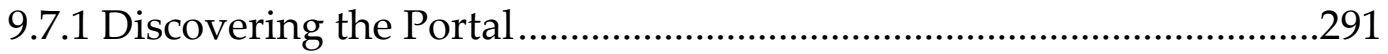

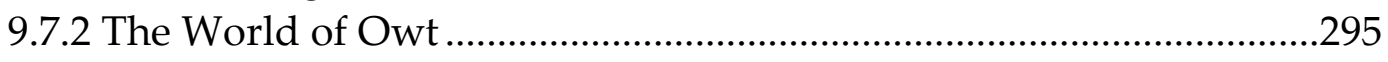

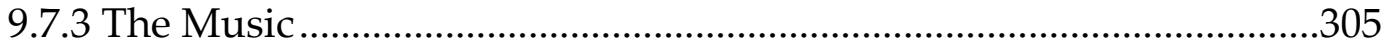

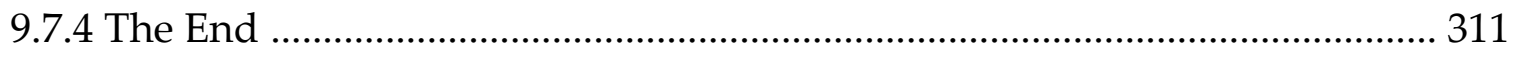

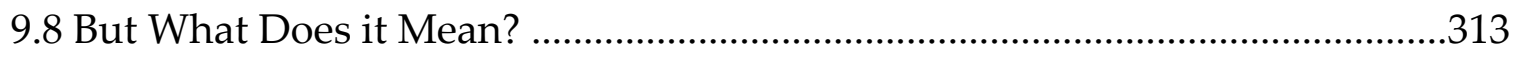

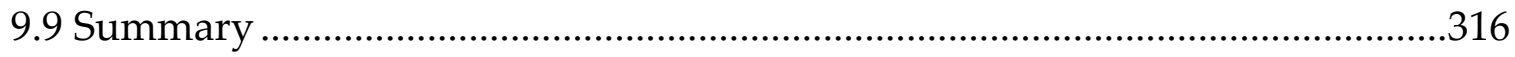

Chapter 10. Conclusion: Activating Change- Key Findings, Contributions to Knowledge and Recommendations............................................................................................ 320 
10.1 Key Findings .320

10.1.1 The current practices of practitioners involved in making theatre by/with/ for young people in Aotearoa/ New Zealand ....................................................... 320

10.1.2 An investigation of standards by which quality in theatre by/with/for young people can be recognised, communicated and encouraged.

10.1.3 Identifying practical strategies for engaging a young audience in the process of the making of TYA work.

10.1.4 Building a model for intergenerational collaborative devised theatre, that encourages agency and empowerment for all those involved in the making, presenting and viewing of the work 328

10.2 The Contribution to New Knowledge .337

10.3 Recommendations .339

10.4 Conclusion .342

Works Cited .344

Appendices

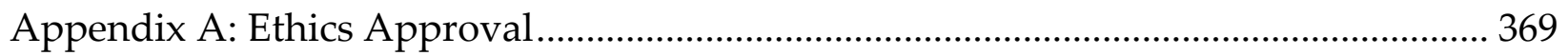

Appendix B: Survey Questions for Theatre Practitioners ................................................... 370

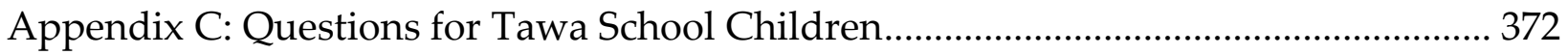

Appendix D: Drama Games used at Tawa and Te Aro Schools ....................................... 373

Appendix E: Child Observation..................................................................................... 375

Appendix F: Dave Brown's Critical Response Protocol................................................... 376

Appendix G: Links to and USB Recordings of Moonlight and In The Attic................... 378 


\section{List of Figures}

Figure 1: In the Attic. (Photo by Maddy Warren) 22

Figure 2: Ivy Saviour Of The Dinosaur. Theatre for Young Audiences. Capital E

National Theatre for Children. (Photo by Stephen A 'Court). 26

Figure 3: Closure- Ensemble Impact. Theatre for Young Audiences. (Photo by Kim

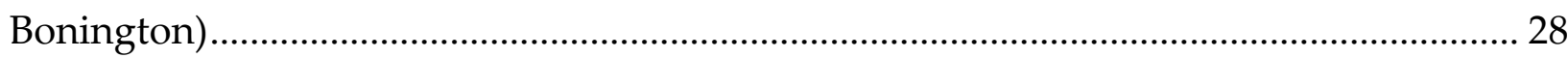

Figure 4: Map of the spread of ASSITEJ national centres. (ASSITEJ)... 43

Figure 5: Around the World and Buck Again. Capital E National Theatre for Children.

(Photo by Stephen A'Court).... 49

Figure 6: Poster for Capital E National Theatre for Children Production: Ivy, Saviour of The Dinosaur. (With Permission) 54

Figure 7: J C Williamson Ltd present Frank Neil's stupendous Drury Lane fairy pantomime "Cinderella". Theatre Royal Christchurch, com. Friday night, July 28th. Wright \& Jaques Ltd., Printers, Auckland [Front and back covers. 1933]. Cabot, Charles Henry, 1890-1978: [Collection of ephemera, posters and programmes. 1900-1976]. Ref: Eph-B-CABOT-Pantomime-1933-01-covers. (Permission from: The Alexander Turnbull Library, Wellington, New Zealand. /records/23191137)... 59

Figure 8: Shalakazap: Calico Young People's Theatre (author on left). (Photo by Bernard Carpinter) 63

Figure 9: Songs of The Sea. Capital E National Theatre for Children. (Photo by Stephen A'Court)

Figure 10: Timeline of The THEA 311 Project $74-77$

Figure 11: THEA 311 students experiment with receipt paper. 81

Figure 12: Quality Principles Table. (Sharp and Lee 4)... 108-109

Figure 13: Children responding to The Eel and Sina. By Jono Soo-Choon, directed by Gaby Solmona. Mythmakers Theatre Company, 20 March 2019, Te Papa Marae, Wellington. 112

Figure 14: Tim Bray Theatre Company: The Lighthouse Keeper's Lunch. (Photo by David Rowland/One-Photo by.com). 
Figure. 15: The Kuri in Kiwi Moon. By Rachel Callinan, directed by Kerryn Palmer. Capital E National Theatre for Children. March 2015, The Hannah Playhouse, Wellington. (Photo by Stephen A'Court)

Figure 16: Songs of the Sea. By Peter Wilson, directed by Kerryn Palmer. Capital E National Theatre for Children. March 2011.The Hannah Playhouse, Wellington. (Photo by Stephen A'Court)

Figure 17: Shalakazap. Written and Directed by Jenny Wake. Calico Young People's Theatre. 1992-1993. (Photo by Bernard Carpinter). 136

Figure 18: Table of TYA Companies Surveyed 2019 $138-140$

Figure 19: The Whole Hearted. Written by Massive Theatre Company. Directed by Sam Scott. (Photo by Andi Crown) 142

Figure 20: Table of Tim Bray Theatre company's funding 2016-2019. $145-146$

Figure 21: The Road That Wasn't There. By Ralph McCubbin-Howell. Directed by Hannah Smith. (Ongoing touring production). Trick of the Light Theatre Company.

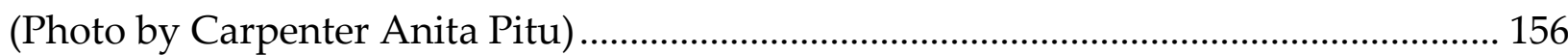

Figure 22: Duffy and the Book Bus Adventure. Duffy Theatre. (2011)............................ 159

Figure 23: MIXiT- A creative project for young people from refugee backgrounds mixing it up with migrants and locals. (Photo by Wendy Preston) .................................. 163

Figure 24: The Class of THEA 311(Photographer unknown)........................................... 167

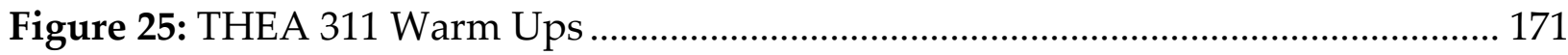

Figure 26: Playing and exploring in a childlike way ........................................................ 175

Figure 27: Photos of a selection of THEA 311 Students aged five years old .................... 177

Figure 28: The Generate- Revise model......................................................................... 181

Figure 29: Screenshot: Dara, Saffron, Georgia M. and Georgia B. 'magically' manipulate

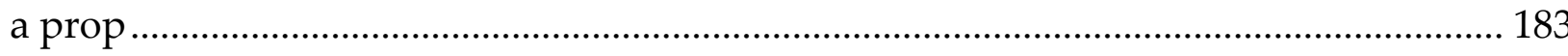

Figure 30: The Binders manipulate objects towards the cauldron. ……......................... 184

Figure 31: The object is carried 'magically' by another actor ............................................ 184

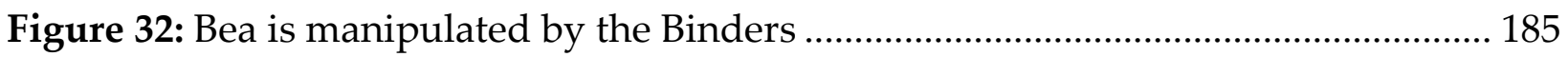

Figure 33: The Tea Witches attempt to manipulate their Tea .......................................... 186

Figure 34: Responses to the question of what engaged us as an audience?.................... 189

Figure 35: The wonderful class of THEA 311 ........................................................... 196

Figure 36: Intergenerational Play. The Students and The Children play "Grandma's

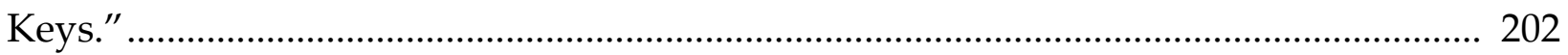

Figure 37: Tawa School students play Bus Stop.............................................................. 204 
Figure 38: The students working with the Children 205

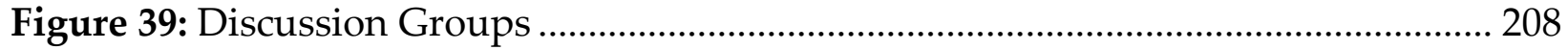

Figure 40: James reads to Kevin............................................................................... 210

Figure 41: Grandma's Keys with Ruma Ti ................................................................... 211

Figure 42: The students playing Grandma's Keys ............................................................. 211

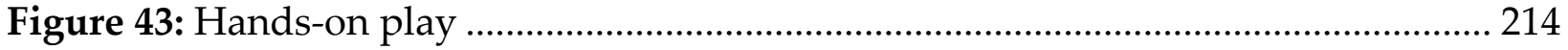

Figure 44: Janaye and Nat listen and share ideas .............................................................. 221

Figure 45: Dara in Moonlight. (Photo by Maddy Warren) ................................................. 222

Figure 46: @ 2008 Blackbird Design Pty Limited (Reproduced by permission of Walker

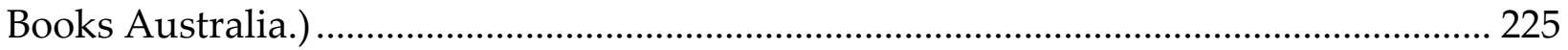

Figure 47: The students in the final tableaux from 'How to Heal a Broken Wing' ........ 226

Figure 48: Screenshot. Exploring the provocation-poem, 'The Road Not Taken' .......... 230

Figure 49: The final Two-headed-Signpost scene. (Photo by Maddy Warren)................ 231

Figure 50: The final Tea Witches scene. (Photo Maddy Warren) ..................................... 231

Figure 51: Luna and The Nightlight. (Photo Maddy Warren) ........................................... 239

Figure 52: Ruma Ti Drawing. (Ti).............................................................................. 243

Figure 53: Drawing the play. (Photo Georgia Ball) ........................................................ 244

Figure 54: Drawing the ending. (Photo Georgia Ball) ...................................................... 246

Figure 55: River's Drawing of the ending, the snake, Mr. Watt and The Target. (Photo

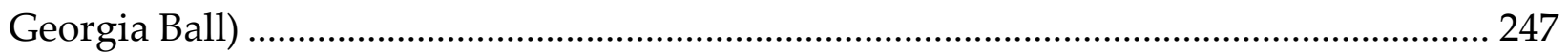

Figure 56: Te Aro Child's drawing of the umbrella scene. (Ti)........................................ 248

Figure 57: A Te Aro Child's drawing of the signpost scene. (Ti) ...................................... 248

Figure 58: The Signposts. (Photo by Maddy Warren) ........................................................ 249

Figure 59: Screenshot. The children acting out The Signpost scene with Pelle .............. 250

Figure 60: Te Aro Child's Initial response to play. (Ti) .................................................... 252

Figure 61: The non-verbal beginning to the play. (Photo by Maddy Warren) ................ 257

Figure 62: Musical Score of The Nightlight Song, by Joel Rudolph. (Rudolph)............. 258

Figure 63: The Tea Witch 'moves' the tea caddy. (Photo Maddy Warren) ...................... 261

Figure 64: Luna shelters under her umbrella .................................................................. 262

Figure 65: Luna and Mr. Watt Fight for the Moonlight. (Photo Maddy Warren).......... 263

Figure 66: The Moonlight Falls. (Photo Maddy Warren) ................................................... 264

Figure 67: Poster for Moonlight, THEA 311 Production. (Design, Alex Robertson)................ 267

Figure 68: In the Attic. (Photo by Maddy Warren) ............................................................. 269 
Figure 69: Illuminations Content Brainstorm Thea 311.31 Group A's Initial Concept

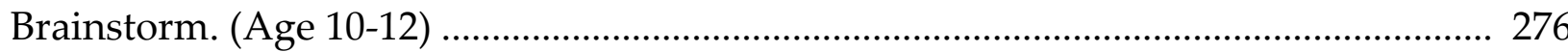

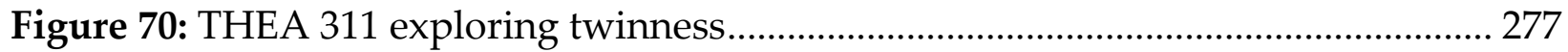

Figure 71: Corey and Peter's initial twin characters ......................................................... 278

Figure 72: Corey and Peter as Sam and Alex- In the Attic. (Photo Maddy Warren) .... 279

Figure 73: Screenshot. Exploring the Attic. (Video by Dan Fraser)................................... 284

Figure 74: Early provocation work-The Hands-Eyes and Foot Creatures ........................ 286

Figure 75: The World of Owt. (Photo Maddy Warren) ........................................................ 286

Figure 76: Screenshot of Feedback session with the trial audience. (Video by Anna

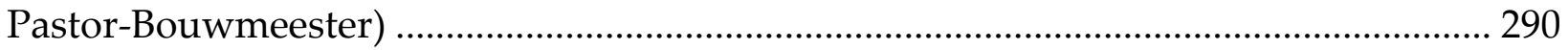

Figure 77: Screenshot of physicalising each scene and facilitating feedback with Room Four. (Video by Anna Pastor-Bouwmeester). 291

Figure 78: Alex, Sam and Bea find the portal- Trial Showing. (Video by Anna PastorBouwmeester). 293

Figure 79: Alex, Sam and Bea find the portal- Final Performance. (Photo Maddy

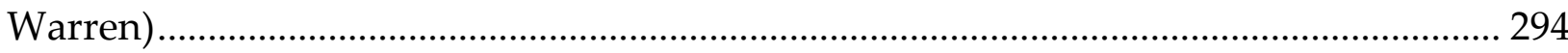

Figure 80: Screenshot. Yek Flirts with Alex. (Video by Dan Fraser) ................................ 297

Figure 81: The Police People. (Photo Maddy Warren) ......................................................... 298

Figure 82: The Binders. (Photo Maddy Warren) .................................................................. 299

Figure 83: The Guides. (Photo Maddy Warren)................................................................. 300

Figure 84: Janaye and Daz. (Photo Maddy Warren).......................................................... 304

Figure 85: The Light Creatures. (Photo Maddy Warren) ................................................... 307

Figure 86: Poster for In The Attic THEA 311 Production. (Design: Alex Robertson) .............. 319

Figure 87: Posters for Moonlight and In The Attic, THEA 311 Production. (Design: Alex

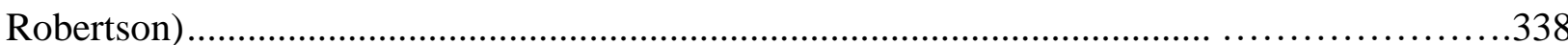

NB: Permissions have been received for all photos and images, unless specified. If a photographer is not credited, then it is by the author. 
Children need to go to the theatre as much as they need to run about in the fresh air. They need to hear real music played by real musicians on real instruments as much as they need food and drink. They need to read and listen to proper stories as much as they need to be loved and cared for.

The difficulty with persuading grown-up people about this is that if you deprive children of shelter and kindness and food and drink and exercise, they die visibly; whereas if you deprive them of art and music and story and theatre, they perish on the inside, and it doesn't show. (Philip Pullman) 


\section{Chapter 1. Introduction}

\subsection{Setting the Scene}

I grew up in the country. We lived on a lifestyle block just out of Featherston, New Zealand, one of the windiest places on earth. One day a touring theatre group visited my tiny country school. I remember black tights, the actors pulsating energy into our dusty hall, and my strong response: a desire to do what they were doing. I wanted to do that; I want to be those people. My parents enrolled me in speech and drama classes. I loved the feel of words rolling off my tongue, the magic of the images, the worlds created and the echo of my voice as I practised reciting poetry loudly in the back paddock. Seeing and doing theatre made me want to be a better person. I couldn't express it as a child, but it simultaneously made me want to cry and explode with happiness. It made me want to tell stories and fill the world with something bigger than myself.

Fast forward several years and directly after graduating from University and Teacher's College I was hired to act in a touring show with the renowned New Zealand Theatre for Young Audiences (TYA) company, Calico Young People's Theatre. This experience shaped my career as a theatre practitioner and I spent the following ten years working as an actor, director, performing arts teacher and travelling (on my $\mathrm{OE}^{4}$ ). In 2004 I completed a Masters of Theatre Arts (in directing) and since then have worked as a professional theatre director, teacher and lecturer in theatre studies. Because of the underfunding of the theatre industry in New Zealand, it is very challenging to have a

${ }^{4} \mathrm{OE} /$ Overseas Experience refers to working travel holidays, often a rite-of-passage for young New Zealanders. 
sustainable career solely as a theatre director. Furthermore, theatre directors rarely specialise in just one field. My directing work has been a combination of new works by New Zealand playwrights, original devised site-specific/generic ${ }^{5}$ historical works, applied theatre ${ }^{6}$ with community groups and devised and scripted theatre for young audiences. In 2004 I also became a mother and the raising of my two children has had an impact on both the type of projects I choose and my style of directing. I don't consider myself a specialist in TYA, because I continue to direct a variety of forms of theatre, however, I have directed over twenty TYA productions - professionally and in educational institutes. TYA is a field that I love and fiercely advocate for, and I firmly agree with theatre reviewer Jo Hodgson's belief that because:

[a]rts education is being severely diluted in favour of pushing the core subjects and children are being lured to the screen more and more, we need to take them to the theatre. We need opportunities for children to engage in stories and imagination, to not just be a passive observer, but to be moved, to relate, to empathise and to experience the beauty of being taken on a journey through the ultimate pop-up book which is live theatre. (Hodgson 2017)

My combined love of teaching, theatre and being a mother has instilled in me a passionate belief that children do need theatre "as much as they need to run about in the fresh air" (Pullman), to ensure a healthy mind and spirit.

\subsection{The Challenge}

Several years into my directing career I found myself consistently trying to validate my work as a TYA practitioner and feeling frustrated by the lack of value, funding and

\footnotetext{
${ }^{5}$ Site specific- performance specifically generated from/for one selected site; Site generic- performance generated for a series of like sites (Wilkie 150).

${ }^{6}$ Forms of dramatic activity that exist outside mainstream theatre institutions and which are intended to benefit individuals, communities and societies (Nicholson 2).
} 
respect within the field. This research began with a desire to examine and identify if TYA was as undervalued and underfunded in New Zealand as I suspected, and attempts to bring understanding and value to the discipline. I began by examining the historical conditions and field of TYA in New Zealand. Although there was evidence of the history of theatre being recorded, there appeared to be little TYA documented, recognised or analysed. I also began to investigate how New Zealand stood in contrast to other global practices. The recognition of the scarcity of research led to an examination of how TYA is created, performed and received in New Zealand. In particular, I was curious how the audience demographic was considered and how TYA practitioners agreed on the content and form of their work. Were children being consulted about what they wanted to see and experience at the theatre? Was thought being given to how children and young people received the work? It was these questions that led to the intergenerational collaborative devising project that forms the basis of this thesis. The research began from a place of frustration but evolved into a genuine enquiry into how the value, perception and quality of TYA in New Zealand could be strengthened.

\subsection{The Method}

When considering the most effective way to approach this research, a colleague suggested that other people might be interested in the methods I use to run a rehearsal room and to create devised theatre. As a result, my journey from practitioner to practitioner-researcher began.

During my director training I often witnessed what I describe as a 'dictatorialstyle' of directing. This refers to a largely non-collaborative style of directing where directors lead from the top down. Within this process there is little room for 
collaborative discussion, the director has a clear vision, and it is the creatives' job to realise this vision. I had also worked with directors such as Jenny Wake, Kathy McRae, and Cathy Downes, who employed a more collaborative style of directing where creatives were encouraged to work collectively to develop and present a shared vision. Through witnessing and observing a wide range of directing styles I began to develop my own personal directing philosophy: that it is a director's job to facilitate, guide and create conditions where creative work can evolve in a safe and supported way. It is worth noting that the directing styles that I was most drawn to were those of female directors. The differences between a male-led and female-led rehearsal room and feminist theatre practices are discussed in detail in Hannah Banks' 2019 thesis: A Stage of Our Own: Women Devising Theatre in Aotearoa New Zealand (VUW). Of particular relevance to my own thesis is her research into the symbiosis between women and devised theatre (Banks 51-52). She cites Alison Oddey's description that the 'natural relationship between women and devised theatre in the 1970s, arose out of an environment ... which encouraged women to find voice together through the collective, democratic process of devising' (Oddey “Devising (Women's) Theatre 119). In her seminal book Devising Theatre (1994) Oddey writes that the idea of a collective working model "grew out of a socio-political climate that emphasised democracy, so that many groups were interested in breaking down the patriarchal and hierarchical divisions of a traditional theatre company" (8). This democratic collective process was one that appealed to me in particular because of the way that as a director I preferred to lead, not from a place of knowing, but a place of collective discovery.

When I was endeavouring to articulate my style of directing, a colleague described it as a 'maternal-style of leadership'. This term suggests a female-led style of leadership that also employs maternal qualities such as patience, empathy, 
supportiveness, and guidance. The key values that I aim to use in a rehearsal room are: empathy, compassion, encouragement, and a structured yet open creative environment. I employ this style of directing because experiencing the 'dictatorialstyle' early in my career led me to feel disempowered and disenfranchised in the creative process. A compassionate, empathetic style of leadership also aligns with my own personal values.

Thus, my style of leadership could be described as a female-led maternal approach to leadership that relies on the following:

-Treating all ensemble members with compassion and kindness.

-Creating an ensemble that is modelled on 'family' dynamics - a warm and caring environment where we share food, spend time together in and out of the rehearsal room, and collaborate equally with united values and goals.

-A focus on thoughtful and pragmatic modes of giving and receiving feedback, and conflict resolution.

-Allowing the ensemble to build trust in me as a leader, a mediator, and for pastoral care and problem solving.

However, this approach also means that I generate specific challenges for myself and for the ensemble, including an avoidance of conflict, a need to be 'liked', oversensitivity, high (often unreasonable) expectations of myself and the ensemble, and a heavy reliance by the ensemble on me for creative input, emotional labour and pastoral care.

In my 25 years as a director, rarely have I had the time to explore and analyse my directing practice. Because of the often-overwhelming workload and under- 
resourcing of theatre in New Zealand, there is limited time to evaluate a process before the next job begins. Therefore, each new rehearsal period becomes another experiment in practice. The purpose of moving from practitioner to practitioner-researcher has been to commit to an arts research method, and through this practice to investigate, record and analyse my processes as a devising-director, to better answer my research enquiries, and to enhance my own work and that of my peers.

\subsection{Outline of Thesis and Key Research Enquiries}

The author of this thesis recognises Te Tiriti o Waitangi/The Treaty of Waitangi as New Zealand's founding document and acknowledges the differences in translation between the Māori and English interpretations. I apply the principles of Te Tiriti o Waitangi/The Treaty of Waitangi to acknowledge Māori as the Tangata Whenua ${ }^{7}$ and indigenous people of Aotearoa/New Zealand, and to embrace my own values of inclusivity of all cultures, religions, genders, sexual orientation and ages of people. The Māori content from Te Ao Māori ${ }^{8}$ in this thesis has been integrated with consultation from Māori practitioners and academics.

This thesis is a practice-led doctoral study examining approaches to devising theatre with and for young people in Aotearoa/New Zealand. Through an arts research theoretical framework and utilising a methodology of devising practices, I facilitate the creation of two original plays for children of different ages: Moonlight and In The Attic. Subsequently, I analyse best practice in the making of the work and develop a model of devising intergenerational and collaborative theatre for and with young people, in Aotearoa/New Zealand. To effectively develop the discourse, the thesis is divided into two phases, consisting of a creative component and an analytical exegesis. In chapters

7 Te Reo Māori for 'People of the land'.

${ }^{8}$ The Māori World View 
two, four and five the exegesis presents a review of national and international literature on TYA, an examination of what constitutes quality TYA, and a critical analysis on the reception, status, historical/cultural context of TYA in Aotearoa/New Zealand. Chapter three introduces the research methods and theoretical framework of the research. Chapters six to nine analyse practical methods of creating theatre with and for young people, including a detailed analysis of the making of the creative component: Moonlight and In The Attic. A USB Recording of Moonlight and In The Attic accompanies the exegesis. Material for this analysis was gathered through group discussions and visual arts-based interactions with two classes of children at Tawa and Te Aro Schools, as well as an examination of practice with the collaborators of both works. In investigating the making of these works in a New Zealand context, I examine the quality, artistic integrity and aesthetics of the work. I study how specifying the ages of the children in the audience can assist in making work that targets the demographic more directly, and how collaboration with children in the making of TYA work can lead to more child-centred productions and methods of instilling agency in a youth ensemble.

This research project was also part of the international PaperBoats Project. In 2016 Australian TYA director Dave Brown developed the project in an attempt to pool and share resources and creative ideas in the often-under-resourced field of TYA. He established it as "an international partnership platform for performance-makers, pioneering new ways of connecting and creating" (Brown "Principles"). The unique project began as a four-way co-creation partnership with four international communities. THEA $311^{9}$ made up the New Zealand component, with groups simultaneously working in the U.S. (Austin, Texas), Australia (Adelaide), and

9 The 300 level Victoria University course that made up the creative component of this thesis, and is outlined in Chapter Three. 
Singapore. The aim was to use a framework of seven creative principles, accumulate and share ideas and content across the four communities, and develop several works of theatre for early-childhood audiences. The seven creative principles will be outlined in Chapter Three of this thesis. Brown states: "What explosion of possibility happens when performance-makers connect with one another across nations, cultures and communities, in a whole range of ways around performance-making for early childhood audiences?" (Brown, Personal Interview)

The purpose of my research is to contribute to an under-researched body of knowledge within New Zealand theatre and enhance the current practice and status of TYA in Aotearoa and beyond. The processes explored here may enable theatre practitioners to make professional, quality theatre that is genuinely accessible for children; work that goes beyond simple entertainment, by putting the child at the centre, giving them greater ownership and a greater connection with the work. My research also aims to recognise and assert TYA as its own genre within the New Zealand theatre industry, increase its value and perception, and investigate best practices in the making of this work.

The primary research enquiries:

1. To investigate current practices of practitioners involved in making theatre by/with/ for young people in Aotearoa/ New Zealand.

2. To investigate and articulate standards by which quality in theatre by/with/for young people can be recognised, communicated and encouraged.

3.To identify practical strategies for engaging a young audience in the process of making TYA work. 
4.To build a model for intergenerational collaborative devised theatre, that encourages agency and empowerment for all those involved in the making, presenting and viewing of the work.

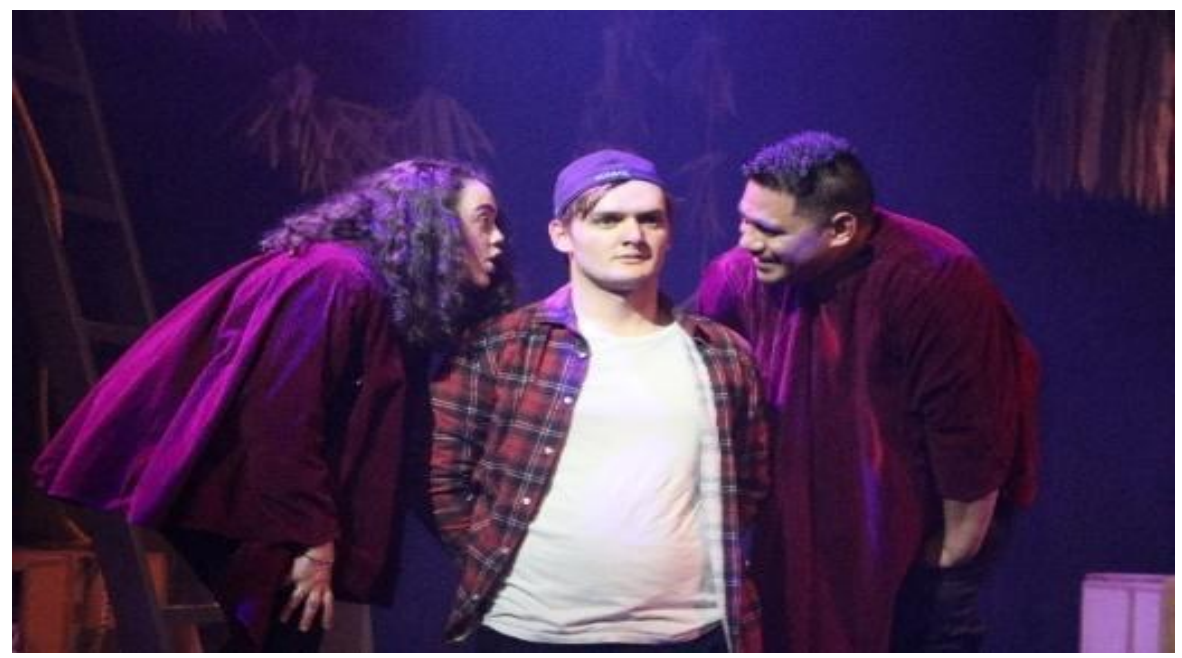

Figure 1: In the Attic.

\subsection{Defining the Terminology.}

The project that this thesis discusses can be described as intergenerational collaborative devised theatre with and for young people. However, according to the Creative New Zealand (CNZ) definitions explained on pages 23-24, it can also be described as theatre with young people (the students and the children), and, because it was created with professionals at the helm, as theatre for young audiences. There are a variety of terms that can be used to describe theatre that involves children, and these terms are debatable, differ internationally, and are constantly evolving.

Children's Theatre is an umbrella term used to cover a range of activities that bring together children and theatre-making in some way.

CNZ defines theatre as including: 
both classical and contemporary theatre and all genres such as comedy, drama, physical theatre, devised theatre, street theatre, musical theatre, circus, puppetry, mask and theatre for children.

It includes customary and contemporary practices of all the peoples of Aotearoa/New Zealand, including Māori and Pasifika peoples and the diverse cultures of people living in Aotearoa/New Zealand today. (Theatre Funding Guidelines)

ASSITEJ International ${ }^{10}$ defines 'theatre' in this context, "to mean the performing arts for young audiences encompassing dance, puppetry and visual mediums, live art as well as text-based theatre" (ASSITEJ).

The formation of ASSITEJ international in 1965 saw a redefining of the Children's Theatre field and the acronym TYA was coined to describe professional theatre for young people by adults.

More specific terms can be used to identify who is making the theatrical event, how, and in what context. The five most consistently used terms in academic literature for theatre involving children are: Youth Theatre; Theatre by Children/Young Audiences/Young People; Theatre with Children/Young Audiences/Young People; Theatre for children/ Young Audiences/Young People and Theatre in Education (TIE); (Creative New Zealand, Davis and Behm, Bennett).

\subsubsection{Theatre By, With or For, Young People.}


New Zealand's main professional funding body Creative New Zealand (CNZ) differentiates between arts activities by, with, or for young people. The definitions provided for these different activities are:

Arts activities by young people:

This means arts activities that are driven, owned, created, programmed, presented or delivered by young people. It may involve the young people being mentoring or taught by experienced artists. If there is a presentation outcome, it is likely to be specifically aimed at young audiences, their whānau ${ }^{11}$ and communities.

Arts activities with young people:

This means activities where young people are actively involved or learn from the work of more experienced artists or organisations. It is about offering young people access to different artforms and arts organisations.

Arts activities for young people:

This means activities by professional artists where the audience for the work is young people, their whānau and communities. (Young New Zealanders I Funding Guidelines)

The definition of each category in a theatre-specific context can be understood as follows:

Theatre by young people is theatre made by young people, yet often led by an adult. The young people create their own work or perform a pre-existing script. If a

${ }^{11}$ Family 
play is presented then it is likely to be aimed at young audiences, and their whānau and communities. Youth Theatre is a term also often used to describe theatre by young people; although the term youth specifically refers to a participant age range between 18-2512 ("Glossary"), not all companies that identify as youth focussed, work specifically in this age range. New Zealand examples of theatre by young people include: Long Cloud Youth Theatre, Wellington Young Actors Company, Northland Youth Theatre and Hawkes Bay Youth Theatre.

Theatre with young people is theatre that has adults and young people involved in it, projects that are led by an adult theatre practitioner working collaboratively alongside young people. New Zealand examples include: The Court Theatre's after school programmes, Auckland Theatre Company's Summer School and Here and Now festival.

Theatre for young people is theatre made by professional artists for young people, and their whānau and communities. New Zealand examples include Trick of the Light and Capital E National Theatre for Children. This is the predominant field that I have worked in professionally, in particular with my work for Capital E.

${ }^{12} \mathrm{CNZ}$ describes Young people as "those aged up to 18 years and Youth as those aged between 18 and 25. ("Glossary") 


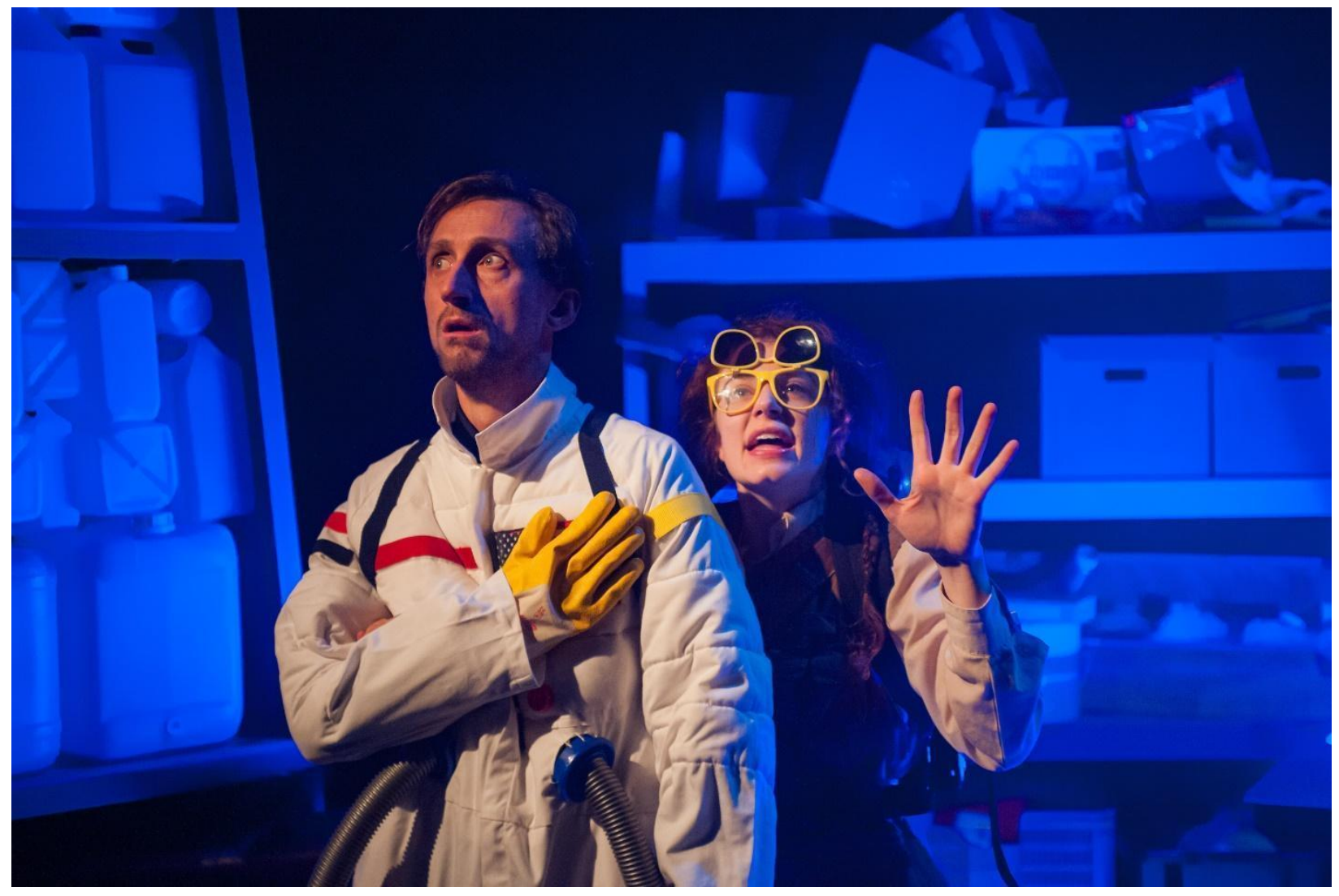

Figure 2: Ivy Saviour Of The Dinosaur. Capital E National Theatre for Children.

Theatre in Education (TIE). TIE is defined by Davis and Behm as: "a complex program involving some formal performance by professional actor-teachers, some classroom creative drama work, and an opportunity for all the participants to interact with the professional performers in role" (261). Landy and Montgomery maintain that "in TIE the emphasis is on education as much as, or in some cases, more than entertainment" (100). In New Zealand, TIE would typically involve professional actors touring schools with educational or applied theatre. Often accompanied by workshops from the visiting actors and an educational resource. However, TIE is now regarded as a somewhat outdated term and is now often referred to as Applied Theatre (Jackson and Vine 1-2). 
Even though the acronym TYA is predominantly used to describe professional theatre made by adults for children and youth, it can be used to describe a wide range of work involving theatre and young people, thus TYA is the term that I will adopt to describe theatre by/with /for young people throughout this thesis.

There are challenges around the defining of theatre by/with/for young people, as well as a lack of clarity around what the benefits of denoting these specific definitions are. In its 2017 review of TYA, CNZ analysed the best practice internationally and adopted the terms by/with/for young people within their basic policy for supporting arts, stating: "Research on international policies for support of activities of young people in the arts, shows that in order to identify high quality projects and the full range of potential activities, it is important to distinguish between [arts by/with/for young people]" (Creative New Zealand 8). However, these descriptions are broad and intersecting. For example, in considering Theatre by Young People and Theatre with Young People the preposition is significant as it points to varying degrees of young people's involvement in each specific project. Young people may write, direct and perform in a piece themselves with little or no adult/professional input into the process; or, as in the case of Young and Hungry, ${ }^{13}$ professional theatre practitioners write and direct the plays, and the young people perform in and contribute to the design, publicity and production elements of the play. The fact that young people have extensive creative agency in the process locates Young and Hungry in the theatre by young people category. However, as the experience is led or delivered by professional artists and practitioners, who are usually adults, it can also be located in the theatre with young people category.

\footnotetext{
${ }^{13}$ Young and Hungry has fostered emerging artists in professional theatre since 1993. The programme commissions youth focussed plays, provides a platform to perform them, and connects youth with professional practitioners. (Young \& Hungry).
} 


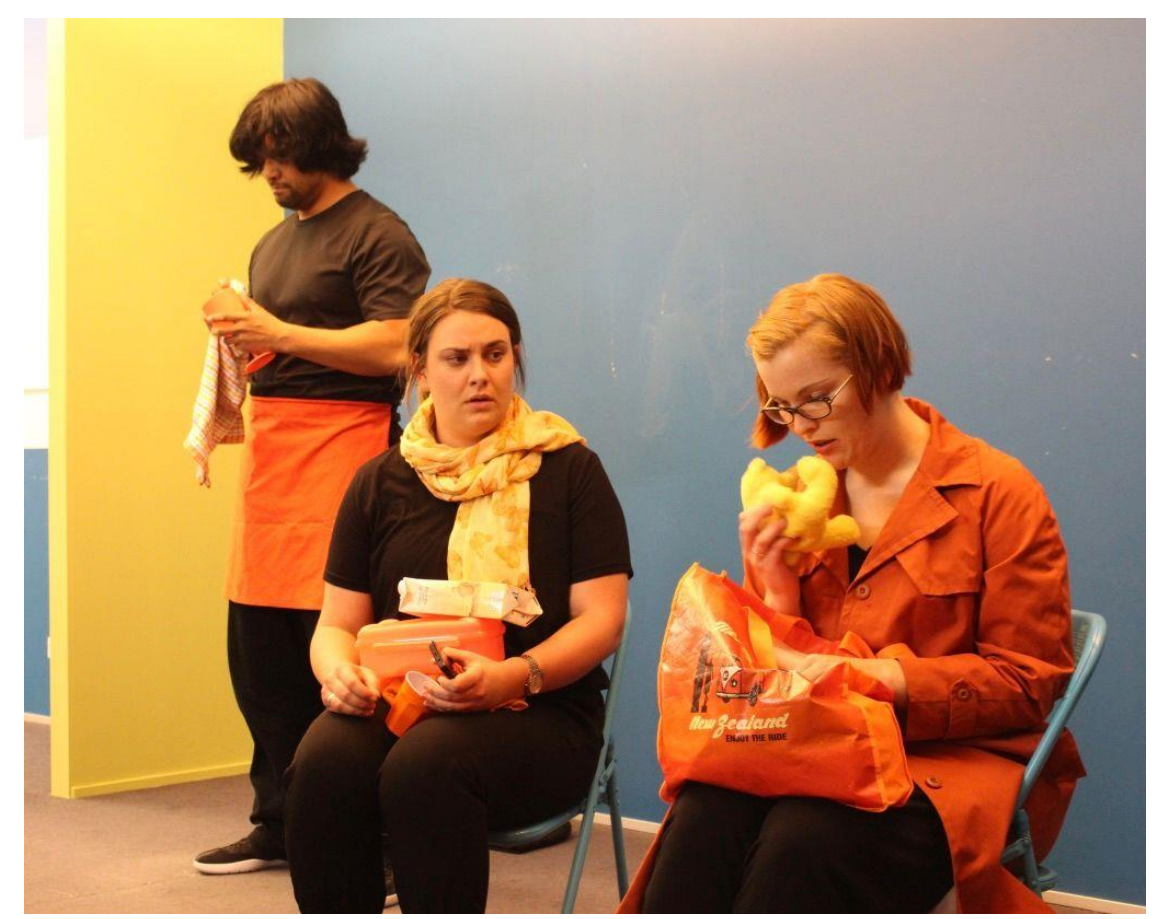

Figure 3: Closure- Ensemble Impact. Theatre for Young Audiences.

Two significant organisations referred to in this thesis are ASSITEJ and PAYPA. ASSITEJ is the International Association of Theatre for Children and Young People. It was established in 1965 as an international alliance of professionals involved in theatre for children and young people (ASSITEJ). ASSITEJ's charter positions TYA as a form of theatre that:

respects its young audiences by presenting their hopes, dreams and fears; it develops and deepens experience, intelligence, emotion and imagination; it inspires ethical choices; it helps awareness of social relations; it encourages self-esteem, tolerance, confidence and opinions. Above all, it helps young people to find their place and voice in society. (ASSITEJ) 
The members of ASSITEJ are national centres, professional networks, and individuals from around 100 countries across the world. (ASSITEJ)

PAYPA (Performing Arts By/With/For Young People Aotearoa) is Aotearoa/New Zealand's National Centre for ASSITEJ. The national centre is a network which encompasses the following categories: professional theatre companies or artists performing for children and young people, non-professional theatre companies or artists performing for children and young people, organisations, institutions, associations or persons actively engaged in the work of theatre for children and young people and supporting organisations, institutions, associations, or persons interested in theatre for children and young people (PAYPA).

Founded in 2016, PAYPA was formally registered as a trust and advocacy body for TYA in 2020. Alongside Jenny Wake, Marianne Taylor, Lynne Cardy and Tim Bray, I have been instrumental in the formation of this New Zealand arm of ASSITEJ International and am a founding board member.

From my childhood days of passionately reciting lines in the back paddock and through my years of parenting, teaching and directing theatre I have held a strong belief that TYA is important and necessary, to individual children and also to the wider theatre industry. These views have not always been shared by those around me. I have consistently been met with challenges especially in a lack of resourcing and validation. I have always held on to the belief that New Zealand's TYA industry has the potential to be one of the best in the world. For that to happen, however, I needed to stop lamenting my personal challenges and frustrations and instead investigate the field as a whole to make fully informed recommendations of how to create sustainable change. Because my 25 years' experience lies in the practices of teaching and directing it was logical to amalgamate the two to create a framework for investigation. My contribution to new 
knowledge is the creation of two original plays for young people, the analysis and understanding of best practice in the making of these plays, a model for devising intergenerational and collaborative theatre with and for young people, and the recommendations made for the New Zealand TYA industry to increase sustainability and excellence. To best situate my research project, the following chapter is an examination of national and international literature on TYA. The analysis of this literature provides a view of the field of study and sets a framework for investigating the field in Aotearoa/New Zealand. 


\section{Chapter 2. Defining the Whakapapa}

\section{Literature Review}

A literature review is described by Davidson and Tolich as an academic whakapapa (genealogy, lineage), where scholars locate their research in a certain context and discover connections with extant ideas and theories (95). This literature review briefly examines global perspectives of how TYA is developed, made and critically analysed. Section One, 'The Broader Perspective', examines theatre as an art form investigating the relevance, benefit and value of theatre for young people. It introduces key debates in the field and reviews TYA in the context of the wider genre of theatre. It discusses Devised Theatre as a method of making theatre and outlines some of the many challenges involved in making TYA, using examples from a variety of recent scholarly literature. Section Two, 'Theatre By/With/For Young People in Aotearoa/New Zealand', considers the status of TYA in the current theatre ecology, as well as the large gap in the whakapapa of the literature in the field. It situates TYA within a specific New Zealand context.

As this thesis is an arts research project, it is appropriate to cite live performance as key resources and exemplars within this literature review. Arts Research scholar Brad Haseman suggests in his Manifesto for Performative Research that Performative Research can be:

expressed in non-numeric data... in forms of symbolic data other than words in discursive text. These include material forms of practice of still and moving images, of music and sound, of live action and digital code. (2006) 
The forms of practice cited in this review include local and international case studies, as well as examples from my own creative practice and experience.

\section{The Broader Perspective: Key ideas, debates and challenges within the field of TYA}

\subsection{Drama vs. Theatre}

The distinctions between the terms Theatre and Drama are often unclear or contradictory. Within the context of TYA it is useful to briefly differentiate the terms since, when young people are involved, there is often an intersect between the two. For example, there is often discussion around the semiotics within the field of drama and theatre in secondary and tertiary education. These range from drama as the study of the play on the page, and theatre as the study of the play on the stage, to the notion of drama as acts that are imagined, and theatre as a broader category which includes drama but also any event that has an audience. In a university context Theatre Studies denotes the teaching of plays as performances, whereas Drama Studies programmes are more closely aligned to English literature and the study of dramatic texts.

Drama in its natural state can be defined as play, as in the Performance Studies definition: "a mood, an activity, a spontaneous emotion. Sometimes it is rule bound. Sometimes very free. It is pervasive" (Schechner 89). This is particularly pertinent when examining theatre and children in the same sphere, as play is often very natural and uninhibited in young children but becomes more rule-bound and self-aware as they get older. Seminal drama practitioner and educator Peter Slade explores this idea in Child Drama (1954): "wherever there is Play there is Drama" (23). Slade's research was revolutionary in linking the play of children to drama and theatre and has had an impact on education, drama, and theatre studies alike. Slade asserts that since drama means "doing" then, in a general sense, all is drama (23). However, Slade's recognition

of play itself as a form of drama, albeit a form of drama that is not always recognisable 
to adults, saw the beginnings of Child Drama being perceived as an art form in its own right (9).

In Drama and Theatre with Children, Charu Sharma maintains "drama is more implicit as a process in developing thinking and learning in children, whereas theatre provides a greater emphasis on performance" (1). Landy and Montgomery define Drama in Education as, "the use of drama as a means of teaching a variety of content areas... [where the] object is understanding rather than playmaking" (253). Canadian academic Sharon Bailin maintains the importance of distinguishing the difference between drama and theatre in education by claiming the essential difference "is that drama is seen as having to do with the experience of the learner whereas theatre is about communication with an audience" (423). Consequently, there is often an intersection in TYA, where young people are learning through the making of the work (drama) as well as communicating with an audience (theatre).

\subsection{Devised Theatre}

Devising is the predominant theatre-making method used in my creative project.

Different from the traditional text-based method, Devised Theatre is usefully defined as "a process for creating performance from scratch, by the group, without a pre-existing script" (Heddon and Milling 3). Although not globally recognised as an independent form of theatre-making until the 2000s, it was foreshadowed in the 1960s and 1970s by experimental, alternative groups in New York and London (Felseghi 63). Devised Theatre is concerned with the collective creation of art instead of the single vision of the playwright and director (Oddey 2). There are many excellent books on devised theatre: for example Devising in Process (Mermikideas and Smart 2010) The Frantic Assembly Book of Devising Theatre, (Graham and Hoggett 2009), Collective Creation, Collaboration and Devising (Barton 2008) For this thesis, Alison Oddey's: Devising Theatre (1994) and 
Heddon and Milling's Devising Performance A Critical Handbook (2006) have been instrumental in defining Devised Theatre and I refer to their work, as well as the devising methodologies discussed in Chapter 3, by Jessica Swale ( 2012), Dave Brown ( 2017) and Joan Schirle (2005). Important to my research enquiries about directing for devising with a young ensemble was Beth Watkins' article "Working from Scratch: The Pedagogic Value of Undergraduate Devising" (2016). Of particular importance is her explanation of the way devising can lead to the empowerment of young people in a devising process:

I am drawn to the devising process because of the challenge of developing a collaborative ensemble as a mode of teaching, as well as the idea of empowering students by encouraging them to draw on the interdisciplinary research training of a liberal arts curriculum... Students are invited to claim ownership of a devising project through their invention and problem-solving (Watkins 169-170).

Empowerment, as well as empathy and agency, are key concepts referred to in the analysis of my creative project. In this context when I am discussing agency, I am referring to the sense of agency. In psychological terms, sense of agency:

refers to the feeling of control over actions and their consequences...When we make voluntary actions we tend not to feel as though they simply happen to us, instead we feel as though we are in charge. The sense of agency refers to this feeling of being in the driving seat when it comes to our actions. (Moore)

The sense of agency is important to this research as I investigate the way that giving young people agency in a devising process can lead to their empowerment regarding the process and the product. Empowerment can be defined as "the state or fact of being 
empowered; ... of acquiring more control over one's life or circumstances through increased civil rights, independence, self-esteem, etc. ("Empowerment"). It is a similar concept to agency, but the differences are important to distinguish:

To speak of empowerment as a result or outcome presupposes a process of change to produce it. So 'empowerment' evidently refers not simply to a state of affairs but to a process of change with a specific kind of outcome. In this respect it differs already from 'agency', which refers either to a given person's degree of involvement in a course of action or to the scope of actions that a person could be involved in bringing about. Thus, an initial difference appears: 'agency' refers to a state of affairs while 'empowerment' refers to a process of change. (Drydyk)

In this research, I investigate ways that devised theatre can increase agency in young people, so that they feel more empowered and can claim ownership of the work.

In "The Feeling of Devising: emotion and mind in the devising process" (2014), Jackie Smart discusses the way that people feel when they create theatre collectively and how these feelings contribute to the devising experience. She describes two key issues that occur in the collaborative devising process- which can be characterised in terms of tensions (101). I analyse these tensions in my devising process: in particular the tension of shaping a coherent theatrical piece from a group made up of diverse voices and visions (101-102); and the need for trust and open communication in the devising process- a process that itself produces anxiety and insecurity (102).

Similarly, discussions on devising practices in Hannah Bank's 2019 thesis $A$ Stage of Our Own: Women Devising Theatre in Aotearoa New Zealand (VUW), are also 
relevant to this thesis. Banks examines female-led devising practices- including my own, ${ }^{14}$ and relevant to my research enquiries are her discussions on empathy:

Emotion and empathy need to be embraced within a devising process and not suppressed. While these ideas are important for any creative process, the uncertainty and intangible nature of devising means that they are even more crucial in a collaborative process. (268)

Banks identifies the culture in her devising room as being embedded with "radical empathy and compassionate honesty" (270). Empathy is a phrase used in a variety of fields. Nursing scholar Theresa Wiseman 's description of the four main attributes of an empathetic person can also be applied to the devising room:

to be able to see the world as others see it to be non-judgmental to understand another's feelings to communicate your understanding of that person's feelings. (Wiseman 1165)

Devising directors will regularly employ different models of devising in their process, for example: Bogart's Viewpoints (Bogart and Landau 5), The Frantic Method (S. Graham 2020), or the R.S.V.P model (Halprin 2). These models often evolve from experimentation in the rehearsal room and are adapted by individual companies and practitioners. Watkins, Smart, and Bank's research were particularly useful to my analysis of the devising process, because of their experiences of being practitionerresearchers. All three write about findings they made while in the devising room, and

14 In Sniper 2014. 
the individual methods they employed with ensembles. The specific devising methods I used in this project are examined in Chapter Three. Because Devised Theatre is defined as having no script as a starting point, involves all elements being developed from the collective work of a group, and often leads to unexpected and innovative discoveries of knowledge, this makes it a suitable method of research for an arts research project.

\subsection{The Relevance and Benefit of Theatre By/With/For Young People.}

To contextualise TYA, it is useful to consider the wider place of theatre, and specifically TYA, in society. Through examining the purpose, relevance and cultural benefits that theatre can offer to young people, a framework for the discourse of TYA can be established. There is considerable literature (Reason; Bennett; Sharma; Slade; Goldberg) which examines the value of drama and theatre specifically by/with/for children. Australian Drama in Education academic Meg Upton for example maintains:

Theatre allows us to imagine a different reality, and in so doing to know that it can be one of our own making - that we can both be its creator and a character within it. We have in ourselves, the power to make choices about who we want to be, to shape the kind of world we want to live in. (Upton 22)

The power of theatre to affect the way the world is shaped is also discussed by The Guardian's theatre reviewer, and fierce advocate for children's theatre, Lyn Gardner:

At a time when the pressures on young people are perhaps greater than they have been at any time since the second world war, and the challenges faced by massive cultural and technological shifts, climate change, and economic collapse are immense, what we need is a rising generation who can use their heads to 
solve those problems but also their imaginations... Theatre, particularly theatre for children, fires the imagination, it gives our children the skills and the creativity necessary to face the world, to understand it and perhaps to change it too. We should value children's theatre and take it seriously and that means treating it with the respect that we would any work of art including reviewing and critiquing it. (Gardner)

Recognition of the benefits for exposing children to drama and theatre can be distilled into four main areas:

The educative benefit is the notion that engaging children in drama and theatre will increase their knowledge and improve their education. "When pupils are thinking and behaving creatively in the classroom, you are likely to see them: questioning and challenging, making connections and seeing relationships, envisaging what might be, exploring ideas, keeping options open, reflecting critically on actions and outcomes" (Woolland 23).

The emotional benefit is the belief that through drama and theatre, people can examine their emotions, feelings, fears and desires, identities, and enhance their emotional intelligence. "Drama classrooms can be a safe place to explore our burgeoning identity. We can try out our beliefs without long-lasting, real-life consequence" (Stevens 15-16).

The cultural benefit is the conviction that the stimulation and development of children's cultural capital and experience of the arts is a valuable part of life. The fact that The United Nations sees participation in the arts as a "basic human right" highlights the perceived importance of cultural life in the development of a child (United Nations Charter). 
Building a future audience is the concept of presenting theatre by, with, and for Young People for future audience development. This is a contentious and yet widely used reason for making and presenting children's theatre. In response to the question "Why should we have children's theatre?", seminal TYA academic Moses Goldberg (1974) suggests that exposure to good theatre will make a future adult more likely to be a theatre-goer but concedes that there is no evidence to support this (13). New Zealand creative producer Stephen Blackburn's 2016 article "Respect the Work" suggests that in recent years major theatre companies have declared an interest in young audiences as part of a need for their organisation to engage in audience development, but believes that this reliance on an audience in the making disrespects the audience (15). Tom Maguire and Karin Schuitema assert that providing good theatre experiences may encourage some children to grow up enjoying theatre, but that investment in the future should not be the main incentive: "we want to give young audiences exciting theatre NOW, for its own sake, rather than do it to create tomorrow's adult audience" (viii). Matthew Reason, a leading UK academic specialising in children's theatre suggests that too much focus on audience development undervalues the importance of children as an audience in their own right: "To perceive young people's engagement with theatre as primarily about audience development is to value the adult audience they might become, rather than the audience they are now" (The Young Audience 30). Thus, the building of a future audience should not be the predominant reason that theatre companies programme TYA work; instead, they should be considering work that is suitable, engaging, and satisfying at that particular moment in their lives: "Children are not the audience of the future. Rather they are citizens of the here-and-now, with important cultural entitlements" (Drury qtd. in Reason, The Young Audience 30). The purpose of presenting TYA, solely for creating a future audience is arguably a way of marginalising the views of children and the TYA genre. 
Reason observes in The Young Audience (2010) that the growth in the status of theatre for children as an art form has been accompanied by the widespread interest in the social and educational benefits for young people of the arts in general, and theatre in particular. He comments on the volume of research and the relationship between arts and education, asserting that there has been little consideration of children's perceptions of theatre and, in particular, their audience experiences have scarcely been investigated: "In the clamour of voices advocating the importance of theatre for young

people, the voice and the perspective of the children themselves is missing" (ix). This is particularly relevant in New Zealand where there is little documented evidence of young people's perspective on or even understanding of theatre. Reason's commitment to encouraging practitioners to become active researchers in children's experiences of theatre, and to facilitate children in becoming empowered and self-reflective audience members (The Young Audience 172), has been a strong motivation for this research.

\subsection{Theatre By/With/For Young Audiences Within the Wider Field of Theatre} ITYARN, the International Theatre for Young Audiences Research Network, is the international research network of ASSITEJ International ("ITYARN"). It was founded in Kristiansand, Norway in 2006 when a contingent of nine representatives from universities of six different countries (Japan, Korea, Norway, Germany, Turkey, and The United States) were invited to examine the status of scholarship in the field of TYA. They identified that "despite the enormous artistic output [of TYA internationally] serious research, such as that seen in general theatre scholarship, in the field of professional theatre for children and youth was in short supply" (van de Water 7). ITYARN was formed in an attempt to bridge this gap and galvanise international TYA scholars and scholarship (van de Water 7). 
Through exchanges of academic material, discourse at festivals, conferences and symposia:

ITYARN aims to advance critical inquiry in the field of Theatre for Young Audiences (TYA) through the exchange and discussion of papers from scholars in and outside of the field of TYA. We intend to bridge the gap in scholarship between theatre for young people and theatre for adults, and between theory and practice, by discussing the field of TYA from multiple historiographical and theoretical perspectives related to the practice and the shifting material circumstances (social, cultural, economic, ideological, and political) under which TYA is generated and perceived. ("ITYARN")

ITYARN organises conferences (in conjunction with ASSITEJ), world congresses, and festivals, facilitates forums and symposiums, and to date it has published four books of essays in the field of TYA from several countries presenting international perspectives on TYA: TYA, Culture, Society. International Essays on Theatre for Young Audiences (van de Water (ed.) 2012 Theater for young audiences: International perspectives. Spanish Edition. van de Water, Manon (ed.), 2012. Youth and Performance. Perception of the Contemporary Child. (Wartemann, et al 2015) and Diversity, Representation and Culture in TYA (van de Water (ed), 2020). ITYARN encourages discourse and scholarship on all areas of TYA and invites both practitioners and scholars to contribute to the discourse. Widely respected TYA researchers such as Manon van de Water, Geesche Wartemann, Tom Macguire, and Matthew Reason all contribute to these volumes, along with many practitioner-researchers around the world.

The global association of theatre for young audiences - ASSITEJ - has membership across the world and unites professionals making theatre for young audiences. 
ASSITEJ's 3-yearly world congress presents theatre from all corners of the Globe, and every year there is an artistic gathering somewhere in the world ("ASSITEJ in the World - ASSITEJ International"). Although it is difficult to get an accurate global overview of TYA, in 2019 I attended an International Directors' workshop in Berlin, funded by ASSITEJ Germany, ${ }^{15}$ where TYA directors from 25 countries met. I discovered that although there are challenges for TYA practitioners in all member countries, some countries are better resourced, have solid government funding and community support. For example, Norway's 'Cultural Rucksack' programme ensures that all children in primary and secondary schools have access to professional arts and culture of high-quality during school hours (Christopherson et al. 5,9). Denmark has approximately 150 professional TYA companies (Valente) and is seen as a world leader. On the other hand, when South Africa began to explore (in 2012) hosting the first ASSITEJ world congress on African soil in 2019, Yvette Hardie (ASSITEJ International President) identified South African TYA as "poorly funded, with few platforms for showcasing work outside of schools and creches, with only two permanent theatre spaces dedicated to work for children in the country" (Hardie).

As shown in Figure 5, the majority of ASSITEJ's national centres are in Europe, but the organisation has a worldwide spread. In Asia, there is a strong component of TYA work happening, in particular in Japan, South Korea, China, Singapore and India. Dave Brown notes that in South Australia "state and federal funding bodies have been very supportive of theatre for young audiences", although recently there have been some dire funding cuts which have affected many companies ("Re: Questions around Value in Australian TYA").

${ }^{15}$ My trip to Germany was funded by CNZ. 


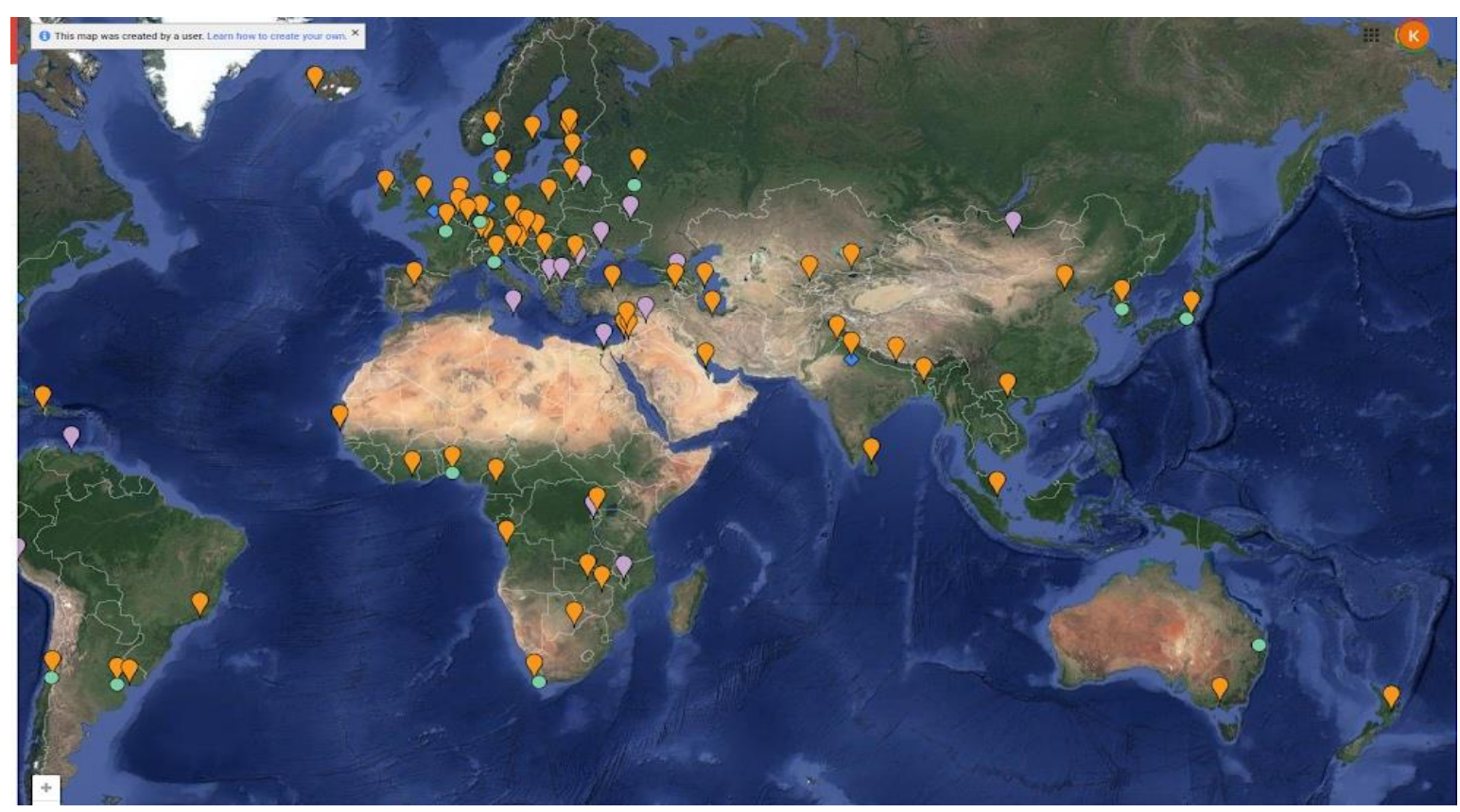

Figure 4: Map of the spread of ASSITEJ national centres. (ASSITEJ)

A commonality amongst the world-wide spread of directors at the ASSITEJ Germany workshop was the perceived undervaluing of TYA, within the wider community, but also in the theatre industry.

Wolfgang Schneider's 2013 article, TYA as Cultural Policy states that "In most countries, TYA is seen as separate from the wider theatre system". Schneider argues that:

Adults can fight for their rights by themselves, but the young generation needs support from society. TYA is not well established everywhere, and it is not well funded by the political authorities. It is often seen as something in between social work, youth welfare, and arts education. But it should be a part of daily life, it should be an experience from the very beginning, and it should be part of the cultural diversity agenda as announced by the United Nations Educational, 
Scientific and Cultural Organization (UNESCO) Convention on the Promotion and Protection of the Diversity of Cultural Expression in 2005. ${ }^{16}$ (Schneider)

Several of the publications cited in this whakapapa also observe that TYA constantly has to demonstrate its value. Contributors to Maguire and Schuitema's Theatre for Young Audiences A Critical Handbook (2012) acknowledge the unique challenges of creating TYA, such as underfunding, low seat prices, and the schism that has developed between Children's Theatre and TIE; where TIE lobbyists describe children's theatre as whimsical and trivial and the children's theatre practitioners describe TIE as too educational and lacking in entertainment value (Wood, "Foreword" viii). TYA Practitioner David Wood maintains "Theatre for young audiences is an art form," and that for too long children's theatre practitioners have been relegated to second division by the assumption that "they are cutting their teeth, aiming to eventually climb the ladder towards the goal of doing grown-up theatre." (Wood vii). This corresponds with Reason's observation that "there is a continuing presumption that theatre for children is second best. Something that actors or directors might do while waiting for something better to come along, but rarely out of choice" (Reason, The Young Audience 35).

Furthermore, Reason cites TYA director Anthony Clark's argument that there is a perception in the UK that TYA is frequently 'an add-on' to a company's programme, rather than something that is integrated within the rest of a company's work (Clark qtd. in Reason, The Young Audience 34). Reason views this as a marginalising of TYA

\footnotetext{
${ }^{16}$ UNESCO encourages "dialogue among cultures with a view to ensuring wider and balanced cultural exchanges in the world in favour of intercultural respect and a culture of peace. (...) [It fosters] interculturality in order to develop cultural interaction in the spirit of building bridges among people. (...) [It reaffirms] the importance of the link between culture and development for all countries, particularly for developing countries, and to support actions undertaken nationally and internationally to secure recognition of the true value of this link" (UNESCO).
} 
within the theatre industry. He also notes that many primary school children only see theatre performances (by professionals) in their schools rather than in a theatre (Reason, The Young Audience 34). Clarke considers this as further marginalisation, because it limits children's experience of the full potential of a theatre show. Moreover, this becomes damaging to the reputation of TYA as theatre becomes synonymous in the children's minds with small scale, school, and educational performances (qtd. in Reason, The Young Audience 34)). Reason challenges the dismissive attitude towards children's theatre from within the theatre industry, as "a deep-rooted, much questioned but continuing presumption that theatre for children is somehow second best" (The Young Audience 35).

Carol Lorenz discusses the evolution of TYA in the USA at length, from early ghettoization within the wider theatre ecology:

By the second decade of the 20th Century, it was already considered an educational hybrid or at best innocuous entertainment whose purpose was to dazzle and beguile in order to transport its young audiences to a world where patriarchal order reigned unchallenged and supreme. It quickly came to be viewed by its adult counterpart as both intellectually limited and artistically inferior. (97)

Lorenz notes that it has only been since the 1970s that TYA in the USA has begun to be seen as equal to adult theatre and worthy of academic discourse (97). Scholar and practitioner Manon van de Water's claims that "theatre for young audiences' practitioners and advocates have grown tired of the perceived need to 'legitimize' their work" ("Constructed Narratives: Situating Theatre for Young Audiences in the United States." 101). Her 2000 paper "Constructed Narratives: Situating Theatre for Young Audiences in The United States" examines the myths and assumptions in the field of TYA and attempts to "shed light on how and why the field obtained and maintains a 
marginalized image" (101). van de Water argues that "the marginalization of theatre for young audiences is not so much a product of the lack of growth and maturity in the field, but rather of the narrative construct of its history" ("Constructed Narratives: Situating Theatre for Young Audiences in the United States." 105), in particular concerning the relationship between "children, education and 'appropriate entertainment'" (105).

Canadian TYA practitioner Monica Dufault reflects that a similar marginalisation and ghettoization of TYA exists in Canada. "This same feeling that artists engaged in TYA are doing so as a 'steppingstone' to adult theatre is still prevalent here" (Dufault). She also reports that before 2020:

the Canada Council for the Arts (our national arts funding body) was prioritizing theatre for young audiences' projects, and a separate stream was established for supporting TYA organizations. Now the funding model has shifted, and TYA companies compete in the same granting pool as theatre companies for adults, as well as dance companies and other live performance practices, resulting in poorer outcomes for TYA. Often because assessors don't understand the unique situation of TYA, and see it as a lesser art form. (Dufault)

Wood, Clark, Reason, Lorenz and Dufaults's observations resonate with my experience of making and viewing TYA in Aotearoa/New Zealand. New Zealand theatre maker Stephen Blackburn observes that "the idea amongst theatre practitioners [is] that theatre for children is something you do in the school holidays. As an opportunity for emerging practitioners before - you know - they can be trusted with grown-up work" (15). This corresponds with some of the attitudes I have come up against as a director, such as actors withdrawing from TYA shows to perform in 
something that they perceive as being better for their career. Likewise, as an audience member, some of the plays I took my young children to were badly performed and patronising. I heard actors and directors using phrases like "it's just for kids, we don't have to try that hard."

My experiences of the devaluing of TYA indicates a marginalisation of the practitioners, the work and the audience. I believe that if TYA is viewed as a lesser form of theatre, then this implies that children are a less important audience than adults. If theatre practitioners treat TYA as something 'easy' and not worthy of monetary and artistic input, then they are undervaluing not only the art form but also children themselves. The tendency that producers and arts marketers have in viewing children solely as future adult theatregoers instead of worthy audience members in the here and now, contributes further to the undervaluing of children's theatre experiences.

\subsection{The Challenges of Making Theatre By/With/For Young People}

There are challenges involved in making all theatre in Aotearoa/New Zealand. Mostly, these challenges revolve around funding, aesthetic considerations, audience retention, relevance and accessibility. However, existing TYA literature suggests there are additional challenges specific to making Theatre By/With/For Young People. In this section and in my arts research project, I narrow my focus to theatre for children where “...the experience is led or delivered by experienced artists and practitioners who are usually adults" (Rees 9) and theatre created with children, that which involves "lead artists working collaboratively alongside young people" (Rees 8-9).

Theatre for/with children is not only the area that I focus on for the creative component of this thesis, it is also the field that I am most experienced in as a practitioner. According to Nonnita's 2013-2017 summary of the theatre work aimed at young audiences and funded by Creative New Zealand (CNZ), thirteen out of fourteen 
companies in this time frame identified themselves as making work for children, and theatre made with children is identified by eleven out of the fourteen companies ("Report on the Priority By, With and For Young People" 5-6). Therefore, theatre for/with children would benefit from a robust investigation and examination of its status in Aotearoa/New Zealand, and it is these categories on which this research is focussed.

\subsubsection{The Conviction That All TYA Needs to be educative}

One of the challenges within the genre is that there are strong differences of opinion over whether all TYA needs to be educative. Different companies naturally have distinct agendas for their TYA projects; educative, entertainment, or commercial. Reason argues, however, that TYA has "always existed in overlapping frames of reference, evoking discourses of education as much as aesthetics, of pedagogy as much as art" (The Young Audience 3-4). He contrasts this with theatre for adults, which is rarely solely perceived as having to be educational. He questions why Theatre by and with Young People is often situated within the educational realm and suggests that because much TYA activity involves making the theatre with children, or by children themselves, it is inherently thought of as having educational benefits and the focus of the work is often didactic. Theatre in Education (TIE) (including educational theatre and theatre made with/by young people) fits naturally into this sphere. In contrast, he argues that Theatre for Children should sit alongside adult theatre as a cultural experience; however, unlike adult theatre, it is often expected to have some sort of educational value. An example of this in my own practice is from during the time I was employed for Capital E National Theatre for Children, where shows that had a didactic theme, such as Seasons ${ }^{17}$ (Wilson) were often easier to sell and attracted greater schools-

\footnotetext{
${ }^{17}$ A play about the four seasons.
} 
based audiences than shows that were presented and marketed with a less didactic emphasis, such as Around The World and Buck Again. ${ }^{18}$ (Patrick)

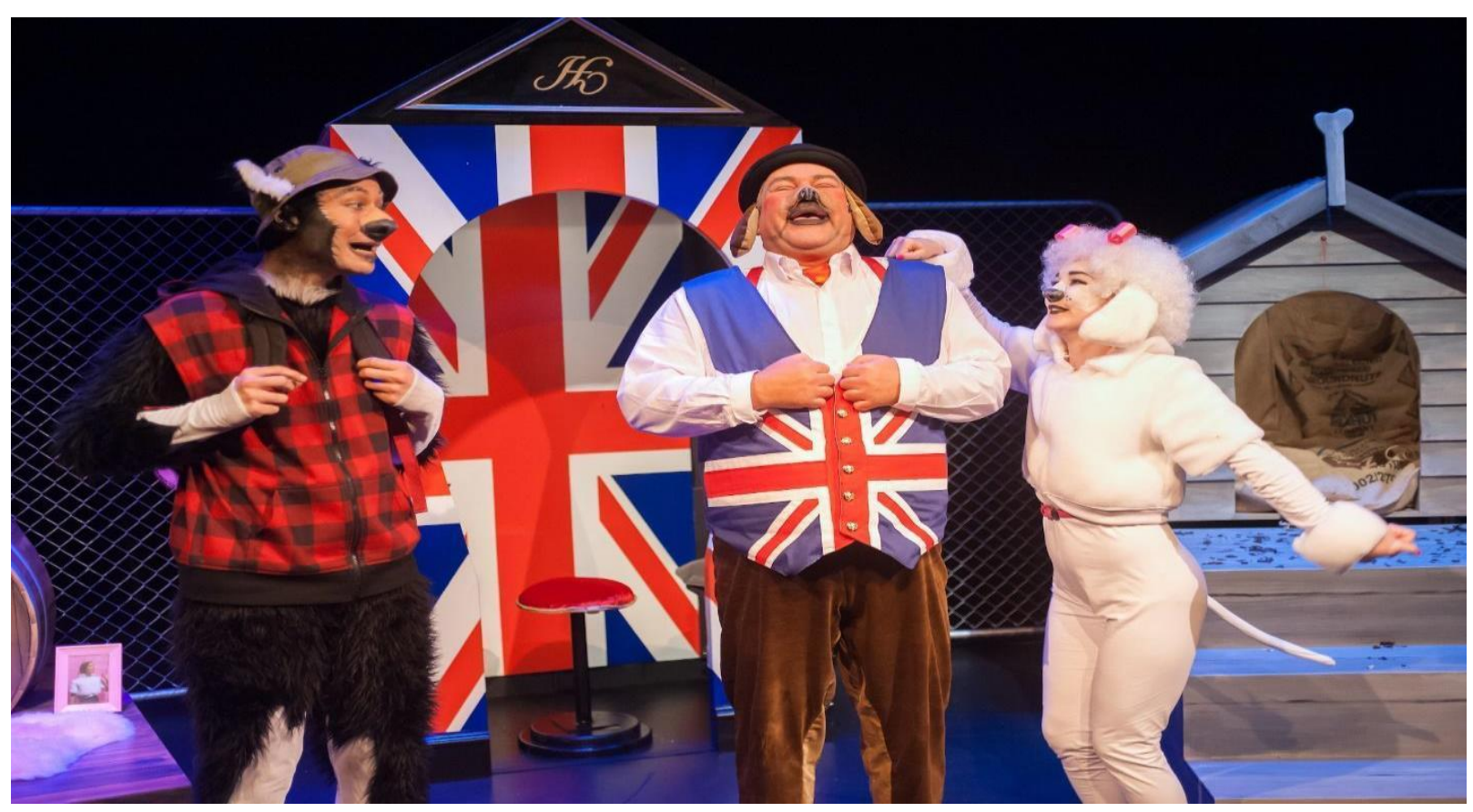

Figure 5: Around the World and Buck Again. Capital E National Theatre for Children

Theatre companies in New Zealand are consistently underfunded and perpetually have to make artistic and financial decisions based on programming to ensure a high percentage of paying audience. Schools and parents also have to make funding decisions based on educative or cultural value. This leads to a tension between spending money on a unique cultural experience, or on an experience that is educational as well. The risk of constantly aligning theatre with education is that theatre becomes a form which is always associated with education and school and not simply a forum to experience art for art's sake. Reason agrees, stating that "discussion about adult theatre is almost always discussion about aesthetics, art and theatre. Discussion about theatre for children is rarely so straight forward and is as often about education as about art" (The Young Audience 3-4).

${ }_{18}$ A play about four dogs from different countries who meet in quarantine. 
van de Water's claim that "[p]art of the problem of theatre for young audiences' persistently marginalised status is that it often needs to commodify the mythical notion of its educational and social significance, in order to legitimize its right of existence and obtain the necessary funds" ("Constructed Narratives: Situating Theatre for Young Audiences in the United States." 107), suggests that aligning theatre with education can be problematic. Shifra Schonmann argues that theatre "has to stop struggling to define its legitimacy as an educational endeavour. It would do better to concentrate on its artistic form and its own aesthetic merits" (10). In TYA work that is not solely didactic, the emphasis for the artist is on the child's development, which is linked to creative and aesthetic awareness and growth rather than placing a central focus on formal educational considerations. It is this creative and aesthetic awareness and growth that Theatre for Young People practitioners often pursue. American academic Chris Vine suggests that TIE's "prime motivation lies in its explicit educational purpose and that its distinctive formal feature is its use of active audience participation" (qtd.in Reason 4). Reason explains further:

There are, therefore, two principal elements at play within the concept of TIE that distinguish it from theatre for children. The first concerns the position of education as the primary motivation and function. In contrast, while theatre for children inevitably operates within contexts of education and learning, this is less frequently presented as its primary function (The Young Audience 4-5).

However, Reason also observes that it is increasingly difficult to see the difference between TIE and TYA in each of its different forms, suggesting that "one strong distinction, however, may be found in the instrumental motivation of much TIE and in the particular relationship that each form seeks to construct with education. (Reason, The Young Audience 5). Perhaps another question to ask is should we care if the 
boundaries overlap? Possibly not. However, if theatre for children is perceived as having to be educative, then we need to ask: is the emphasis of educational goals in TYA overriding our aesthetic concerns? Are they mutually exclusive? And if children continue to view theatre purely as another form of education, then where do they learn about aesthetics, art, and theatre magic?

\subsubsection{Adults Assessing What is Best for Children}

In many of the scholarly discussions of the creation of TYA works, adults (scholars and practitioners) are seen to be constantly assessing what they believe children want to see and, in turn, determining what is 'good' TYA based on these presumptions. Reason suggests that if we do not pay attention to the child in the audience and what they are experiencing, then TYA becomes theatre for children that is defined and produced solely by adults ("The Possibility of Theatre for Children" 26). The adult assumes that they know what the child wants to see and therefore what is best for the child. Reason urges that children need to have agency and subjectivity over their own experiences, which will, in turn, make culture for children more ideologically possible (26). Reason maintains that in our culture, theatre for children is a product made for children but is made and consumed in a way that is not democratic or equal: "Children are a benevolently coerced audience, brought to the theatre by schools, parents or other guardians. They are taken to the theatre perhaps in the same way that children are sent to school or taken to the dentist -because it is good for them" (17). Therefore, when researching this field, it is necessary to consider the relationship between adults and children. TYA is dependent on an often unspoken but usually absolute, division of power between adults and children, where "the adult comes first as author, maker, performer, programmer and the child comes after-as audience" (Reason, 18). If adults are responsible for producing theatre work for children, then how do they know if what 
they are producing is targeting their intended audience in a way that is respectful and enlightening?

David Wood argues that children have a lack of critical facilities, which makes our responsibility to entertain them with integrity all the more critical (Wood and Grant 7). One approach to discover what would best entertain young people would be to directly ask them; however, PaperBoats founder Dave Brown argues that if we ask children what they want to see, then they will predominantly want only what they know - for example if they have only listened to Britney Spears then they will only want to hear Britney Spears. This, however, means that they miss out on the experience of Beethoven because they do not know Beethoven exists (Brown). Brown believes that it is up to us as makers of TYA work to educate children in quality children's theatre (Brown). The theory that children do not know what they like until they see it makes it challenging to test or research specifically what it is children want to see at the theatre. It highlights a major challenge in the field. How do we solicit information from children about what it is they want to see if they themselves don't know all that is out there? Furthermore, as practitioners, how do we treat the information we receive? With my arts research project I wanted to challenge the assumptions that some adults make about what is 'best' for children, as well as test methods of gathering useful feedback from children. This decision evolved from reflecting on my own assumptions about what children want to experience at the theatre, the recommendations about best practice for making TYA from CNZ (Rees, Personal Interview), as well as considering the work done in the field of childhood studies (discussed in Chapter Three), that validates children's experiences in the here and now and values their perspectives and responses.

When reflecting on my creative practice, I realise that I have regularly made TYA work in a way that assumes what children want to view/experience, for example, fast paced action and upbeat music. A turning point for me in my practice was when I 
began to bring my own children to rehearsal. I could actively test what worked in the room by observing my children's levels of engagement, as well as focusing the actors on the demographic that they wanted to engage with their performance. This engagement resulted in much more awareness, by me and the actors, of how children might respond to work as we were making it. In creating Moonlight and In The Attic, I decided to engage directly with children during the process of making. I hoped to discover the children's thoughts, attitudes, beliefs, and opinions, in the hope that we could get a sense of what they wanted to see, while simultaneously opening them up to alternative artistic realities that they may not have previously been exposed to.

It is also important to consider that children should not be expected to understand the theatrical convention of watching a play performed (Wood and Grant 20-21). This resonates with an experience I had accompanying a school group to a Capital E show, Ivy: Saviour of the Dinosaur, in July 2013, where many of the children kept talking about 'seeing the film.' They had very little concept that what they were about to see was a live performance and that going to the theatre was different from going to the movie- theatre. This suggests that adults have to help children to understand the conventions of theatre, as well as guiding them in experiencing what 'good' or quality theatre is. 


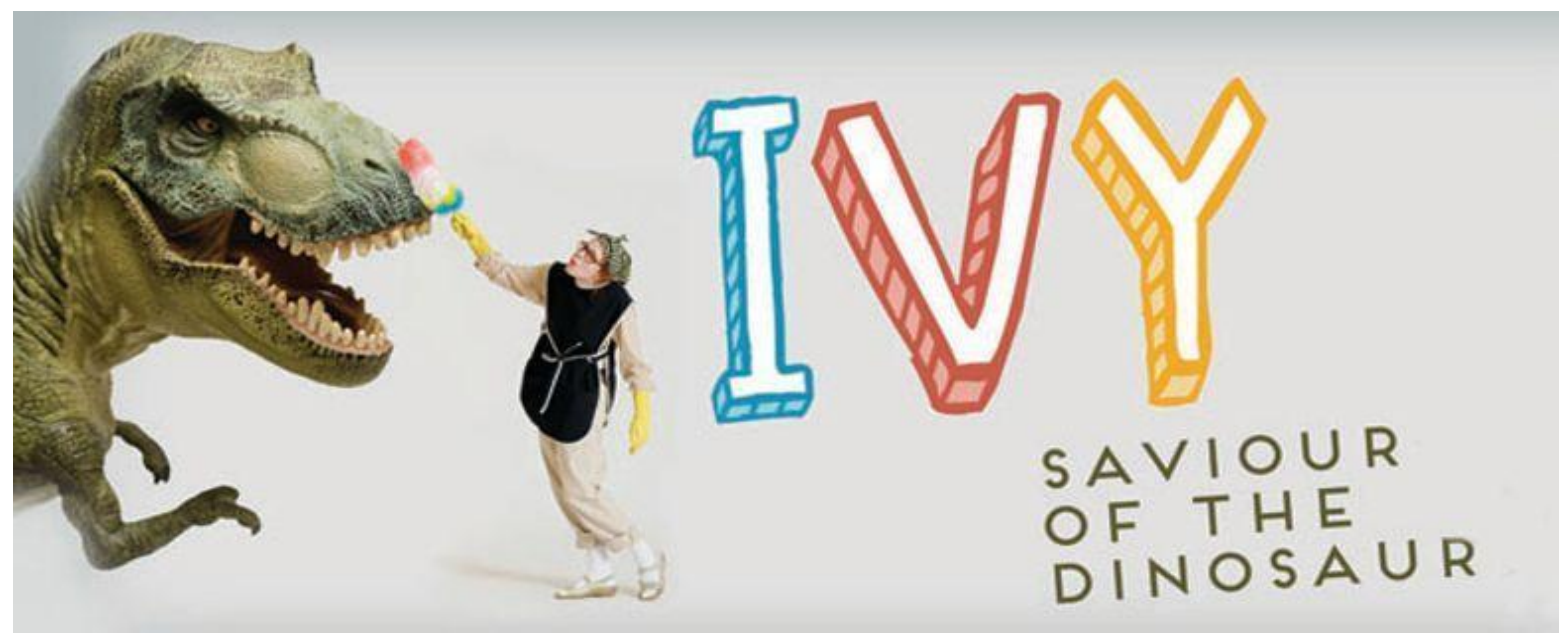

Figure 6: Poster for Capital E National Theatre for Children Production: Ivy, Saviour of The Dinosaur.

My arts research project aims to make theatre that will create self-reflective audience members, empower children, and make the experience of going to the theatre more appealing for children. It is nearly impossible to get around the fact that adults will consistently be financially, as well as artistically, responsible for what children watch at the theatre. When it comes to children's theatre, adults are the gatekeepers. It is adults who program events in theatres and festivals, who write policies pertaining to TYA, who decide which TYA productions are allocated funding; and adults who ultimately get to decide which productions children are exposed to. Thus, as well as working with the children themselves to develop their own theatrical competence, ${ }^{19}$ there needs to be a cultural shift in what it is that children are exposed to artistically by educating the adults in what constitutes quality TYA. Chapter Four discusses this in detail.

One way to increase children's theatrical competence and empower children is to engage them in the creation of the work. Long-time New Zealand TYA practitioner and

\footnotetext{
19 "Theatrical Competence: the sum total of knowledge, rules, skills that account for the ability to produce performance texts as well as the ability to understand them" (DeMarinis 171).
} 
director of Calico Young People's Theatre, Jenny Wake, adopts an immersive approach to making TYA, preferring to rehearse her works in schools:

If you're developing a show or rehearsing a show in a school, then you are surrounded by kids and teachers...you can't help but be infused by it. You're in touch with your audience already. It's very easy to forget what makes them laugh and what captures their interest and what their language is and what appeals to them. But if you're among them every day you're reminded of those things. (qtd.in Warrington 91)

This suggests that a genuine relationship with children throughout the process of making the play leads to a deeper and more complex understanding of children's responses to the final product. Jenny Wake is one of the few New Zealand practitioners who specialises in TYA, and has done so since the 1980s. ${ }^{20}$ In 1979 she gained a Masters,' degree from California State University Humboldt in children's theatre and brought her knowledge back to New Zealand. Wake's process of rehearsing in schools suggests a way of working that gives children agency and puts them at the centre of the work. I was curious to know if Wake's method was common practice with other practitioners and began by examining the evolution of the TYA field in New Zealand.

\section{Theatre By/With/For Young People in Aotearoa /New Zealand.}

\subsection{The Whakapapa of TYA}

Pre-European New Zealand Theatre traditions can whakapapa to the whare tapere, or “traditional village-based 'houses' of entertainment, storytelling, music and dance"

\footnotetext{
${ }^{20}$ Wake has continued to be a champion for TYA in New Zealand and is still a key collaborator in the TYA industry in New Zealand. She has also singlehandedly fronted the New Zealand arm of ASSITEJ for several years.
} 
(Royal 194). Whare Tapere included: Ngā Waiata (songs), Ngā Haka (dance), Ngā Kōrero (stories), Ngā Taonga Pūoro (musical instruments), Ngā Taonga-oWharawhara (body adornments), Ngā Karetao (puppets), and Ngā Tākaro (games and amusements) (Royal 201). These were community events and young people were included in the activities (Royal 197, 199). After the signing of Te Tiriti o Waitangi in 1840 and until the 1890s, the effects of colonisation led to live theatre in New Zealand being predominantly limited to amateur Western theatre forms, foreign touring companies - mostly from Australia - and the occasional brief local venture (Derby 2014). The first amateur theatre producer was James Marriott (Derby). In 1848 he staged Marcilina, which is referred to as the first original New Zealand play. The play was performed in Wellington, in Marriott's own Britannia Saloon (Derby). As the population of New Zealand grew, so did the local theatre scene. Local and international touring companies and imported theatre productions battled against the popularity of cinema, and early theatre companies such as Unity Theatre, Community Arts Service Theatre and The New Zealand Players emerged in the 1940s and 1950s (Derby). Sunny Amey ${ }^{21}$ recalls how a TIE arm of the New Players (The New Zealand Players Quartet set up by Richard Campion) toured New Zealand in the 1950s (Amey). Also, in the 1950s, Bruce Mason became prolific as a playwright, and New Zealand began to experience plays with a distinctly New Zealand flavour (Edmond).

In 1952 Neta Neale began the Canterbury Children's Theatre (which still exists today), with the intention "to let young people see plays suitable to their age and understanding presented by adults to the highest possible standard" (Harcourt 134). David Smiles set up the professional company The Children's Arts Theatre (CAT) in

\footnotetext{
${ }^{21}$ Sunny Amey. New Zealand's first professional female theatre director. She trained with drama
} pioneer Peter Slade in the UK (Amey). 
1967, which toured to over 700 schools over two years, and employed five professional actors (Derby). Smiles had worked with drama pioneer Brian Way, in Way's Children's Theatre in England, and on his return to New Zealand formed his own company based on Way's model (Minifie). Paul Minifie joined the company in 1968 and remembers his first show being The Magic Circle (The Sorcerer's Apprentice). They rehearsed for four to five weeks, opened in Whangamomana ${ }^{22}$ and then toured schools and country halls. "Production values were very high with high-quality sound, some lighting, a focus on comedic action with always two kids from the audience gathered into the show. Each show was based on a quest! There was always classical music, a foreign language and dance" (Minifie). Actor Kate JasonSmith also toured with the company in 1969:

We did 3 shows a day, five days a week, [for six months] around primary schools in the North Island, except for the Auckland region...When I was with CAT, I was in 2 different shows "The Pipes of Pan" that David Smiles wrote - based in ancient Rome, and "The Bluebird of Happiness" written by Scott Thornbury... Always lots of slapstick comedy, and highbrow jokes for the teachers. There was always a lot of educational stuff in there e.g., historical facts (JasonSmith).

Minifie recalls that some 'financial angels' helped with financing the productions, and schools collected 20 cents per child. He recalls being paid $\$ 16$ a week for rehearsals and $\$ 34$ a week for performing on the road, and that the actors were all billeted for accommodation (Minifie). When asked about other TYA groups in the '70s in New Zealand, Minifie recalls Story Theatre which was an arm of Theatre Corporate led by Raymond Hawthorn and Gillian Sutton in Auckland in the early 1970s, as well as a TIE programme at Centrepoint Theatre in 1975-1979, which was run by Sue Lister (Minifie).

${ }^{22}$ A small rural township in the Taranaki region of the North Island. 
In the 1960s, Nola Millar worked extensively with drama and classes for young people (Harcourt 132), and eventually founded the first training school for actors in New Zealand, now Toi Whakaari: New Zealand Drama School, in 1970 (Atkinson). The establishment of the Queen Elizabeth II Arts Council in 1964 saw the funding of professional theatre in New Zealand with ten regional theatres being set up in the 1960s and 1970s (Atkinson). Actor Hilary Norris recalls touring in the 1970s with The Fortune Theatre TIE Company almost continuously over four years. These shows were predominantly for primary school levels and funded by QE2 Arts Council. Norris recalls that "these were often Maori myths performed by four white actors!" as well as Eurocentric plays such as Alice in Wonderland. She recalls often performing a gruelling four shows a day to schools throughout Otago and Southland of New Zealand. The Court Theatre in Christchurch had their own TIE company that covered the north of the South Island (Norris). 


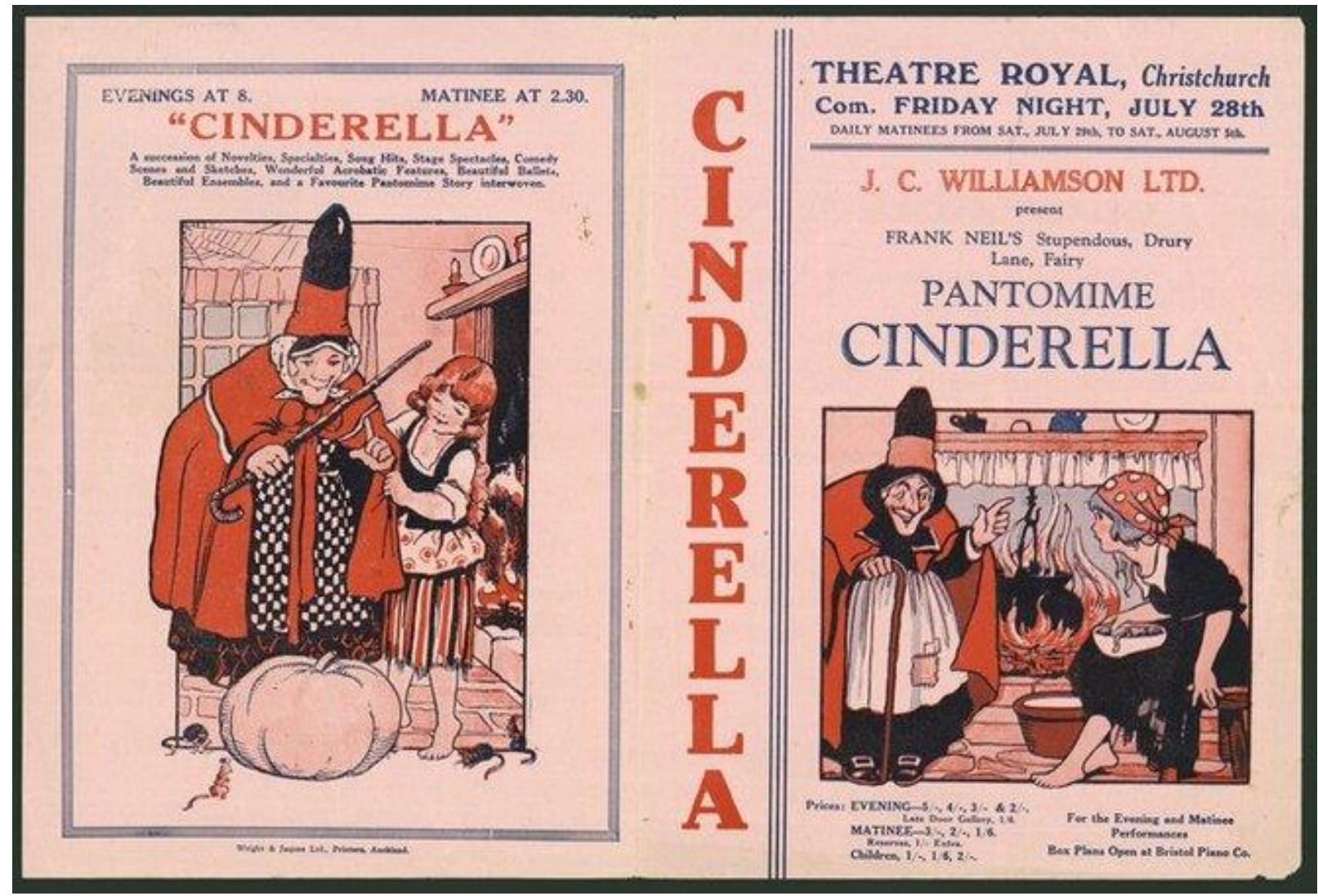

Figure 7: J C Williamson Ltd present Frank Neil's stupendous Drury Lane fairy pantomime "Cinderella". Theatre Royal Christchurch, com. Friday night, July 28th. Wright \& Jaques Ltd., Printers, Auckland [Front and back covers. 1933]. Cabot, Charles Henry, 1890-1978: [Collection of ephemera, posters and programmes. 1900-1976]. Ref: Eph-B-CABOT-Pantomime-1933-01-covers. Permission from: The Alexander Turnbull Library, Wellington, New Zealand. Lrecords/23191137

In 1990, US educational theatre academic Lowell Swortzell compiled an account of children's theatre throughout the world from 1960-1990, including a brief chapter on children's theatre in New Zealand by respected theatre pioneers Sunny Amey and Nonnita Rees. ${ }^{23}$ Amey and Rees observed that development in the area of children's theatre was "[s]poradic and piecemeal with occasional bursts of excellence" (243). They noted that since the 1960s, several professional theatres had been established and TIE often created by divisions of these professional companies (e.g. The Fortune TIE company,) - was the largest and most consistent continuing contribution to theatre for

${ }^{23}$ Nonnita Rees. Former Manager Policy Services, Creative New Zealand. Former theatre practitioner. 
children. They observed that although there was a significant improvement in New Zealand playwriting (243), work for children had largely been based on a European tradition and they saw a pressing need to relate to New Zealand's identity as a Pacific nation so that young people could gain an understanding of their current society in a global context (243). In the late 1980s, several issues were addressed through a collaboration among artists, educators and arts-policy makers who were concerned with the needs of young people, and recognised that young people should have a stake in decision-making about the programmes they would see and which they would take part in. The 1990s saw an escalation of economic factors that contributed to few groups remaining in operation due to lack of financial viability and burnout amongst members (244). Rees and Amey conclude: "In the main, quality performances of plays for children have been the responsibility of the professional theatres, which largely offer plays during school holidays. In recent years the theatres have performed a number of plays by New Zealand writers"' (246).

There has been little recorded and synthesized evidence which can be analysed to assess the overall state of TYA in Aotearoa/New Zealand since Rees and Amey's 1990 chapter. One of the few published sources is material gathered by Playmarket, the national playwriting agency. ${ }^{24}$ Each year, Playmarket publishes a review of the theatre sector, 'Playmarket Annual New Zealand Theatre', devoting a section to an area in the industry that appears to have a pressing need for attention.

In 2016, Playmarket commissioned a publication on TYA in New Zealand, which the Playmarket board had determined occupied too low an industry profile (Lynch). The publication focused on TYA in New Zealand schools and the quality of drama for young people in Aotearoa/New Zealand, including articles on theatre activities with

\footnotetext{
${ }^{24}$ Playmarket, New Zealand's playwright's agent, advisor and bookshop.
} 
young people in an educational context, such as Abby Howells's " 5 reasons why Theatre in Schools is important" (12) and "The Play in The Playground" by Kate Prior (19).

Stephen Blackburn, former Creative Producer of Capital E National Theatre for Children, and a long-time collaborator of mine, makes a strong argument for the value of theatre for young people in his 2016 article "Respect the Work". He argues that TYA is undervalued in Aotearoa, is often allocated meagre resources, and that many actors believe that children's shows are fillers, something actors may dabble in before they can be trusted with grown-up work. "Why? Because the sector doesn't truly respect the work" (Blackburn 15). Blackburn acknowledges that not all TYA in New Zealand is "a candy-floss like experience, a momentary sugar-rush" (15); however, he discusses the importance of a sector-wide change in attitudes to children as an audience if New Zealand is going to make work at the level of quality seen in other countries. Blackburn argues that in recent years, major theatre companies have declared an interest in young audiences; however, a number have often articulated this as a part of a need for their organisation to engage in 'audience development activity', which suggests a future audience, not a here and now audience. The consequences of this are scarce resources, and a commitment to quality that is sometimes non-existent (15-17). Blackburn also maintains that arts funding in Aotearoa/New Zealand is inequitable with only $3 \%$ of the bulk of the total $\mathrm{CNZ}$ budget going to arts for children under 15 years, despite children making up nearly $21 \%$ of the population (15).

In "Theatre to Schools or Schools to Theatres?" Jenny Wake discusses the benefits and history in New Zealand of theatre in schools and in contrast to Blackburn, maintains that "New Zealand theatre for young audiences is coming of age. Companies are busy creating wonderful work, drawing schools and families into theatres and presenting work overseas" (44). Wake examines the 2013 priority by CNZ to support 
arts by, with, and for young people, noting that there is no distinction by CNZ between theatre in schools and venue-based children's theatre. She discusses key TYA companies such as Ensemble Impact, Capital E, Young and Hungry, and Little Dog Barking and remarks that theatre makers are chasing 'twin goals of quality and accessibility" (47). She concludes with the view that it doesn't matter where theatre is presented as long as young people are given as many different kinds of quality theatre experiences as possible (47). It was thought-provoking to read such contrasting views about the state of TYA in the same publication. The varying opinions indicate the need for more substantial research into the status of the sector.

In 2005, the Australasian Drama Studies Journal published a special issue entitled "Young People and Performance in Australia and New Zealand". Editors Mary Ann Hunter and Geoffrey Milne state that "the volume itself makes no claim for comprehensive national coverage but is the first publication of its type for many years" (13). It includes Lisa Warrington's “Shalakazap! - Empowerment in Young People's Theatre, Aotearoa/New Zealand: An Interview with Jenny Wake of Calico Theatre", which gives a brief overview of TYA in NZ and an interview with Wake, specifically focusing on empowering children and audience participation. The article begins by stating that it is tempting to conclude that young people's theatre is the best-catered sector of the New Zealand arts community because of the diversity of lively and varied work in this sector (89). Warrington describes opportunities available such as children's theatre classes, script development, health education, storytelling, puppetry and the commissioning and touring of new works. She lists examples of many companies that are still functioning today such as Massive, THeTA, Capital E, and Te Rakau. ${ }^{25}$ This article, and Wake's article in the Playmarket Annual, also have particular relevance to

\footnotetext{
${ }^{25}$ Wake's company Calico Young People's Theatre is also still functioning today. Currently it is selffunded through its work at schools (Wake "Text message to author").
} 
me and my research. My first TYA role was in the play Shalakazap! with Jenny Wake, and since researching Wake's values and beliefs around TYA, I have realised that many of my personal philosophies, empowering children in particular, were shaped by my experiences working with Jenny.

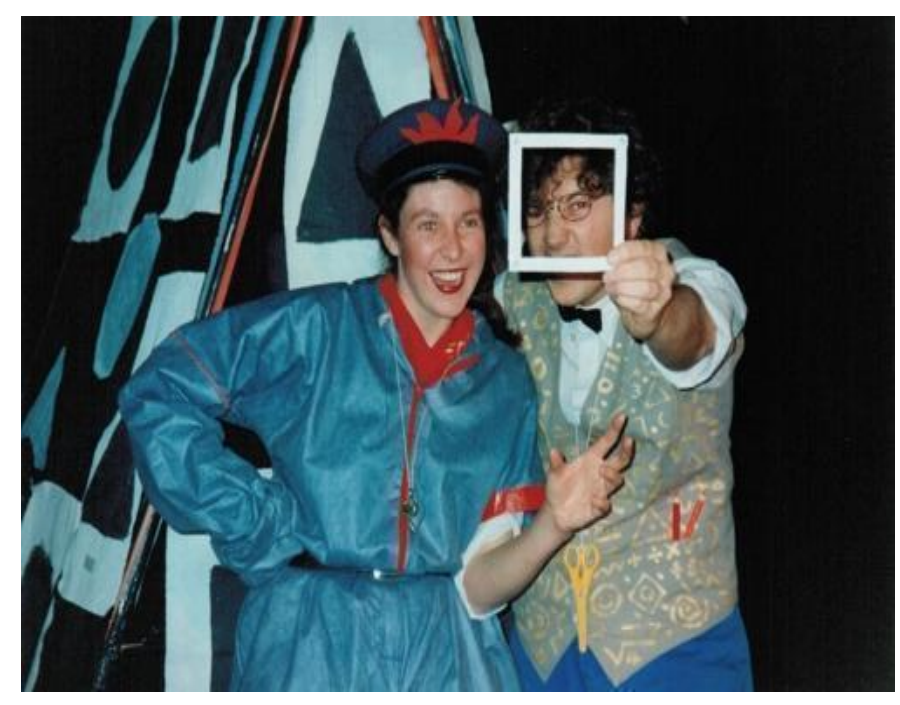

Figure 8: Shalakazap. Calico Young People's Theatre (author on left).

In "Young People and Performance in Australia and New Zealand", issue editors Hunter and Milne emphasise that the leading work in TYA places children and young people at the centre, as intelligent and critical audiences, and respected co-artists (3). Hunter and Milne also note that TYA in Australia was developed in the 1960s and 1970s as an antipodean response to British educational models, and was driven by the desire to provide young people with aesthetic experiences that engage and inspire (3). They note that New Zealand companies were different in that they were not as dependent upon English ex-pats, although Dorothy Heathcote, who was brought out to New Zealand in 1978 and 1984 by Sunny Amey to increase the awareness of drama as a medium for learning, influenced the making of New Zealand TYA work in the 1980s (Amey). 
Annie Forbes" "From Animism to Digital Animation: Puppetry in New Zealand /Aotearoa," provides a comprehensive overview of the history of puppetry in New Zealand. Puppetry is a form used both in adult and children's theatre. Forbes is a professional puppeteer whose work has been seen in a variety of production companies, including Capital E and Calico Young Peoples Theatre. She discusses the evolution of puppetry in New Zealand, from early Maori puppetry Ngā Karetao to Raymond Boyce and Geraldine Kean's The Puppet Theatre, Peter Wilson and Little Dog Barking, and her own company, The New Zealand Puppet Theatre (Forbes).

In 2012 arts educator Sally Markham was employed by CNZ to compile an internal report on young people and the arts in New Zealand. CNZ commissioned this study before developing their own policy for arts and young people. The study was conducted in all arts disciplines. In the report, Markham notes that "At first glance, a snapshot of what is on offer in New Zealand for children and young people indicates there is a great deal happening "(3). However, on closer examination, she noted the emergence of several factors and trends. Most relevant to my research enquiries in TYA are the following issues:

[An] uneven (in terms of quality, quantity and variety) provision across the arts, education and community sectors. Training for arts practitioners working...with children and young people is patchy and at best most often "learned on the job." Quality control of arts provision for children and young people therefore is mostly maintained through reports to funders rather than as a result of evaluation against established guidelines and strategies...Most arts companies and organisations provide arts experiences for and with children and young people that relate to their main bill programming or activity. Only a few have a profile in work by young people or present work with a strong youth voice. (3) 
Markham summarised that " $[t]$ here is currently a significant gap in leadership in the area of arts provision for children and young people in New Zealand" (48), and recommended that $\mathrm{CNZ}$ develop a forward-looking policy, by considering international models that work in collaboration with social and education agencies. (49). Following this report, CNZ decided to prioritise arts by, with, and for young people, as a leading policy for the period 2013-17 (Rees, Personal Interview). Markham's 2012 report is one of the few extensive compilations of theatre by/with and for young people in New Zealand, and has proved a reference point for my own research to assess the current ${ }^{26}$ status of TYA.

For the five years between 2013 and 2017, CNZ set arts by, with and for young people as a priority across the Toi Uru Kahikatea (Arts Development) investments programme and Arts Grants programmes. It was preceded by a National Arts Conference funded by CNZ that was themed Arts by, with, for Young People, held in Auckland in 2013. The object of the conference was to provide New Zealand's Arts Sector with an opportunity to focus on: good practice; increased participation; the development of young audiences; promoting the value of arts education; arts activity; and engagement with leaders in related sectors (Rees, Personal Interview). In 2017, after five years of focused policy on arts by/with/for young people, a summary of the findings was reported by Rees. She stated that there was now a reasonable level of delivery to arts by, with and for young people across CNZ's funding categories, and concluded that prioritising this policy across all art forms signalled to the sector the importance that Creative New Zealand attaches to arts by, with and for young people (Rees, Personal Interview). CNZ again collated information about the range of activities by, with, and for young people, noting that the differentiation between types of activity is in line with best international practice for youth arts. Important gaps were identified

${ }^{26} 2019 / 2020$. 
in the areas of by and with young people, as well as in the regional delivery of theatre $b y$, with and for young people. The report recommended that priority of the arts by, with and for young people be discontinued, but that Creative New Zealand maintain its support through Arts Grants, Quick Response, and the Toi Kahikatea and Toi Totara Investment Programmes (Rees, Personal Interview). The funding of TYA companies in New Zealand and CNZ's role in funding is discussed in Chapter Five.

Catherine Swallow's master's thesis, Faces of the Captives (VUW, 2012), specifically addresses children's theatre within a New Zealand context. Swallow compiles extensive research on the differences between child and adult audiences, and explores the concept of double knowledge - the extent to which children comprehend pretend and real qualities within a play (43). She discusses the suspension of disbelief within a child audience, and the emotional involvement of children within a theatrical setting, exploring three case studies. Although two of the case studies were New Zealand TYA works, Songs of The Sea which I directed for Capital E National Theatre for Children in 2012 - her thesis has not investigated TYA as a genre within Aotearoa/New Zealand, and has not examined the significant differences between theatre by/with and for children, particularly the methods by which quality TYA work is developed in Aotearoa/New Zealand. 


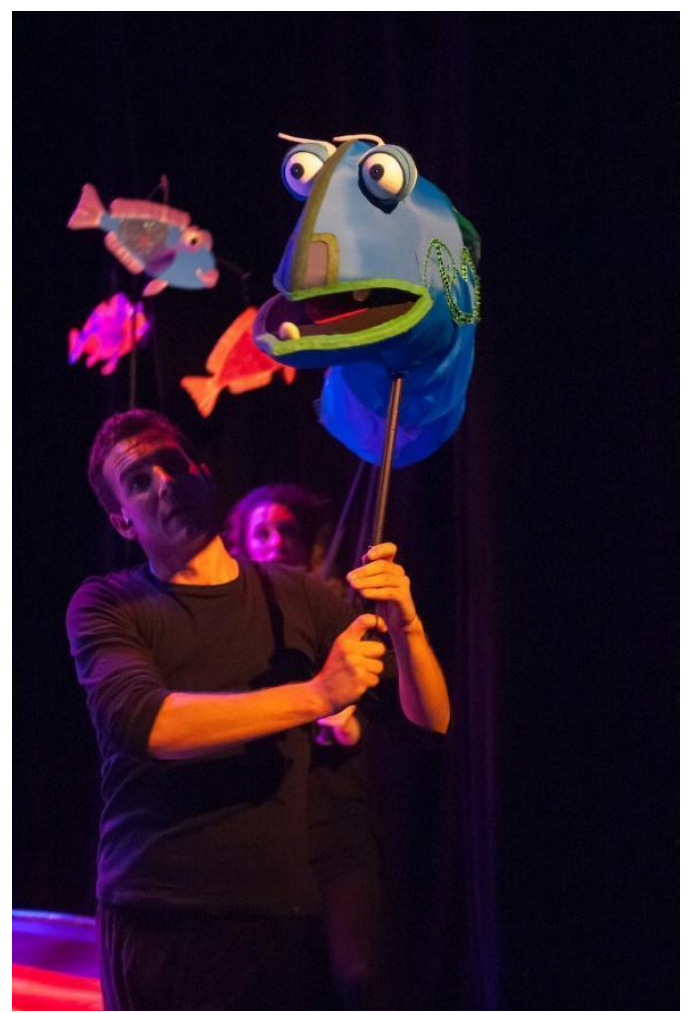

Figure 9: Songs of The Sea. Capital E National Theatre for Children.

\subsection{The Intersect between Theatre and Education}

Because of the intersect between theatre and education in TYA, it is also important to note the place of the performing arts in The New Zealand School Curriculum. It currently includes four arts disciplines: (dance, drama, music and visual arts) while creative writing is part of the English learning area. Years 1-8 include all four disciplines; years 9-10 include at least two; and students in years 11-13 can choose to specialise in one or more arts subjects (Pollock).

When I trained as a primary school ${ }^{27}$ teacher from 1990 to 1994, the Wellington College of Education was dedicated to educating well-rounded teachers in all areas of the curriculum. We had classes in individual arts subjects and the arts were valued

${ }^{27}$ For children aged 5-12/13 
highly. Teacher's Colleges in the 1960s-80s in particular seemed to be a hotbed of artistic talent, nurturing the careers of many of New Zealand's pre-eminent theatre practitioners (such as Sunny Amey, George Webby, Jan Bowell, Ralph McAllister, and Laughton and Jenny Patrick.) Many of these people returned to teachers' colleges and taught emerging teachers - such as myself - who were able to pass on this knowledge to our own students, re-enforcing the value of the performing arts. In 2005, the Wellington College of Education (formerly Wellington Teachers College) merged with Victoria University (Wellington Faculty of Education). This merger saw a change in pre-service teacher education.

Each New Zealand University has its own training programme. At Victoria University of Wellington, student teachers need to have a Bachelor's degree and then participate in a one-year course for primary or secondary teaching. ("Teacher Education") They can study either in a graduate diploma or in a master's degree. Victoria University lecturer in primary and secondary drama, Delia Baskerville, describes current art teacher education: "For primary teacher education in the arts graduate diploma and master's courses, students are limited to one two-hour workshop in each of the four arts disciplines (dance, drama music and visual arts). Students are then able to choose one arts discipline for a further six hours of training" (Baskerville). However, in 2020, due to teacher's council requirements, these time allocations and the nature and delivery of current arts education will change. New courses and more hours will be allocated for each discipline (dance, drama music and visual arts) in the primary arts education courses. Baskerville also explains the secondary performing arts teacher education course:

In our one-year course, secondary pre-service teachers enter the performing arts course with a specialist subject (dance or drama) and participate in two papers, 
one each trimester. They participate in six, three-hour weekly practical workshops and, after a teaching experience, two weeks of on-line study, this occurs for both of their secondary performing arts trimester papers. Currently, there is not an opportunity to study dance or drama for secondary school teacher education on the master's education course. (Baskerville)

The vast difference of the teaching of arts in primary education from the 1960s-1990s to 2020 is notable, which undoubtedly must contribute to an under-teaching and undervaluing of the arts. Professor Peter $\mathrm{O}^{\prime}$ Connor debates the loss of arts in schools, over the past ten years in particular, in his article "Teachers Hope to End 'Near Death' of Arts in Schools":

Visual arts, music, dance and drama, the lifeblood of a creative education have been systematically dismantled from schools. National standards in literacy and numeracy narrowed the curriculum in primary schools and the biggest casualty was the arts. Although the standards have gone in name, their ghost still hangs over classrooms restraining both what and how things are taught and measured. The arts either totally disappeared, or were relegated to optional "what do we do on a Friday afternoon". ( $\mathrm{O}^{\prime}$ Connor)

$\mathrm{O}^{\prime}$ Connor argues that overseas evidence has proved that students in arts-rich schools do better than students at schools that focus on numeracy and literacy and suggests that, "the cost for the near-death of the arts in school is high... When schools deny children the arts, they deny them their imagination" (O'Connor). In June 2020 (postCOVID 19 lockdown that included the closure of New Zealand theatres) the New Zealand Government announced a funding increase for the Creatives in Schools 
programme ${ }^{28}$ to help boost the arts in schools and keep creatives in work, stating "Particularly in the wake of COVID-19, the value of creative learning experiences cannot be over-estimated." ("Funding Boost") Optimistically the new extra hours for arts subjects introduced into teacher training in early 2020 and the extra funding and acknowledgement by the government, will lead to more confident teaching and a greater valuing of the arts in the classroom and New Zealand society.

\subsection{Summary}

My 2019 survey- as explored in Chapter Four - identified a variety of creative work happening in the field of TYA in Aotearoa/New Zealand. Main stage theatres, Circa Theatre in Wellington and ATC in Auckland for example, are programming TYA on an annual basis. Companies such as Trick of The Light Theatre Company ${ }^{29}$ are beginning to receive international recognition for their work. New companies, such as Cubbin Theatre Company: Theatre for The Very Young, ${ }^{30}$ are also receiving national funding and recognition.

However, as this review of literature demonstrates, there is still very little in the way of scholarly research on TYA in a New Zealand context. There is a lack of documentation of works to date, the archiving of TYA performances is minimal, and shows are rarely archived professionally, although many scripts are curated and managed by Playmarket. There is no complete published overview of work from the 1960s to the present day. Pertinent to my thesis, there is also meagre research and analysis into the methods of making TYA, as well as the ways that young people receive and respond to TYA. Because of this scarcity of research, I have had to look to

\footnotetext{
${ }^{28}$ A partnership between schools and professional arts practitioners ("Creatives in Schools").

${ }^{29}$ A Wellington-based company that regularly tours internationally. ("Trick Of The Light Theatre").

30 A Christchurch-based company specialising in work for children under five. ("Cubbin Theatre.").
} 
international findings to frame and support this study. I propose that New Zealand TYA connects firmly with ITYARN ${ }^{31}$ and continues to strengthen its relationship with ASSITEJ, so that New Zealand practices and scholarship be connected with global practice. Furthermore, this lack of a New Zealand specific enquiry into the field of TYA signifies the importance of this research, and validates the intention of making a valuable and new contribution to the field. The following chapter examines my creative project, the devising and research methodologies utilised as well as the theoretical frameworks that I employed to investigate TYA in Aotearoa/New Zealand.

${ }^{31}$ In December 2020 I became a member of ITYARN and am subsequently now the New Zealand representative. 


\section{Chapter 3.}

\section{Research Methods and Theoretical Frameworks}

For the creative component of this thesis I designed a project that employed my skills as a director and teacher, to best investigate my research enquiries into the way TYA is made, perceived, valued, and measured in Aotearoa /New Zealand. This chapter begins with an outline of this project and the THEA 311 course at Victoria University that supported it. Included is a timeline of the three months spent exclusively on this project. Following that is an examination of the devising and research methodologies used and the theoretical frameworks that supported this arts research project.

\subsection{The Creative Project}

The project brought together participants from across several institutions and generations from July to October 2017. The goal was to facilitate a group of youth (the students) from a senior-level undergraduate theatre course (THEA 311: Collaborative Production) to create two original theatre plays, with two classes of school children (the children), for a public audience of young people.

THEA 311: Collaborative Production saw nineteen 300-level university students accepted for the course offered in Trimester Two of 2017. I led a devising process with the students in the making of two original theatre works for young audiences. The parameters of the project were as follows: the group were to produce two original plays of approximately 35-45 minutes in length; each play would be targeted at a specific age group of children; the content and form of each play would be informed by research on 
quality TYA, and by the interaction and collaboration of the university students with a sample group of their intended audience.

The THEA 311 students made three visits to two different schools during the process. Te Aro School is a full ${ }^{32}$ primary school in central Wellington, a multicultural school with around 221 children from 36 different countries ("Te Aro School"). The class of twenty children THEA 311 collaborated with - Ruma $\mathrm{Ti}^{33}$ - were aged five to six years. Tawa School is also a multicultural full primary school. Situated in a suburb fifteen minutes north of central Wellington, with a roll of approximately 340 students ("Tawa School”). THEA 311 collaborated with Room Four, a senior class of 40 children aged $10-12$ years.

The initial stage of the project involved the THEA 311 students interacting with the children, talking with them and engaging in a series of drama games as well as some unprompted creative play in the playground. Through my direction, students subsequently employed a combination of devising methodologies, outlined below, and began to create the plays. Two weeks before the scheduled performances, the students presented the plays as 'works in progress' to the children. The children provided detailed feedback about the work, which then informed the next stage of making for the students. The next two weeks were spent back in the rehearsal room, refining and remaking the plays, which were then presented to a wider public audience over five public performances. During the final stage of the process, I gathered both written and oral feedback from the students involved in the making process, and the children that

\footnotetext{
${ }^{32}$ From Years One to Eight.

${ }^{33}$ Ruma is the Te Reo Māori word for room. Ti is a type of tree. Each of the classrooms at Te Aro school are named after a native New Zealand Tree.
} 
had been involved in the making of the plays, as well as young people who attended the plays but who were not directly involved in the making.

The bulk of my exegesis for this thesis comprises a comprehensive analysis of this creative project. It includes a detailed description of the building of the ensemble, the devising work in the rehearsal room, the preliminary and evaluative work with the children of Te Aro and Tawa schools, and an analysis of the final productions. Throughout the project drawing on arts research methodologies, (such as systematic reflection, video blogging and recording and reviewing), I recorded and analysed each rehearsal through the method of daily blog posts, accompanied by video footage and photography. The interaction with the school children was also recorded, and a series of interviews, feedback reports, and drawings were collated and analysed. The feedback discussions with the children were filmed, and the older children gave written and verbal responses to the work. The timeline below describes the key steps in the 14-week process.

\subsection{Timeline}

\begin{tabular}{|l|l|l|}
\hline Week/s & Date & \\
\hline 1 & 17 July 2017 & THEA 311 Begins \\
\hline 2 & 24 July & THEA 311 visit Room \\
& Four at Tawa School \\
& 26 July & THEA 311 visit Ruma \\
& & Ti at Te Aro School \\
\hline
\end{tabular}




\begin{tabular}{|c|c|c|}
\hline 3-6 & $\begin{array}{l}31 \text { July 2017- } 24 \text { August } \\
25^{\text {th }} \text { August }\end{array}$ & $\begin{array}{l}\text { In-class devising. } \\
\text { Class splits into two } \\
\text { groups. } \\
\text { THEA } 311 \text { becomes } \\
\text { Paper Bag } \\
\text { Productions (In The } \\
\text { Attic) and } \\
\text { Illuminations } \\
\text { (Moonlight). }\end{array}$ \\
\hline $\begin{array}{l}7-8 \\
\text { (Mid-tri } \\
\text { Break) }\end{array}$ & 28 August $2018-8^{\text {th }}$ September & $\begin{array}{l}\text { Intensive devising } \\
\text { workshop with Dave } \\
\text { Brown }\end{array}$ \\
\hline 9-10 & $\begin{array}{l}11 \text { September-19 September } \\
20 \text { September }\end{array}$ & $\begin{array}{l}\text { In class devising } \\
\text { In The Attic } \\
\text { performed to Room } \\
\text { Four Tawa School at } \\
\text { Victoria University. }\end{array}$ \\
\hline 11 & 25 September & $\begin{array}{l}\text { Moonlight performed } \\
\text { to Ruma Ti Te Aro } \\
\text { School at Victoria } \\
\text { University }\end{array}$ \\
\hline
\end{tabular}




\begin{tabular}{|c|c|c|}
\hline & $\begin{array}{l}28^{\text {th }} \text { September } \\
29^{\text {th }} \text { September }\end{array}$ & $\begin{array}{l}\text { Students return to Te } \\
\text { Aro School for } \\
\text { Feedback } \\
\text { Students return to } \\
\text { Tawa School for } \\
\text { Feedback }\end{array}$ \\
\hline 12 & 2 October -9 October & $\begin{array}{l}\text { Both groups } \\
\text { incorporate } \\
\text { children's feedback } \\
\text { and continue } \\
\text { working. }\end{array}$ \\
\hline 13 & $10,11,12,13,14$ October & $\begin{array}{l}\text { Public Showings of } \\
\text { Moonlight and In The } \\
\text { Attic }\end{array}$ \\
\hline 14 & 18 October & $\begin{array}{l}\text { THEA } 311 \text { finishes } \\
\text { Debrief with } \\
\text { Students. }\end{array}$ \\
\hline & 27-30 October & $\begin{array}{l}\text { Interviews with } \\
\text { THEA } 311 \text { students }\end{array}$ \\
\hline & 9 November & $\begin{array}{l}\text { Kerryn to Tawa } \\
\text { School and Te Aro }\end{array}$ \\
\hline
\end{tabular}




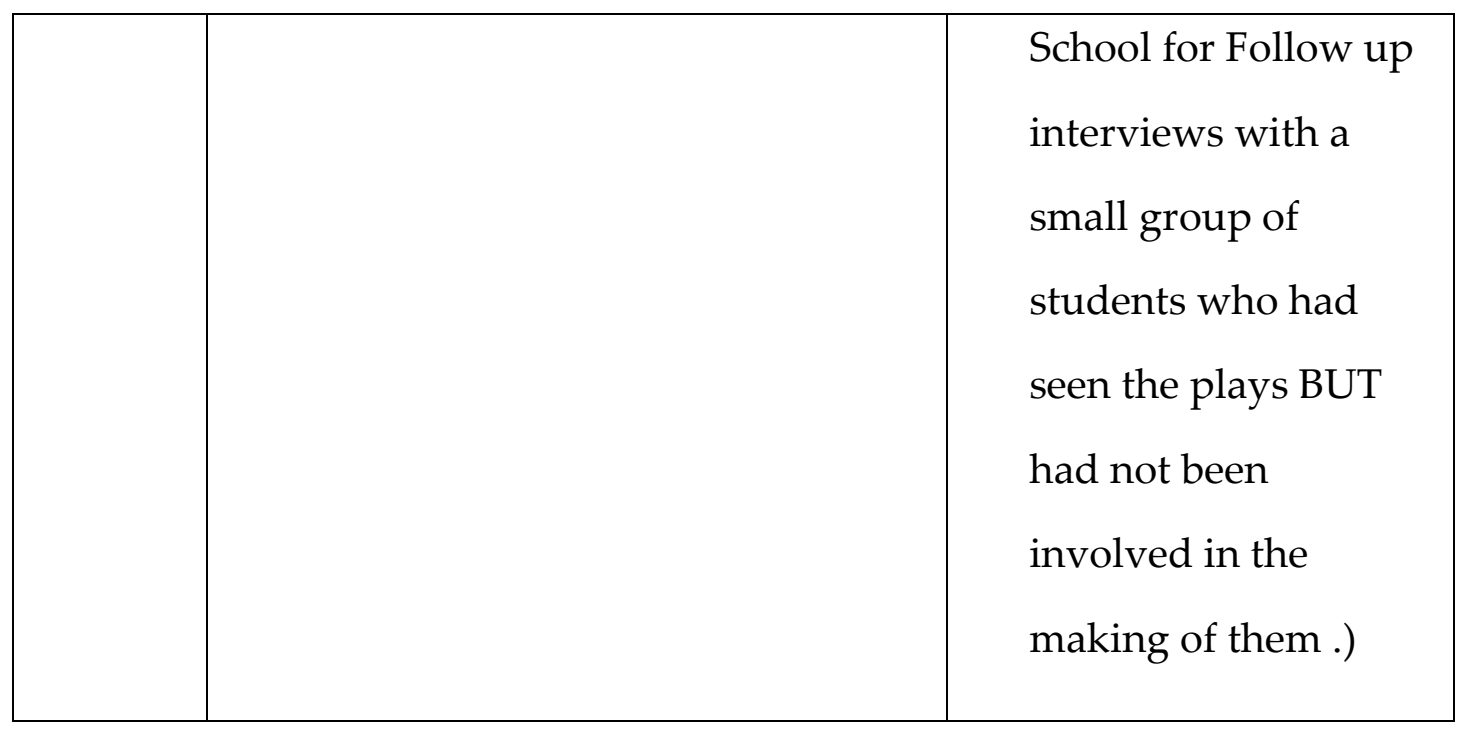

Figure 10: Timeline of The THEA 311 Project.

\subsection{The Approach - Devising Methodologies}

As outlined in chapter two, devised theatre is a collaborative method of making theatre that creates a performance from scratch, without a pre-existing script (Heddon and Milling 3). I drew on a variety of devising models for my project, which led to the creation of my own model of devising with young people, for young people.

Each new devising process begins uniquely, and from there the work is developed collectively. Over many years of making and teaching devised theatre, I have experimented with a variety of methods, frameworks, and strategies to strengthen this often-challenging process. These include site-specific devising (e.g. My Shout, Adrift), historiographical devising (Sniper, Black November), and devising with a playwright in the room (Pandemic). Significantly, I have discovered the importance of incorporating parameters for a group early on in the process. Having a framework to operate within eliminates some of the panic that comes from having too many possibilities, thoughts, and ideas that can cause a group to become paralysed with indecision. DevisingDirector Jessica Swale describes this as "the feeling of dread as the yawning chasm of 
rehearsal time opens up in front of you, unplanned and empty" (xxviii). To help alleviate panic within my devising practice, I encourage two fundamental requirements based on the work of devising pioneer Alison Oddey. The first is for the group to identify the what around which they want to create the work. The creators are encouraged to begin with a passion or a desire to say something about, for example, politics, identity, cultural appropriation, relationships, gender, or climate change. This can be in the form of a question, a need to make sense of an idea, or a problem. According to Oddey, this starting point is what encourages further investigation through a variety of processes and close enquiry (42). The second fundamental requirement is to closely question why the group wants to make a piece of theatre about a particular topic. Articulating the what and the why of the process at the outset helps guard against self-indulgent devised theatre. Swale cites Mike Leigh' ${ }^{34}$ warning about the "dangers of setting out to create 'art'; an objective which often leads to rather pretentious and self-indulgent creations" (xxvii) to support this idea, and suggests that good devised theatre should have a sense of truthfulness and integrity (xxvii). Alongside these fundamentals, THEA 311 sought to discover a framework to devise within and consequently explored the following devising models.

\subsubsection{Jessica Swale's Five Stages of Devising}

Swale asserts that devising is a constant process of expansion and contraction, and her model of five stages in the devising process provided a useful and clear framework for the students to create within:

Stage One: Preparation, in which we prepare to jump off the edge;

Stage Two: Generation, in which we create an array of starting points and ideas;

${ }^{34}$ Renowned film director, who uses devising to create films. 
Stage Three: Exploration, in which we develop and expand our ideas;

Stage Four: Distillation, in which we selectively develop and hone our ideas and watch the play start to emerge; and,

Stage Five: Presentation, in which we move from the rehearsal room to the wings.

(Swale xxx-xxxi)

Swale aims to encourage devising through collaboration to create work that is organic, original and dynamic (xv). Her method is flexible enough to allow for play and imagination, but it also provides an adequate structure that allows devisors to feel confident that the process is moving forward in an organised way.

\subsubsection{The PaperBoats Seven Creative Principles}

The PaperBoats seven creative principles were articulated at the beginning of the project by Dave Brown, and conceived from his wealth of experience as a theatre-maker for young people in Australia. Although the PaperBoats project was initially aimed at creating work specifically for early childhood audiences, we discovered that the creative principles were easily transferable for use with an older age-group. The seven principles, outlined below, were adopted to varying degrees by the THEA 311 class.

Principle One: "The Animating Framework": is the evolving pool of thoughts, ideas, resources, and activities that underpin each of the PaperBoats projects. Each project evolved from the same development or germinal idea. The germinal idea of "Tw2 $2 \mathrm{o}^{35}$ of a Kind- of exploring twoness in every which way-lines that connect AND lines that divide transcending differences and the power of two" ("The

35 This is a phrase specific to the PaperBoats project. 
PaperBoats"), was conceived by Dave Brown and utilised to generate a collection of ideas via a set of tasks, thought experiments, provocations, improvisation, and games. From this collection 'golden moments', or small scenes, were collected that resonated with the group. From combining a series of these golden moments, 'meaning' began to emerge, and consequently a narrative and overall concept of the piece was retrospectively created.

Brown describes this as 'retrospective meaning-making.' Thus, the meaning of the piece was generated from the creation of moments devised by the actors, as opposed to the meaning being imposed on them by a director/playwright. This is explored further in Chapter Six.

Principle Two: “Limiting the Palette": This principle provided a clear way of introducing parameters into the devising process. Brown hypothesised that introducing limitations, specifically in the type of props used, would enable devisors to focus on the exploration of just these specific props. PaperBoats American collaborator Professor Brant Pope discusses this in detail in his article about Brown's project, Theatre for Early Childhood: The Work of Dave Brown, suggesting that "[1]imiting the palette provides the parameters for the creative play consistent with that governing idea. Limitations on space and material serve the same function as a specific premise for an improvisational exercise" (Pope 13). Brown suggested a palette of four props: receipt paper, bowling balls, cardboard boxes, and hoops. The THEA 311 students found cardboard boxes and the receipt paper the most useful props to experiment with. 


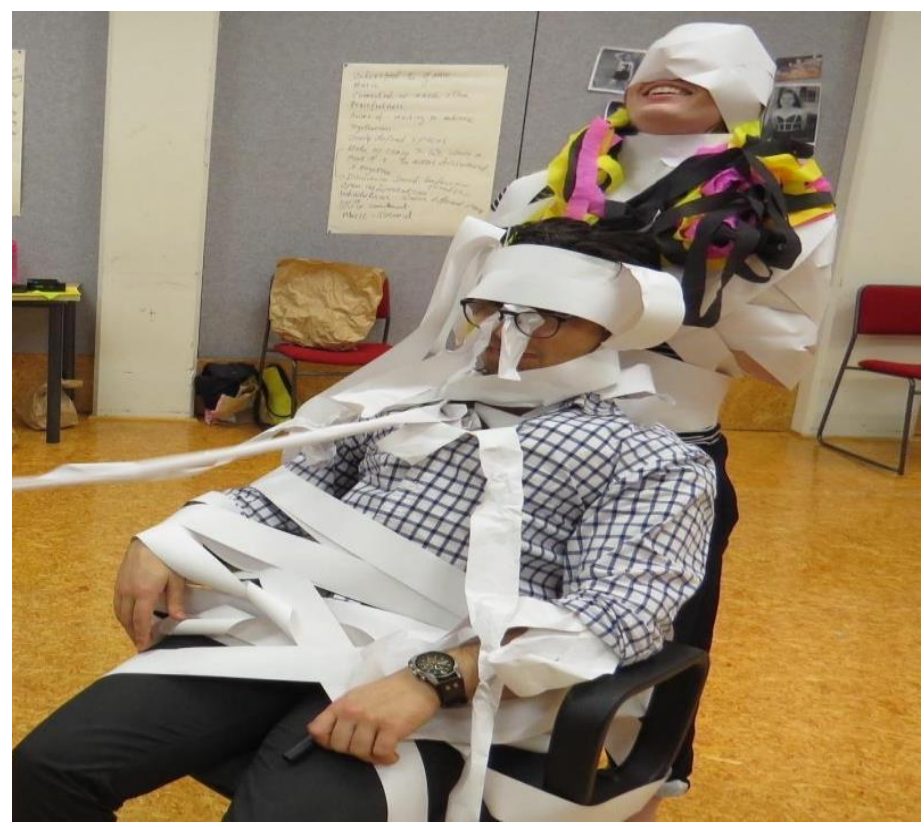

Figure. 11: THEA 311 students experiment with receipt paper.

Principle Three: "Whimsy and Logic": Whimsy is expressed by Brown as being the generator of ideas with logic being the organiser of these ideas. Principle Three's focus on whimsy seeks to mimic the creative play of children (Brown, "Principles"). This was the principle that guided the way we created material.

$85 \%$ of the material that comes from whimsical play ends up on the cutting floor. there's a lot of waste. Finding ways to manoeuvre the interesting content (the $15 \%$ ) into meaningful and compelling material is a rigorous process of sifting out the "gold" and forging it into something beautiful. (Brown "Principles")

Principle Three's logic was subsequently achieved by arranging these whimsical moments into a meaningful structure. 
In our project the students were eager to play and had no trouble creating a multitude of moments of whimsy through their playful collaborations. I helped guide them through the logic-making stage, by acting as a dramaturg.

Brown's aspiration to create extra-ordinary performances is supported by his Principle Four: "Slow Brewing:"

the process must be given time... time for the whimsy of open-ended play, tinkering and slow-brewing invention. Time for obsessive immersion. Time for shaping dramatic tension, building depth and layers of meaning. Time for the logic of dramaturgy. Time for loving attention to detail and meticulous rendering. (Brown "Principles.")

The ideal is to have an extended amount of time to play and create material, before defining and presenting the piece. This was a principle that was in direct conflict with our university schedule, and I noted that sometimes the pressure the students felt to create a product within this specific timeline impacted the generation of genuine whimsical and playful moments.

Principle Five "Collaboration, Co-creation, Participation": This focus on collaboration, co-creation, and participation relates to the wider PaperBoats model of the sharing of ideas between different communities. We interpreted this principle as a collaboration not just with the PaperBoats community and Dave Brown, but integrally as collaboration, participation, and co-creation with our two groups of children.

Principle Six "Modularity": This principle is the key organising structure for the individual PaperBoats performance groups. Brown intended that the different 
communities make a series of modules that could be easily shared with other groups (Brown "Principles.") Instead of creating a series of two to five-minute modules that could easily be shared with other groups, THEA 311 were inspired to create two full plays. We did however create a series of small modules in our generation and exploration stages that led to the final full plays.

Principle Seven: "Artistry": focuses on how the method of making can contribute to each group creating and delivering extraordinary performance experiences (Brown, "Principles"). This principle relates to the concept of quality which is discussed in Chapter Three. Being able to define quality, and what constitutes good, great, or amazing work, became an ongoing interrogation within my devising process.

The introduction of two different devising models highlighted to THEA 311 that a variety of methods can be employed during a devising process, but ultimately it is up to the group to discover which one, or which combination, suits their needs best. Swale herself suggests that her "process is merely a suggestion, a starting point. It is a method I have discovered in my own work; I find it useful, but it is by no means meant to be definitive" (xxix). Significantly, by exploring and experimenting with different methods, each group in THEA $311 \mathrm{did}$ form a unique way of working, and just as importantly they realised the importance of having a method of working: "For me, the key to successful devising is decision-making: set yourself parameters; plan ahead; do not be scared to experiment, but ensure you allow sufficient time to work on detail" (Swale xxix). Oddey also highlights the importance of having a structure to the rehearsal process. "The devising experience is often contradictory, unclear and confusing. I need a structure that allows me to clarify, verify, and understand where I am going with the process" (Oddey 167). The devising methodology utilised in this arts research project was a combination of Oddey, Swale, and Brown's approaches to 
creating theatre. They were examined and synthesised to provide a comprehensive and unique model of devising, that the class of THEA 311 utilised for the creation of their two plays. Oddey provided fundamental questions and exercises. Swale's method of expansion and contraction within her five-stages of devising framework allowed the group the freedom to play but also gave them a clear sense of structure. Dave Brown's seven creative principles provided solid parameters for the group to work within, and aligned them with the other PaperBoats groups. By weaving together these different models of devising and using my previous experience in devised theatre, I was able to establish an effective and unique model for creating theatrical work by young adults for children.

\subsubsection{Collating Material and Systematic Reflection}

The class of THEA 311 created a volume of material using Oddey, Swale, and Brown's approaches to devising. Video proved to be a highly effective way to record and collate this material. We used two cloud-based storage platforms for curating the work. The Evernote Platform, open to Dave Brown and the other PaperBoats Collaborators, as well as the class, was used as a specific recording tool to blog daily about the process. Each night I would analyse the day's rehearsal and link my reflections to the videos and photographs taken. Having a shared Google Drive account for the class meant that we could all easily access material, and later in the process this became a highly effective way of making script changes and ensuring that we were all working off the same draft of the script.

The model of idea-sharing via a digital platform is integral to Brown's PaperBoats concept, which operates as a platform that pioneers new ways of connecting and creating for TYA practitioners. Systematic reflection during a working process is also a key component of practice-based/practice-led research. In her 2006 guide to practice- 
based/practice-led research, Linda Candy suggests that keeping a written record, either online or in a handwritten notebook is important, but so too is designating time for reflection, recording reactions and thoughts (8). The method of writing daily about the devising process meant that as director/facilitator I was constantly having to analyse and critique each stage of the work. I would comment on what had happened in the rehearsal and ask further questions, for example:

I love the way this group chose not to use too many words and physicalised the story in a simple and stylized way. The use of percussion also was simple and effective. I thought that this was a small piece that could potentially be explored, in particular the moment of the pen being gifted and received, was it a gift or a challenge.? (Palmer "Re: Thea 311.15 Day Seven Blog)

In my previous devising work, this type of analysis would be done in a much less formal and detailed way. I had created a similarly vast array of material, but by not analysing and examining further, the material was not always developed into elements that could be utilised in the final product. Thus, the process of systematic reflection, analysis and critique during this early phase served to better ensure more usable moments evolved from the initial provocations.

\subsection{Visual-Based Arts Workshops}

Collecting and analysing the Tawa and Te Aro School children's responses to 'works in progress' performances of each play was an integral part of the research. As a guide, we adapted ideas from Matthew Reason's: Visual-Based Arts Workshop (Reason, "Young Audiences" 47-58) and Talking About Theatre techniques (Reason, "Young Audiences" 154-166). Because young children are in the process of developing both their language 
skills and emotional self-awareness, Reason has generated a unique reception-based theory to examine the way children view and respond to theatre:

My research into young audiences is interested in examining their experiences of theatre as theatre, in the meanings, memories and sensations that they take away from the performances, and in how they can become active spectators who have a sense of autonomy over their experiences and their opinions (Reason, "Young Audiences").

Reason's ongoing research and, in particular, his book The Young Audience (2010), is dedicated to researching children's lived experiences of theatre. He states that very little field-based qualitative research exists that illuminates what the actual theatre experience means to young people (ix). There is much anecdotal evidence, but Reason's research and methodology focuses on children's lived experiences in particular: the meaning they construct from theatre and the stories they tell (Reason, The Young Audience 46). "In the clamour of voices advocating the importance of theatre for young people, the voice and the perspective of the children themselves is missing" (Reason, The Young Audience ix). Considering children as a valid and integral part of the theatremaking process seems to be a vital step that needs to be studied if we are analysing the genre as a whole.

Reason's visual arts-based tools, developed to investigate the nature of young children's experiences of live theatre, was a useful guide for us to access during our research with the younger children at Te Aro school. Reason uses participatory artsbased workshops as his central methodological tool for young children: where children are asked a series of questions, and asked to draw pictures of and discuss their responses to a play. Children are encouraged to draw or paint what they remember 
about a theatre performance, which can serve as foundations for conversation between researchers and children. Reason believes that engaging children with theatre involves more than just sitting down in front of a production; it also involves a responsibility to contextualise the experience (The Young Audience xiii). I based my qualitative audience research methods on Reason's methodology; in particular, the interview methods and questions for children which are grounded in his model of aesthetic enquiry, that can be used by children and teachers in response to a theatre performance. Reason explains the motivation behind his visual-based arts method:

Approached cold by a stranger and asked to talk about their experiences of art or theatre, most people would be a little hesitant, unforthcoming, unengaged, perhaps even suspicious. With children these elements are enhanced, and their likely answers would be short and lacking detail. The methodology adopted for this project [Visual-based Arts Research] therefore, was motivated by the need to find a way of facilitating and continuing a conversation with young children about their cultural experiences that would be engaging, reassuring, and appropriate for their levels of understanding, their interests, and their particular skills and abilities (Reason, "Did You Watch the Man or Did You Watch the Goose?" 338).

The object of Reason's methodology is to provide a structure which enhances discussion. Drawing is used as the tool to engage and interact with children, the drawings become objects to initiate and mediate conversation through abilities (Reason, “'Did You Watch the Man or Did You Watch the Goose?"339).

For the older children from Tawa School, we initiated a series of age-appropriate written and verbal questions. These were guided by Reason's "Talking about Theatre" 
model which was developed as a method of aesthetic enquiry for children and teachers to enhance discussion after a theatre performance (Reason, The Young Audience 151-152). The specific questions used within this research and based on Reason's model, are outlined in Appendix C.

A fundamental component of my research is how we can create TYA that is genuinely accessible for children, and to identify practical strategies to engage them. For this to happen it was logical to look at how children respond to theatre. The participatory arts-based workshops and questions were implemented during our postshow discussions and school visits with both the Te Aro and Tawa School children. The results of these discussions are explored in detail in Chapters Eight and Nine.

\subsection{Autoethnography}

As a theatre practitioner with 25 years of directing experience in TYA, it is appropriate and essential that I use my personal experience and stories to frame this research. The use of stories as opposed to theories in academic research is an example of distancing by academics from the traditional (and arguably narrow) scientific research paradigm: "Autoethnographic stories are artistic and analytic demonstrations of how we come to know, name, and interpret personal and cultural experience" (Ellis et al.1). Ellis et al. maintain that an autoethnographic approach uses a researcher's personal experience to describe and critique beliefs, practices, and experiences, as well as valuing the researcher's relationships with other people (Ellis, et al. 2). As a theatre practitioner, stories are my key method of entertaining, educating and challenging an audience. Moving from practitioner to practitioner-researcher, the analysis of my own practice and work as a teacher lends itself to an autoethnographic approach that acknowledges subjectivity, emotion, and my own influence on the research (Ellis et al.3). Ethnographic researchers retrospectively and selectively write about epiphanies and use their skills to 
analyse these experiences (Ellis et al.4). It is this analysis that is key. For this project I have drawn on tenants of autoethnography, in particular: Interactive Interviews - indepth and intimate understanding of people's experiences (Ellis et al 6-7); and Community Autoethnographies - the experience of researchers-in-collaboration, to illustrate how a community manifest particular social or cultural issues. (Ellis et al. 7) There is also an element of Personal Narrative - where I discuss the learnings I have made as a theatre practitioner to frame and debate epiphanies and challenges I discovered during my project (Ellis et al.7). The belief that auto-ethnographers value the need to write and represent research in evocative and aesthetic ways suggests that it is a valid methodology for arts research, in particular, theatre (Ellis et al.11) I have chosen to use elements of autoethnography in my research as I am dealing directly with personal epiphany, experience, and the experience of communities - in this case the experiences of the students, the children, and the TYA sector. I have placed myself at the centre of this research as a director of devised theatre. This makes me the subject of the research alongside the children and the students. This approach of using and analysing the personal experiences of the people involved in the project to understand their cultural experiences, meant that autoethnography was an appropriate research method to apply to the research.

\subsection{Arts Research}

To support the use of performance as my key method of investigation and knowledge production in this research, the predominant framework for both my theoretical framework and methodological approach is the evolving arts research paradigm. Arts Research (AR) bridges the terrain of theory and methodology in this thesis. Scholarly research conducted through performance is still a relatively new and experimental field that at times also conflicts with the traditional academic paradigm: 
[I]t is no longer outrageous to claim that performance can be a method of investigation, knowledge production and scholarship, but...there is work to be done in exploring how particular performance practices can be commensurable with the accumulation, verification and dissemination of what counts as academic knowledge (Gluzman 105).

AR represents an umbrella concept that encompasses a diversity of methodological approaches relating to the creation of knowledge in the arts (Barton 4). The range of sub-categories can lead to some confusion around what term to use. In the field of Arts Research - research that uses performance as the key methodological approach - terms include: Performance as research (PAR), Practice as research (PaR), Practice-based research (PBR), Practice-led research (PLR), Arts-based research (ABR), Research-led practice (RLP), Research-based practice (RBP), Research practice (RP), Research through practice (RtP), Research creation (RC), Creative research (CR), and Studio research (SR) (Barton 4).

Key contributors to the field include Carole Gray (1996), Brad Hausman (2006), Lynda Candy (2006) Baz Kershaw (2009), Robin Nelson (2013), and Bruce Barton, Annette Arlander, Melanie Dreyer-Lude, Ben Spatz (2018). Arts Research doesn't attempt to fit the traditional model of theoretical framework and research methodology. Instead, it can be viewed as a more fluid symbiosis of the two that comprises a variety of approaches. Practice-Led Research, for example, can be defined as the theoretical field of practice within my research, and a key methodological approach, using a multimodal enquiry. Nelson notes that the legitimisation of the field happened when arts practices came to be submitted as research in academic institutions, but that this was not without difficulties and misunderstandings (24-25). Individual institutions continue to articulate their own specific requirements for a practice-based/practice-led 
$\mathrm{PhD}$, but the research must sustain the fundamental tenet of conducting a research enquiry to establish new knowledge (Nelson 25).

One of the key purposes of this form of research is that "the kind of knowledge and insight pursued in creative fields (not only performance and theatre but also design, architecture, music, and arts at large) often needs to be expressed in ways other than words" (Signore 85). Theatre's unique ephemeral and tangible nature cannot always be defined in a written format. At the heart of drama and theatre is a live, shared exchange of ideas and energy that can often be better explained by the expression of feelings in a physical way: "What makes drama drama is precisely the element which lies outside and beyond the words and which has to be seen as action-or acted to give the author's concept its full value" (Esslin 14). Therefore, it is apt to consider a non-traditional research paradigm that doesn't rely solely on written text, to effectively explore the uniqueness of the theatrical form. Peter $\mathrm{O}^{\prime}$ Connor and Michael Andersen claim that Arts-Based research provides a platform for understanding that creates "different ways of knowing, understanding and representing the world" (23), and that knowledge within the world should not be reduced to words and numbers. They state that "representation through image, sound and movement and colour are equally valid ways of expressing knowledge" (24).

Although not specifically discussing theatrical performance, in An Invitation to Performative Research (2013), Kitrina Douglas and David Carless express the irony of using words to describe a performance, and how seeing a performance live is the best way to experience its impact (54). However, they suggest that by exploring the process of the making of the work, analysing responses from audiences, and being a reflective practitioner are ways practitioners can use Performative Research as a valid research methodology: 
We have experienced artistic and creative processes, that comprise performative research, to offer different but nonetheless powerful ways through which we can gain understandings and insights into human experience. Through these processes, it has sometimes been possible to 'make sense' of social phenomena in ways that would otherwise have proved elusive. Of course, traditional scientific and social scientific methods can and do provide important understandings and insights. Yet, we suggest, these ways of working tend to privilege certain types of understanding that differ in important ways from those elicited through performative methods (Douglas and Carless 54-55).

Theatre practitioners, such as myself, will often become practitioner-researchers and begin to write about their work in a scholarly fashion after they have established a professional profile in the industry; examples of this pattern include Tim Etchells of Forced Entertainment (Etchells 1999), and Mike Pearson of Brith Gof (Pearson, 2010). In New Zealand, this form of Arts Research is still an evolving practice, in particular in the field of TYA where there has been little academic research at all, and very little in the form of practice-based, or practice-led projects conducted within New Zealand universities.

Within an academic institution, Arts Research encompasses a diversity of approaches which serve to focus and define a project's method. Some approaches articulate the research preceding and informing the practice (research-led), some see the practice as the 'test' of the research (practice-led), while others recognise the practice as both theory and the methodology (practice-based). As a theoretical field, Arts Researchers "seek their co-ordinates through a relationship to the production of knowledge" (Barton 9). Arts Research recognises 'practical work' as the scholarly 
method. It is particularly useful as a theoretical discourse within the performing arts, making investigation through experiment and performance part of the intellectual enquiry. Arts Research embraces some of the research strategies and methods employed in qualitative research, such as collaborative enquiry and participatory research, all of which I have utilised in my project. However, it differs in the way that the research is led or based on the practice.

In Practice-Based Research: A Guide (2006), Linda Candy describes the two models most commonly used within practice-related research as practice-based research and practice-led-research. Candy maintains: " 1 . If a creative artefact is the basis of the contribution to knowledge, the research is practice-based. 2. If the research leads primarily to new understandings about practice, it is practice-led" (1). I began this thesis by employing a practice-based research methodology as the predominant theoretical framework:

Practice-based research is an original investigation undertaken in order to gain new knowledge partly by means of practice and the outcomes of that practice. In a doctoral thesis, claims of originality and contribution to knowledge may be demonstrated through creative outcomes in the form of designs, music, digital media, performances and exhibitions. Whilst the significance and context of the claims are described in words, a full understanding can only be obtained with direct reference to the outcomes. (Candy 1)

In reviewing the final outcomes of the creative component of my thesis, the creation of two original plays, as well as retrospectively analysing my methodology, I believe that there is an argument for the project also having tenets of practice-led methodology in its delivery. 
Practice-led research is concerned with the nature of practice and leads to new knowledge that has operational significance for that practice. In a doctoral thesis, the results of practice-led research may be fully described in text form without the inclusion of a creative work. The primary focus of the research is to advance knowledge about practice, or to advance knowledge within practice. Such research includes practice as an integral part of its method and often falls within the general area of action research. (Candy 1)

When I began this project, I set out with the intention to create two quality professionallevel plays for children, with the intention that the final plays would be a significant creative artefact that would situate the project as a practice-based project. However, as creating two quality professional- level plays while working with untrained actors in a university environment was such an ambitious goal, the project evolved into more of an inquiry about the process of devising. This resulted in the creation of an intergenerational devising model, which has led to new knowledge that has operational significance for the practice of devising with and for young people. This then situates the project more as a practice-led project, where the final plays are not held up as professional standard polished creative artefacts, but instead as a valuable part of the process for leading to new understandings about the practice of creative devised intergenerational TYA.

However, since my research enquiries were only able to be answered through the practice of creating the plays, and the final plays were important to view so that a full understanding of the process could be made, then this is a paradigm that locates the project as practice-based not practice-led. I believe that arts research is still an evolving field, and there are many challenges in the specific labelling of research frameworks 
when practice is used as a mode of enquiry, in particular as aspects of the research can shift over the course of a project. I believe that this project has tenets of both practicebased and practice-led research as defined by Candy, and consider that arts research is an appropriate overarching term to use when discussing the specific methodology.

My work as a theatre practitioner and the way I have experimented with form, devising methods, and collaborative practice over my career, was significant in the decision to use arts-based research as a key theoretical field. The validation of AR as a different and yet important way to research, meant that I was able to utilise my skills and prior knowledge as a TYA theatre practitioner to investigate a previously underrepresented field of theatre in New Zealand. I used a combination of PracticeBased Research and Practice-Led Research as my theoretical frameworks and research methodologies, to measure and test the central research enquiries of the thesis. Full understanding of the exegesis is best supported by directly referencing and viewing the two plays created as part of the practice. This analysis of practice in how and why I made each decision in the journey towards the creation of the plays, is essential in examining and answering my research enquiries. The enquiries were only able to be answered through the practice of creating the plays - specifically, the creation of a youth ensemble, the devising of the material, the children's responses to the plays, and the impact of the process on the children and the students. The practice of creating an intergenerational, collaborative devising model and investigating ways to work authentically with young people, led to new knowledge in practice that will have significance to the field of TYA in New Zealand.

Arts Research is used in place of the more traditional framing of problem-led research, which can be addressed by the usual paradigm of qualitative and quantitative 
measures. Haseman suggests that instead of beginning with a problem, Arts Researchers begin with an "enthusiasm of practice... they tend to dive in, to commence practicing to see what emerges. They acknowledge that what emerges is individualistic and idiosyncratic" (100). He also suggests that it is something best done by practitionerresearchers as the method of research "captures the nuances and subtleties of their research process... Above all, it asserts the primacy of practice and insists that because creative practice is both ongoing and persistent, practitioner-researchers do not merely "think" their way through or out of a problem, but rather they "practise" to a resolution" (Haseman, "Rupture and Recognition", 147). This enthusiasm of practice, openness to discovery, and eschewing of narrow problem-solving, are some of the values that make arts research a strong methodology for theatre projects. My arts research project is investigating live performance, language-lean visual imagery, ${ }^{36}$ and methods of making theatre. These ideas also align strongly with the method of devised theatre, where the product eventually reveals itself through the practice of the process.

\subsection{Childhood Studies}

Children, young people and youth are the key participants of this research. Discourse related to the cultural, social, psychological, and educational experiences of young people today is important in framing the practical and analytical aspects of my thesis. As such, a key theoretical field adopted in this thesis is Childhood Studies, a multidiscursive and evolving discipline delineated by Anne B. Smith in her chapter "A Theoretical Framework for Childhood" as "a paradigm for the study of children and childhood with an aim to produce better knowledge about childhood and children's experiences, as well as contributing to social justice for children and empowerment" (A. Smith 29).

\footnotetext{
${ }^{36}$ Strongly physical images that don't rely on dialogue to tell the story.
} 
Drawing from a range of critical fields, Childhood Studies reinforces that children have rationality, intelligence and autonomy. There is a strong emphasis on children being social agents who have their own perspectives and make important contributions to society, not as future adults but as people now (A. Smith 29). This concept of being rather than becoming is a critical idea in Childhood Studies; the compelling argument is that viewing childhood as a journey and children as incomplete beings draws attention away from what children are experiencing in the here and now (A. Smith 40). In the TYA field, this relates to the practice of theatre companies who programme TYA work to curate an audience for the future, as opposed to treating children as worthy audience members in the now. This concept of 'futurity'- where children are seen in terms of what they will become, rather than what they are - is criticised by many childhood studies theorists as it leads to children's current rights and perspectives being ignored and their responses belittled (A. Smith 40). This research investigates children as co-collaborators and as an audience, by analysing their current perceptions and world views. As discussed in Chapter 2.3, children are viewed as worthy of their own views, opinions, and creative input in the here and now.

Theories into Practice: Understanding and Rethinking Our Work with Young Children (Nolan and Raban-Bisby 2015) identify theories which influence the interpretation of children's learnings and development and specify how the understanding of these theories can influence practice when working with children. Nolan and Raban-Bisby categorise the different theories which inform children's learning and development within five main fields: developmental theories, socio-cultural theories, sociobehaviorist theories, critical theories, and post-structuralist theories (7). Identifying these key theories has been useful in analysing the methods used to work with the children in my practical project. 
In investigating the making of TYA in New Zealand and interrogating the practice of adults making assumptions about what children want to see at the theatre, I draw on socio-cultural theories which propose that educators need to understand children's development by viewing them in the context of their own communities (Nolan and Raban-Bisby 9). Sociocultural theories of children recognise that agency arises out of social relationships (A. Smith “Children and Young People's Participation Rights in Education" 153) and that "[c]hildren are unlikely to be able to express a view, unless they have the conditions which help them to formulate their views" (A. Smith "Children and Young People's Participation Rights in Education." 154). For this to happen children need the opportunity to participate:

Participation rights are very important within a societal context where adult authority and power is absolute. Children's role as citizens and understanding and awareness of democracy, is determined by the extent to which their participation rights are respected. Participation rights support a sense of belonging and inclusion but more importantly teach children how they can bring about change. (A. Smith “Children and Young People's Participation Rights in Education." 154)

Going into the children's own environment and inviting them to be active participants was crucial in giving agency to the children, encouraging them to express their views, thoughts, and beliefs about theatre, and allowing them to have important input into the project. Additionally, we employed a model of reciprocal learning in our interactions with the children. Reciprocal learning is often used in a knowledge management paradigm (Tempest) and is applied to the discussion about working with children in Chapter Seven, alongside the concept of Intergenerational learning through play (Davis et al.42). I also refer to Paulo Freire's Problem-posing education approach, 
which regards a two-way reciprocal approach to education as ideal (Freire 80). By employing the lens of sociocultural theory, the models of reciprocal and intergenerational learning and a problem-posed educational approach, I generated an environment that allowed both the students and the children to develop agency within the project.

Childhood Studies also applies a post-structuralist perspective to the subject of childhood, specifically in the belief that there are multiple ways of learning. Educators are encouraged to be responsive and reactive and view children as individuals (Nolan and Raban-Bisby 13). I utilised this perspective in the way I viewed the children and students as groups made up of individual people, holding unique viewpoints. This became a significant concept in my development of the youth ensemble, listening and responding to individual students rather than applying a 'one size fits all approach'. This was key to the development of a healthy, productive devising ensemble. The perspective that there are multiple ways of learning, rather than one absolute truth, gives agency to children, another important theoretical concept in Childhood Studies. The Australian Early Years Learning Framework defines agency as "being able to make choices and decisions, to influence events and to have an impact on one's world" (Department of Education, Employment and Workplace Relations DEEWR 47). The corresponding framework in New Zealand - Te Whāriki: He whāriki mātauranga mō ngā mokopuna o Aotearoa Early Childhood Curriculum - states: "In an empowering environment, children have agency to create and act on their own ideas, develop knowledge and skills in areas that interest them and, increasingly, to make decisions and judgments on matters that relate to them" (Ministry of Education 18). This principle of empowerment is one of the four fundamental principles of Te Whariki. 
Te Whäriki adopts Te Tiriti - the Treaty of Waitangi as a key guiding policy in its document. The four fundamental curriculum principles are: Empowerment Whakamana; Holistic Development - Kotahitanga; Family and Community - Whānau, Tangata; Relationships - Ngā Hononga (10): “Underpinning Te Whāriki is the vision that children are competent and confident learners and communicators, healthy in mind, body and spirit, secure in their sense of belonging and in the knowledge that they make a valued contribution to society" (6). This concept of empowering young people through the adoption of Te Tiriti - the Treaty of Waitangi and its principles is discussed further in Chapter Nine.

By applying knowledge specific to the field of Childhood Studies such as agency, empowerment, being rather than becoming, interacting and responding to young people in their own community, in addition to introducing a practice of reciprocal and intergenerational learning, I ensured that the young people, the students and the children, remained at the centre of this research.

\subsection{Summary}

This project integrates theoretical material from a range of fields with the lived experiences of the children and young people involved in the process. It critically analyses the field of TYA in New Zealand, how it is created, performed and received. Through utilising an arts-research paradigm, and a practice based/practice-led research methodology I presented two original plays for children, established a youth ensemble and analysed the process of the making of the works using a variety of research methods. This chapter has identified the research methods and theoretical frameworks that supported my creative project. The following two chapters investigate the identification of quality theatre by/for/with young audiences, and a mapping of the 
field of current practices of practitioners involved in making theatre by/with/for young people in Aotearoa/ New Zealand. 


\section{Mapping the Field}

\section{Exploring the Field of Theatre By/With/For Young People}

PaperBoats collaborator Dave Brown defines quality theatre for children as experiences which:

provide an antidote to the clutter, banality and allure of commercial culture.

Quality theatre offers a powerful connection to children's inner lives. It is a place where they can share transforming experiences that can enrich them and sustain them. The theatre we create for children seeks optimism in humanity and honours the spirit of resilience that can endure and overcome difficulties. (Brown, “Re: Hi.")

This chapter examines how quality TYA can be recognised, and investigates the programming and performing of TYA in New Zealand. Some of the challenges in the field were outlined in Chapter Two, for example, adults assessing what is best for children, and the conviction that all TYA needs to be educative. Another critical challenge in the field is the definition of quality. One of the reasons I began this research was the frustration I felt in taking my children to plays that were patronising and, in my opinion, low-quality theatre. Assessing quality in art however is hard because of its subjectivity. My third research question is to identify and articulate standards by which quality in theatre by/with/for young people can be recognised, communicated and encouraged. When using the word quality in this context the Oxford English dictionary's definition of quality as 'A particular class, kind, or grade of something, as determined by its character, esp. its excellence', (Oxford English Dictionary) is helpful. Quality in this sense refers to the standard of excellence shown in a product. In the case of theatre, quality means the standard of excellence 
displayed in all areas of production. Although it is complex and subjective to define, I believe that articulating standards of quality or excellence in TYA is important in the quest to challenge some of the beliefs that exist around TYA being less important than adult theatre. Low quality in a TYA work can be identified in a production where little thought or effort has been made in the standard of excellence in areas such as script, performance, and scenography.

Gary Henderson, one of the first New Zealand playwrights to specialise in TYA, was prompted to write his own TYA plays while teaching at an intermediate school, after finding a lack of quality scripts available for large casts of young people (Henderson). He wrote six large scale musical plays for intermediate-aged children, and then left teaching and presented a series of TYA plays at professional Wellington theatres. Henderson recalls seeing a TYA work in 1990 that fuelled his writing:

I remember being angered by how little attention had been given to good writing and good technical theatre craft. It was crap. And it was a packed house. Instead of being put on during the school holidays where it would stand on its own merits, it had been marketed to teachers (it dealt with a worthy educational topic) and staged during school hours. The children fidgeted all the way through, yelled and laughed during the obligatory 'audience involvement' bits, then suffered through a question time... [S]o I decided my next project would be on a worthy educational topic (the environment), marketed to teachers and staged during school hours. And it would be a high-quality, engaging piece of theatre. It was The Big Blue Planet Earth Show (Henderson).

The Big Blue Planet Earth Show (1991) was a critical success and was the first children's play to win the Adelaide Fringe Festival award for excellence in 1992 (Oxenbridge). 
A perceived lack of commitment to quality in TYA led Stephen Blackburn to challenge the New Zealand theatre industry and funding bodies in the 2016 Playmarket annual:

The commitment to quality [by major theatre companies of TYA] is, in some cases non-existent... we add insult to injury by inflicting the audience with derivative fairy tales or didactic educational message work. At best it may offer a candy-floss like experience, a momentary sugar rush, and then nothing. At worst it puts them off theatre for life. Any audience at any age deserves better (15).

Henderson and Blackburn's frustrations resonated with me. Also thought-provoking were the experiences of taking my own children to under-rehearsed remakes of tired old fairy-tales in the late 2000s, compared to the excellent original work I participated in with Calico Young People's Theatre in 1994. It led me to question what is quality TYA and how can such a subjective concept be recognised and articulated in a meaningful way?

\subsection{Defining Quality in Theatre by/with/for Young Audiences}

Reason asserts: "Quality in theatre for children might be considered wholly or largely subjective, a matter of taste or fashion" (The Young Audience 35). Moses Goldberg suggests that "[high] standards in children's theatre means basically the same thing as 'high standards' in the adult theatre: artistically unified productions that achieve the highest possible quality in each area of theatrical endeavour" (23). Drama academic Dennis Eluyefa develops this idea stating: 
Goldberg's claim that 'children's theatre' is basically the same as the 'adult theatre' is about the aesthetic merits and the level of professionalism in children's theatre. Professionalism and perfection, even if it is difficult to attain, is considered important in adult theatre possibly because of the ability of its audience to make critical judgement. (83)

From working in numerous 'adult' professional theatre contexts, I have experienced a range of practitioner and audience attitudes which reinforce that 'quality' in theatre is wholly subjective. However, standards by which 'quality' can be assessed can be clarified through academic discourse around how audiences engage with theatre, discussions between artists and funders, as well as published reviews of specific productions. Theoretically, these standards relate to the production values, aesthetic expectations, the level of skill employed in each production, contribution of the work to knowledge, and audience impact such as standing ovations, awards, extended and return seasons. The interpretation of 'quality' in TYA is, likewise, also subjective, and yet in New Zealand TYA is often not exposed to the same rigorous discourse, discussions, and public reviews as adult theatre. I suggest that if TYA is not subject to the same degree of discourse, discussion, and reviewing as adult theatre, then the quality of TYA becomes harder to recognise. In connection with this is the reality that it is adults who are leading the research and debate where quality is considered. Consequently, the perception of quality is viewed through an adult lens, not through the eyes of young people.

When questioned about how Denmark defines and measures what is quality TYA, ASSITEJ International Secretary-General and Executive Director of ASSITEJ Denmark Louis Valente explained: 
The experience of a performance differs very much from one audience member to the other depending on their personal, social and cultural backgrounds and that concepts and conversations of quality should respect this complexity. The complexity should also be respected by organizations and funding bodies whenever possible. (Valente)

In part, to achieve this respect for complexity, Denmark has adopted a unique approach to marketing TYA. It produces an annual festival - Aprilfestival. Denmark has adopted a unique approach to marketing TYA. It produces an annual festival - where all Danish professional theatre companies are invited to present their work. A booklet - The Red Brochure - is also published. Schools, theatres and venues attend the festival or view the booklet and decide what productions to programme. Valente suggests that "this approach of letting consumers decide respects the complexity of quality, is more inclusive and stimulates a diverse TYA landscape, as opposed to a centralised organisation choosing which companies they will programme" (Valente). However, the process does not fully take into account that children are generally not able to programme or buy tickets to a theatre show, tasks usually left to adults. To counterbalance the many decisions made by adults, Aprilfestival runs a programme called "Culture Crew" where children are invited to select shows for their school or community (Valente).

Culture Crew is a cooperation between the organizations of culture for Children in Theatre (Teatercentrum), Dance (Dansehallerne) and Music (Levende Musik I Skolen). When a new school creates a culture crew it starts with a workshop where the pupils who are part of the crew have practical workshops and learn about how to receive and promote cultural events at their school. Once the crew is created, one of their activities is to attend Aprilfestival and the youth delegate 
programme we have. At the festival, some of them are given the role of programmers and have a name tag stating that they are programmers. (Valente, "Re: Culture Crew")

The encouragement of young people to view a variety of works and then choose what is programmed is an example of giving young people agency and empowering them to make choices and develop aesthetic judgement. Valente states that Culture Crew is generally a success and is now a nationwide programme (Valente "Re: Culture Crew"). He also remarks that a way to get around judging quality because of its subjectivity is to say: "We need to take TYA as seriously as we do adult theatre" (Valente).

In addition, the Danish government reimburses $50 \%$ of the performance fee to the school or venue that buys the show (Valente). These approaches taken by Denmark are conceivably the reasons that it is seen as a world leader in TYA. With a population of only 5.8 million, slightly larger than New Zealand at 5 million, it is impressive that it sustains 150 professional TYA companies, (Valente "Re: Culture Crew") compared to the approximately 45 companies in New Zealand (Palmer). Denmark's multimodal approaches to making, programming, and promoting quality TYA, and the excellence of their TYA sector prompted me to look more closely at how excellence and quality are measured in New Zealand.

One approach CNZ historically has used to define quality in New Zealand has been to get artists to define what quality means to them, and how they themselves might measure it (Monro). Furthermore, $\mathrm{CNZ}$ is beginning to engage with quality metrics which have been developed in the UK. By feeding into a platform called Culture Counts, they are investigating the measuring of quality of artistic work by using a standardised set of metrics that artists themselves shape (Culture Counts - We 
Value Culture.) The UK-based quality metrics were developed in 2014 with the aim to "raise the standard of work being produced by, with and for children and young people" (Quality Principles I Arts Council England) The Arts Council of England worked with several arts and cultural organisations that work with children and young people to develop a set of seven principles that relate to quality (Quality Principles I Arts Council England) The overall aim of the subsequent report was to "draw on the evidence base and work with the sector to co-create a set of principles which describe quality and excellence for work for, by, and with children and young people" (Sharp and Lee 7). These principles were summarised in a set of clear statements with accompanying questions relating directly to TYA (Sharp and Lee 4). The UK Arts Council is now working closely with the TYA sector to integrate these quality principles into TYA work. (Quality Principles I Arts Council England) The seven principles and associated questions developed are:

\begin{tabular}{|c|c|}
\hline $\begin{array}{l}\text { 1. Striving for excellence and } \\
\text { innovation }\end{array}$ & $\begin{array}{l}\text { Is there a real commitment to achieving } \\
\text { excellence by with and for children and } \\
\text { young people? }\end{array}$ \\
\hline 2. Being authentic & Is it authentic; The real thing? \\
\hline $\begin{array}{l}\text { 3. Being exciting, inspiring and } \\
\text { engaging }\end{array}$ & $\begin{array}{l}\text { Are children and young people excited, } \\
\text { engaged and inspired? }\end{array}$ \\
\hline $\begin{array}{l}\text { 4. Ensuring a positive and inclusive } \\
\text { experience }\end{array}$ & $\begin{array}{l}\text { Does it ensure a positive and inclusive } \\
\text { experience? }\end{array}$ \\
\hline $\begin{array}{l}\text { 5. Actively involving children and } \\
\text { young people }\end{array}$ & $\begin{array}{l}\text { Are children and young people actively } \\
\text { involved? }\end{array}$ \\
\hline 6. Enabling personal progression & $\begin{array}{l}\text { Do children and young people progress } \\
\text { and know where to go next? }\end{array}$ \\
\hline
\end{tabular}




\begin{tabular}{|l|l|}
\hline $\begin{array}{l}\text { 7. Developing belonging and } \\
\text { ownership }\end{array}$ & $\begin{array}{l}\text { Do children and young people feel they } \\
\text { belong and it belongs to them? }\end{array}$ \\
\hline
\end{tabular}

Figure 12: Quality Principles Table (Sharp and Lee 4)

Alongside these principles, and in the spirit of CNZ's ethos to get artists to define their own concept of quality and ways to measure it, I would add that quality theatre productions for children and young people should consist of productions that have:

1. High production values and aesthetic standards.

2. A professional ${ }^{37}$ team of highly skilled practitioners ${ }^{38}$

3. A realised budget and funding that can assure reasonable remuneration and high production values.

In articulating the quality of arts in his UK report Supporting Excellence in the Arts (2008), Brian McMaster writes:

Excellent culture takes and combines complex meanings, gives us new insights and new understandings of the world around us and is relevant to every single one of us $[\ldots]$ The best definition of excellence I have heard is that excellence in

\footnotetext{
${ }^{37}$ Professional Artists - include people who: have acquired advanced knowledge or training within their chosen artform; have received the recognition of their peers through the public presentation of their work in a professional context; have a serious commitment to their arts practice and consider it a major part of their working life, rather than as a pastime; and have maintained professional practice for at least three years. ("Glossary")

38 Practitioners - include people involved in organising the project and can include producers, stage managers, technicians, publishers, editors, translators, curators, agents and dealers, as well as community-based practitioners. The term includes those people who may not necessarily classify themselves as artists, but who may be necessary to creating, presenting or distributing an artwork. ("Glossary")
} 
culture occurs when an experience affects and changes an individual. An excellent cultural experience goes to the root of living. (9)

Reason agrees with McMaster's linking of quality to the "excellence of the experience" and clarifies this to mean that quality is neither abstract nor technical but has a direct co-relation to the nature of the audience's engagement (Reason, The Young Audience 38). Reason believes that "quality in a cultural experience is its enduring resonance as it engages us intellectually, imaginatively or emotionally. A marker of quality in a work is its ability to make us look longer" (The Young Audience 38). It is this enduring resonance and engagement - the antithesis to "a momentary sugar-rush, and then nothing" (Blackburn 15), that perhaps goes some way towards defining quality TYA. Reason maintains that a piece of TYA should not be viewed as a self-contained entity, separated from the rest of a child's life:

One criterion of quality in theatre for children, as for adult theatre, is the ability to provide pleasure in the moment of the experience and pleasure in an enduring, extended engagement. This interest in the extended encounter is a feature of philosophical conceptualisations of what it means to experience art. These place emphasis on not only the immediate sensory engagement but also what the individual does reflectively with and through that engagement ... With theatre, therefore, what is important is not just what happens on the stage but also what happens within the minds, imagination and memory of the watching audience... [this] increased engagement marks a deepening and extending of the children's knowledge and ownership-creative, imaginative, emotional and technical- of the performance" (The Young Audience 111-112). 
The challenge for TYA practitioners lies in how we achieve this enduring, extended and authentic engagement with a young audience. Asking a child what they think of a show to monitor their enjoyment directly after a performance is an oftenutilised practice. In 2019 for example, I observed a post-show debrief with Myth Makers Theatre Company after their production of The Eel and Sina, a fast-paced comedic retelling of a Samoan myth with upbeat Pasifika music. After the play finished the actors asked the audience two questions. The first was: 'Who can remember a new word they learnt during the show?' This elicited a range of answers, particularly the recalling of Samoan words used in the production. The second question was: "What was your favourite part of the show?" The first child's response was "I didn't actually like it" and he went on to discuss something else that was in the forefront of his mind. This appeared to confuse the actors slightly, although they respectfully listened to the child's story and then re-asked the question. This response made me consider the way performers often ask for reassurance that an audience of young people 'liked' the show after the play has finished, in a way that they wouldn't if the audience members were adults. Perhaps companies want to elicit a collective audience response after a TYA show in an attempt to further engage with the children, after what has often been an adrenaline-fueled exchange of energy. Possibly it is a genuine invitation for feedback. However, this practice, which is rarely used in theatre for adults, elicits a forced group response, which does not necessarily allow for individual audience members' true thoughts and feelings.

Reason discusses these familiar, stilted post-show opening questions: 'what did you think?', or 'did you enjoy it?' (The Young Audience 137). He proposes that such questions mean the audience are not given the chance to consider and explore the subtlety and complexity of the performance they have just viewed (The Young Audience 137). If, as Reason believes, quality lies in the enduring resonance of a cultural 
experience (38), then how can practitioners elicit authentic opinions of the play after it has finished, while increasing the enduring, extended engagement of their audience? In my arts research project the class of THEA 311 and I experimented with different ways of gathering feedback from children after a show, which are explored in Chapters Eight and Nine.

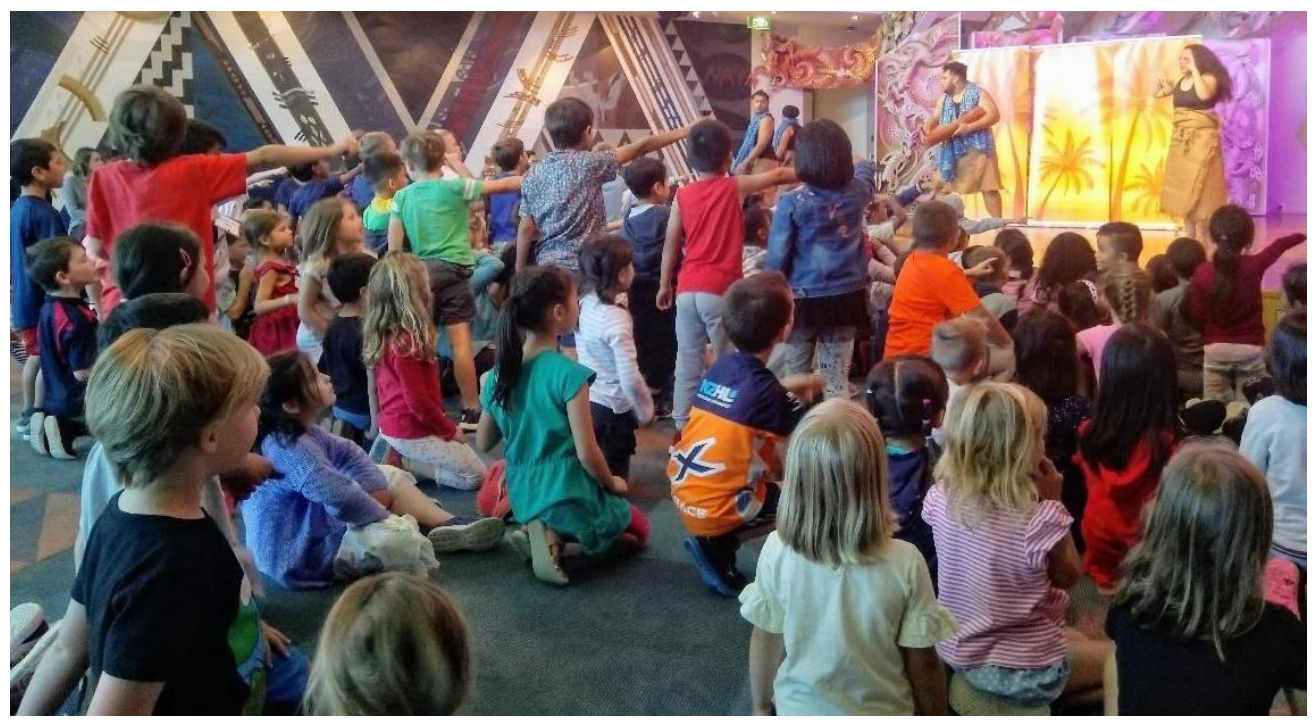

Figure 13: Children responding to The Eel and Sina. (Mythmakers Theatre Company)

\subsection{Programming and Content of TYA}

In February 2019 in order to look more closely at the field, I conducted a survey on Theatre by/with/for Young People in New Zealand (Palmer), the principal findings of this survey are analysed in Chapter Five. One area I investigated was the type of work being presented and how companies chose what to present.

\subsubsection{Fairy Tales and Pantomimes}

The survey revealed a variety of forms of TYA being made across New Zealand by a diverse range of companies. Notably, although many independent TYA companies are devising new work, there are still several companies who consistently programme 
remakes of fairy tales. Kidstuff Theatre in Wellington, for example, have done so since 2006 (Kidstuff) The Pantaloons founded in 2013 predominantly present fairy tales (Pantaloons). Significantly, several mainstream theatre companies, such as The Court Theatre, Circa Theatre, and the Fortune Theatre ${ }^{39}$ have relied heavily on fairy tales for their TYA material. In 2018, two of the four TYA plays presented by The Court Theatre in Christchurch were Hansel and Gretel and Thumbelina ("Kids Shows 2018 /2019"). Circa Theatre in Wellington programs an annual pantomime, usually based on a fairy tale and has done so for thirteen years (L. Wilson). There appears to be a predilection for retelling fairy tales and presenting fairy-tale based pantomimes, which led me to ask: What is the appeal of these narratives for a New Zealand audience? Are these arguably conservative and predominantly Eurocentric stories ones we should be retelling?

One reason to interrogate the use of fairy tales in TYA is suggested by Davis and Evans. They advocate that most fairy tales are disempowering and are not about children at all; they are about young adults, and often promote blatantly sexist and oldfashioned attitudes: "Sleeping Beauty does nothing to bring about the denouement of her story - it happens to her. An active protagonist makes things happen and addresses the conflict of the story directly. This is empowering for a child audience" (XXV11, 1). Davis and Evans believe that the most important thing TYA should be about is children: "Stories like Cinderella, Sleeping Beauty and Rapunzel are about first love. Children who have not reached puberty cannot understand and think about sexual love - they know it exists intellectually, and can readily accept is as a plot device - but in a real sense they cannot empathise with it." (XXV11, 1). If fairy tales are sexist, old-fashioned and disempowering to children why then, are they still prevalent?

39 The Fortune Theatre closed in 2018. 
In her MA thesis, Catherine Swallow (2012) asserts that one of the main advantages of programming fairy tales is that children are less likely to miss important plot details if they are already known (19). In his analysis of fairy tales in terms of Freudian psychology, controversial Austrian psychologist Bruno Bettelheim asserts that children need fairy tales. His argument centres around a correspondence between the fairy tale world and the experience and thinking of children, suggesting "that fairy tales give children the opportunity to understand inner conflicts which they experience on the phases of their spiritual and intellectual development, and to act these out and resolve them in their imagination" (qtd. in vom Orde 17). He believes that the stories help children to cope with life, learn the difficulties of growing up, and provide optimism with their happy endings. Ultimately, fairy tales help children to cope with their feelings (qtd. in vom Orde 17-18). Fathu Rahman writes of another widely held belief: that fairy tales are entertainment told to children by their parents that involve strategic use of parable to convey a greater message (336). Therefore, the purpose of telling fairy tales can be morally educative (336).

An interview with the Fortune Theatre's education liaison officer Shannon Colbert in 2018 revealed that five out of the seven TYA works programmed in 2017 and 2018 were based on fairy tales or folk tales: Snow White, Rumpelstiltskin, Little Red Riding Hood, Hansel and Gretel, and Baba Yaga. When questioned about the programming of fairy tales, Colbert replied: "it was the feeling that parents liked to know what they are bringing their kids to" (Colbert). Likewise, two out of three shows presented by independent theatre company Kidstuff Theatre in Wellington in 2019 were adaptations of the fairy tales: Hansel and Gretel and The Pied Piper (Kidstuff). Kidstuff creative director Amalia Calder explains the reasoning behind this choice: 
My understanding was that back in the '80s/90s this [programming remakes of fairy tales] was considered more the norm. It was harder to get audiences to new Yage Zealand works than well-loved fairy tales....it is still now, harder to sell New Zealand children's stories over traditional fairy tales unless you have a huge advertising budget and even then, it can be challenging. (Calder)

Jenny Wake from Calico Young People's Theatre also considers this challenge, "it's particularly hard to get audiences to new work with unfamiliar titles- adults tend to take children to shows with titles they recognise. e.g., based on fairy tales, classic books or TV Shows, making it extremely risky to develop original new work" (in Palmer 25). Long time TYA practitioner Tim Bray, QSM, states: “I would love to create and present original work, but the company is so reliant on box office income to survive that we need to programme well-known titles to guarantee the audience numbers required" (Bray). This appears to be a dilemma; without a solid audience base, TYA companies would be unlikely to survive and therefore cannot develop original works. However, in order to deepen the breadth and depth of what young people experience at the theatre, companies need to present original work. One of the survey participants commented that: "we do do well creating original works, BUT these need more industry and public support to combat the 'default of companies staging fairy tale adaptations. Which have their place but shouldn't be the default" (Palmer 38). This discussion reveals one of the greatest challenges with TYA in New Zealand: how to attract and sustain an audience while maintaining artistic integrity.

In my opinion, the regular programming of fairy tales should be challenged. It does little to expose children to new ideas and new stories. Significantly, programming fairy tales and pantomimes does not respond to New Zealand's multicultural society 
and the wide range of cultural stories that exist in the whakapapa (lineage) of many New Zealand families. Even when companies give fairy tales a cultural 'twist' or remaking, at their core fairy tales are Eurocentric stories. It is pertinent here to briefly discuss the presentation of non-European myths and legends in TYA in New Zealand. Although there seems to be less of an adoption of such tales by our mainstream theatres, myths and legends are still adapted by some TYA companies. (e.g., The Eel and Sina p.110). I see the presentation of such stories as different from the retelling of fairy tales, predominantly because they can be a critical and important way for young people to understand their identity and history, and are connected directly to the cultures of Aotearoa/New Zealand and the Pacific in a way that European fairy tales are not. However, I believe that there does need to be a reexamining of the way TYA productions are marketed to encourage children, parents, and educators to take risks on TYA works unfamiliar to them.

\subsubsection{Adapting Children's Picture Books}

One method to avoid programming adapted fairy tales and still attract an audience is staging adaptations of well-known children's books. Tim Bray Theatre Company has been following this formula for twenty-nine years, with Bray's own adaptations of wellknown New Zealand children's books, such as Witi Ihimaera's The Whale Rider (published in 1987, stage adaptation premiered in 2006 ), Margaret Mahy's A Lion In the Meadow (published in 1969, stage adaption premiered in 1992) and The Lighthouse Keeper's Lunch (Ronda and David Armitage, published in 1977, stage adaption premiered in 2006), as well as international adaptions such as the hugely popular, We're Going On A Bear Hunt (Michael Rosen and Helen Oxenbury, published in 1989, stage adaption premiered in 2019 ) ("Tim Bray Theatre Company").Worth noting is that that 
some of these 'classic' books retold for theatre are over 30-40 years old - the age of many of the parents in the audience.

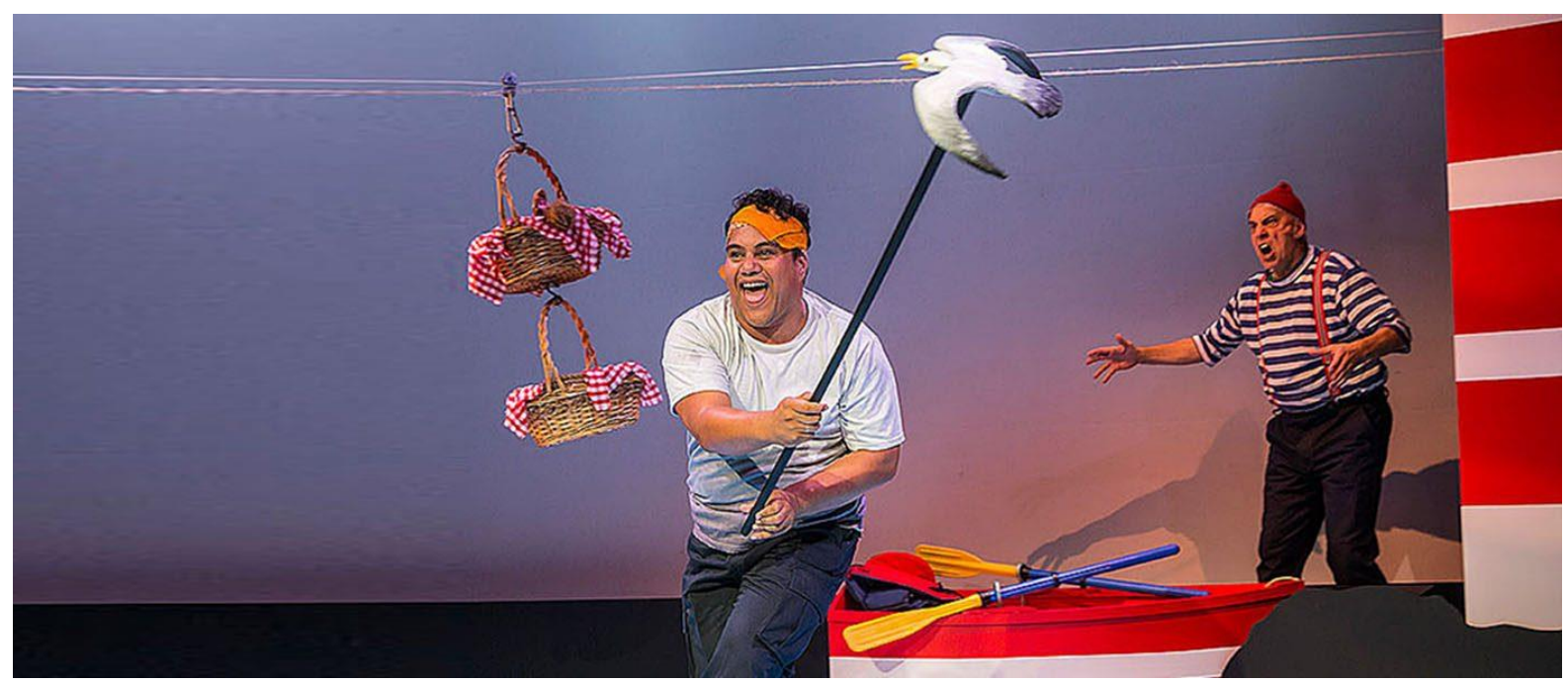

Figure 14: The Lighthouse Keeper's Lunch. Tim Bray Theatre Company.

In 2019, Taki Rua Theatre Company held a national tour of a Te Reo Māori adaptation of iconic New Zealand children's book Te Kuia me te Pūngāwerewere (The Kuia and The Spider) written in 1981 by Patricia Grace ("Te Reo Maori Season"). UK company Tall Stories regularly tour New Zealand with their adaptations of internationally renowned children books such as Julia Donaldson's The Gruffalo, The Gruffalo's Child and Room on the Broom, Andy Griffiths' The Treehouse series, and David Walliams' Mr Stink. They command both large venues ${ }^{40}$ and expensive ticket prices ${ }^{41}$ for these acclaimed adaptations of children's books (Tall Stories). Like fairy tales, children's books have the advantage of being recognisable and accessible; even if they are not known prior to the production. Parents and teachers have the option to read the book to the children prior or after viewing the play, helping children understand plot

\footnotetext{
${ }^{40}$ Such as Wellington's Opera House which can seat approx. 1350 ("The Opera House In Wellington")

${ }^{41}$ Tickets in 2019 cost $\$ 35$ per person over 12 months of age. ("Room On the Broom.")
} 
details. This may also be an effective way of achieving Reason's enduring, extended and authentic engagement with a young audience (The Young Audience 111-112).

An important difference between children's books and fairy tales is that the content in children's books is often more child-centred than fairy tales, with many protagonists in children's stories being children, such as Pai in Whale Rider and The Boy in A Lion In The Meadow, which as suggested by Davis and Evans (XXV11, 1) can lead to greater empowerment for children. According to Tim Bray, parents are more likely to bring their children to a "well-known title" and this can reduce barriers to attendance. Titles with a wide appeal can create a great framework for access to TYA and this was an early strategy for the company (Bray). Naturally, this is good for box office success. But it also leads to the question: where is the place for new and original stories? Are we destined to have a finite number of 'traditional stories' that companies make into plays because children are familiar with them? How does this open young people up to new, and potentially better, cultural experiences and stories as suggested by Brown in his Beethoven, Britney Spears argument? ${ }^{42}$ Regarding quality, Lyn Gardner identifies another crucial point in her 2009 Arts Council of England Theatre report:

Whilst there has been much encouraging progress [in TYA in the UK] there are still theatres who do not engage with this work, thus neglecting a major portion of their potential audience, and there are still examples of unimaginative work which rely on well-known titles to sell the work regardless of quality (13).

This highlights another challenge: just because the play is well known, it doesn't mean that it will be a quality production.

${ }^{42}$ See $\mathrm{p} 52$ 


\subsubsection{Challenging Subject Matter}

When discussing the programming of TYA, challenging subject matter also deserves consideration. In their article The Taboos in Theatre for Children and Young People, Argentinian TYA practitioners and scholars Jorge Dubatti \& Nora Lía Sormani debate the censoring of taboo and awkward subject matter:

Beyond the definition of taboo (... a concept that extends to the conducts or actions which are prohibited or censored by a group of people due to cultural, social or religious matters) we refer to the installation, in this zone of experience which is the theatre for children, of topics that are awkward, dense, nuanced, dramatic, contradictory, absurd and painful, and (all of which) "can bring out doubts and questions", involving an existential, living, challenge for the spectator. These topics had been historically left out of the art for children since they were considered by adults to be harmful and inappropriate. (385)

In considering taboo subjects in TYA, David Wood suggests that: "there are few areas that are totally out of bounds, save those where children are incited to violence or intolerance" (59). However, he maintains it is important not to set out to frighten and disturb children just for the sake of it, the age range of the audience must be considered, and practitioners have the responsibility to treat sensitive issues carefully. Conversely, practitioners should not be influenced by extreme political correctness (59).

Death, for example, can be a difficult subject to stage in TYA, in particular for young children. However, it is not necessarily one that should be avoided because of doubts and questions that may arise from a young audience. In 2015 I directed a national tour of Kiwi Moon, with Capital E National Theatre for Children, aimed at audiences aged 2-7 years. Based on the children's book by the same name (Bishop), in 
both the play and the book, Little White Kiwi's mother is killed by a Kuri (dog). I had seen an earlier production with my then 2-year-old son, where this had been portrayed quite graphically with Mother Kiwi's death happening on stage. My son had been visibly affected by this scene and did not want to watch or hear any more. It made me consider how children manage seeing death on stage. I wanted to approach the scene with sensitivity, but also not steer away from staging the death just because this was a TYA show. In retrospect, my work on the scene may have benefitted from some more research and trialling into how children respond to such topics. However, after much experimentation with the actors, we chose to stage it so that the Kuri and Mother Kiwi had an intense on-stage fight and when the Kuri was frightened off, Mother Kiwi limped into her burrow. The next day, Little White Kiwi delivered his Mum a tasty worm for breakfast. The audience saw the worm go into the burrow and then seconds later, come out again. This made Little White Kiwi sad and he packed up his things and left the burrow. The implication was that Mother Kiwi was dead. Many children in the audience understood this and openly commented on the fact that the mother had died. However, in post-show discussions, other children in the audience said they believed that the Mother Kiwi was actually 'just sleeping.' This was mirrored at the end of the play when Little Kiwi gets caught in a forest fire and 'jumps' into the arms of Te Marama (The Moon). Many children interpreted this as Little Kiwi dying; others, however, chose to believe that the Kiwi had indeed been lifted out of the fire by Te Marama. These observations suggested to me that children were creating their own narratives from what was being shown on stage. If they understood and could cope with the idea that Mother Kiwi was dead, then that is what they believed. However, if that idea was too hard or disturbing for them, then they would tell themselves (and others) that Mother Kiwi was actually 'just sleeping'. 


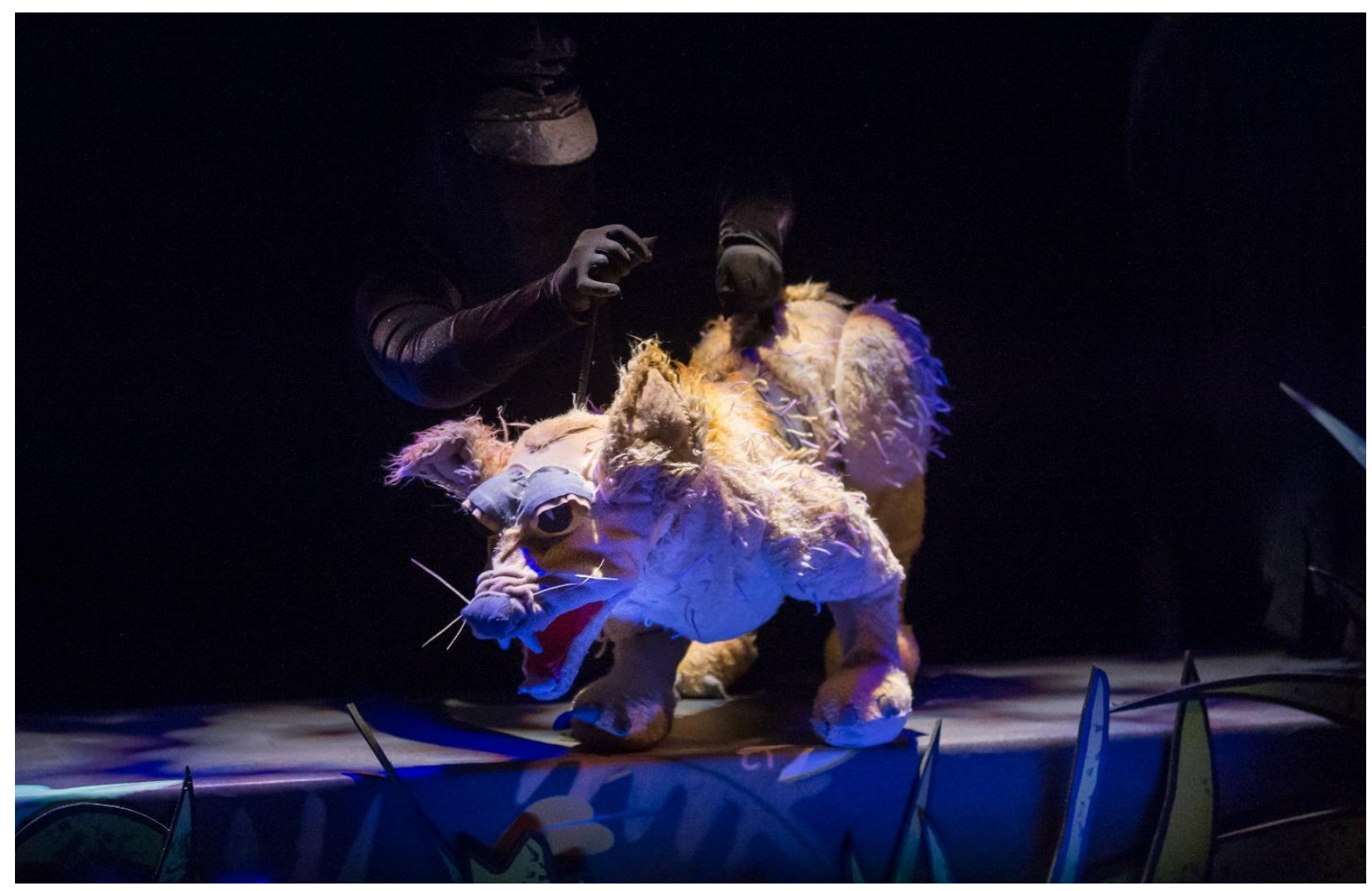

Figure 15: The Kuri in Kiwi Moon.

This idea of self-censoring by children reiterates the importance of Dave Brown's concept of providing an open narrative - discussed in depth in Chapter Eight - so that children can come to their own conclusions. Highlighting the importance of not avoiding taboo subjects, celebrated children's author Morris Gleiztman, who has written books encompassing several taboo topics, believes that offering children challenging topics is healthy:

If we slam the lid down on certain areas of the world that they [children] inhabit and already know a fair bit about ... well, there's nothing more fearful for a young person than to see that an adult they trust and love just doesn't want to talk about some aspects of life. (Gleiztman qtd. in Kelsey-Sugg) 
The programming of TYA within a New Zealand context is examined further in Chapter Five. Interrogating assumptions about what young people want to see, or can cope with seeing, by questioning the content, form and subject matter in TYA is crucial in examining the field. In considering the content of what is being presented and interrogating how that content empowers, challenges and entertains young audiences is conceivably a way to better place young people at the centre of the TYA being programmed in New Zealand, and may lead to greater quality work being presented.

\subsection{Performing and Staging TYA}

Not only are programming choices important to what might constitute quality TYA, but, fundamentally, the performance and production styles are also significant. Matthew Reason describes some of the worst habits exhibited by actors within theatre for children:

It is possible to get away with a lot through audience participation, loudness and effectively driving your audience into a state of distracted hyperventilation ... it is possible to get away with a lot and deliver very little if a production is immediately diverting. (The Young Audience 37)

Reason suggests there is nothing wrong with sheer entertainment if nothing more is claimed or desired, however, he argues:

[t]here is a suggestion that theatre for children has, particularly in the past, but at times still today, often settled for doing nothing more. It does not say much about our perceptions of the abilities of young children if we settle for baseline productions. It suggests that for young audiences it is not necessary to do more 
because children either do not need more, would not understand greater subtlety, or would not actively appreciate greater variety. (The Young Audience 37)

Caryl Jenner concurs with this idea arguing further that this underrating of children's powers of perception is what leads practitioners to make plays that are too simple or one dimensional (Jenner qtd. in Reason, The Young Audience 37), an observation that resonates with many of my own experiences and frustrations of working in the TYA industry in New Zealand. What follows is a brief examination of some of the conventions and assumptions I have observed in TYA, that can lead to an undervaluing of young audiences.

\subsubsection{Audience Interaction/Participation in TYA}

When observing a children's school holiday show in 2017, I noted a constant insistence of participation by the actors which resulted in forced interactions with the children. The actors encouraged the audience to participate by completing hand actions, coming up on stage, answering questions, and singing. Intriguingly, I observed only a few children that seemed to want to participate. Many were content simply to watch. Some sat back in their chairs, indicating a strong objection to being actively involved. Interestingly, there were several parents and caregivers who, perhaps being alert to existing TYA conventions and expectations, appeared to feel compelled to interact and answer the actors' questions themselves.

Gareth White examines the 'aesthetics of invitation' in his book Audience Participation in Theatre (2013). Not specifically aimed at a young audience it is however a comprehensive interrogation into the practice and purpose of audience participation and highlights the complexities involved when inviting an audience to participate. 
White defines audience participation as "the participation of an audience, or an audience member, in the action of a performance" (4). In TYA, audience participation is a common practice and involves a variety of methods of encouraging the audience to participate such as calling out, coming onto stage, solving problems, and assisting characters.

In examining the roots of audience participation, TYA director and academic David Broster remarks that it is a characteristic that has been particularly developed in TIE: "The synthesis of educational thinking, childhood development and theatre practice ultimately resulted in a [TIE] participatory aesthetic that located audience participation as an integral part of both process and product" (118). With Magic Attic Theatre he has explored the convention of audience participation extensively (119-127), and concludes that "when handled sensitively the experience of being involved and especially physically involved in the action is an exciting one and a positive addition to an otherwise end-on experience" (127).

David Wood views audience participation as an important but optional ingredient of children's theatre. In pantomime he believes that it is used often to galvanise a family audience, which is fun, "but often the aim seems to be to get the audience to shout as loudly as possible and create a diversion from the story" (46). Wood adds that audience participation works better when it is not asked for but comes spontaneously: “Simple warnings - 'He's behind you' - work well, but they work better if they are not directly asked for ... far better for the warning to come spontaneously as a result of the audience being unable to contain their desire to be helpful" (46). He remarks that when writing or directing a TYA play even though sometimes audience participation would be irrelevant or out of place, it is worth considering as "young children suffer few inhibitions when given the chance to join in" (46). 
In a New Zealand context, Jenny Wake discusses seeing a production of Spike Milligan's Bad Jelly the Witch, loaded with audience participation. During the performance the children seemed to be engaged by screaming out things such as "he went that way" or "oh yes, he did/oh no he didn't," at the top of their lungs. However, after the show, when Wake asked a child who was involved with this participation, "you really enjoyed that didn't you?" he replied, "er, it was ok." From this, Wake surmised that although he had been evidently participating vocally, and seemingly enjoying it, the experience itself was hollow: "it was just getting into the shouting thing and it wasn't meaningful. It wasn't a rich experience by any stretch of the imagination in terms of their participation" (qtd. in Warrington 95-96). This aligned with my own experience in 2017 and several additional experiences of taking my own children to TYA. Considering the research by Broster and White, the discussion by Wood and Wake, and my own observations, I decided to further investigate audience participation/interaction in my creative project. I wanted to test a theory that audience participation/interaction is an element that needs to be carefully curated and integrated into the overall dramaturgy of the piece. Rather than being inserted as a staple of children's theatre, it needs to serve as a method to advance the story in a meaningful way, as opposed to inciting the audience to be as loud as possible or answer questions that the actors obviously know the answers to. This led to an exploration of ways to make meaningful interactive theatre that was integrated into the action, and an experimentation with levels of active to passive audience engagement. Although these findings are discussed in Chapters Eight and Nine, one opinion worth noting here is John Smythe's review of In the Attic, where he asks, "Has thought been given to the question of audience interaction - which most experienced theatre-going children welcome and tend to expect?" (Smythe). This demonstrated that even though we had carefully considered and then deliberately avoided traditional styles of 
audience interaction/participation, there are still adults that view it as a requisite for all TYA.

\subsubsection{Children have 'Short Attention Spans'.}

Another common preconception within TYA is that children have a shorter attention span than adults. It is this which perhaps precipitates the loud, colourful and fast-paced action in many TYA productions, as well as the insistent encouraging of audience participation to keep the children engaged. Jenny Wake experimented with this presumption in her 1992 production Shalakazap, and based the production on her philosophy that children have no shorter attention spans than adults:

I believe that children can be engaged and sit quietly and attentively, for an hour-long production or more. But you have to (as with an adult audience) you have to structure the show in such a way that they're engaged in it in different ways and if you do all the same thing...you might even find an adult audience isn't hooked into it for that whole hour. (qtd. in Warrington, 97)

Funded by a CNZ Project grant, Shalakazap experimented with a variety of ways to keep an audience engaged. I was an inaugural cast member in the production which toured around New Zealand in 1992. The theme of Shalakazap was mathematics and problem solving. The audience participation was carefully integrated, aligning with Wake's ideas to involve children in varied and meaningful ways. We performed nearly 100 times and my memory of performing this show is the way it consistently engaged the audience for the full fifty minutes. A year after we performed Shalakazap, I revisited a school with a new production. I was proudly presented with a full-scale drawing and map of my Shalakazap character's journey, demonstrating the lasting impact the show had had on this child. Not only did she recognise me as the actor from the previous 
year, but she remembered in detail my character's journey, demonstrating a level of enhanced engagement with the play a full year after she had viewed it. This enhanced engagement by children with characters is further examined in Chapter Eight, where our school children re-enact scenes from Moonlight. The emotional journey the children were taken on in Shalakazap was delivered through Wake's principles of structuring the show so that the children were engaged in it in different ways (Warrington 97). These included active participation through solving riddles and mathematical equations, as well as watching and listening. The play was cleverly structured so that the actors would take the audience from complete uproar and excitement to absolute quiet and suspense. The use of theatrical structure and spectacle, such as a part of the set revealing itself like magic when the audience and the characters got a maths question correct, was in my opinion, one of the greatest strengths of the production.

Furthermore, Wake structured Shalakazap so that the audience participation was often spontaneous or integrated into the action of the play. Because of this we rarely had to break the theatrical illusion with comments such as, 'please sit down while we continue with the story'. Wake developed several techniques as a director, which I believe encouraged us as actors to create a dynamic and yet more respectful method of performing Theatre for Young Audiences. These included techniques such as: creating a strong visual style of performance; avoiding characterisations that used clichéd physical attributes; empowering children to be part of the action by helping to tell the story; and employing different methods of engagement to keep the children engrossed.

Importantly, we rehearsed the production in a school, giving us direct and extended contact with children, which meant we were constantly reminded of what appealed to them, their manner of speaking, and the language they used. The production was educational, but not at the expense of theatricality. When discussing her aims for the play Wake explained: "Shalakazap! is designed to foster a positive attitude towards 
maths by drawing audiences into a series of problem-solving activities built into the plot of the play. Its objective was to offer curriculum-related material without theatrical compromise" (qtd. in Warrington 96). Wake has consistently aimed to challenge preconceptions and attitudes towards children's theatre. In particular, she challenges the idea that theatre for children is a poor relation of adult theatre. In an interview with arts reporter Mike Houlahan in 1994, Wake stated “[Children's theatre] is often dismissed as childlike because it is aimed at children, or it is seen by aspiring but outof-work- actors as a quick way to get work" (qtd. in Houlahan). What is both intriguing and frustrating to reflect on is that in 1994 Wake was challenging some of the same issues I am investigating in this thesis in 2020. This indicates that while some factors have changed in twenty-six years, there are still recurring issues and challenges within the industry.

\subsubsection{Adults Playing Children and Acting for a Young Audience}

In her work Wake also interrogates the practice of adults playing children, noting that it can lead to actors "falling into choosing clichéd physical attributes: a sort of innocence or cuteness or squeaky voice or toes turned in" (qtd.in Warrington 92). She asserts: “Every single kid thinks they're pretty big, because they're older than they were a year ago and so they think they're pretty grown up and mature [...] So, you don't want to come and see some actor come along and take the mickey out of you in effect by doing the cutesy, pigeon-toed thing" (qtd.in Warrington 92). To avoid such clichéd and patronising portrayals, Wake directs her adult actors not to try to be kids, but to be kids by interpreting the situation of the play, the circumstances, the actions, and the language used rather than putting on some sort of physical persona (92). Swallow investigates this issue further by discussing the way that child protagonists are extremely difficult to play. She discusses how companies will employ a variety of strategies in order to portray child-like characters, such as offering adult characters who 
are childlike (21). Yet this in-between representation, where adults perform for child audiences in a heightened way that is neither naturally 'adult' nor 'child', is also a problematic trope.

Caryl Jenner, the founder of the Unicorn Theatre Company, ${ }^{43}$ was conscious of the way children responded more readily to truthful theatre. As a result, she issued a booklet to all new company members with the following instructions for actors:

Great imaginative ability is required to attain belief in the fantastic characters and situations found in infant plays, and this is essential if you are to play them with conviction in a technique which demands frequent direct contact with the audience, as well as fellow actors. Absolute care must be taken when first approaching these plays in rehearsal not to fall into the trap of "talking down" to the children. The actor must see through the children's eyes, and play with the directness and simplicity that he would find from the child itself. (T.Graham 77)

Jenner set extremely high standards for writers, directors and actors in TYA. She professed that it takes a very perceptive person to get into the mind of a child and to know what will work, and that all too often adults underestimate children's comprehension (T. Graham 76-77). Similarly, Wood discusses how TYA actors need to respect children, and have flexibility and commitment by being able to "share with the audience a genuine delight in the story being presented and find a real pleasure in the fantasy and the magic"; but they also should avoid "playing a role over the heads of children in the audience towards the adults, as if to say 'Look how clever I am at entertaining children'"' (Wood and Grant 225-226). Wood also suggests TYA actors avoid underestimating children's ability to absorb information, be aware of unexpected

\footnotetext{
${ }^{43}$ The first children's theatre company to gain national recognition in the UK, which was formed in 1947(T. Graham 76).
} 
interruptions or comments, and aligns with Jenner's suggestion to never talk down to children. "Never talk down to the audience in a singsong voice. Don't think of them as infants... Don't fall into a silly, childish style of acting. Respect the audience and they will respect you" (228-229).

Stanislavski's system of training actors based on the principles of nature and truth (Moston 157) was developed, in part, as the antithesis to the broad overacting that was commonplace in Russia in the 1890s. Stanislavski founded a methodology that aimed at encouraging actors to strive for truth and believability (Moston 161). The complex methods of actor training and the nuanced differences between acting that is truthful, natural, and authentic, as opposed to untruthful and forced, are the topics of much academic discourse. In relation to TYA however, I have observed that many actors when auditioning or performing for children, seem to revert to the style of overacting that Stanislavski was working against and in doing so, neglect being authentic and truthful in their performance. The challenge in performing for children is that actors need to be entertaining and playful in a way that still respects their audience's intelligence. They need to be able to access Stanislavski's truth while simultaneously being accessible to their unique audience. Jenner, Wood, and Wake have all developed methods that challenge TYA actors to be more authentic and genuine, and to respect their audience.

This authenticity, however, is not always easy to achieve. When I directed Songs of The Sea for Capital E in 2011, I was determined to avoid the actors talking down to children. I encouraged them to create a sense of play in a childlike fashion, by employing a sense of lightness, curiosity, and whimsy, without being patronising and clichéd. I constantly reminded the actors to just 'be themselves', to be present on stage, and find the childlike essence in themselves. Despite these efforts, reviewer Hannah 
Smith observed: "The performances are energetic and the singing is nice, in the classic chipper enthusiastic style that marks much children's theatre. It toes the line of seeming condescending, but is successful at holding the attention of the audience, particularly the younger members" (H. Smith). 'Condescending actors' was what I was desperately aiming to avoid, and Smith's comments compelled me to question my method of work. I realised that we had at no time during rehearsal engaged with children, or observed them playing, and we had failed to ask actual children if they felt the characters were patronising or condescending. I had missed one of Wake's key strategies for success.

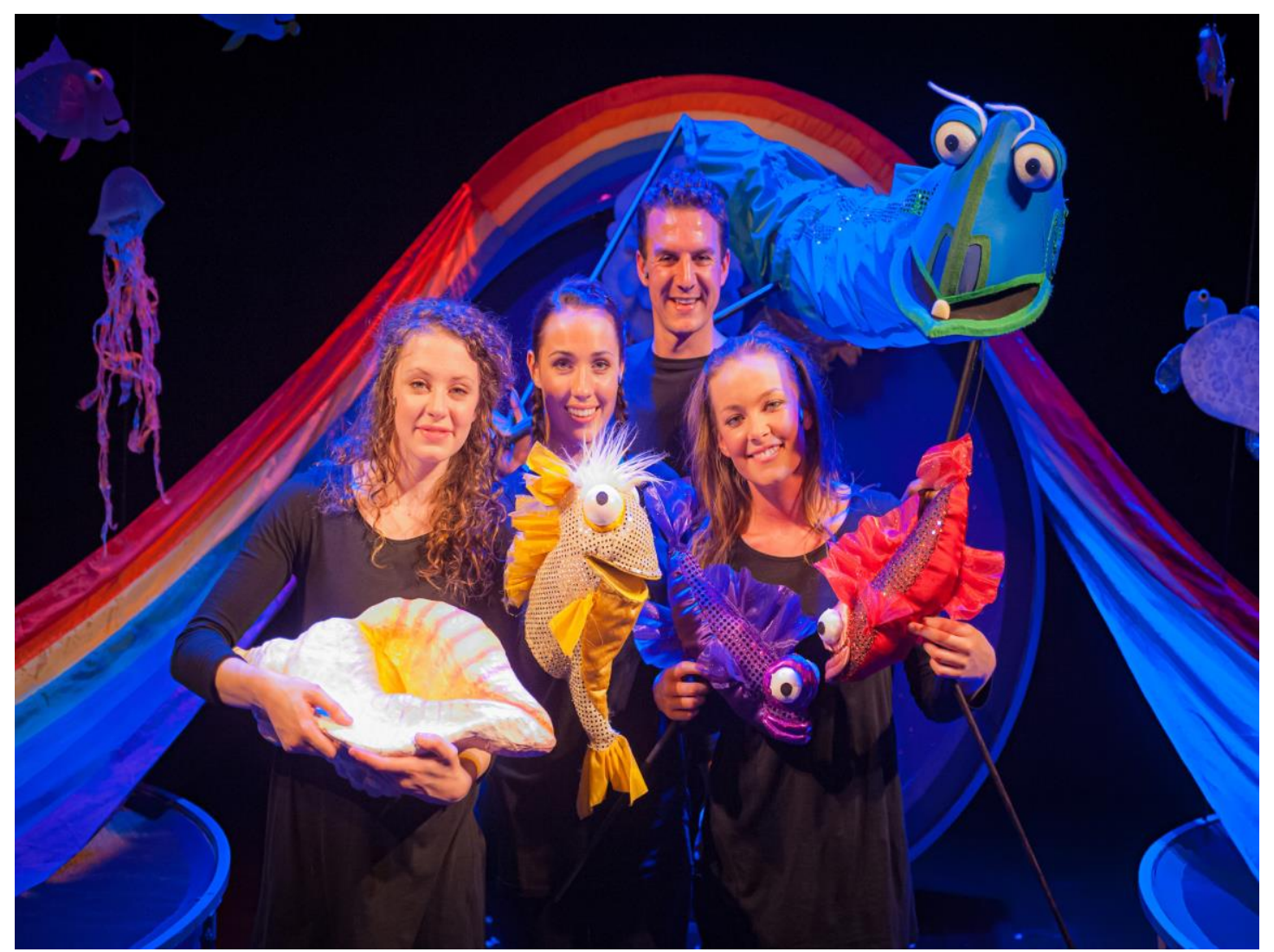

Figure 16: Songs of The Sea. Capital E National Theatre for Children.

Director Vicky Ireland describes her practice and ways she has discovered to mitigate such issues: 
At the start of the production I take my cast to visit a local school so they can meet the age range they're playing and talk to the children, reacquaint themselves with young people. When we return the actors often reproduce the behaviours they've seen, but then we work to tone this down. The challenge is not to act 'being a child' but keep the spirit inside and let it inform your behaviour. (Ireland 148)

This representation of adults playing children for an audience of children has become an ongoing area of interest in my directing practice, and it greatly informed how I began the creative component of this thesis. It also prompted me to question the way actors are trained in New Zealand, which is explored further in Chapter Five.

\subsubsection{Scenography in TYA}

When analysing how TYA is presented in New Zealand, it is important to acknowledge not just way the work is presented by the performers, but also the associated design elements.

After graduating with a master's degree in directing I was employed to direct a holiday children's show at a mainstream New Zealand theatre. The artistic director of the theatre had not read the script before programming the show. When I pointed out the poor quality of writing, the artistic director said that I could 'do what I wanted with it'. The collaborators and I were employed for a challengingly brief two weeks of rehearsal. We rehearsed and performed on top of the extensively large set of the current adult production. This set had been carefully, expensively designed and built; our set consisted of sheets being thrown over the adult set and a few specific design elements that helped to 'set the scene'. The under-rehearsing and the deficiency of care taken by 
the artistic director of the theatre implied that their adult play was more important than the one for children. It also highlighted the lack of attention given to a vital area of theatre - scenography.

Scenography can be described as 'a holistic method of visual theatre making' (Howard xx). In her second edition of What is Scenography, Howard explains that the question 'what is scenography?', even amongst sceonographers, results in a lively debate, and a spectrum of views from all over the world, proving how difficult the term is to quantify (xv). For example, Peter Cooke (Australia) describes it as 'the visual lexicon of theatre making' (xv); Mohammed Hamzah Tahir (Malaysia) as 'an artistic illusion of stage design with visual metaphor and highly poetic images (xvii); and Vicki Mortimer (UK) describes it as 'an open-ended conversation between design and performance'(xviii). Simply put, scenography is a holistic term that refers to all the elements that contribute to the atmosphere of a production, including lights, set design and costumes. Within TYA it is an important element to consider. Perhaps given the way that young children are often drawn to pictures, colours, and design before words, and their ability to use their imaginations creatively and extensively, it could be considered more important than the narrative of a play. David Wood suggests that “design is an integral part of a children's production. It demands considerably more invention and imagination than might be required for an adult play" (157), however as demonstrated by my earlier example, it is not always at the forefront of a TYA production. Ali Maclaurin writes in her article A Collective Approach to Designing for Devised Theatre that design is often 'viewed in a distorted manner both in a professional and pedagogical context as mere decoration' (97). She suggests a much greater symbiosis between designers, directors and performers, and states that a devising process is an ideal space to allow this to happen. Her proposed method for using design in a devising process with young people, that leads students to a deeper understanding 
of stage design (98), suggests a collective design experience: “Design as a process must be part of the devising journey for all those involved so that the final design is an appropriate as possible to the piece" (104). In New Zealand, although the marginalising of design in TYA exists, there are designers that accomplish excellent TYA designs that are fully integrated into the productions, including Brian King, Emma Ransley, Sean Coyle, and John Parker in their work for Duffy Theatre, and Hannah Smith from Trick of the Light. Although this thesis does not focus directly on scenography in TYA, I believe that it is a vital element to be considered when creating quality TYA.

\subsection{Summary}

The question of what constitutes quality theatre by/for/with Young Audiences is a complex and subjective one. However, quality can begin to be measured through the discourse and examination of production values, aesthetic expectations and the level of skill employed within each individual TYA production. By examining the programming of TYA works and the methods of performing them, instead of relying on preconceived assumptions, the genre can begin to be analysed more clearly. It was thought-provoking to discover that many of the above examples of tired tropes and stereotypes of what makes good TYA were expectations held by the students of THEA 311. At the beginning of the course, I surveyed the class to determine their attitudes and understandings of TYA. I asked about what elements they thought should be incorporated into TYA. Their list included: pantomimes, Hi 5, ${ }^{44}$ The Wiggles, ${ }^{45}$ magic, comedy, talking animals, high energy, fairy tales, large facial expressions, interactive theatre, audience participation, stock characters, spectacle, slapstick, and bright colours (Palmer, "Preconceptions in Children's Theatre"). They understood that TYA needed to have lots of audience participation, be loud, colourful, and fast-paced; and that in order

\footnotetext{
${ }^{44} \mathrm{Hi} 5$ is an Australian television series known for its education and musical content.

45 The Wiggles is an Australian children's musical group.
} 
to relate to children, actors themselves needed to play children. Yet as Sharpe and Lee assert: "striving for excellence and innovation, being authentic, exciting, inspiring and engaging" (10) does not have to mean being large, over-expressive, colourful, or speaking down to children; "Ensuring a positive and inclusive experience, actively involving young people, enabling personal progression and developing belonging and ownership" (10) doesn't necessitate a patronising 'who's behind me?' directive. All these qualities need to be developed carefully and rigorously throughout a dedicated rehearsal period.

Interrogating the way practitioners engage with children in making work also has the potential to upend inaccurate assumptions about what young audiences will respond to. In my arts research project, I explored methods used to make TYA, to see if some of the recurring challenges in the New Zealand TYA industry could be mitigated if we give more consideration to our audience whilst making the work. Reason asks, "If we are not interested in how children engage with [the work], then how seriously are we taking our audience in the theatre that we make for them?" (169). In Chapters Eight and Nine, I examine how the class of THEA 311 worked to challenge these preconceived ideas in the making of two original New Zealand works. In particular, we attempted to avoid the following: talking down to a child audience, clichéd child-like portrayals, audience participation and assuming what a child audience will respond to. The next chapter examines more closely the contemporary field of TYA in New Zealand. 


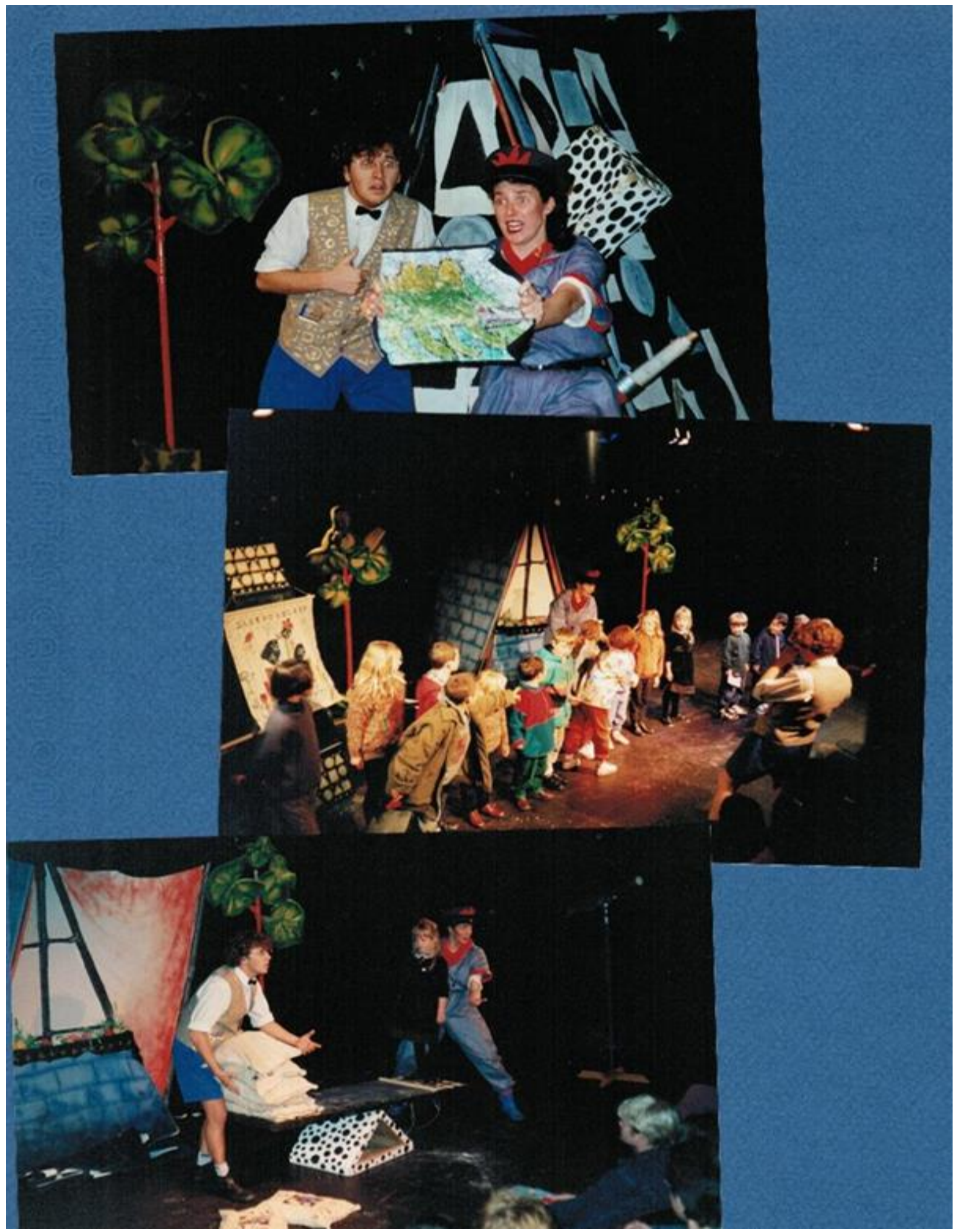

Figure 17: Shalakazap. Calico Young People's Theatre (Author in Blue and Red hat). 


\section{Whakaari Mō Ngā Tamariki ${ }^{46}$}

\section{An Analysis of TYA in Aotearoa/New Zealand in 2019/2020}

This Chapter explores the TYA sector in New Zealand in 2019 and 2020. The survey which gathered the majority of the data was completed in 2019. I have attempted to continue updating information as it changes, in particular in terms of funding and new companies. Although I have attempted to capture all relevant TYA companies and practitioners, there are certain to be some that have been missed. ${ }^{47}$ Surveys were distributed to artists and companies identified through the following sources: the PAYPA Website, The CNZ database, Playmarket New Zealand, and via my own professional network. The intention is to keep this list open and continue updating it so that a comprehensive database of all TYA practitioners and companies in New Zealand can be developed.

\subsection{Sector Overview}

From the survey results and follow-up correspondence, I have identified thirty-seven professional TYA companies, defined as companies that employ paid creatives and create theatre by/with/for young people in Aotearoa/New Zealand. Of these, twentyfour companies predominantly or solely produce TYA works, such as: Capital E National Theatre for Children, Tim Bray Theatre Company, and Little Dog Barking Productions. Fourteen companies produce one or two TYA works a year supplementary

\footnotetext{
${ }^{46}$ Theatre for Children- With permission from Tānemahuta Gray- Kahukura of Taki Rua Theatre company.

${ }^{47}$ One of the omissions in this survey was the work that is presented at Māngere Arts Centre - Ngā Tohu o Uenuku - including the annual school holiday show that has been presented since 2014 and the work of Black Friars Theatre Company. This is a regrettable omission and the work that is presented at Māngere Arts Centre - Ngā Tohu o Uenuku will be added to the PAYPA inventory of companies making TYA work in Aotearoa/New Zealand.
} 
to their adult theatre work, including companies that have a dance/theatre focus, such as Java Dance Theatre and Kahurangi Dance Theatre, and larger theatre companies that have a youth arm, such as Auckland Theatre Company and The Court Theatre. Eight companies self-identify as Youth Theatre companies; however, these are not deemed professional TYA companies by the above definition. I also identified sixteen independent playwrights who write predominately or extensively for young people. Thirty-three of the forty-five identified companies (73\%), responded to the survey, and six (38\%) of the sixteen TYP playwrights responded. The majority of the thirty-seven professional companies identified, produce theatre for and with young audiences. This is opposed to theatre work by young audiences, which predominantly is the domain of youth theatre companies, after-school drama classes and schools, and educationally based projects. I have chosen to focus on the professional companies producing theatre for and with young audiences for this analysis. The companies are spread geographically throughout New Zealand and are funded via a variety of sources, which are explored in more detail in this chapter.

\section{List of professional companies that employ paid creatives and create theatre for/by/with young people in Aotearoa/New Zealand}

The shading identifies the companies that responded to the survey. In brackets is the geographical area that the company resides in.

\section{Companies which make predominantly TYA work}

Calico Theatre Company (Hawkes Bay)

The Theatre in Health Education Trust (THETA) (Dunedin)

NZ Playhouse (Christchurch)

Shakespeare Globe Centre New Zealand (Nationwide- central office in Wellington)

Massive Theatre Company (Auckland)

Little Dog Barking Theatre Company (Wellington) 


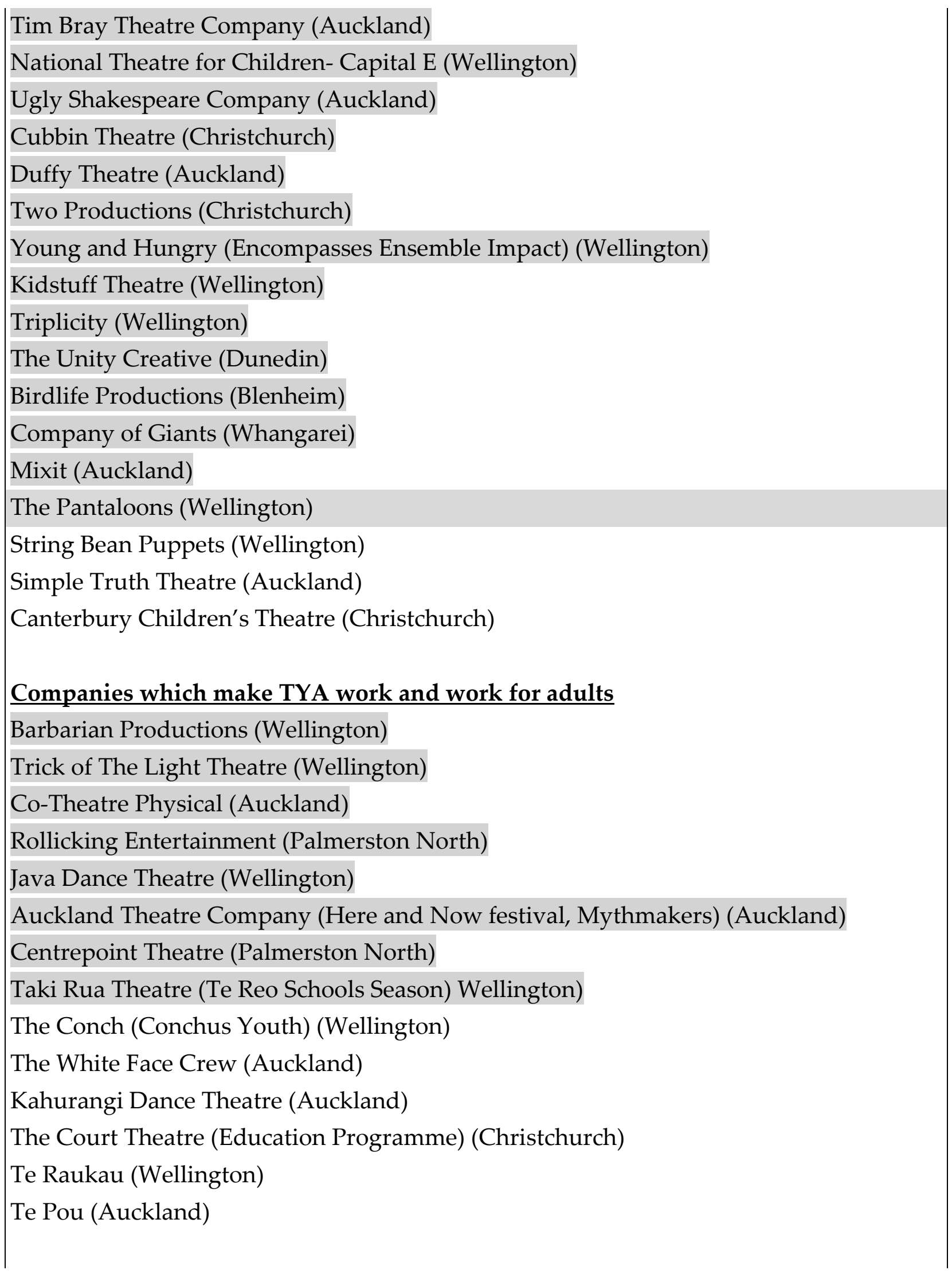


Youth Theatre Companies (theatre made predominantly by young people aged 18-25) Howick Youth Theatre

Hawkes Bay Youth Theatre

Northland Youth Theatre

Nelson Youth Theatre

Hagley Theatre Company (Christchurch)

Hawkins Youth Theatre

Wellington Young Actors Company

Long Cloud Youth Theatre (Wellington)

Figure 18: TYA Companies Surveyed 2019

When questioned about what we do well in the TYA sector, many practitioners addressed the calibre of the work being produced, offering a range of comments such as "I think we have really great companies making TYA, we have a range of work being made and it is of a high standard" (Palmer 40) to "We provide fantastic content that inspires a new generation of performers" (Palmer 54), and "There is lots of great work going on" (Palmer 11). The diversity of the work was also remarked on, with one participant noting "increasing cultural diversity in the high-quality work being made" (Palmer 4). Positive comparisons with international work in the field were also observed:

Having attended Imaginate ${ }^{48}$ for several years, the quality of NZ work matches, if not excels, that of the work in this curated festival. I think our isolation means we present a unique style which in some ways isn't hampered by seeing lots of

\footnotetext{
${ }^{48}$ Imaginate is the national organisation in Scotland, which promotes, develops and celebrates theatre and dance for children and young people. They annually produce the Edinburgh International Children's Festival. (formally known as Imaginate) ("Imaginate- What We Do.")
} 
other work. And that NZ TYA proudly present quality NZ, Māori, Pasifika and Asian stories is a huge thing. (Palmer 9)

Also notable was the commitment of the practitioners involved in making TYA: "[We] have a sense of professionalism and continue to challenge ourselves about what and how we present this work" (Palmer 15), "If there's something we want to do, we go ahead and make it happen" (Palmer 25), "The workers are doing amazingly. Teams out on the road and people creating shows" (Palmer 33). Furthermore, many acknowledged the innovation necessitated by making TYA with few resources: "I see the passion and commitment from practitioners to make innovative work for young audiences on the smell of an oily rag!" (Palmer 54), and, "NZ TYP/TYA practitioners are creative, passionate, dedicated and resourceful. We are fantastic at making fabulous theatre out of hardly anything at all" (Palmer 25).

It is heartening to see such optimism about the work. On the other hand, several practitioners admitted they had not seen other companies work. This lack of connectivity between TYA practitioners was commented on several times:

[As a sector we need to] have more opportunities to network and discuss together what is important now - we need to have regular forums where we can each contribute to a discussion of what issues we are all facing no matter what organisation or funding we have - and where we can all talk about what we'd like for our futures. (Palmer 14)

I would like to find ways to attend conferences (preferably here in New Zealand) in order to upskill myself and continue learning. I think we could also communicate more with each other about contracts and rates of pay. (Palmer 73) 


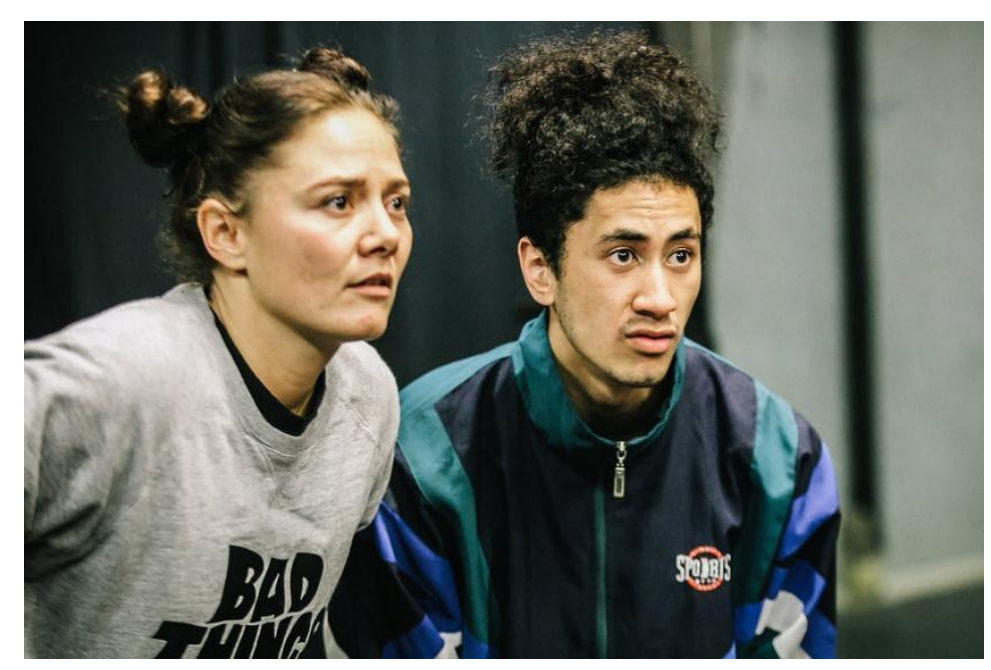

Figure 19: The Wholehearted. Massive Theatre Company.

Significantly, as well as the sense of enthusiasm in these responses, there were several recurring challenges that practitioners and companies identified. One of the main challenges identified by most of the companies in creating TYA was a lack of regular funding. This was validated by the fact that twenty-nine of the thirty-three companies who responded to the survey articulated that a lack of funding was one of the predominant challenges for them:

Typically, compared to theatre companies for adults of a similar size, we are woefully underfunded. (Palmer 8)

Financially it is difficult, as prices need to be kept as low as possible for young families/schools to afford, while funding sources "trusts etc." have many competing demands. (Palmer 6)

The costs of touring for longer are far outweighing the potential box office we can get to pay for this activity. (Palmer 17) 
In Christchurch, box office numbers and interest for TYP is strong and funding is basically non-existent. (Palmer 62)

Prices of course are low and do not cover the cost of production. (Palmer 29)

The survey highlighted a desire for TYA practitioners to have a greater sense of community and to be connected with other companies making similar work, in particular to be able to discuss shared challenges. It also emphasised a sense of frustration with the limited funding available and granted to TYA work, which led me to conduct a more in-depth investigation into how TYA work is funded in New Zealand.

\subsection{Funding TYA in Aotearoa/New Zealand}

In 2017, CNZ researched and presented an internal report on "The Arts by/with/for Young People in New Zealand" (Rees, "The Arts") to inform policy setting within the organisation. It outlined a broad account of how CNZ allocated funding for young people over all art forms. Data from this report, specific to theatre, has been useful to analyse and support ideas in this section. The report specified the different tiers of funding programmes with key roles that are directly related to young people: the Toi Tōtara Haemata ${ }^{49}$ (Arts Leadership) Investment Programme, and the complementary Toi Uru Kahikatea (Arts Development) Investment Programme ${ }^{50}$ (Rees, “The Arts”).

\footnotetext{
${ }^{49}$ Toi is Te Reo Māori for Arts. The tōtara is a native tree to Aotearoa. Haemata refers to the human qualities in this case growth, development, power, strength, protection, and leadership. ("Glossary") ${ }^{50}$ Toi is Te Reo Māori for Arts. Uru refers to a grove of trees. Kahikatea are native trees that often grow together and can be among the tallest trees in the New Zealand forest. A Kahikatea of 56 meters (185 ft) is the tallest native tree in the country. Kahikatea can grow in quite marginal land and are noted for the density and purity of the stands it forms in swampy areas and along river banks. It is also known for its strength ("Glossary").
} 
The Toi Tōtara Haemata Investment Programme would provide up to five years support to established, well run, financially sound arts organisations that fulfilled agreed key roles in creating, presenting, distributing, or encouraging participation in high-quality New Zealand arts experiences. The Toi Uru Kahikatea programme was more flexible in the range of activities that could be funded, and provided support to established New Zealand artists, arts practitioners, groups and arts organisations for periods of one to three years.

In 2017 there were seven Toi Tōtara Haemata funded organisations that identified as producing theatre by/with/for young people: Auckland Theatre Company, BATS Theatre, National Theatre for Children - Capital E, Taki Rua, Court Theatre, Massive Company, The Basement Company, and Playmarket. All of these companies were still Tōtara funded in 2018/ 2019, with the exception of The Basement Theatre. Toi Uru Kahikatea funded companies in 2017 with a focus on TYA included Barbarian Productions, The Conch, Shakespeare's Globe Centre New Zealand, and the Young and Hungry Trust. All of these were still funded under this investment programme for the 2018/2019 period, until the funding structure changed. It is important to note that, out of these twelve companies, only three - National Theatre for Children - Capital E, Shakespeare's Globe Centre New Zealand, and Young and Hungry - focus exclusively on TYA. The remaining companies incorporate work by/with/for young people in differing degrees of regularity into their programming. Of the forty-five professional companies identified in my survey that produce some level of TYA work, the majority were not Tōtara or Kahikatea funded. Instead, these companies rely on funding from CNZ's general arts grants, independent sponsorship, local council, and trust funding. 


\subsubsection{Tōtara, Kahikatea, and Project Grant Funding}

One of the key advantages of being Tōtara or Kahikatea funded is that companies do not have to apply for funding every year. These companies are also readily able to access CNZ's capability building programme, which provides organisational development and capability building in areas such as audience development, governance, fundraising, and volunteer management. For the rest of the companies, however, they are thrown into the mix of CNZ's general arts grants funding rounds. These funding rounds involve a variety of opportunities for funding for both emerging and established artists, groups and organisations ("Find Funding"). Tim Bray, from Tim Bray Theatre Company, explains the challenges with this model:

We only get project [general Arts Grants] funding from CNZ. This is our last three years turnover (net sales; box office, youth theatre enrolments, Gift a Seat ${ }^{\mathrm{TM}}$ donations and funding combined) and the percentage of successful CNZ funding each year:

\begin{tabular}{|l|l|l|}
\hline Year & Company Turnover & CNZ Funding \\
\hline 2019 & $\$ 939,059$ & $\begin{array}{l}\$ 31,700 \text { towards Gift a } \\
\text { Seat } \text { TM }^{\mathrm{TM}} \text { tickets for low } \\
\text { decile schools and admin } \\
\text { for Auckland Regional } \\
\text { Tour }\end{array}$ \\
\hline 2018 & $\$ 816,077$ & $\$ 7,500$ towards \\
& & Northland tour; $\$ 7,500$ \\
\hline
\end{tabular}




\begin{tabular}{|l|l|l|}
\hline & & $\begin{array}{l}\text { towards Board } \\
\text { development }\end{array}$ \\
\hline 2017 & $\$ 786,921$ & $\$ 0$ \\
\hline 2016 & $\$ 835,978$ & $\begin{array}{l}\$ 43,536 \text { towards Tour to } \\
\text { Northland, Hamilton and } \\
\text { Tauranga* }\end{array}$ \\
\hline
\end{tabular}

Figure 20: Table of Tim Bray Theatre company's funding 2016-2019.

*A similar Arts Grant application in 2017 was declined so we didn't tour.... we have no multi-year recurring funding so [we] begin each year with $\$ 0$ in funding and need to gather together $\$ 500 \mathrm{k}$ in funding by piece-meal applications through the year (Bray).

Other companies not funded by Tōtara or Kahikatea funding are in similar situations to Tim Bray Theatre Company. Some Tōtara and Kahikatea funded companies that were not identified as having a direct role with TYA in the 2017 report, such as Auckland Theatre Company and Circa Theatre, commission TYA work from independent TYA companies. This allows individual companies to bypass writing their own independent funding applications for these productions. Some companies also choose not to apply to CNZ, and find alternative methods of funding such as commercial sponsorship or community grants. But many, such as Tim Bray Theatre Company and the internationally renowned Little Dog Barking, have to apply for general arts grant funding on a project-by-project basis. This results in TYA companies having to compete against each other for an already small pool of funding. Furthermore, there is no category specific to TYA, which means TYA artists have to compete with general audience theatre companies and practitioners for the same pool 
of funding. ${ }^{51}$

\subsubsection{Current Funding Streams for TYA}

CNZ's 2017 tri-annual research report into New Zealanders and the Arts revealed that all young people (10-14 years) surveyed had engaged in the arts in the previous twelve months. The report noted that, "Schools continue to be the key driver of attendance and participation but $91 \%$ of young New Zealanders were also actively involved in the arts outside of school hours" ("New Zealanders and the Arts" 6).

Most young New Zealanders (67\%) feel positive when they are being creative. Of these a third (35\%) feel "brilliant" and a further third (31\%) feel "really good" ... The majority of young New Zealanders view the arts as a positive influence on their lives. They agree that being involved in the arts helps improve their confidence $(67 \%)$, as well as feel good about life $(62 \%)$ and make new friends 58\%. ("New Zealanders and the Arts" 6)

CNZ, via research company Colmar Brunton, conducted 751 online interviews with young people ages 10 to $14 .{ }^{52} \mathrm{CNZ}$ found these results largely encouraging but noted that enjoyment and participation in the arts decline as young people move into their teenage years and to high school. Importantly, the results revealed a gender distinction with $77 \%$ of girls responding positively to involvement in creative activities, as opposed to $57 \%$ of boys (Creative New Zealand 6). The report also found that young people (defined as ages 10 to 14) and young adults (ages 15 to 25) wanted more access to the arts and would do more arts activities if they were cheaper or free or closer to where

\footnotetext{
${ }^{51}$ In the May 2018 General Arts Council Grant round, CNZ received 31 theatre applications of which 10 (32\%) were successful (Adolph) but the percentage of applications for TYA projects was not disclosed. 52 There was a response rate of $20.5 \%$ (Creative New Zealand 25).
} 
they lived (Creative New Zealand 6). Briar Monro - Arts Practice Director, Community and Youth Arts - from CNZ notes that this trend is consistent across the years of research, but that they are seeing an increasing trend of young people aged 12 to 14 feeling less confident about their creativity than the 10 to 11 age group (Monro). The research also noted a decline in young people's enjoyment in the arts as they entered their teenage years (Creative New Zealand 6). CNZ express in the report that they need to understand more about the lower levels of enjoyment and participation among young people in the early teenage years, and, in particular, amongst boys (6). The categories included in the survey were performing arts, visual arts, digital arts, Māori arts, literary arts, and Pacific arts. In regard to the types of arts that young people wish to be more involved in, performing arts is a close second, after digital arts (21).

Performing arts - which includes ballet, dance, plays, concerts, musical performances and circus - is also the most popular art form that young people attend, with $64 \%$ noting attendance at least once in the previous 12 months (22). Crucially, although Performing Arts participation rates have declined from $88 \%$ (in 2014) to $82 \%$ (2017), young people's obvious desire to be more involved in the performing arts indicates a potential for growth in the future (23).

As a result of trends identified during their ongoing research, in 2019 CNZ initiated three new funds for arts projects targeted towards young people:

The Toi Rangatahi ${ }^{53}$ Participation Fund - supports artists/organisations to provide opportunities for young people aged 10-14 to participate in highquality arts activities. Grants up to $\$ 65,000$ are available.

The Toi Rangatahi Engagement Fund - supports established organisations that

\footnotetext{
${ }^{53}$ Young people.
} 
want to provide opportunities for people aged 15-25 to engage in high-quality arts experiences. Grants up to $\$ 65,000$ are available.

The Toi Rangatahi Leadership Fund - supports young people aged 15-25 to lead high quality arts projects by, with and for other young people. Grants up to $\$ 10,000$. (“Young New Zealanders to Get More Opportunities for Arts Experiences").

These funds are part of a five-year initiative which include an investment of $\$ 500,000$ in the first year across the three funds. Creative New Zealand's Senior Manager of Arts Development Services, Cath Cardiff stated: “We want more young people to have the opportunity to explore their creative potential. These dedicated funds will help to generate more opportunities and also support young people to create the arts experiences that appeal to them" ("Young New Zealanders to Get More Opportunities for Arts Experiences").

In March 2019 CNZ revised their funding structure. Their objective was to align the grants system better with their investment structure and to simplify the system for arts practitioners. There were no significant funding structure changes (Monro), the main changes that affected TYP practitioners were in the structuring of the general arts grant's funds. There are now two funding rounds a year for proposals up to $\$ 10,000$ (up from $\$ 7500$ ), two rounds for proposals between $\$ 10,000$ and $\$ 75,000$ (previously the limit was $\$ 65,000$ ), and one round per annum that grants up to $\$ 150,000$ ("Changes to Creative New Zealand's Grants Programme").

Also implemented in 2019 were changes to the Toi Tōtara Haemata and Toi Uru Kahikatea Investment Programmes. The changes meant that now Toi Tōtara Haemata companies will secure funding agreements for six years, with a review of the funding 
level after three years; previously the maximum funding period was five years. CNZ also identified five priorities for investment clients which included New Zealand arts by, with, and for young New Zealanders. The Toi Uru Kahikatea Investment changes mean that funding agreements are secured for either two or three years, instead of the current one to three years ("Changes to Creative New Zealand's Grants Programme"). CNZ hopes that these changes will contribute to increased sustainability of arts practice and less time by practitioners spent doing arts grants proposals ("Changes to Creative New Zealand's Grants Programme").

These changes have impacted some TYA companies. Capital E is the only dedicated TYA company to now be part of the Toi Tōtara programme. Massive Theatre Company and Shakespeare Globe Centre are the only dedicated TYA companies to receive Toi Kahikatea funding. Most notably absent is funding for one of New Zealand's longest-running professional youth theatre initiatives, Young and Hungry, which had previously been Kahikatea funded. Young and Hungry had been operating for 25 years. It provided an annual season of plays performed and designed by and for audiences of 15 to 25-year-olds, and mentored by professionals. It moreover encompassed the annual Ensemble Impact ${ }^{54}$ tour to secondary schools (Palmer 6-7). Also absent from this new pool, are funds for arts involving young people aged 0-10, as is any dedicated research specific to this age group. Nonetheless, even when taking into account the fact that these CNZ funds are available to projects in all art forms not just theatre, this new initiative is a positive step by CNZ to address some of the funding shortcomings that exist for many TYA companies. TYA companies now have four ways of accessing CNZ Funding: as clients of the Tōtara or Kahikatea Investment

\footnotetext{
${ }^{54}$ Ensemble Impact's show is a compilation of scenes from New Zealand plays.
} 
Programmes, through general arts grants, the three Toi Rangatahi Funds and through Creative Communities ("Find Funding").

Update: COVID 19 has impacted the arts sector and Creative New Zealand have had to readjust their funding structure for 2020 and 2021. On July 13 2020, CNZ's Arts Practice Director Briar Monro responded to my enquiries regarding post-COVID arts funding available for TYA companies:

In the 2020/21 financial year Creative New Zealand's funding programme will be specifically tailored to respond to the Covid 19 environment. TYA companies that are not already clients of the Tōtara or Kahikatea Investment Programmes will be able to access funds through Arts Grants, Annual Arts Grants and a new initiative 'Ngā Toi Ā Rohe' and through Creative Communities. The three Toi Rangitahi funds (Toi Rangitahi Participation Fund, Toi Rangatahi Engagement Fund and Toi Rangatahi Leadership Fund) have been suspended. (Monro)

The purpose of the Ngā Toi ā Rohe - Arts in the Regions Fund is to focus on funding Arts in the regions outside the main centres of Auckland, Wellington and Christchurch. It aims to incentivise community groups to partner with CNZ in developing and presenting local arts activities ("Ngā Toi ā Rohe "). The intention is to increase arts investment, encourage high quality arts in communities, and increase attendance and participation in the arts. ("New Fund Focusing on Arts in the Regions to Open in 2020")

\subsubsection{Financial Challenges}

Where and how TYA practitioners can access funding is important to detail, as it can often be confusing to know exactly what funding is available, in particular for independent companies. What is crucial to note, however, is that the level of funding 
that $\mathrm{CNZ}$ awards is rarely enough to fully fund a production. For example, Hannah Smith of Trick of The Light Theatre Company states the costs for the company's initial season of their award-winning production The Bookbinder were $\$ 8271.72$. They received funding of only $\$ 3500$, leaving a shortfall of $\$ 4771.72$ (H. Smith). This means that outside grants, sponsorship, and box office takings also have to contribute to the overall running costs of each company. Relying on box office income is problematic in TYA. The target audience do not have independent income and rely on guardians making the financial decisions and there is an entrenched perception that: "Ticket prices have to be low to be affordable for families. Costs such as theatre hire, production design, promotion, etc, are as high for theatre for young audiences as for other productions" (Palmer 25). This reliance on box office income has a cumulative effect on the wages or fees that support creatives, as well as production values and aesthetic considerations of the shows. The low wages and fees of theatre practitioners within the sector as a whole in New Zealand makes a career solely in theatre non-sustainable and rarely viable. A CNZ report published in May 2019 reveals:

The median personal annual income for creative professionals in this survey is around $\$ 35,800$ - compared to $\$ 51,800$ for all New Zealanders earning a wage or salary or $\$ 37,900$ for self-employed New Zealanders. However, when you take away other sources of income, the median income from creative work is only $\$ 15,000$. (“A Profile of Creative Professionals 2019”)

Several of the practitioners I surveyed also spoke of their frustration at having to supplement their income with non-theatre jobs: "Most [TYA practitioners] have to have day jobs to get by, and this limits their availability as theatre collaborators" (Palmer 26). Having to find alternative income streams and/or spending precious creative energy sourcing funds to make work invariably has an effect on both the quantity and the 
quality of work being produced. Also, worth considering is the report's findings on sustainability in the wider sector:

Creative professionals in the acting and theatre production and music and sound making sectors appear the least sustainable. They are the least satisfied with their career, and are more likely than average to feel there are insufficient opportunities in New Zealand for them to sustain a career, and to feel they need to go overseas to develop their career. ("A Profile of Creative Professionals 2019")

This report validates many of the challenges that TYA practitioners articulate in the survey. One of the largest frustrations that many TYA practitioners face is not that we have a lack of ideas and creativity to produce outstanding work, but that the infrastructure and funding models do not support the creation of TYA to a sustainable level. Practitioners often experience burnout and exhaustion in the pursuit of making quality work while simultaneously trying to survive in the 'real world' of rent-paying and food-buying. Sam Scott relates how the staff at Massive Theatre Company are spread very thinly and have to do everything between them, which results in very long workdays, plus weekends and evenings. She believes that this results in many of Massive Theatre Company's producers and general managers leaving the company because they don't earn enough money and are often exhausted by the job (Palmer 2-3).

\subsubsection{The Impact of Funding Restrictions}

Other companies also relayed frustration at how lack of resourcing leads to burnout and a lack of pastoral care:

Resources and personnel are not always up to scratch. Sometimes teams are sent 
out without pastoral support e.g. 3 or 4 young people on the road for months doing set up and pack down without an older team member to really support their wellbeing. I hear some bad stories from actors (Palmer 33).

This is, unquestionably, an area that needs to be addressed to ensure a healthy TYA industry. Well-funded companies make it a priority to send a stage manager and/or tour manager on the road to assist in driving, set up, and pack downs, attend to administration duties, and administer pastoral care. For example, Capital E send a stage manager and a technician as well as a tour manager, in addition to the actors on tour. Underfunded companies, however, only have enough resources to send a troupe of actors on the road. My own experience with this style of touring is that it can create a very stressful environment. The hours are long, as are the road distances travelled, and the workload is itself high. The relative youth of many of these touring actors can compound the problem, due to a lack of resources for maintaining their physical and mental health.

Other challenges commented on by practitioners are the outside costs of rehearsing and presenting TYA work, such as venue hire. Lauren Jackson (Brick Works Theatre and Duffy Theatre playwright) makes an excellent point about the lack of accessibility for arts:

I often think about the fact that the arts are just as vital as sports to children's development. Sports fields are readily available, council-owned, and free to book and use. However, arts venues or community spaces almost always come with a hireage fee. So, I think the fact that theatre has a long way to go until it as normal as Saturday morning soccer, is a cultural restriction in Aotearoa. (Palmer 72) 
Stephen Blackburn argues that sports organisations know the more they fund early on in a young person's life, by giving them access to a variety of sports and accessible facilities, the less they will have to fund later on and the better the professional results:

They know that [children] provided with opportunities could be the next elite sportspeople or, at the very least, a dedicated follower of the sport, willing to part with their future disposable income to watch the elite sports people-thus reducing the need for subsidy for the elite sports event. (Blackburn 17)

The comparison of funding between arts and sports would benefit from more in-depth research. However, as Jackson and Blackburn suggest, the arts - compared with sports are most likely being undervalued by the government in terms of allocated funding. Perhaps if theatre was funded in a similarly sustainable way as rugby and netball, in particular for young people, then maybe our theatre could be comparable to world champion sports teams such as The All Blacks ${ }^{55}$ and The Silver Ferns. ${ }^{56}$

Prior to the COVID 19 funding announcement by CNZ, there was a level of optimism from some of the Tōtara/Kahikatea Investment clients that I spoke to informally about the 2019 changes. Both Capital E and Taki Rua, for example, expressed enthusiasm in having a longer dedicated period of funding, hopeful that it would lead to new options being considered, with less time spent on funding applications. Sam Scott welcomes the change for her company from Tōtara's new six-year funding cycle to the shorter span of Kahikatea funding: "As we are a company which responds to those who engage with us, we felt we couldn't take the 'pulse' and plan for 6 years ahead" (Scott). Although it is disappointing that some companies have been excluded from the

55 New Zealand's National Rugby team

${ }^{56}$ New Zealand's National Netball team 
new funding structure, it is possible this will make way for new companies to thrive. Having a bigger pool of money for arts grants may lead to a higher quality of work through more resourcing. However, I would also recommend that the money goes towards fairer remuneration for the practitioners involved. In order for the sector to survive, thrive and retain its excellent creatives, I believe it needs to remunerate them better and more in line with - at the very least- the median income earned in New Zealand.

\subsection{Touring TYA}

A unique challenge for New Zealand is our geographic location and size. As stated by one of the surveyed practitioners: "Our small population necessitates touring offshore [to achieve economic viability]; a tyranny of distance makes touring expensive and limits exposure to new work and ideas at home" (Palmer 5).

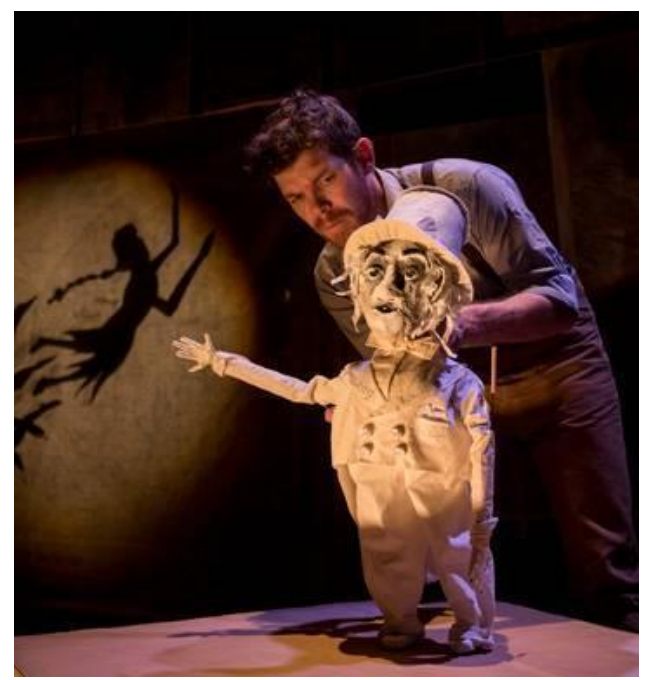

Figure 21: The Road That Wasn't There. Trick of The Light Theatre Company.

Touring overseas from New Zealand is hugely expensive. ${ }^{57}$ In addition, touring at home

\footnotetext{
${ }^{57}$ Hannah Smith of Trick of The Light Theatre Company, estimates the costs for a tour to Australia is approx. \$10 000 NZD and to the UK or the USA approx. \$24, 000 NZD (H.Smith).
} 
is also challenging, because of New Zealand's unique size and the expense of travelling around the country. There is a particular challenge in getting quality TYA theatre to the regions beyond the main city centres. Taki Rua Productions has been touring its Te Reo Māori season ${ }^{58}$ for over 25 years. Kahukura/Chief Executive, Tānemahuta Gray remarked that as part of their annual funding from $\mathrm{CNZ}$, the company is expected to tour their TYA work into more of the regional areas. The challenge with this is that $\mathrm{CNZ}$ only partially subsidises the tour, and the costs of touring to more areas is beginning to outweigh the potential box office they receive. Also challenging their income is their staggered box office, where smaller schools are subsidised by the larger schools. These challenges mean: "we have to find significant funding from other trusts, foundations and sponsors to keep our outreach as wide as it currently is" (Palmer 17).

Distance is not the only challenge with touring TYA work. Sacha Copland from Java Dance Theatre sees challenges in the current approach to booking TYA work and advocates:

We need a centralised booking system where schools can access high quality relevant work in a range of forms. At the moment it is so random and everyone tries to do it independently. Schools get inundated with promotion and it is hard for busy teachers to tell what will work for them. The major theatres don't offer all the art forms. We need one place where teachers can access the options. (Palmer 69)

This proposal is in line with Denmark's successful model of Aprilfestival and The Red Brochure as discussed in Chapter Four, and suggests that a capability study on the best

58 An annual theatre work for young audiences entirely in Te Reo Māori. 
practice in centralised booking systems, or a method of brokering relationships between TYA companies and schools could be beneficial in strengthening the TYA industry in New Zealand.

\subsection{Value in The Theatre Community}

Another area of commonality between TYA practitioners, and one that resonates with my own practitioner experience, is that of being undervalued by the wider theatre industry. Many practitioners commented about feeling marginalised: "[TYA] can still be marginalised by other arts practitioners and not seen as important"(Palmer 1); and the lack of perceived value of TYA work: "Many [in the wider industry] don't see any value in TYA" and "TYA is chronically undervalued in terms of industry respect and recognition"(Palmer 21). There were observations made about the absence and shortage of industry recognition: “Wouldn't it be great if TYA featured more in media and in things like theatre awards, annual theatre round-ups by commentators?" (Palmer 9). Several practitioners commented on feeling frustrated by attitudes from other theatre practitioners that TYA is easier to make and less important that adult theatre: "Even actors often see it as casual work not to be taken seriously enough!" (Palmer 47); and “Our own arts industry needs to acknowledge children's theatre as a valuable art to start with. Not treat it like the awkward, less talented, less reputable cousin" (Palmer 54). David Rumney from Duffy Theatre noted a challenge in attracting graduates with his observation that "graduating actors in the general terms have a mindset of wanting to be available for screen work in case they get their 'big break'" (Palmer 23). Lynn Cardy of Auckland Theatre Company commented on the lack of pathway for actors interested in TYA, noting that graduating actors didn't often realise that TYA was a valid option (Cardy). Reflecting on what work drama school students look to after graduation prompted me to look more closely at what training was available in New Zealand. 


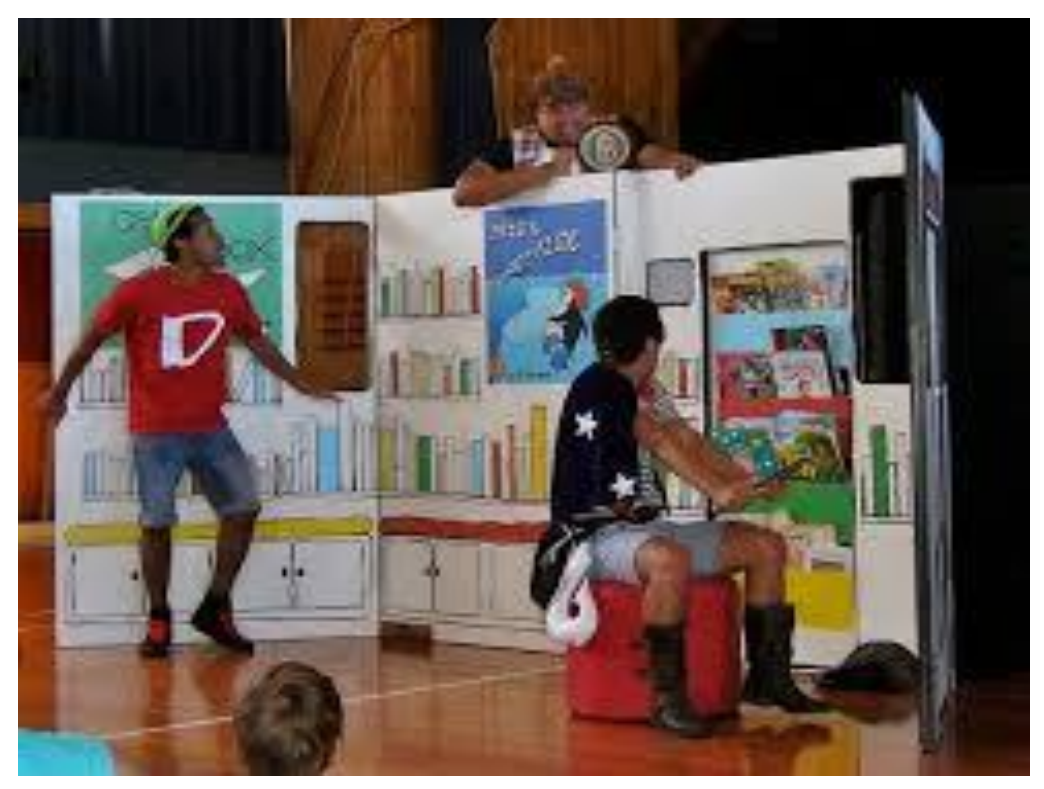

Figure 22: Duffy and the Book Bus Adventure. Duffy Theatre.

\subsection{Training TYA Actors}

David Wood suggests that TYA actors have to work harder than actors for adults because of the dedication and energy that they have to give, as well as the volatility of the audience they present to (221). Stanislavski stated that: "It is necessary to act for children as well as for adults, only better" (qtd. in Goldberg, 23). Because of the specialist nature of performing for children I contacted three leading actor-training schools in New Zealand to ask if they trained actors specifically in TYA. Toi Whakaari: New Zealand Drama School's Bachelor of Performing Arts degree trains actors in both screen and live performance. Over three years actors are trained in a variety of skills and methods (Toi Whakaari.) The only training programme in TYA is an annual Wellington High schools tour of a classic text - usually Shakespeare - which is directed by Toi Whakaari tutors and performed by 2nd-year students. The students rehearse for 80-90 hours and do ten showings to local schools over one week (Thomas). Michelle Hine, from the one-year intensive industry-based course The Actors Programme, 
replied "We don't train actors specifically for working with TYA at The Actors' Program - our focus is more on adult screen/stage performance" (Hine). John Davies, of Unitec (New Zealand Institute of Skills and Technology) in Auckland, responded that, although they don't specifically address TYA in their curriculum, they train actors in a technique that means they are able to adapt to a variety of arenas (Davies). He emphasised that Unitec actor-training focuses on ensemble-building and telling the story, both skills that are important in TYA. He also highlighted that Unitec was very supportive of their students and graduates working in TYA, and currently had a student seconded to Tim Bray Theatre Company. Unitec actively promote auditions and work within TYA companies, and this has led to many Unitec graduates working in this field and importantly, understanding the value of creating and performing TYA (Davies).

Worth noting here is that P.I.P.A, The Pacific Institute of Performing Arts, that closed in 2017, had an annual TYA work as part of its programme, and was known to produce several students that were enthusiastic TYA makers - including several I employed as part of Duffy Theatre. The closure of P.I.P.A highlights the lack of commitment to TYA by tertiary institutions in Aotearoa/New Zealand.

It could be argued that good actor training prepares actors to respond to any job, and that they do not need to train in a different way to work with child audiences. But if, as Wood suggests, acting for children is harder than acting for adults (Wood and Grant 221), then perhaps trainee actors should be made aware that performing for a young audience is different than performing for adults, as well as being made aware of the opportunities and pathways available in TYA 


\subsection{Talking with The Audience/The Audience Voice}

Another issue integral to the creative component of this thesis is the way TYA practitioners involve young people in the making of their work. A significant finding from the survey was that not all TYA companies consult young people in their making processes. A small number had not even considered involving young people in the creation of TYA work. Some companies create works based solely on their personal understandings and beliefs of what children will respond to. Others employ limited creative agency from young people, which typically involves relying solely on a retrospective analysis of the work, such as reviews. However, what was motivating to observe was that many companies did involve young people in some way in the creation of their work. This comprised a variety of methods such as young people being involved in programming panels at ATC, internships, and at planning, delivery, and board levels. For instance, Massive Theatre Company has representation on its board from emerging artists (Palmer 2).

Audience response in the form of discussion, written feedback, focus groups and surveys was identified as a method of involving young people. Several companies work with young people at the early development stage. The methods employed at this point are also varied, including asking young people specific questions; sending drafts of scripts to children to review; visiting schools; and getting young people to draw and design characters and set elements. Also utilised were workshops, play sessions, and invitations for young people to view and comment on works in progress. Several companies - in particular those that worked with youth - cited having young people as part of the devising process as integral to the content and creation of the work. For company Mixit: "The voices of the youth are always at the front of the mahi (work)" (Palmer 42). 
Playwright/producer Renee Liang discusses methods she employs when making TYA work, such as having children in the rehearsal room and constantly watching the audience when one of her plays is being performed. Particularly resonant was her observation of director Tainui Tukiwaho who has five children, aged five to twelve, “which was very useful when directing Sofija's Garden [aimed at five-twelve -year old's]". She relays how Tukiwaho's kids would sit in rehearsals and watch; if they didn't laugh, she would consider rewriting that moment. In addition, Tukiwaho would constantly be asking the kids for their opinion, giving them further agency in the creative process (Palmer 77). Liang and Tukiwaho's work aligns with my own prior experience of having children present in the rehearsal room and the way that it encourages actors and other creatives to be responsive to and engage with their audience throughout the rehearsal period. Although in the THEA 311 project we didn't have children regularly in the rehearsal room, mainly due to the complexities of arranging school visits, we engaged with children at different points in our project to ensure that we listened to children's opinions and practiced responding to and engaging with them.

The fact that some TYA companies do not consider engaging with their audience in the devising process could suggest a lack of understanding of the value of this approach. But combined with the struggles that many TYA practitioners are expressing, it may also suggest that they simply do not have the time and resources to undertake this sort of deeper engagement. I chose to curate a relationship between two groups of young people in my arts research project so I could test the value and practicalities of such interactions, and the idea that engaging young people in the creation of TYA work is crucial to making work that is resonant with and responsive to a young audience. 


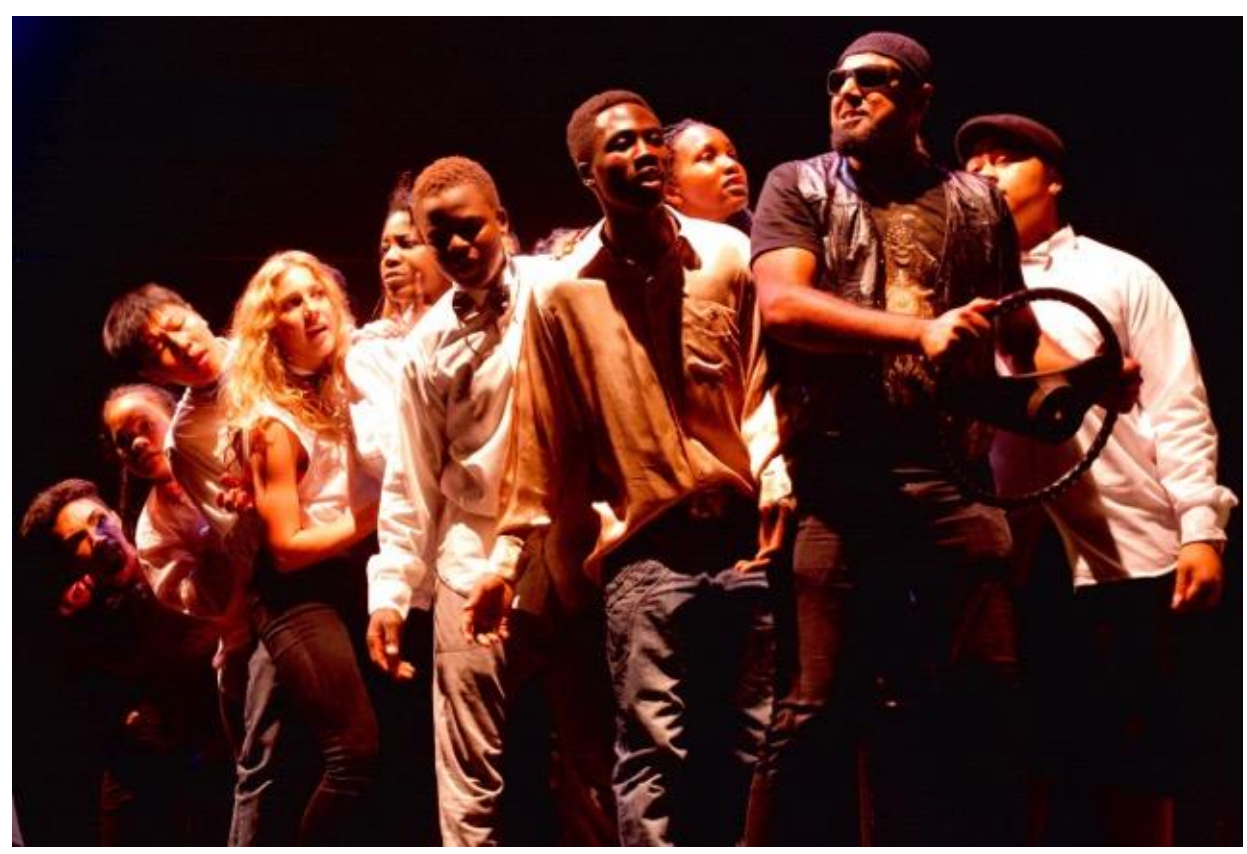

Figure 23: MIXiT- A creative project for young people from refugee backgrounds mixing it up with migrants and locals.

\subsection{Summary}

The survey data and subsequent findings presented above provide an overview of the sector and generate the beginnings of a way forward to strengthen it: to identify the things that need to change, to make it better funded, less marginalised, to create more sustainable career paths and safer working conditions. The responses confirmed many of the issues that I have had first-hand experience with as a TYA practitioner, and supported my theories around the undervaluing and underfunding of the sector. It is disappointing that a lack of adequate funding, and the underrating of the importance of TYA, are prevalent, and have the potential to lead to practitioner burnout. However, it was heartening to see that there are many companies creating quality TYA work in New Zealand. It is particularly encouraging that our main funding body, CNZ, has recognised many of these issues and although there is a long way to go, this survey suggests that there is the talent, potential and willingness to create a vibrant TYA industry in New Zealand that is sustainable and healthy. 
My own creative project came from a desire to test if making theatre with young people is a productive and effective way to create theatre for young people. How do we as creatives give real agency to the young people in a way that empowers them and increases the overall quality of the work? These questions are investigated in the following chapters. 


\section{He Whānau Kotahi ${ }^{59}$}

\section{Directing the Youth Ensemble}

“What do you mean, we have to create a play from scratch?!' (Swale, xvi)

\subsection{Introduction}

One of my key research goals is to build a model for intergenerational collaborative devised theatre which encourages agency and empowerment for all those involved in the making, presenting and viewing of the work. This chapter focuses on the building of the ensemble of young people in THEA 311. It analyses methods used throughout the devising process to establish an environment that encouraged agency and empowerment. It also explores the process the group employed to create the material that led to the plays Moonlight and In The Attic, and the way this process contributed to the building of the ensemble.

TYA director Constance Cauers observes:

A rehearsal process with young performers is a voyage of research. It is in the nature of things that this sometimes involves a considerable amount of material suggestions and scenic translations, of which only a few selected ones will ultimately be used. Trial and error, evaluation and rethinking: everything is open until the very end. And I do not spare my actors this theatrical reality, although

\footnotetext{
59 We are one Family- from the whakataukī, as discussed later in this chapter
} 
this is not always pleasant - and sometimes very exhausting - for everyone. (Cauers 25)

In this 'voyage of research' I aspired to establish a method of collaboration with a group of young theatre-makers, the THEA 311 students, that was flexible, engaging, safe, and empowering. I wanted the students to create two devised plays from scratch, with the goal that through this process they would:

1. Experience a collaborative process that empowered them and helped them to become generous and self-reflective practitioners.

2. Learn skills and gather confidence so they could lead devising processes after the course had finished.

3. Engage with the TYA genre. I hoped that some would see this as a valid career option and that all would recognise the importance of this often-undervalued sector of the theatre industry.

The ensemble participants were:

Mentor: Dave Brown (PaperBoats Founder)

Director/Devisor: Kerryn Palmer

Assistant Director: James McKinnon

Stage Manager/Production Manager: Samantha Tippet (MFA Intern)

Composer and Sound Designer: Joel Rudolph (MFA Intern)

Technician: Anna Pastor-Bouwmeester

Devising Ensemble:

Illuminations: (In The Attic): Peter Bolsover Rogers, Terri Cochrane, Cassidy Cruz, Daniel Gagau, Janaye Henry, Georgia May, Gemma Revell, Saffron Troughton, Corey Wills, Natalie Wilson 


\section{Paper Bag Productions (Moonlight)}

Georgia Ball, Dara Flaws, Yasmin Golding, Emma Maguire, Pelle Himmelmoe, Kevin Orlando, Alexander Robertson, Nicole Topp-Annan, Finnian Nacey.

Note: All participants have given express permission, via signed consent forms, detailed in the ethics section, to be mentioned as part of the process and outcomes of this project.

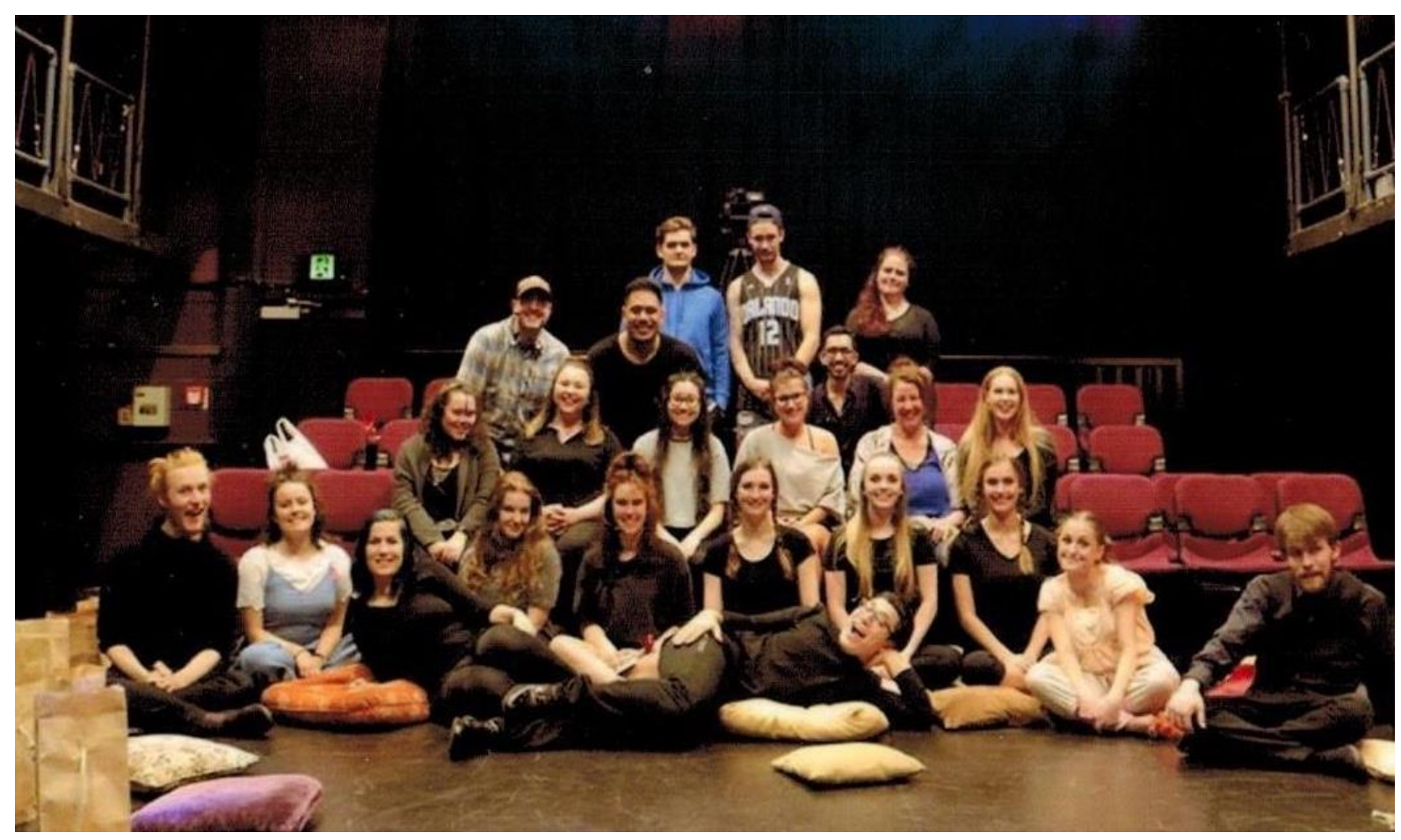

Figure 24: The Class of THEA 311.

The students were aged between nineteen and twenty-four years and had varied life and devising experiences. The majority were New Zealand citizens, with the addition of one American and one Norwegian student. The ethnic breakdown of the New Zealand students included one Samoan, three Māori, and one Filipino, with the rest identifying themselves as Pākehā (European-New Zealanders). This is pertinent because of the way that different cultural backgrounds and upbringings can influence 
the way students work in the rehearsal room. They were all theatre majors, most in their final year of undergraduate study. Twice as many students applied than could be accommodated into the course, so there was a demonstrated level of competency within the group selected. I was also fortunate to have two Masters of Fine Arts students interning to the class, an accomplished technician, a mentor who was a specialist in TYA, and a teaching colleague who wanted to learn more about leading a devising process, and asked to work alongside me as an assistant director.

The ages of 18-24 years can be termed as Late Adolescence/Young Adulthood. As specified in Developmental Tasks and Attributes of Late Adolescence/Young Adulthood (Ages 18-24 Years), this stage of adolescence can be viewed through a development lens as: "a period of frequent change and exploration that covers many aspects of their life: home, family, work, school, resources, and role...early adulthood experiences vary greatly by gender, race and ethnicity, and social class"' (Teipel 1).

The developmental tasks and attributes of this age group that most relate to the collaborative work we were doing are:

- developing and applying abstract thinking skills;

- defining a personal sense of identity;

- adopting a personal value system;

- developing stable and productive peer relationships; and

- meeting demands of increasing mature roles and responsibilities (Teipel 1-2).

These attributes also aligned with my research enquiry of giving the students more agency in the devising process. 


\subsection{Preparation - Building the Ensemble}

Using Swale's methodology, the ensemble-building part of the devising process is Stage One: Preparation (Swale, xxx-xxxi). Swale maintains that "there is no sure-fire recipe for success when it comes to devising" (xxix). As directors leading a devising process, we become facilitators of a practice that is experimental in its nature. Directing an ensemble of young theatre-makers requires a unique set of skills. TYA director Ariel Doron observes:

The challenge is to create an environment in which everybody has an equal chance to play, contribute and even change the rules of the game during the game itself, while still taking the role of a responsible adult: i.e. being attentive both to each individual's needs and the needs of the entire group, but also constantly checking and ensuring that the group and the game we are playing are still on the same path to our self-imposed goal, even when this is dynamic and constantly changing. (Weyrauch et al. 34).

The environment I was aiming to create is modelled on a 'family' dynamic, in line with my personal directing philosophy as discussed in Chapter One: to facilitate, guide, and create conditions where creative work can evolve in a safe and supported way. I wanted to establish a warm and caring environment where students were encouraged to collaborate equally on united values and goals, one that was responsive and open, but still had parameters so that the ensemble felt safe and supported. In a university environment, there is an intersect with pedagogical expectations where the line between teacher and director/collaborator can become blurred. Although I had directed university productions with young theatre-makers before, this project encompassed a unique set of circumstances: an international collaboration, undergraduate students, 
post-graduate students on internship, two classes of children, and a $\mathrm{PhD}$ arts research project.

A family dynamic refers to the way that families will not always agree with each other, but their values, goals, love and care for each other remain united. Also integral to my directing practice is the goal to treat all ensemble members with compassion and kindness. I allow the ensemble to build trust in me as a leader and mediator for pastoral care and problem solving. The main methods I employ to ensure these values are integrated into the rehearsal room are:

1. To be empathetic, non-judgmental and listen actively to ensemble members,

2. To be approachable and reasonable by having an 'open-door policy,' where students can approach me to discuss any problems,

3. To speak respectfully and positively.

This is a style of directing that I am comfortable with and proud of, but the process and the retrospective analysis of it has made me question my directing style, and specifically if this 'maternal' style of directing is conducive to creating an empowering devising experience for young people.

\subsubsection{A United Vision}

THEA 311 began in July 2017 as two three-hour classes, held weekly on Mondays and Wednesdays. Our time together increased incrementally until the class were eventually meeting for fifteen to twenty hours a week. At the beginning of the course the classes were structured and director/teacher led. Each day would begin with a circle check-in, where everyone would individually give a number between one and ten, to indicate 
how they were feeling physically and emotionally. This 'took the temperature' of the room, and signalled if anyone had any physical or emotional needs that needed attention. Shelia Kerrigan writes: “Check-ins air out secrets and hidden agendas ...You can check in spiritually, mentally, emotionally and/or physically ...You can ask for what you need...check-ins clear the air about conflicts" (90-91).

A fun or silly icebreaker would follow, such as: what animal do you feel like today? One of the main focuses of coming together as a whole group at the beginning of the class was to ensure we were all present in the room. Phones were put away and the students were expected to be focused. We would then do a fifteen to twenty-minute physical and vocal warm-up.

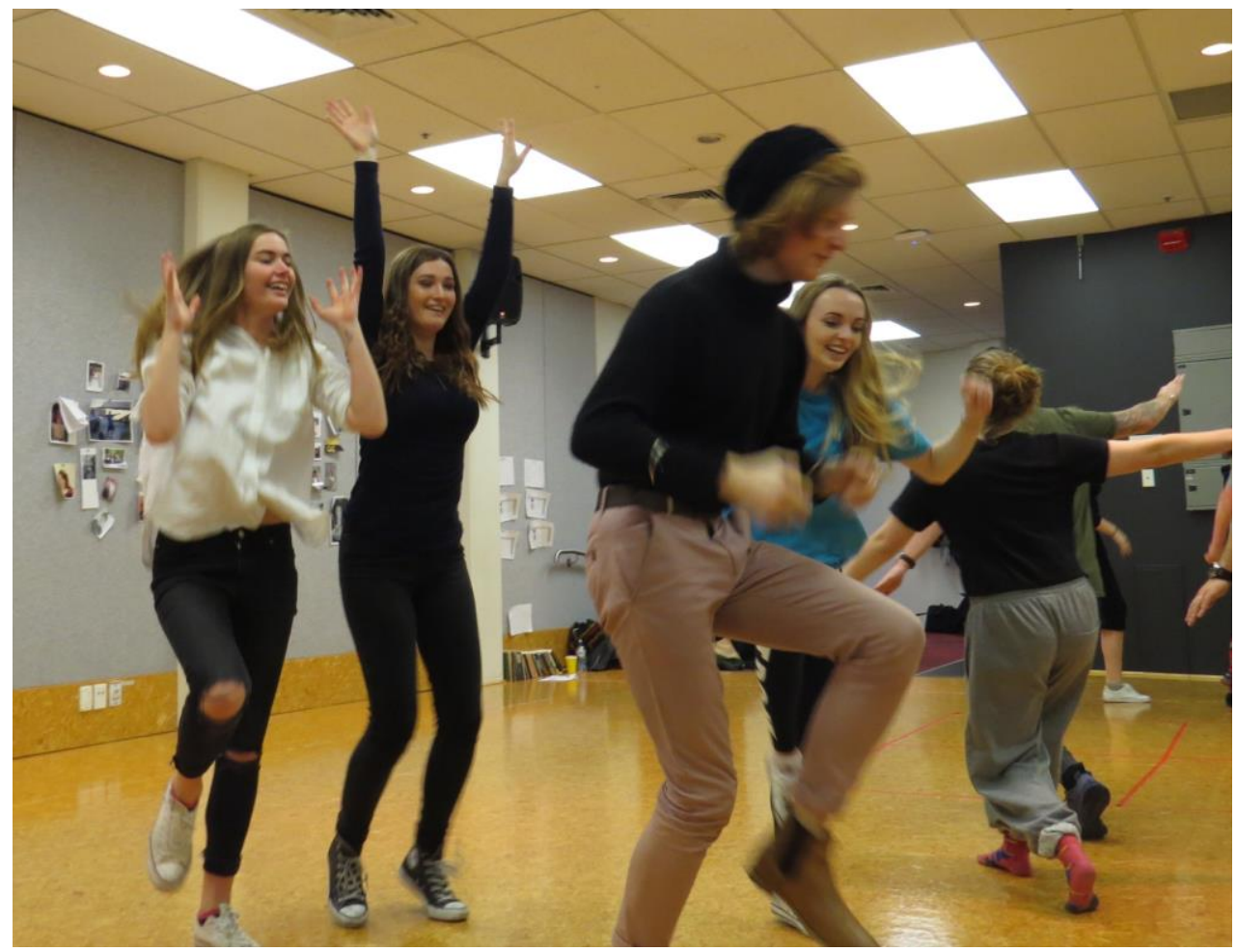

Figure 25: THEA 311 Warm-ups 
Next, I would give a rundown of the work that was planned for the day and the purpose behind each activity. We would spend the rest of the session focussing on the provocations and devising activities. The class would finish with a 'check-out'. The purpose of which was to air anything that had happened in the class, to set homework, and to encourage students to briefly evaluate the work that had been done. The students were also encouraged to keep a workbook where they would analyse and reflect. To give the students more agency as the term progressed, I encouraged them to lead the warm-ups, check-ins, check-outs, and devising activities, with the intention that eventually the group would be able to run the rehearsals without me in the room.

Alison Oddey suggests a fundamental requirement for a successful devising process is the positive and creative collaboration of the group:

Devising begins with the interaction between members of a group and the starting point/stimulus chosen. The group absorbs the source material, responds to it and then generates a method of working appropriate to the initial aims of the company and the project. (Oddey 24)

Oddey clarifies that it is necessary early on in a devising process to make decisions about how the group will operate throughout (42). In the past I have found that setting a clear pathway for how the group will work and agreeing on shared goals for the project, helps create a positive ensemble. Because devised theatre relies on collaboration and democracy, the bigger the group, the more diverse the ideas, opinions, and previously learned methods of working are. With twenty-five members of the ensemble, we needed to navigate our collaboration and democratic process on a large 
scale. On day one I introduced a whakatauk $\bar{i}^{60},{ }^{60}$ Māori proverb, as a guiding principle for the class. Whakataukī are an important part of Māori culture used as reference points in speeches and to guide everyday life (Māori Proverbs Whakataukī). The purpose of using this whakataukī was to guide the way we worked as a group.

\section{He Whānau Kotahi}

He Kaupapa Rangatira

He Waka eke noa

We Work as one family

With a chiefly/united vision

We are all paddling the same boat

(Keane \& Ombler)

'He waka eke noa' represents the concept of a group working together collectively towards a unified goal. In relation to the class, it meant agreeing to an ideology to articulate our vision and to work collaboratively towards this vision. The family-centric view in this whakataukī also resonated with my style of directing.

\subsubsection{Looking to Childhood for Inspiration}

One of our key goals was the desire to create quality theatre that was engaging to a young audience. We began by looking to childhood and children for inspiration, and asking 'what engages a young audience?' There were beneficial links between this question and the processes we used to answer it. Devising is an ideal mode to investigate engaging with a young audience, as the practices of the form are frequently connected to playfulness and play, which are attributes inherently associated with children.

\footnotetext{
60 This whakataukī, was shared with me by Moss Patterson of Atamira Dance Company.
} 
Qualities and behaviours that are perceived to be innate to most children such as spontaneity, improvisation, make-believe, and play, are practices used in devising theatre which relies on the adoption of similar techniques to create imaginative work; in addition to reinforcing the benefits of 'unthinking' learnt behaviours. Dave Brown claims:

Young children see the world through fresh eyes. They are largely unfettered by experience. They think radically because they know "no better." They reside freely in their imagination. They are open to "the new" because everything is new for them. They play and explore and learn naturally and joyfully." (Brown, "4. Provocations and Insights")

Playing, exploring, and learning joyfully like children also felt in keeping with the creation of a family-centric and fun ensemble. Therefore, in the first two workshops of THEA 311, the students were encouraged in their warm-up sessions to reminisce on their childhoods by playing games they remembered, such as Four Square, Crocodiles, Heads Down Tails Up, and Wink Murder. They were urged to recall what it was about these games that they enjoyed as children and how the games made them feel. The purpose of playing these childhood games was an attempt to get the students to reconnect with their childhood, to remind them of what games and activities as children they engaged with, and to recall the physical and emotional ways in which they may have responded. 


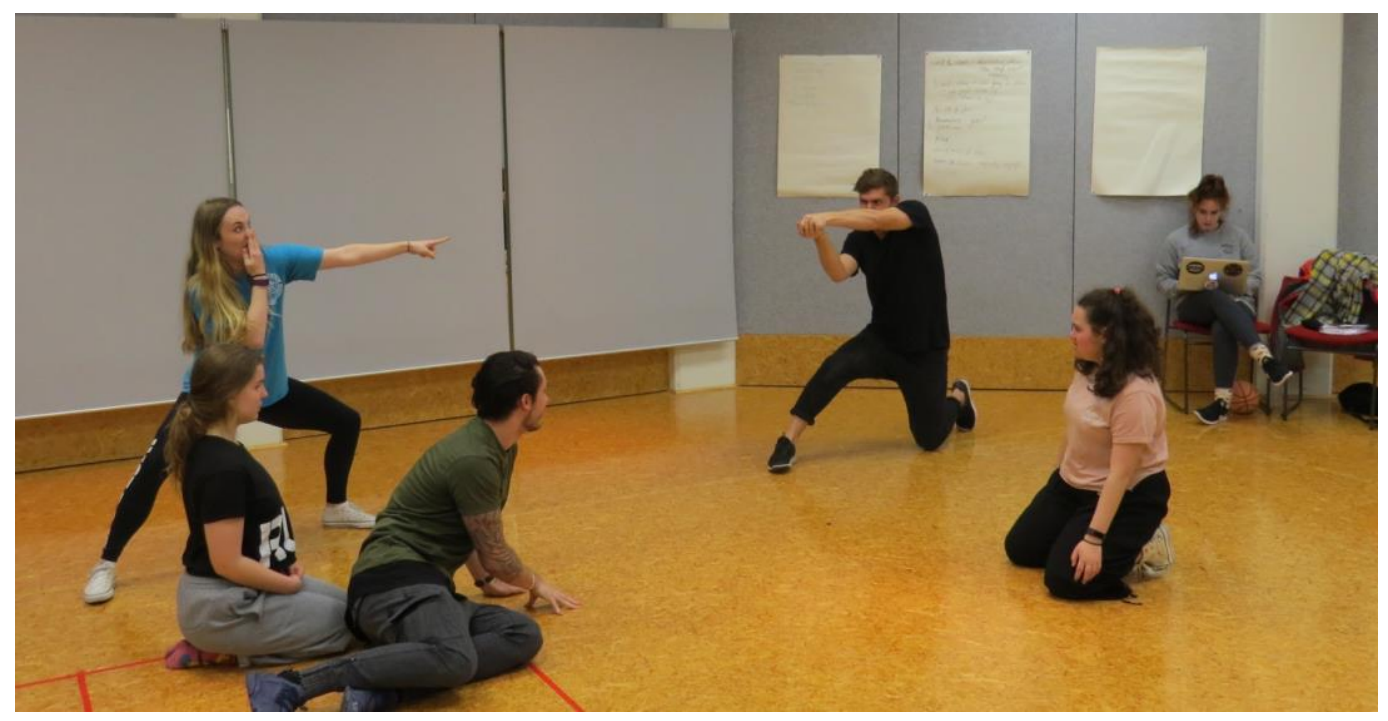

Figure 26: Playing and exploring in a childlike way.

Dave Brown articulates the logic behind this type of reminiscence in his initial PaperBoats blog: "Our work seeks to discover the image of the child in ourselves and ourselves in the child. Believing that the essence of our humanity is cradled and expressed in creative play, we playfully investigate our innate human need to "make meaning" and our associated longing for connection, love, understanding and fulfilment (Brown "4. Provocations and Insights"). This method of using play as a process in creating a culture of freedom and spontaneity in the devising room is not unique. Swale alludes to it in Drama Games for Devising, while Sam Scott uses play as a core tenet in Massive Theatre's philosophy: “We love people who love to play. We love to be competitive and irreverent. Playing is at the heart of everything we do" (Scott "Our Story"). However, these exercises with THEA 311 had the dual objective of encouraging the students to get to know each other through play, as well as urging them to remember the emotions and feelings that came from being a child.

Another method that proved particularly useful for reminiscence was the collection of photos of the students aged five and twelve - the ages of the children we 
were about to work with. The photos readily led students to autobiographical storytelling and nostalgia and were a productive way of encouraging them to discuss their childhood behaviour. They each shared with the class what was happening in the photo and then answered questions and elaborated further about their personality as a child, where they grew up, and often something about their families. This opened up many discussions around childlike behaviour and the experience of being a child.

Peter spoke about being a twin and in particular a non-identical twin and how he was very different from his twin brother. Georgia talked about being an only child and her incredibly close bond with her parents. Pelle relayed stories of growing up in Norway. The photos were a useful provocation for connecting with ourselves as children, and to share childhood memories and stories. 


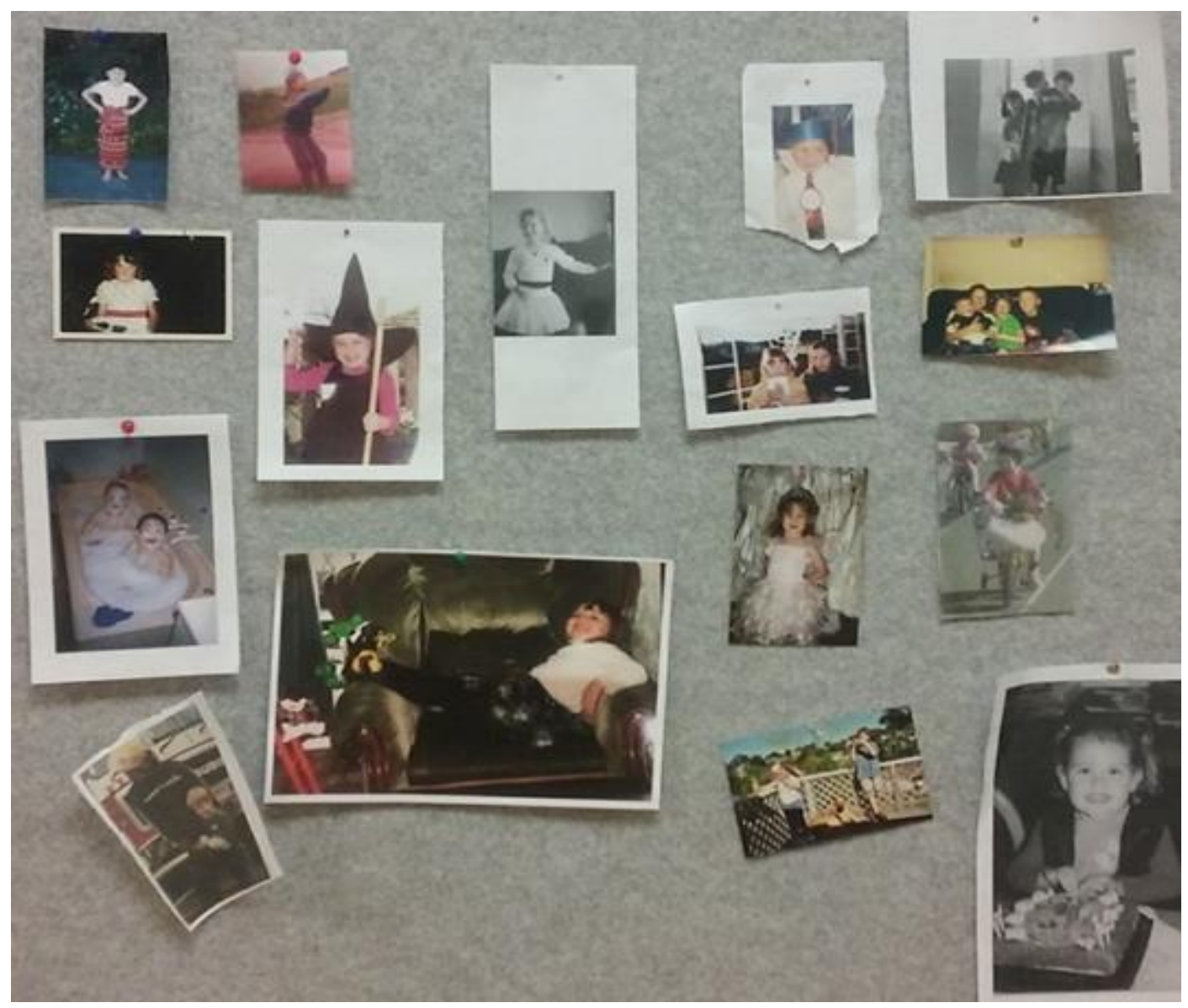

Figure 27: Photos of a selection of THEA 311 Students aged five years old

Bogart and Landau compare a devising group working well to kids in a playground: “They are usually running around, with one-person shouting: 'I'll get the broom!' Or someone leaping up and down in the air, saying 'Oooh, oooh, I got it! I got it!' Or two people talking over each other at once with 'Yes!' and 'What if...' (138). It was exactly this atmosphere that I was aiming to create in the initial classes of THEA 311. The warm-ups and provocations led the students to create spontaneously and freely, connect to a child-like state, and access autobiographical memories of childhood. They were also fulfilling Swale's Preparation Stage aims of getting to know each other, finding a common language, and warming up the body and mind ready for work 
(Swale $\mathrm{xxx}$ ) In this preparation stage, a collective contract and a method of checking in and out were also introduced.

\subsubsection{A Collective Contract-Check-Ins and Check-Out's}

In The Performer's Guide to the Collaborative Process (2001) Sheila Kerrigan asserts that a collective contract clarifies the working processes, and that when everyone helps to compose the rules, they all assume responsibility for sticking to them, and thus everyone has a stake in enforcing them (85-87). The overall intention of our contract was to encourage group unity and clarify our working process, specifically: to help ensure that everyone takes responsibility for upholding the agreed methods of working and communication; that everyone takes responsibility for the outcomes of the devising process; that everyone's voice is heard; and that there is an environment of mutual respect and bravery.

While establishing a group contract is a common method employed in a devising room, it is not always used effectively, as was the case with our contract. It was developed at the beginning of the process, but we did not often return to it. We neglected to have it clearly displayed, and it subsequently became more of a token document rather than one fully integrated into our process. This resulted in it not being particularly useful. Had we updated it regularly, displayed it, and referred to it, we may have been able to negotiate times of tension better. We also didn't refer back to the whakatauki that described our initial collective goal of 'He waka eke noa'. Referring to it regularly may have helped reinforce the idea of a collective goal during the times when we were not always travelling in the same waka.

The check-in/check-out process was more successful. Having a coordinated start to each rehearsal offered a clear pathway to discovering how everyone in the group was 
feeling, and for resolving conflict. It modelled for the students a structured beginning and end for each session that they could use when they were running rehearsals themselves. I also used it to model empathetic listening. Each student would have the chance twice a day to air how they were feeling, I would publicly respond to each student positively and empathetically, and sometimes privately return to the student later with problem-solving suggestions. For example: one student was consistently late to class. Checking-out she articulated her apologies and confessed she was "struggling". Later I spoke to her privately and she revealed a relationship break-up was affecting her mental health. We strategised some ways for her to find help, and agreed to share with the class some of the reasons she was often late. This took away some of her anxiety and guilt, and also made the class more empathetic and understanding, as opposed to just being frustrated that she was late. This example emphasises the extra emotional labour required from a maternal and empathetic style of directing. However, it also emphasises the reality of working with this specific age group. Working with young people means responding to their challenges. The students were at an age where they were experiencing adult challenges, responsibilities, and relationships, and yet didn't always have the resources to cope with them. They would therefore often look to me, as an adult, and as a mother-figure, to guide them. Teipel suggests that this development period can be an "in-between time where young people see themselves as neither an adolescent nor an adult" (2). It is a time of "identity exploration" as young people take on roles "expected of them in adulthood" (Teipel 2). I view it as a critical time where young people need both autonomy and guidance. The type of guidance I employed in THEA 311 required extra emotional labour from me as I attempted to solve multiple student issues; it also strengthened the director-devisor relationship as most students seemed to value this guidance and support. 
Another challenge with the check-in/check-out process was that several students found it difficult to articulate to the whole group when they felt frustrated, angry, or annoyed. Although the check-outs were intended to resolve any issues that happened in the rehearsal room and close the discussions, they would often just consist of positive statements about the rehearsal and would circumvent 'hard' conversations and avoid conflict. Some students would then email or discuss their issues and challenges with me after the rehearsal, which again demonstrated their need for 'adult' guidance.

Introducing both a collective contract and Kerrigan's check in/check out processes was an attempt to give the students strategies to develop a sense of agency. I was aiming to encourage them to take control over their actions and the consequences of these actions (Moore). It was also a way of encouraging them to negotiate the balance of autonomy and independence, and connection with an older adult that is described by Teipel as a key task of later adolescence/early adulthood (2). Reflecting on these processes, I realise that in my leadership of both strategies I did not go far enough in giving the students autonomy. I was too quick to solve problems rather than encourage the students to solve them. Despite that, I was also a teacher of a group of young people and I had a certain level of professional responsibility. Both processes had some success in creating a united vision and providing a platform for discussion; however, I realised that the students needed clearer methods of giving and receiving feedback, so that they could rely less on me during the creative process.

\subsection{Generation and Exploration - Creating Material}

The building of the ensemble was further strengthened through the process of creating the material. Devising theatre provides an opportunity to develop 'abstract thinking,' where young people learn to think, as Teipel asserts, "abstractly and hypothetically; can 
discern the underlying principles and apply them to new situations; and can think about the future, considering many possibilities and logical outcomes of possible events" (1). THEA 311 created the material for their two plays by assimilating Swale's 'Generation and Exploration' stages with Dave Brown's PaperBoat's Principles and methodology. Brown compares the developmental ${ }^{61}$ idea of a theatre piece to germinating a 'seed' in the director's head. This seed is then 'fertilised' through research, discussion, provocations, and on-the-floor play, which spark creative ideas. These ideas lead to improvisations and scenes being created (Brown. "1. Provocations and Insights.")

On day one of devising, I introduced a method for creating material and the developmental idea of twoness. ${ }^{62}$ The method involved generating material, through games, improvisations, and provocations, from the developmental idea; analysing the material; choosing a 'golden moment' to generate further; and then analysing again.

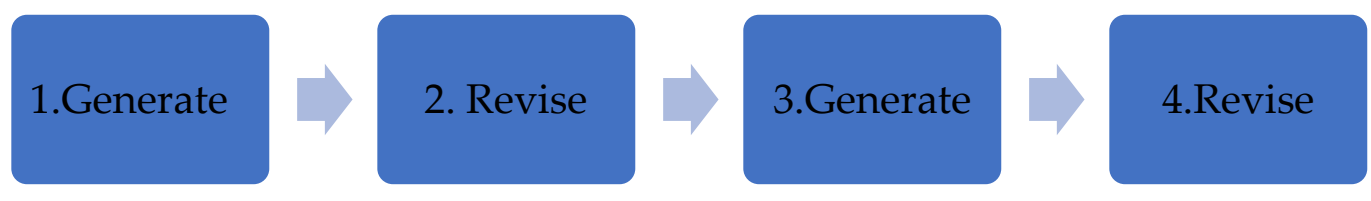

Figure 28: The Generate- Revise model

1. Generate material from developmental/germinal idea, through a series of games/activities/provocations

2. Revise: using reflection and critical response/analysis

3. Generate: A 'Golden Moment' chosen and developed further

4. Revise: Critical Response/analysis

\footnotetext{
${ }^{61}$ Dave Brown sometimes refers to this as the 'germinal idea.'

62 Twoness came from the overall PaperBoats germinating/developmental idea of; Tw2o of a kind, as conceived by Dave Brown. (Brown. "1. Provocations and Insights.")
} 
After generating a response to a provocation, one group would present their scene and the rest of the class would observe and critically analyse it. The students would then collectively choose a 'golden moment' for the performing group to extend and investigate further, and this would eventually be presented for further critical response and analysis. This concept of a 'golden moment' came from Brown's advice that "a provocation in itself is a pointless exercise unless you look back and find out what you've learnt by sifting a little gold from the dirt" (Brown, “Thea 311.16").

An example of the way the students used the generate-revise model and developed their provocations into full scenes can be illustrated by one of the early activities on day three of our devising process. A provocation emerged from the improvisation games of objects and props, where objects do not have to be what they appear to be: "Players endow the object by using their imaginations, to become something else. The object then influences who the players are and what they become" (Matthews 66-67). The groups were given a selection of props and the instruction to create a scene in five minutes, where the props transform into something else. Dara, Saffron, Georgia B., and Georgia M. generated a scene where they manipulated their props in a highly theatrical and non-verbal way. During the critical analysis and reflection of this scene, the other students identified a key 'golden moment', when Dara raised her hands and 'controlled' Georgia B's teddy bear to move towards her, like it was flying magically through the air. Even though the audience could see Georgia moving the prop, through the commitment of the performers and the audience's 'suspension-of- disbelief', they were able to believe that Dara was magically manipulating the teddy bear independently. This led to a rich discussion from the group around puppetry, the suspension-of-disbelief, and how even when children in particular can see the puppeteer, they still believe that the puppet is a real entity. The 
scene galvanised the students into thinking about ways to move props, as well as endowing them with new identities.

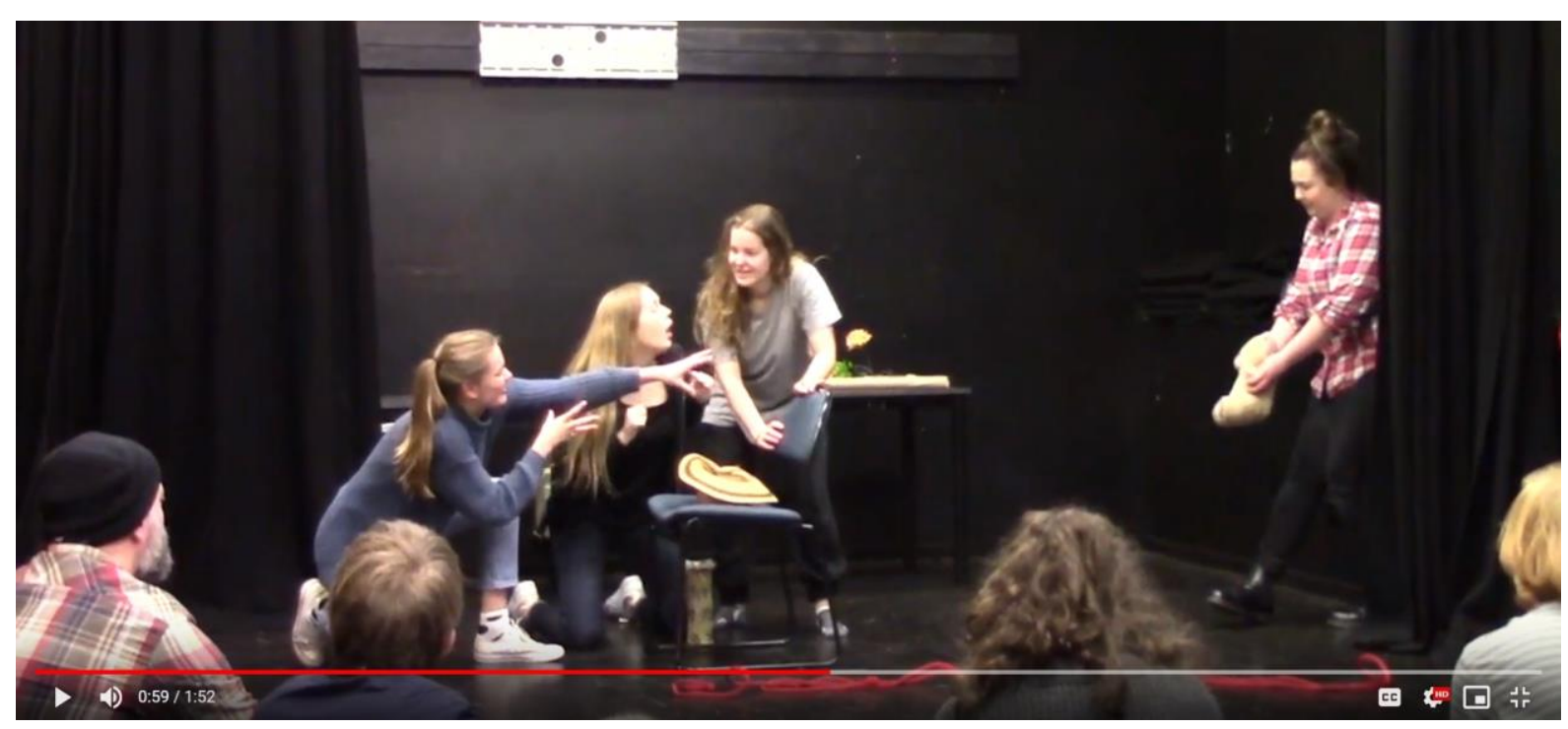

Figure 29: Screenshot: Dara, Saffron, Georgia M. and Georgia B. ‘magically' manipulate a prop.

Dave Brown responded to the daily blog and provoked the students to consider further:

We keep on finding with object and visual theatre that it's most interesting when the human movement has a sense of being in the service of the object rather than vice-versa... it's the object that moves us ... not us that moves the object... an object that has life has magic... we become more interested in the object than the performer. (qtd.in Palmer, "THEA 311.25”)

This prompted the group to further develop the idea. From this one 'golden moment', both groups kept exploring object manipulation, and critically reflecting and analysing their work. Subsequently, both groups incorporated scenes that reflected this exploration in their final plays. 
One of the most effective scenes in In The Attic was set in 'The Binders lair'. Here the two Binders displayed their magical powers by controlling a series of objects through the air with their hands. Raising their hands simultaneously they drew various spell ingredients towards them, which were carried and deposited in their cauldron by two other actors.

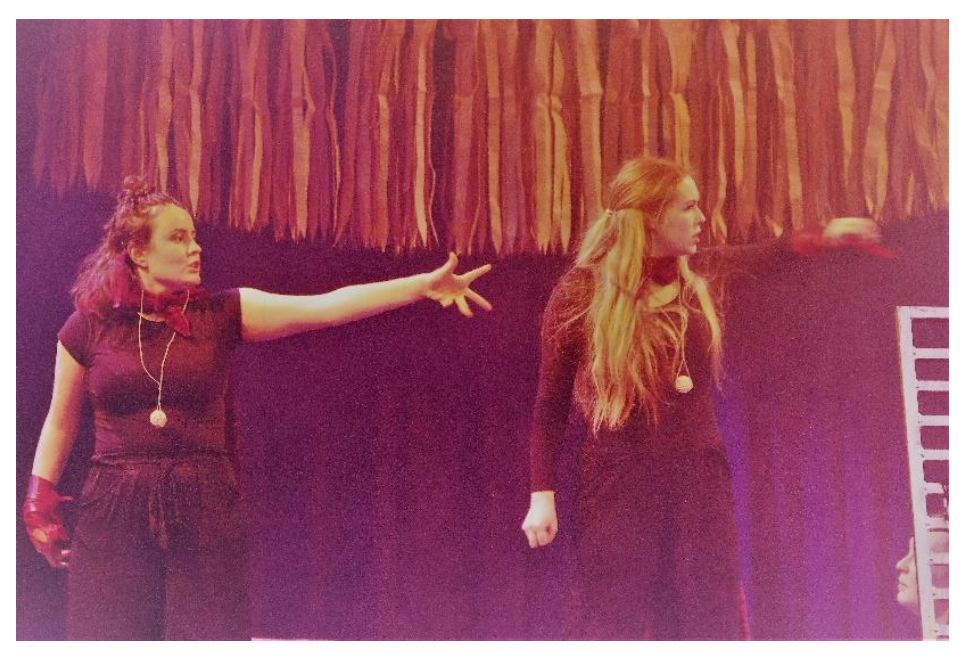

Figure 30: The Binders manipulate objects towards the cauldron.

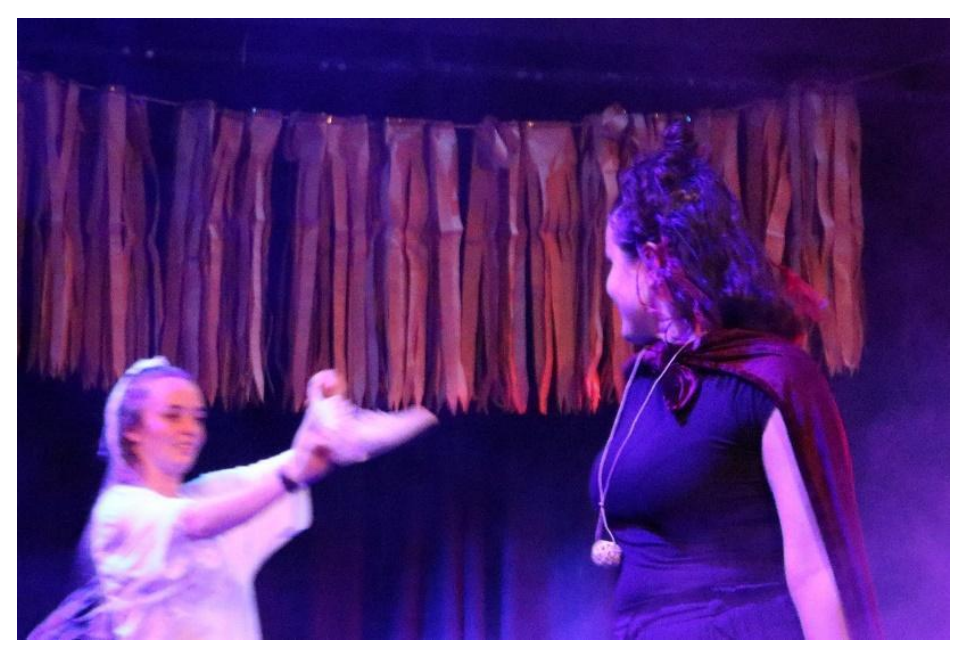

Figure 31: The object is carried 'magically' by another actor.

The Binders then extended this idea by manipulating the movement of other characters as well as objects. Our Tawa School audience particularly enjoyed this technique: 
I liked the songs and the part when they were using the mind control.

I liked it when the binders could control people, it looked pretty real.

The most interesting moment was when the binders showed up because they had telicaneses [Telekinesis]. ("Tawa School Feedback" 24 July 2017)

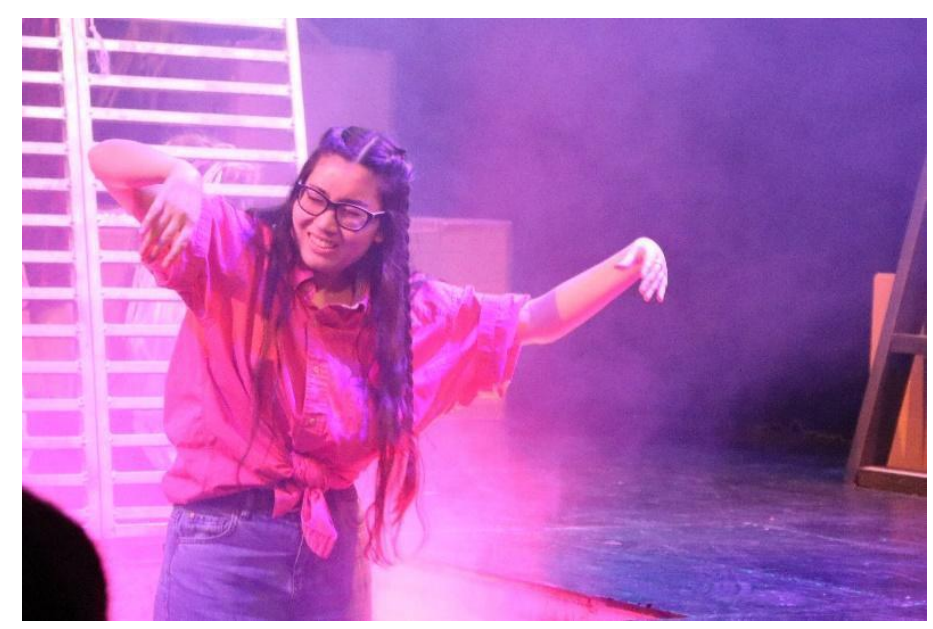

Figure 32: Bea is manipulated by the Binders.

The Moonlight group also used the magic-object-manipulation technique. Figure 34 shows the Tea Witches attempting to control their tea-making utensils using 'conjuring' techniques. Ultimately, they fail, and the objects drop to the floor, indicating a waning of their magic and the first hint in the play that something is awry in the forest. 


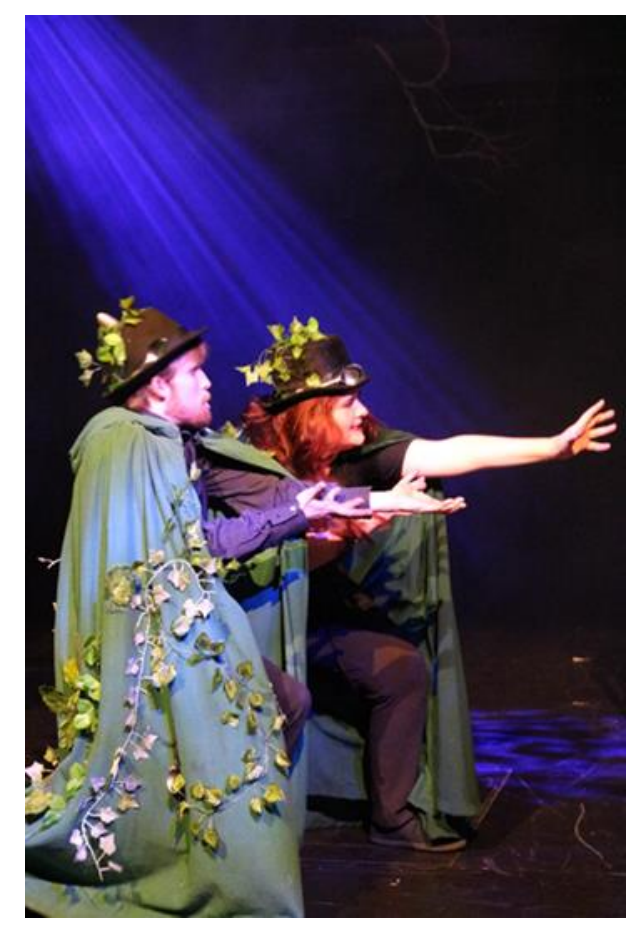

Figure 33: The Tea Witches attempt to manipulate their Tea.

This type of object work and the way that children relate to it demonstrates one of the major differences between theatre, and film and television. Phillip Pullman explains: “Theatre has limitations. That isn't a real room, it's painted canvas, and it looks like it; that isn't a real boy, it's a little wooden puppet. But the limitations leave room for the audience to fill in the gaps. We pretend these things are real, so the story can happen" (Pullman). As theatre is unable to present a fully realised world, it must leave gaps between reality and illusion. It is these gaps that a theatre audience fills with their own interpretation and imagination that makes theatre unique.

In the magic-object-manipulation examples, children of both age groups responded to the illusion that the objects were moving through the air; they pretended that they were being magically manipulated so that they could let the story continue. Reason explores this relationship between the 'referential' and 'embodied' experience of theatre in great depth. Relevant to this, is that puppet or object manipulation is an 
example where the gap between "the stage reality and the evoked illusion is very much explicit and transparent" (Reason, 'Did You Watch the Man or Did You Watch the Goose?" 342). This theory of the suspension-of-disbelief is explored further in Chapter Eight.

The successful integration into both plays of the object manipulation technique, reinforces the effectiveness of the generate-revise model. By identifying a key 'golden moment' early on in the devising process, returning to it, analysing why it resonated with them and enhancing it, students were able to develop it into a scene in each play which then became a favourite moment for many children in the audience.

\subsection{Encouraging Constructive Feedback}

A crucial phase in the Generate/Revise model and another opportunity to develop 'abstract thinking' skills (Teipel), is the critical analysis by the group of the material and scenes developed from the games, activities, and provocations. Brown's advice to "[sift] a little gold from the dirt" (Brown, "Thea 311.16") implies that for the material to be useful, it needs further interrogation. However, this can be a delicate process, as interrogation of creative work has the potential to trigger insecurity and angst. Teipel's assertion that considering "different points of view at the same time can result in increased empathy and concern for others" (1), indicates that this is an important stage in the development of young adults. Therefore, in an attempt to facilitate this delicate process, I introduced Brown's critical response protocol, ${ }^{63}$ which gave clear guidelines for analysis.

${ }^{63}$ Outlined in Appendix F. 
Brown suggests that instead of asking 'What do you like?', when viewing a scene, it is more productive to ask, 'What does this remind you of?' The questions are designed to encourage devisors to reflect on and discuss a scene, specifically: what they noticed; what they were reminded of; what engaged them as an audience; how it made them feel; what questions it raised; and to speculate further on the essence of the piece. This prompts the spectator to connect their own life experiences to what they saw and reflect on how the scene made them feel (in Palmer "THEA 311.29, Potholes in the Road").

Often, when asked for feedback, those new to the devising process give limited or unrelated feedback that is based on their own personal taste. Such feedback can block ideas, be unrelated, tangential, or simply state 'it was good/it was bad', without further justification. I observed that Brown's critical response protocol was helpful for prompting the students to reflect more analytically, and view the material in connection to their own life experiences. It was more conducive to gathering feedback that could be used to generate further creative material. As the students reflected on and probed the work Sam, our stage manager, or I would write up the reflections, suggestions, and ideas that evolved from each discussion. These were then written on large sheets of paper and displayed around the room, making it easy to select 'golden moments'. (Figure 27 shows Sam, top right, taking notes and the sheets of paper displayed on the walls.) 


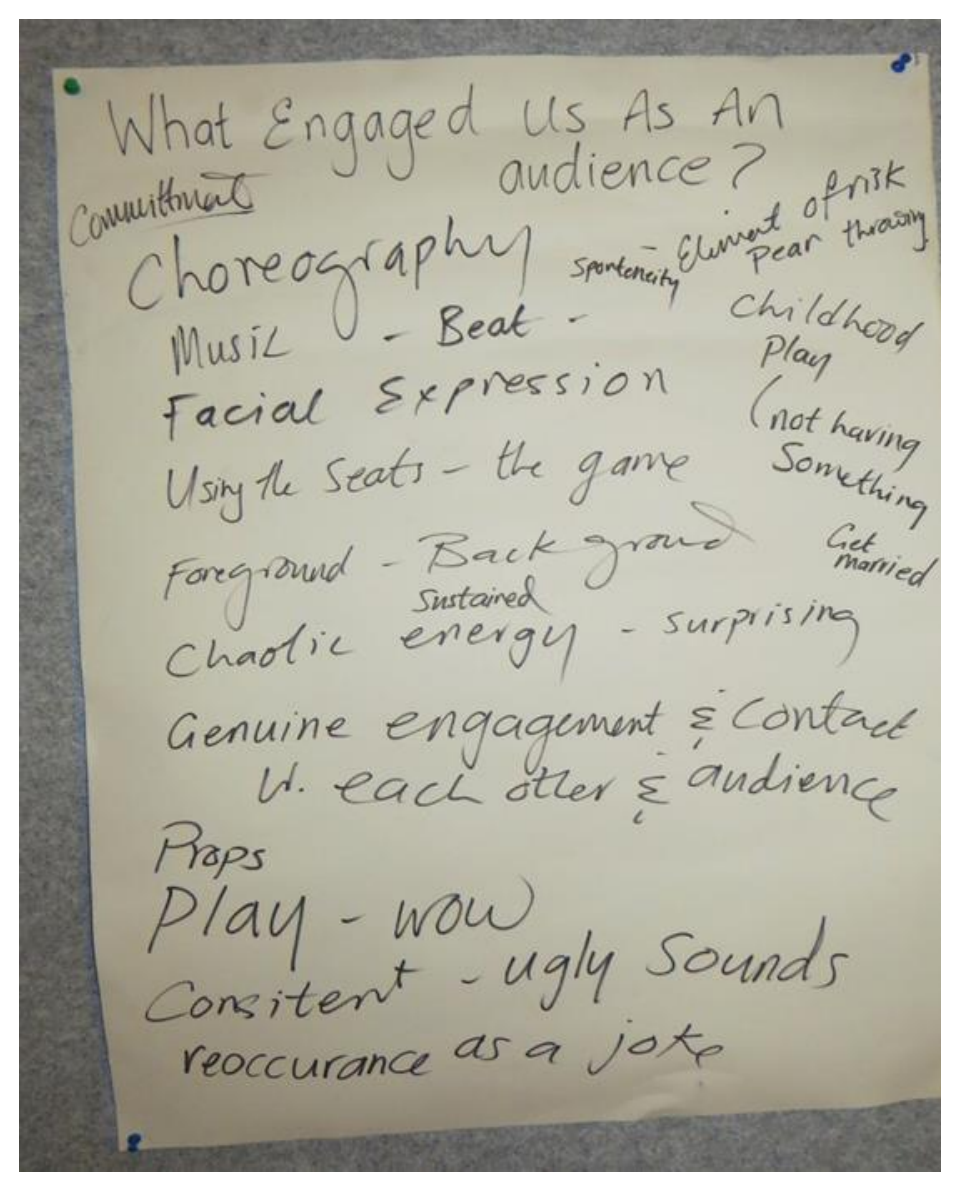

Figure 34: Responses to the question of what engaged us as an audience?

Brown's questions are designed to elicit positive and encouraging answers that are descriptive, and don't make judgements or offer personal preferences (Appendix F). However, what became obvious fairly early in the process - and was increasingly articulated in check-out sessions and in emails and discussions with me - was that, even though the questions were framed positively, some of the students were struggling with this method of critical analysis. They felt that by improvising and creating, they were putting themselves 'out there' in a creatively vulnerable way only to then be 'criticised' by their co-collaborators. This led to feelings of anxiety and a loss of confidence.

These were key moments for me as a director. I believed that, for the work to develop, this analysis was crucial; however, I observed that at times students were 
being 'oversensitive' to the criticism and taking it personally. Reflecting on Jackie Smart's belief that "all groups need to go through [a] process of establishing a place of emotional safety before they can make themselves vulnerable" (111), I realised that not all of the group felt a level of emotional safety which allowed them to be creatively vulnerable. I also noted that some students were perceiving any feedback as criticism and some needed guidance on how to give feedback in a constructive way.

Initially I attempted to solve these problems by privately advising individual students how their approaches could be modified. On reflection this was another example of me being compelled to solve problems, and antithetical to giving the students autonomy in their process. It also was not productive. A better strategy was when I encouraged the students to have an open discussion and focus on finding their own solutions. This led to the group having a frank, and occasionally uncomfortable, discussion in class. After the initial discussion one student, demonstrating leadership and agency, emailed the group with a suggestion for a set of guidelines for feedback. These were intended to make the receiver feel 'safe' in receiving feedback but also to encourage a safe environment for the people giving the feedback:

Feedback is about observation and noting effective moments more than a simple "it was good/shit/boring", so maybe think about structuring your feedback like... "I noticed [...] was an effective way of [...] BECAUSE"

"The use of [...] was clear/unclear in my opinion BECAUSE" "I really liked [...] BECAUSE.

If you have any questions about your feedback, to wait until the end and then ask the specific person to clarify... This is a work in progress and it's about making sure we all feel safe to play and express ourselves, both as an audience 
member and as a performer. (qtd. in Palmer, "THEA 311.29, Potholes in the Road")

The students agree to adopt these as a loose framework for future feedback. What this discussion and adjustment to the process established was a clearer process for the students, and incorporated practical strategies for working such as:

- Disengage the ego by being less defensive about the work

- Let go of ideas

- Make clear and succinct reflections about the work

- Give honest and yet respectful feedback

- Remember feedback is an important part of the devising process.

In retrospect it would have been useful to have included these strategies in the collective contract - rather than generic phrases used such as 'have mutual respect.' Also significant was how I had discussed the process of feedback at length at the beginning of the course. I had given examples of other devising processes and emphasised the reality that devising theatre is challenging. I had stressed that often what an individual considers is a worthy idea is not always seen this way by the rest of the group, and that critical feedback is part of the process. It became obvious that offering this advice to the students at the beginning of the process did not immunise them from feeling unworthy and hurt later on, suggesting that the students had to experience the challenges of the process to fully understand it.

It's important to note that after the new strategies were introduced the environment did improve. Conflicts still arose, people's feelings still got hurt; nonetheless, but by relinquishing my urge to solve problems and encouraging the students to create their own strategies, I had gone some way to empowering them to 
take control of their own devising experience. By encouraging them to rely on themselves and their peers for feedback, they were learning to be less reliant on the 'expert' in the room. I hoped that this would result in the students having more confidence and autonomy to analyse and critique their own work when they went into their groups, and ultimately into their own devising experiences in the future.

During the first six weeks of the course, provocations were introduced to the group, including prop and object work, a response to twoness, and accessing childhood memories. Each provocation was analysed by the group through a series of critical response questions. We used images, songs and children's picture books to stimulate ideas and to create an array of golden moments. Chapters Eight and Nine explore in depth the processes the students undertook to create each play from these early devising experiments. To ensure the creation of two plays for different age groups, the class, after several weeks of generating material, made a fundamental shift, and separated into two groups.

\subsection{When One Becomes Two}

Twenty-one students constitute a large devising ensemble and the size of the class created possibilities for tension and disconnection between the creative and pedagogical objectives. All the students wanted and deserved opportunities to develop, practice, and showcase their creative skills; however, meeting these desires might have resulted in a play that was too long for our young audiences, or which was organised according to the needs of the performers, rather than those of the audience to be entertained. I made the suggestion early on that the group devise two original plays, each targeting a different age group. Devising in two small groups would potentially create an easier collaboration. It would permit students to showcase creative skills, be heard in their group, and tailor two plays for two distinct age groups. This also aligned with my 
research interests and the hypothesis that different developmental stages deserve curated works. Many TYA companies market their work for "children" which is too broad an age range and does not take into account children's different development stages.

However, creating two plays simultaneously also imposed exceptional demands, in particular on the production team. The decision to present two plays also raised the level of anxiety and stress within the devising room. When the students were free to create without the immediate pressure to perform publicly, they seemed to be more relaxed and generous, and the sense of play and fun in the room was greater. As soon as they started to feel the pressure of creating a full play for an audience, as well as the pressure of their individual performances and grades, tension within the group began to emerge. As our process developed, I recognised that the processes of 'expansion and contraction' (Swale) were useful for devising tangible material, and for analysing the way the group worked together. We would work productively for one or more sessions, and then some angst or disagreements would arise, and we would need to pause the making process to reflect on the best way to continue. This was not necessarily counterproductive to a prolific and creative working relationship; however, when I realised that the anxiety of some of the students was beginning to affect the creative work in the room, I decided to separate the group earlier than previously planned.

In order to facilitate the students' development of 'a personal sense of identity' (Teipel), they were free to choose what age group they wanted to create for. This was a chance to achieve a sense of agency over who they worked with - both in terms of the other students, and the specific class of children. Two groups, 'Paper Bag Productions' (creating for ages 5-6 years) and 'Illuminations' (ages 10-12 years), were formed. One of 
the students made a valuable observation at this stage around the benefit of breaking into smaller groups:

Throughout this process, I have learned how to work with a range of different personalities that vary far from my own. I have also learned that 20 is a hell of a lot of people to have in a devising space, and at times so is 10 . Working with so many people made me learn that sometimes smaller is better, and I'm very glad that we split off into the groups of 10, rather than working with the whole company the entire time. I found that it can often be helpful to go off into smaller groups to work on specific things, and then to bring them all together in order to stop the issue of having too many bodies and voices in the space (Troughton).

Creating two full plays in a trimester was an ambitious and demanding aspiration. It was arguably also a rich learning experience for the students and myself. The fact that the class evolved into two groups, which was a lot for me to oversee, meant that there were times that I was forced to leave the students to rehearse on their own. These moments of leaving the room allowed the students take ownership of the work and led to them finding their unique voices and methods of working. I noted that they began to develop as devisors in their own right, rather than being students of devising. This gave them agency on the content of the work as well as in the process of making the work.

\subsection{Summary}

Analysing personal directing practice is not always possible, as often when one project finishes the next one begins. Having the chance to reflect and examine my directing process has been enlightening and challenging. With this group of 19-24-year-olds I realised that although they were in the stage of developing and applying abstract thinking skills, defining a personal sense of identity, and meeting demands of 
increasing mature roles and responsibilities (Teipel 1-2), they also needed support, guidance, and empathy from me.

I conclude that there is a delicate balance between providing adequate pastoral care - creating an environment where students feel supported and safe to create - and being overly protective, solving problems, and constantly reassuring. It is this balance that is hard and yet vital to achieve when directing a group of young theatre makers; in particular, knowing when to leave them to find their own autonomy, and when to 'rescue' them. At times I think my maternal style was not conducive to fully empowering the students in the process. There were times I could have given them space to solve problems and make mistakes, instead of reassuring and rescuing them. I discovered that it was not until the students had experienced some of the challenges of devising in a group, and developed their own set of strategies around feedback, that they began to demonstrate more confidence in the process. It was significant to note how early on in the process anxiety developed around feedback and the way the group was interacting. Although the check-ins and check-outs were useful, it took time to develop a place of emotional safety within the group, so that the students felt they could be creatively vulnerable (Smart). I believe that by establishing a 'family dynamic', and treating the ensemble with compassion and kindness, I was able to create an environment that was a positive collaborative experience for the students, encouraged them to become more generous and self-reflective practitioners, helped many of them in their post-university devising experiences, and encouraged a recognition and love for TYA.

"You create such a lovely warm and positive environment to work in and always inspire us to be the best we can be, encouraging generosity, honesty and play." 
"You have an amazing intuition about a room, and right from day one created an environment that was always engaging, warm and comfortable for us to play and fail."

“Thea 311 absolutely influenced how I make art. Empathy, communication, and good creative boundaries are the backbones of my work with Tempest. ${ }^{64 "}$

"It made me realise that there is so much creativity bubbling within children, and that they need outlets (like quality TYA) to enable them to use and express their creativity." (THEA 311 “Feedback")

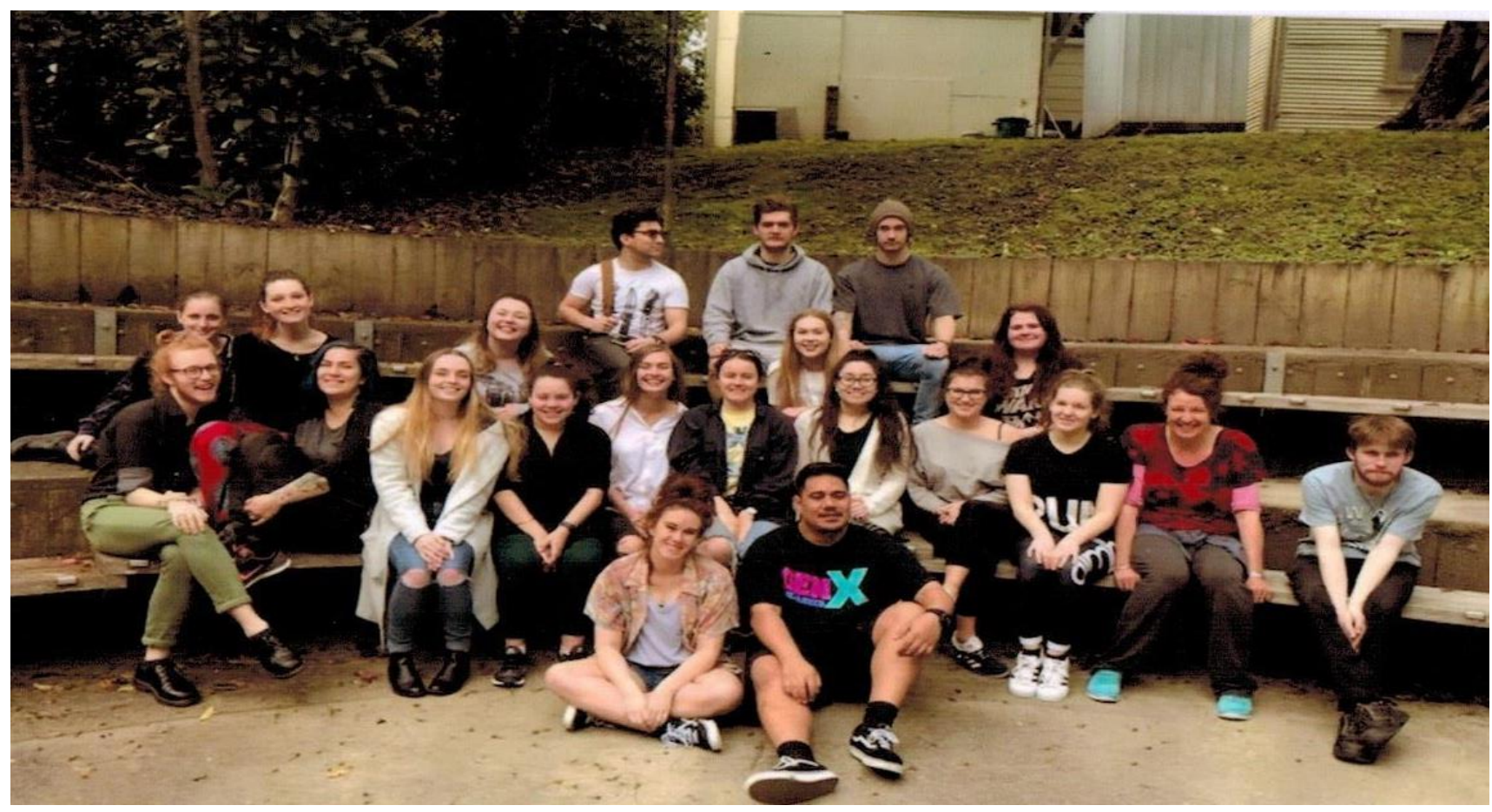

Figure 35: The wonderful class of THEA 311

${ }^{64} \mathrm{~A}$ Wellington-based theatre company Emma Maguire created post-course. 


\section{Working with Children}

\section{for Inspiration and Agency}

But who knows what the young and the very young already know, what they want from theatre, and what stories would be sensible to tell? The best thing to do is stay in contact, initiate communication, understand the performing arts as a process between actor and the specta(c)tor. (Schneider, "Enabling Cultural Participation." 7)

\subsection{Introduction}

This chapter explores the ways that THEA 311 worked with two classes of children to get an understanding of the audience they were creating for, and to actively test ideas in engaging them. I challenged the group to avoid assumptions about what their audience wanted to experience. Such assumptions by adults and the creation of TYA work based on these assumptions can generate disempowering theatre experiences for young people. Reason maintains that: "The concept of theatre for children situates children as the audience, which can be perceived as a largely passive and disempowered position: watchers rather than actors; observers rather than participants; spoken to rather than speaking" (The Young Audience 170). What I was exploring with THEA 311 was a method of making TYA which engaged children in the creative process. Rather than guessing what their audience would like, the devisers would engage with members of their target audience before and during the creation period. The hope was that the group would respond to the children's interests, get a sense of what they wanted to see 
a piece of theatre about, and learn what fascinated and absorbed them in terms of artistic and cultural elements.

The challenge in creating genuine child-led or activated work comes from finding out what young people like and what they want to see performed. As outlined in Chapter Two, directly asking the children themselves what they want to see is problematic. Brown reminded us at the beginning of the process that the danger of delivering something that kids tell you they will like, limits makers to delivering what the kids already know (Palmer, "THEA 311.9"). Asking children what they want to see in a theatre show can also be problematic because the theatrical competence (DeMarinis 171) of individual children is vastly different.

In the two schools with which we collaborated, we discovered that there were differing opinions of what a theatre 'show' or a 'play' was, and varying degrees of cultural experience meant that some children had been to the theatre and others had not. New Zealand school children are often first introduced to plays in the New Zealand School Journal, the longest-running serial publication for children in the world ("Throwback Thursday"). Each journal publication consists of New Zealand-centric stories, poems, art and at least one play. Plays are in the format of a written story designed to be read and 'performed' aloud. As the plays are situated within a collection of written works, the emphasis tends to be on 'reading' the plays as opposed to acting them out in a more theatrical way. As summarised in Chapter Two the New Zealand school curriculum has four arts disciplines. In years one to eight students learn in all four disciplines. In years nine to ten, they learn in at least two disciplines, and after that the arts become optional (The New Zealand Curriculum). While it is customary for many schools to take students to the theatre or invite visiting theatre groups into their schools, not all do. This results in a varied theatrical competence and understanding of theatre 
by New Zealand children. Aware of these challenges, the THEA 311 class had to strategise how to authentically engage with the children.

\subsection{Intergenerational Play/Learning}

Intergenerational play is explored as part of Childhood Studies discourses. Davis, et al, describes the purpose of such activities is to provide:

rich and stimulating opportunities for older adults and children to enjoy each other's company and learn from one another. It also acts as a connecting force between these skipped generations. Playing with a child affords older adults the occasion to reminisce about their own childhood, while children can gain an enriched learning experience from interacting with positive role models. Together, they share a special time which only intergenerational play can bestow. (Davis, et al.42)

Although this chapter is specifically discussing the interaction between children and older adults, we discovered that the claims made here were equally as relevant to children and young adults: there was still a generational gap, albeit smaller.

Intergenerational Learning is a term also used in Knowledge Management. Particularly useful is the idea of 'reciprocal learning', and the debasing of the theory that concepts such as 'knowledge' and 'expert' imply that experienced workers are more knowledgeable and more valuable to learning than the novice (Tempest 181). Intergenerational Learning is described by Tempest as "a term to capture the potentially rich, reciprocal process of learning that builds from marrying the diverse knowledge bases of workers with different levels and types of work and life experiences"' (183 Tempest). She suggests that an openness to new possibilities and opportunities is just 
as, if not more, important than a predisposed level of knowledge to effective learning. Tempest gives an example of music practitioners such as David Bowie whose work with younger emerging talent was not only productive for the new talent, but also productive in a reverse-mentoring sense, where the 'expert' learns about the latest trends and possibilities in youth culture (Tempest 190).

This approach can also be linked to the work of Brazilian pedagogue Paulo Freire. In The Pedagogy of the Oppressed (originally written in 1972), he defines two contrasting approaches to learning. Banking education is where "knowledge is a gift bestowed by those who consider themselves knowledgeable upon those whom they consider know nothing," and thus, "education becomes an act of depositing, in which the students are the depositories and the teacher is the depositor" (Freire 72). Freire offered an alternative, reciprocal approach to banking education, which he calls 'problem-posing' education. This approach embodies communication and ensures that "The teacher is no longer merely the-one-who-teaches, but one who is himself [herself] taught in dialogue with the students, who in turn while being taught also teach" (Freire 80). .65

With THEA 311's interactions with the two groups of school children, we were aiming to create a reciprocal learning environment, beginning with the assumption that both the students and the children had something important to impart. The children could learn from the students about drama, theatre, and being at university; and the students could learn from the children about current trends, ideas, and what it is to be a child in 2017. These interactions with the children comprised the second part of Swale's Generation phase (Swale xxx-xxxi). The students visited the children at their respective schools. Both schools chosen for this creative practice were ideal but also 'exceptional'

\footnotetext{
${ }^{65}$ Freire' s Pedagogy of The Oppressed inspired theatre maker Augusto Boal, creator of Theatre of the Oppressed. ("Theatre of the Oppressed")
} 
for this research. Te Aro and Tawa schools are inclusive, arts-focused and multicultural teaching environments. Both are diverse, culturally aware, and have a culture of inclusivity that made them open to working collaboratively with us. The diversity of voices within the schools seemed to contribute to more varied perspectives from the children, and getting to know them as individuals helped us to shape our work to a range of children's tastes and ideas.

Prior to our first school visit, THEA 311 had a planning session. We shared ideas on how each session might run and decided on a detailed plan. Each session was broken into three sections: an introduction phase led by me, where I would explain the project; a games session, where groups of students would lead basic improvisation and drama games, and other students would observe; and a discussion session, where the students would get the chance to have detailed discussions in small groups about favourite books, movies, and shows, to explore what the children get excited about, how they hold conversations, and to get to know the children better. The students were also tasked with observing a child from each school and analysing their observations. ${ }^{66}$

66 See Appendix E 


\subsection{Tawa Primary School}

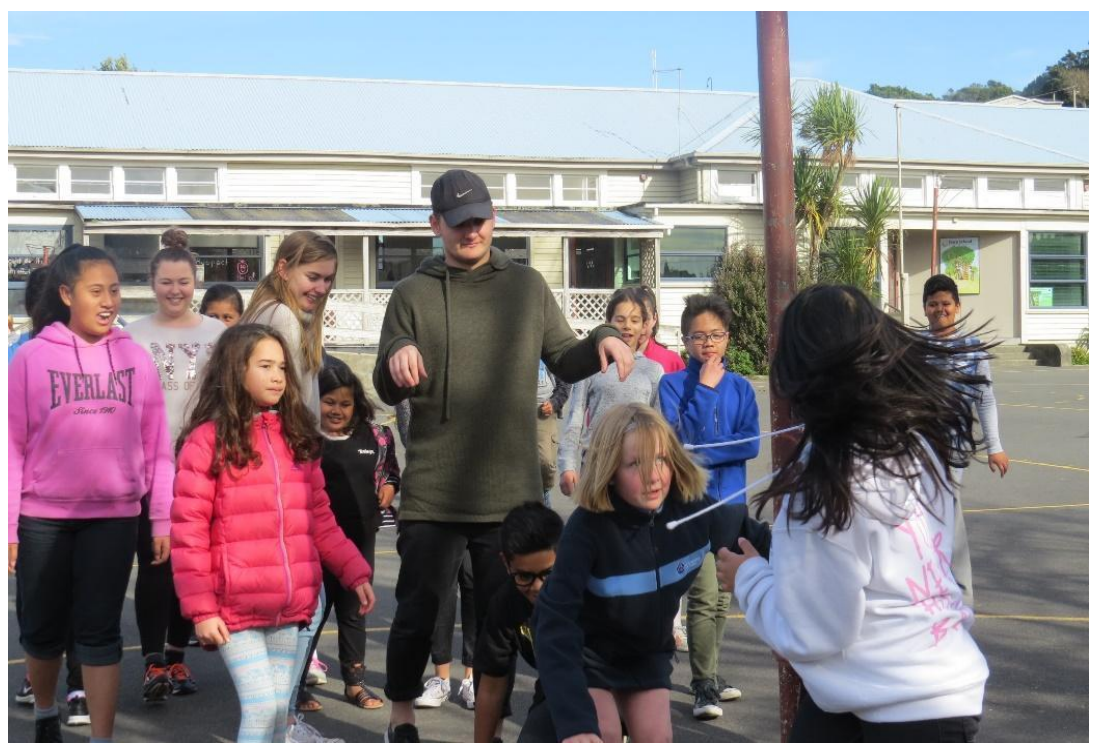

Figure 36: Intergenerational Play. The Students and The Children play “Grandma's Keys."

Our first visit was to Tawa Primary School. Tawa is a suburb of around 15,000 people, fifteen minutes north of central Wellington. The school is a full primary school, one of the oldest in New Zealand, opening in 1855, and has around 320 students. The students who attend predominantly live in Tawa, but also the adjoining lower-socioeconomic areas Porirua and Titahi Bay (Tawa School). Room Four 2017 was a combined double classroom of forty-nine children with two teachers, Ms. Campbell and Ms. Webb. The children were aged from ten to thirteen years old.

Taking the THEA 311 students out of their comfortable university environment and bringing them into an environment that was 'owned' by the children helped dissolve immediate intergenerational barriers. The children were in the playground when we arrived. My son was in the class and therefore many of them knew me and were comfortable with greeting the undergraduates and engaging them enthusiastically in conversation. Some of the students towered over the children; however, some blended right in, and were the same height or smaller. This perhaps helped to facilitate 
an immediate rapport with the children. The students, looking at the pictures on the walls of the classrooms, began to reminisce about their own primary school days. I presented the project to the children and discussed our intention to share ideas and discoveries reciprocally. I clarified that we were not there to teach, but to play with and to learn from them. This switch in the pedagogical norm by creating a context for social interaction is strongly advocated in research on intergenerational play (Davis, et al, 44), and can be linked to Friere's problem-posed reciprocal approach to education (80). We noted that the children seemed to feel validated and excited by the fact that we had come with a genuine inquiry about what their interests were so that we could create something that they liked.

The students began by guiding the children in a combination of improvisational games and physical activities. These were games that the students either enjoyed from their own classes or remembered enjoying when they were children. Although some of the children were familiar with the games, most had to be explained fully. The most popular were: Bus Stop, Grandma's Keys, What are you doing? and Clumps. ${ }^{67}$ Bus Stop was a particular highlight where the children each got the chance to say or do something that would make their partner move in a hurry. They experimented with sneezing, cuddling, boring, bombing, and pretending to have an infectious disease to get their partner to move. The children seemed to love this chance to play and be observed playing, and there was lots of laughter and playful improvisation.

${ }^{67}$ See Appendix D. 

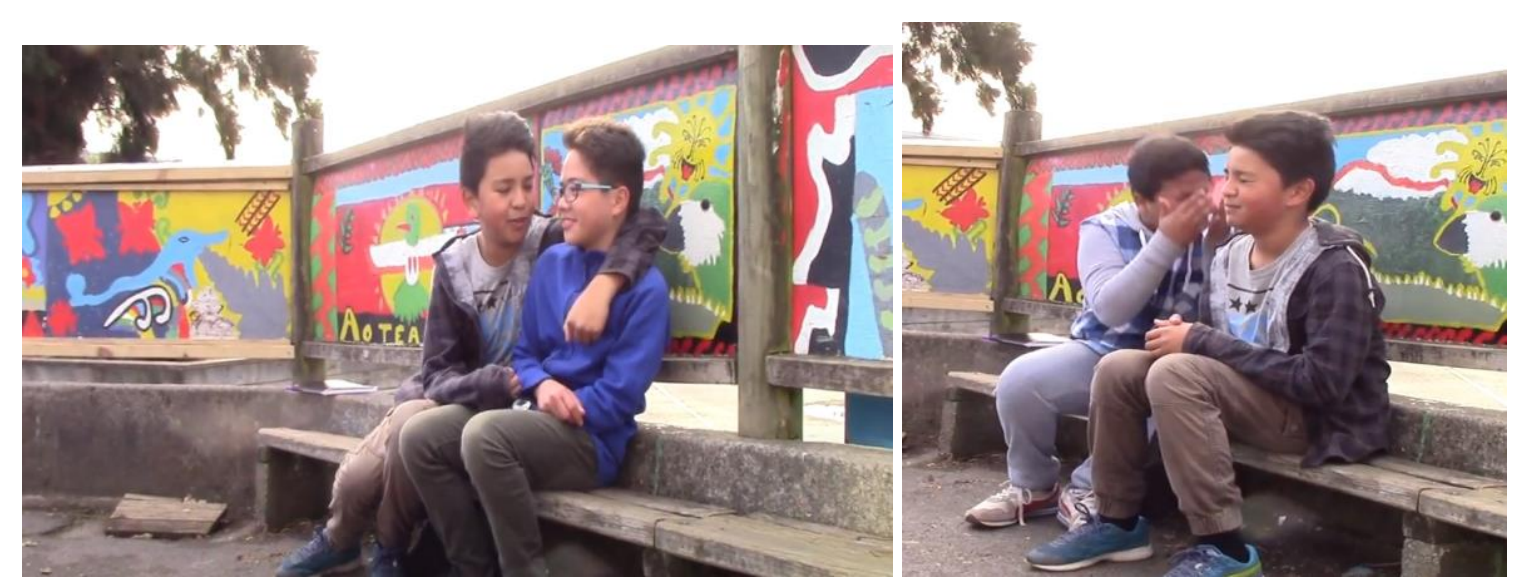

Figure 37: Tawa School students play Bus Stop.

Each student had the chance to lead a game, interact with the children while other students were leading, and also to observe. The sessions, although planned, did seem to flow organically and were noisy and at times chaotic. The students had predetermined who would be running each activity and there would always be some students joining in with the games, which seemed to give the children extra confidence to join in. The children were invited to participate in the games but could choose to sit out. They were also given autonomy to select their own groups both during the games and the discussions. The classroom teachers commented that they loved watching the children play and were surprised at how different some of them were in the environment of a drama session as opposed to 'normal school.' They commented on one student in particular, who was usually disruptive in class, who absolutely thrived in these activities and showed great skill in improvisation.

Overall, the children responded enthusiastically to the session. There was a combination of children who were keen to jump in immediately and participate, those who stood back and quietly observed before participating, and others who seized the opportunity to really 'perform' to others in the class. The diversity within the group of children was significant for the students to note as it reiterated David Wood's 
observation that performers must not forget that "the audience en masse is composed of individual children" (Wood and Grant, 20).

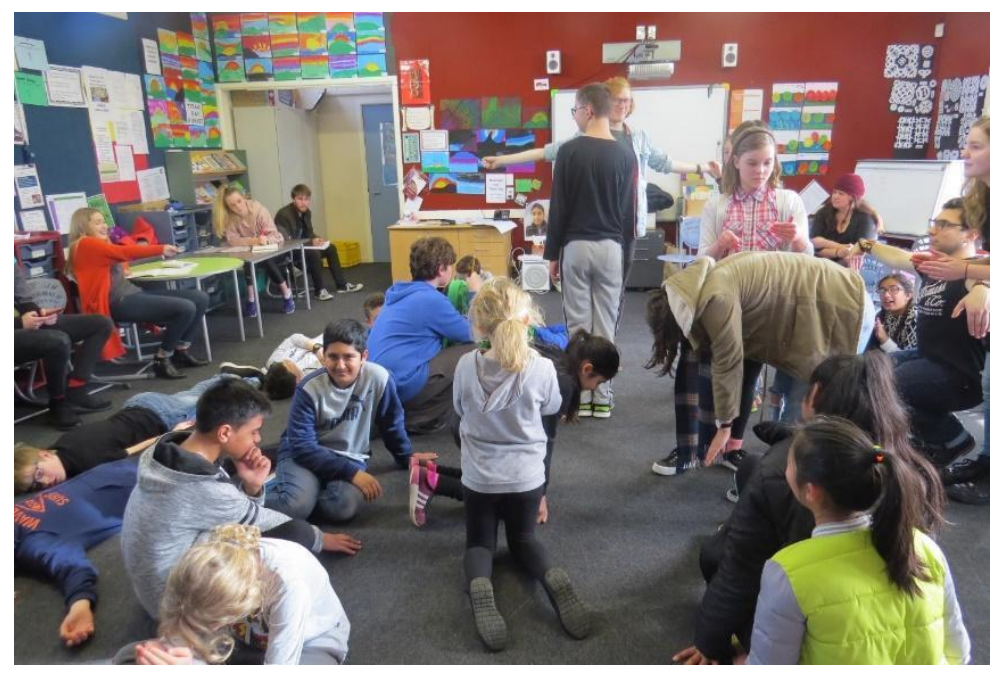

Figure 38: The students working with the Children

After the games, we assembled in small groups of about five children and two undergraduates. This was an opportunity to chat, to reflect, and to get to know each other better. Interestingly, the children gravitated towards groups of like gender. When the children were split into discussion groups, for example, eight of the eleven groups were made up of children of the same gender. The older children also predominantly formed groups of their own ethnicity. One group of young Pasifika girls were particularly keen to talk with Daz, the only Pasifika student. This interaction perhaps indicated a greater level of comfort in sharing and discussion within their own cultural and gender groups. The children asked questions, in particular about performing and being a drama student, and the students reciprocated with questions about the children's likes, dislikes, hopes, and dreams. I observed a genuinely warm feeling in the room, both groups talked to each other as equals, listening, respecting, finding mutual interests, hobbies, likes, and dislikes. Even though the students considered themselves adults, it became apparent that ten years was not such an insurmountable age gap, and both groups were surprised by how much they had in common. One child commented 
how much she loved discovering that the students have many of the same interests and likes as her. Back at university, I discovered that this was a revelation to the students as well:

What I found most interesting was the discussion we had in small groups afterwards. The children I spoke to gave very specific and useful advice when we asked about their interests and what they might like to see in a play. I was surprised and delighted to hear that the four boys were interested in politics. (Himmelmoe)

Another student commented on the variety of themes the children expressed interest in:

Overall the themes that I could pull from these conversations were a wish to play in open worlds where they could explore things like magic. Time travel also seemed to be a popular motif with them. Social media and the internet was also a frequent answer when asked what they did outside of school. It seemed like they watched more YouTube than television. However, what surprised me was how much they enjoyed reading. I remember at that age I was just starting to not enjoy reading. (Orlando)

The observation also highlighted the 'dark nature' of some of the children's thinking:

At Tawa school, I observed Corey running a game of 'What Are You Doing?' with some of the kids, and it struck me how quickly and how often some of them went with really dark options, such as 'killing someone' and 'committing suicide', enacting them in an enthusiastic and trivialised manner. This helped me to realise that these kids aren't unfamiliar with these terms and ideas, but 
perhaps (and this is a bit of a generalisation) don't fully grasp the gravity of it. (Nacey)

I observed a range of comfort levels among the university students. Some instinctively knew how to engage with children. Peter jumped in as soon as we arrived, during the morning tea break, and played soccer with a group. He was an instant favourite, talking to the children as equals and intuitively knowing how to run an engaging session. Others were nervous about interacting with the children. Back at University during the post-visit debrief some students explained their anxiety about 'doing the right thing,' the children 'liking' them, and their ability to hold the children's attention. The differences in comfort levels likely reflected previous experiences of interacting with children. However, most of the students relaxed once they began to interact with the children, and accepted that they were not there to be a 'teacher' of drama, but were collaborating with the children in a combined project. I observed that the majority of the children were very open to working with the students and expressed an interest in them and a level of comfort in interacting with them. This was reiterated by the teachers afterwards who commented on how much the children had enjoyed the session and how they had observed a high level of participation in the games.

On the whole, the THEA 311 students were surprised and pleased at the openness, generosity, and maturity of the Tawa school children and in particular how they could get into detailed and multifaceted conversations with them quickly. This suggested that the reciprocal exchange of ideas and play that we established at the beginning of the session was fundamental to the openness of many of the children at this point in the process. 
Tempest's reciprocal learning and reverse-mentorship concepts (190) and Freire's problem-posing approach (80) were demonstrated in this interaction at Tawa school. The students were being reminded of their own childhoods, and were also learning about what it was like to be a child in 2017. Both the children and the students were showing that they were 'experts' in their own fields, and the intergenerational learning that was happening here was a two-way interaction. The interaction with the children also helped the students to understand the unique and diverse attitudes and behaviours of this age group, which greatly assisted them when they began to devise the play for this group as explored in Chapter Nine.

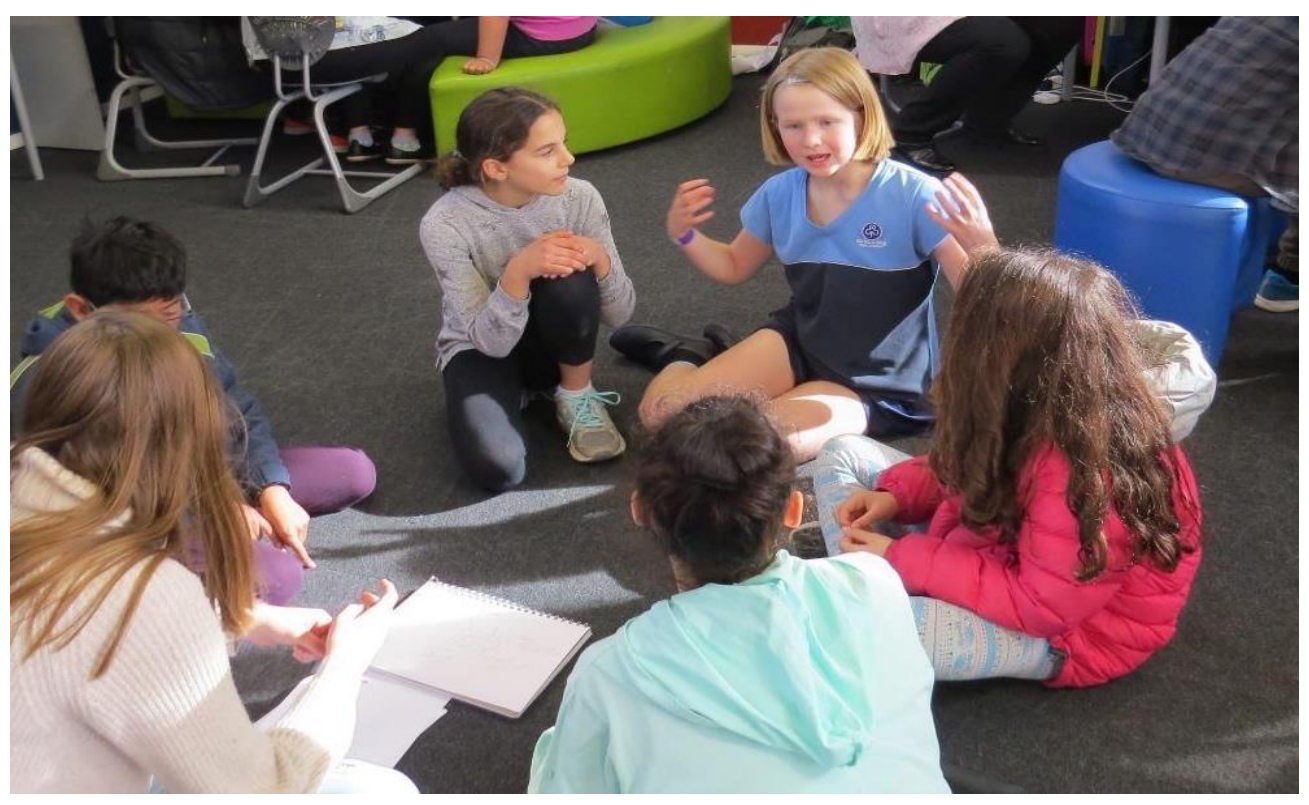

Figure 39: Discussion Groups.

\subsection{Te Aro School}

Our second visit was to Te Aro School, which is also a full primary school with a roll of approximately 220 students, aged $5-13$ years. It is an inner-city school, situated close to the university, with children from a diverse ethnic background (Te Aro School). We arrived at mid-morning break time and were invited to interact with the children. The 
students were all much larger than the Te Aro children, in comparison with those at Tawa School. Once again, some of the students immediately engaged with the children, and asked if they could join in their games, while others were far more apprehensive. The students were, on the whole, less comfortable with the younger group, and seemed more anxious about doing the 'wrong thing'. Almost immediately one of our students was reprimanded by the principal for riding a scooter in the wrong part of the playground-- a scooter he had been invited to borrow from a child, who also was not abiding by the rules. This mutual breaking of rules, however, instantly placed the child and the student on the 'same side' and created a genuine bond and sense of trust between them.

At Te Aro School we worked in Ruma T⿳亠丷厂 with twenty children aged five and six. Their teacher, Nicole, was young, warm, and passionate, and the children called her by her first name. Our first observation involved watching the children enthusiastically participate in reading time. The students observed how engaged the children were, and commented that reading, and in particular reading books, appeared a valid and exciting activity for these particular children. The students gently encouraged them and before long all of the children were reading to a student. Each child had a selection of books in their 'reading box' that had been previously selected, depending on their reading ability, by the teacher. The children self-selected books from their box to read to the students. Kevin relays his experience in connecting with James:

When we went inside I sat next to a boy named James. He seemed a bit shy, but when I asked him to read me the book he had in front of him he quickly changed tone and became excited. This excitement made a bond between James and I that I think helped him open up later in the day. After that, he read me his favourite book about foxes. (Orlando) 


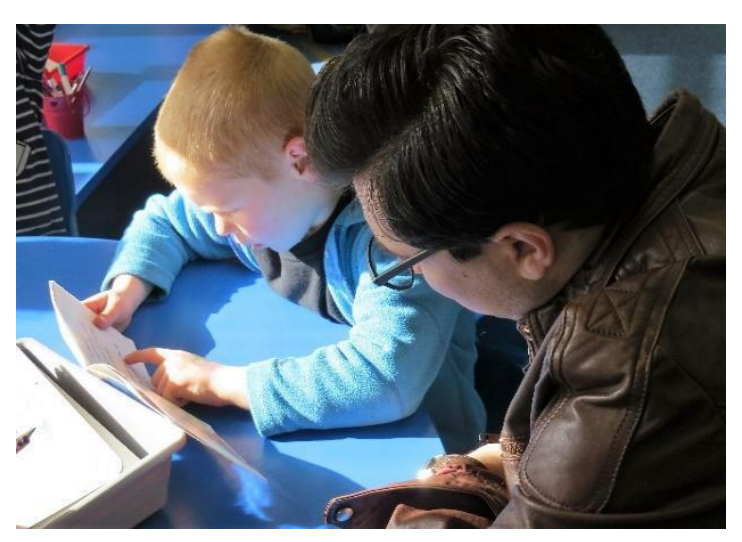

Figure 40: James reads to Kevin.

The children relished the chance to read aloud and appeared to love having someone to listen to them. Once the students had gained the attention and the trust of the children, this seemed to prompt them into talking about the stories, about life, or about things they like to do. Some of the children asked the students to tell them stories. The students began to improvise, and it was a moment of connection between the groups. I noted how once again by coming into the environment of the children we had dissolved barriers in age, size, and education. Spending time on a simple shared activity, built trust between the two groups and helped the children speak freely with the students. This interaction provided the 'connecting force' as referred to by Davis et al., and encouraged the students to reminisce on their own childhood and the children to have an enriched learning experience through their interaction with positive role models (Davis, et al.42).

In the second half of the session, we moved into a large space and participated in a drama games session led by the students. This was similar to the one at Tawa School, but the games had been adapted to resonate with the younger age group. Favourites were: Grandma's Keys, Fruit Salad and Clumps. ${ }^{68}$

\footnotetext{
68 See Appendix D.
} 


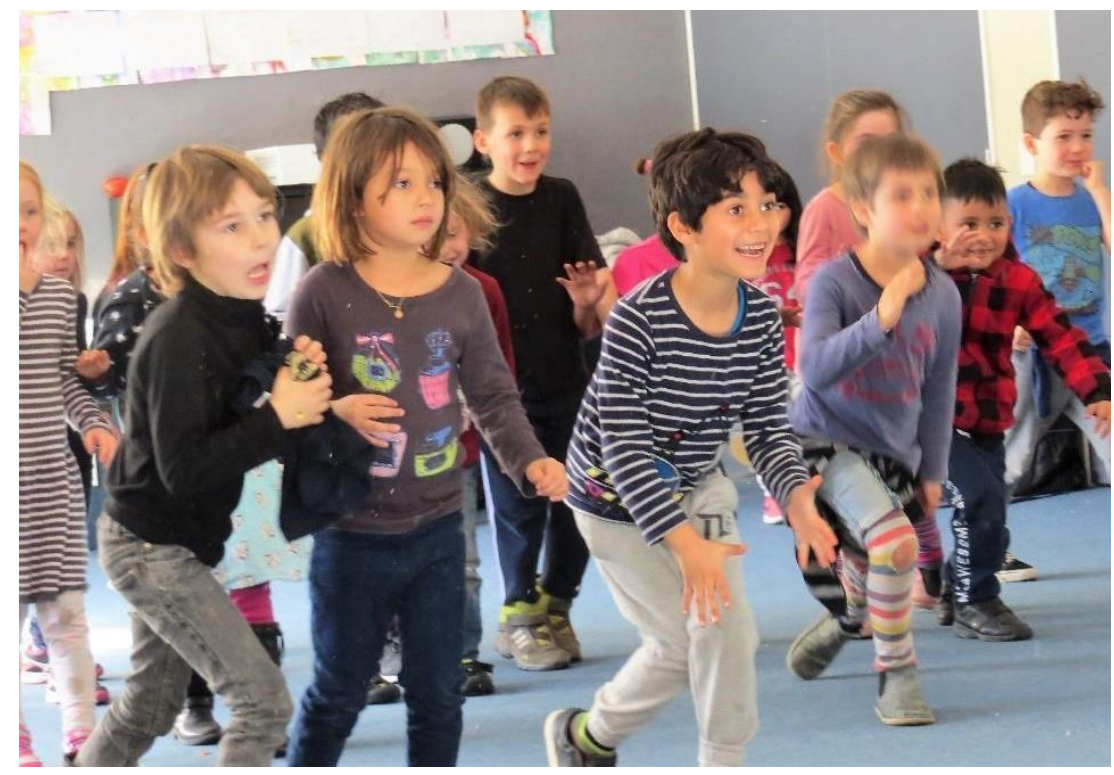

Figure 41: Grandma's Keys with Ruma Ti.

The children responded enthusiastically to the participation of the students in these games. A particular example of this was in Grandma's Keys when one of the children played 'Grandma' and all the students had to attempt to steal the keys. The children loved being in this position of power, and most wanted to have a turn. The other children also loved watching the students and loudly helped 'Grandma' send them back to the start line.

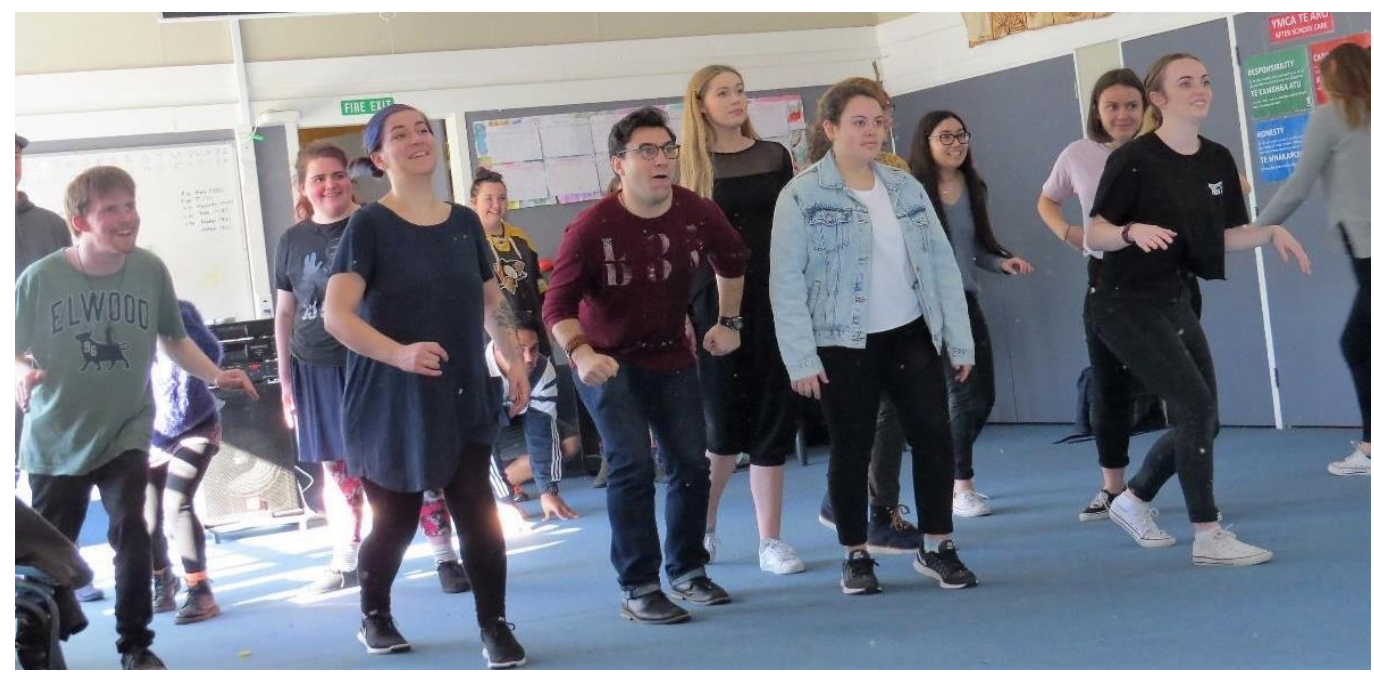

Figure 42: The students playing Grandma's Keys. 
The students made detailed observations of the interactions with the children and analysed these after the session. Pelle comments on the bond made between the generations:

I found it very touching how trusting most of the children were with us and noticed that several of them made instant bonds with some of the adult students. The communication between the children and the students was refreshing. They were so open and eager to engage with us, with very little filter. (Himmelmoe)

Finn recognised the way even this younger age group could respond to sophisticated ideas such as politics:

The kids at Te Aro recognised quite a lot about the current state of US politics. When Penny [Pelle] and I mentioned Trump to them, they recognised his name and mentioned things such as his orange skin and funny hair, and that their parents didn't like him. They even recognised names like Obama and John Key, though they struggled to place larger context on them (and understandably so!) To me, this shows they have relatively good recognition in regards to current events-- more than I anticipated, at least! To me, this shows that kids aren't immune or blind to the world that's around them, they just see it in a different manner than we might expect. (Nacey)

Kevin made some pertinent observations about the children's ability to play and use their imagination at this age: 
Something I noticed and that was great to see was how easily their imaginations would grip onto something as silly and unstructured as the stories we told them... It was clear that imagination was an incredibly powerful tool within this age group...Somethings I noticed during our games with the kids inside were; 1. [The] need to bond or pair with an older student. 2. Hesitation to speak alone in front of the class 3 . A love for animals 4 . Most were accepting of any groups they were placed in. 5. A yearning to play for fun, the kids didn't enjoy singling each other out but rather liked to have fun as a collective. (Orlando)

The session concluded with the students and the children in small groups, a sharing of likes and dislikes, and ideas around theatre and performance. In contrast with the older children, we discovered age-specific differences such as it being easier to get these younger children to form a circle when instructed. The older students often questioned 'why' when asked to perform or participate in something, compared to the younger five- and six-year-olds who would often just leap into an activity and try it immediately, even if they did not fully understand it. Free-thinking, play, and imagination were more evident in the group of younger children than in the group of older children. They followed seemingly random trains of thought, often jumping quickly to a new idea. They wanted to be heard and to be paid attention to. They would often mimic the behaviours of the students. For example, if the students spoke to them in a baby voice, they would respond similarly. Some children physically attached themselves to the students. Several were surprisingly tactile; one girl even pulled up her jumper to rub her bare skin against one of the students. Many children wanted to be carried or jump onto the students. This at times was overwhelming and surprising, but many of the students embraced the opportunity to interact fully in a child-like and playful fashion. 


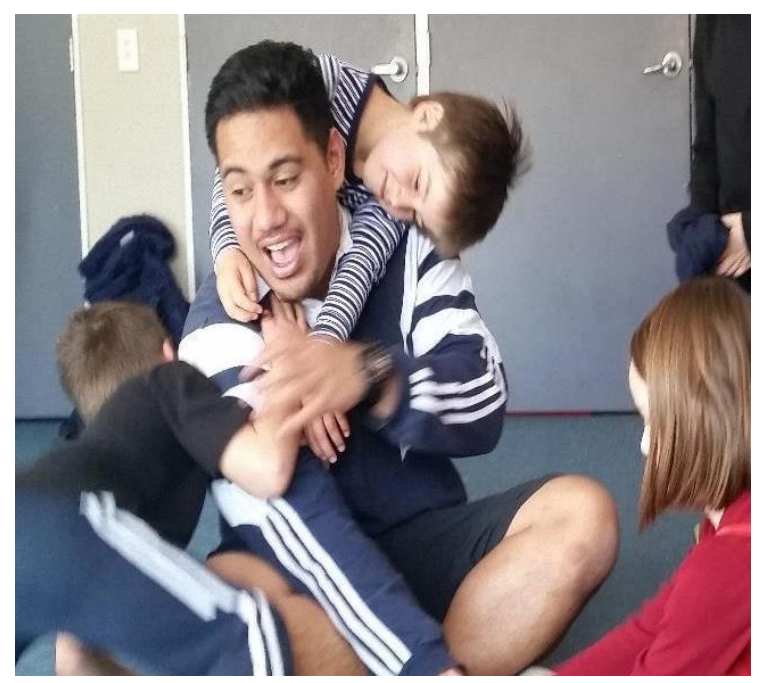

Figure 43: Hands-on play.

The visit to Te Aro school demonstrated to us the importance of creating relationships with an audience, and the positive response that came from the children when they felt listened to and respected. Later, reflecting on how excited they were to create personal connections, the THEA 311 class discussed how, when presenting a theatre show, we could make each child in the audience feel like we were creating and performing the show just for them. It was also significant for the students to experience the uninhibited nature of children at this age, as well as a practical understanding of children's attention spans. The students observed that while some of the children responded quickly to structure and rules, others did not care to follow the rules of the game at all and would frequently break them if it gave them a greater sense of fun. The children, on the whole, displayed a relentless flow of energy, with constant movement. The students realised that their dramaturgy would need to take into account this dynamic, unpredictable energy. They were challenged to create a play that was multifaceted and surprising, in an attempt to appeal to varying degrees of audience attention-span. 
The facilitation of this intergenerational play saw a pairing of children and young adults. Even though the age spans between the students and the two groups of children were not vastly different, there were still reciprocal learnings for all age groups, and the various forms of play created a context for social interaction and learning between the generations (Davis, et al.44). The interactions with the children also reminded the students of their own childhoods, what it was like to be a child, and to contemplate Brown's advice to, "discover the image of the child in ourselves and ourselves in the child" (Brown, "4. Provocations and Insights"). This placing of the audience at the centre of the work they were to create, was an important step towards encouraging the students to produce "theatre which does not simply regard its audience as passive consumers but as people who are active, thoughtful and sensitive" (Taube, "Editorial"). Gerd Taube describes how TYA that considers the audience in this way, enables its young audiences to emancipate themselves:

It regards its audiences as partners and offers them a space and an opportunity to judge and act for themselves. Children and young people are mature responsible spectators when they are allowed to decide for themselves on the significance of what they are shown and its meaning for their own lives, independent of the ideas and goals of the accompanying parents and teachers, and without the need for special instructions on how they should understand the art of theatre. (Taube 9)

The interaction with the children also raised the stakes for the students: they were inspired to make quality work for the children. The audience was no longer a faceless vacuum, but real children that they liked and wanted to entertain and impress. 


\subsection{Trialling with an Audience}

After these school visits the students returned to the university to work on generating and exploring material, which led to the creation of the two plays. The initial interaction with the community of children was integral to the way we shaped each piece. The students consistently reminded themselves of the children's ideas. Some ideas were common to both age groups: the love of stories, being surprised, escaping to another world, comedy, and every child's desire to enter into a relationship with the actors on stage. There were ideas specific to the Tawa children such as un-happy endings and sophisticated stories. The Te Aro children had indicated a love of playfulness, freethinking, and imagination. They had demonstrated that they didn't always want to follow the rules but wanted to be listened to. Because of their conversations and interactions with the children, the students decided to steer away from realism and instead work in the genres of magic, myth, and fantasy. The students in both groups kept a clear picture of the audience in their minds during the entire devising process. They would remind each other of what the children had discussed and the behaviours they had observed. This led to important decision-making around the form and content of both plays. These interactions and discoveries with the children, and the way we used the information gathered from them, are discussed in detail in Chapters Eight and Nine, but a pivotal moment in the process was when we invited the children to the University to view the works in progress.

Six weeks after our first encounters at Tawa and Te Aro schools, we had created rough drafts of two fairly cohesive narratives. We wanted to test how the children would respond to the work we had created so far. We also had some specific questions to ask the children. The Moonlight devisors were concerned that the piece would be too scary for its young audience. In the Attic's devisors couldn't decide how to end the play. To help resolve these questions, we turned back to our two school groups, inviting 
them to come to the university to watch the plays. They then gave feedback in two stages: directly after the showings, and several days later.

This resulted in some important contributions from the children that directly impacted the way the shows were developed. Of particular note (and explored further in Chapter Nine) was the method that we used with the Tawa School group of presenting an unfinished play to them and soliciting their ideas for the ending, which included a democratic vote for what they wanted to see. One of the main advantages in trialling in front of an audience was that the students had the experience of performing for children. There were some significant revelations made. One that spanned both age groups was that children do not have to be noisy or actively reacting to be engaged in the play. Saffron describes her experience from the first showing of In The Attic.

Throughout the performance, quite a few of the kids weren't really reacting to the things we thought they would react to, especially in scenes that weren't filled with slapstick comedy. At this point it made me feel that because they weren't reacting at the time, they weren't enjoying it, however, after going back to Tawa school and talking to the kids, I found that the parts I thought they didn't enjoy were actually some of the things they enjoyed the most, which made me think that perhaps they aren't reacting as much because they are so focused on the performance (Troughton).

Yasmin noted that the younger children were even quieter than the older ones, surprising perhaps because of the very busy and noisy session we had experienced at Te Aro School. 
[The] Young children were much quieter. They were quite shy and were very silent. This was surprising to me and during the performance, I felt like we were performing badly, but when I would look at the kids' faces it was clear they were just extremely interested in what was happening. I didn't know that kids that age go so quiet if they were enjoying a show. (Golding)

This realisation affected the way that the students responded to their audience and can be connected to the discussion on audience interaction and participation in Chapter Four. Because the students had been alerted to the different ways that children respond, this meant that they did not feel that they had to force the audience to participate and engage in a loud and pantomime-style way, and could instead relax and focus more on telling the story and responding to their audience.

An unexpected benefit of our trial showings was the way that it transformed and recharged the creative dynamic for both devising teams:

It was amazing what the pressure of having an audience did to us on the morning of the showing to our creativity and work drive. We achieved so much and solved many of the plot-holes and problems we'd been struggling with just fixed themselves. It showed us what we were capable of creating under pressure and necessity and how far we could really push ourselves to get there, which was really cool and enlightening. (Cruz)

Problems that they had been grappling with for days were solved quickly when the students were confronted with a deadline and the reality of a live audience. Feasibly the students were more invested in making a quality show for their audience because of their previous interaction with them. The relationship that the students had created 
with the children became a strong motivator to create something 'good'. This was strengthened by further interactions with the children. "When we went back to Te Aro School, the reaction from the kids was quite surprising and it gave us the encouragement to really polish the show" (Golding).

The intergenerational collaboration highlighted shared interests and experiences between the groups. Some students had strong responses to discussions with the children that made them consider the content of the plays. This indicated the value of the collaboration in reminding students of what it felt like to be a child, and the way that stories could make them feel. It helped them to consider more deeply what story they would tell.

In relation to the challenge of directly asking the children what they wanted to see a play about, the students discovered that by playing with the children and asking them about their interests and beliefs, the students began to get an idea of what the children would enjoy. Then by showing an interpretation of these ideas directly to the children, and eliciting feedback, they were able to get clarification on this. The whole process became a method of experimentation: trialling ideas from the initial interaction, receiving feedback, and then trialling again.

\subsection{Summary}

In her 2020 article "Perform Direct(Ing) Responsibility: How Directors Can Make the World a Better Place," German TYA practitioner Julia Dina Heße suggests that directors need to take responsibility for the audience in their work. This includes considering how an audience is involved in a production and how the voices of children and young people can be heard (Heße 14) by being: 
in direct exchange with the children and young people for whom they are currently working...[and] interested in gaining an insight into their views and viewing habits in order to establish an appropriate relationship between narrative strategies and aesthetics. (Heße 15)

By interacting with the two primary school classes, THEA 311 was gaining insight into the views and viewing habits of children and the ultimate audience of the project. Feedback from both groups of children following the showings became a scaffold for further creative work over the remaining three weeks of rehearsal. The devisors often returned to the comments and suggestions that the children had made to help them shape the final show. This direct exchange with the classes at Tawa and Te Aro was an endeavour to give the children agency over the content and form of the theatre works we were about to make. Instead of assuming what the children wanted to see or would be interested in seeing, the students were engaging with the children in a way that gave evidence of their interests, thoughts and feelings, which the students could then respond to. The connecting force of 'Play' created an environment for the two generations to learn from each other via a reciprocal exchange of knowledge. This also created a relationship between the two groups which affected how the work was created and how it was received. By not making assumptions about what the children would respond to, the students of THEA 311 were engaging the children throughout the making process. They were allowing them to have a say over what was made, in the hope that the children would feel more agency in the final product. 


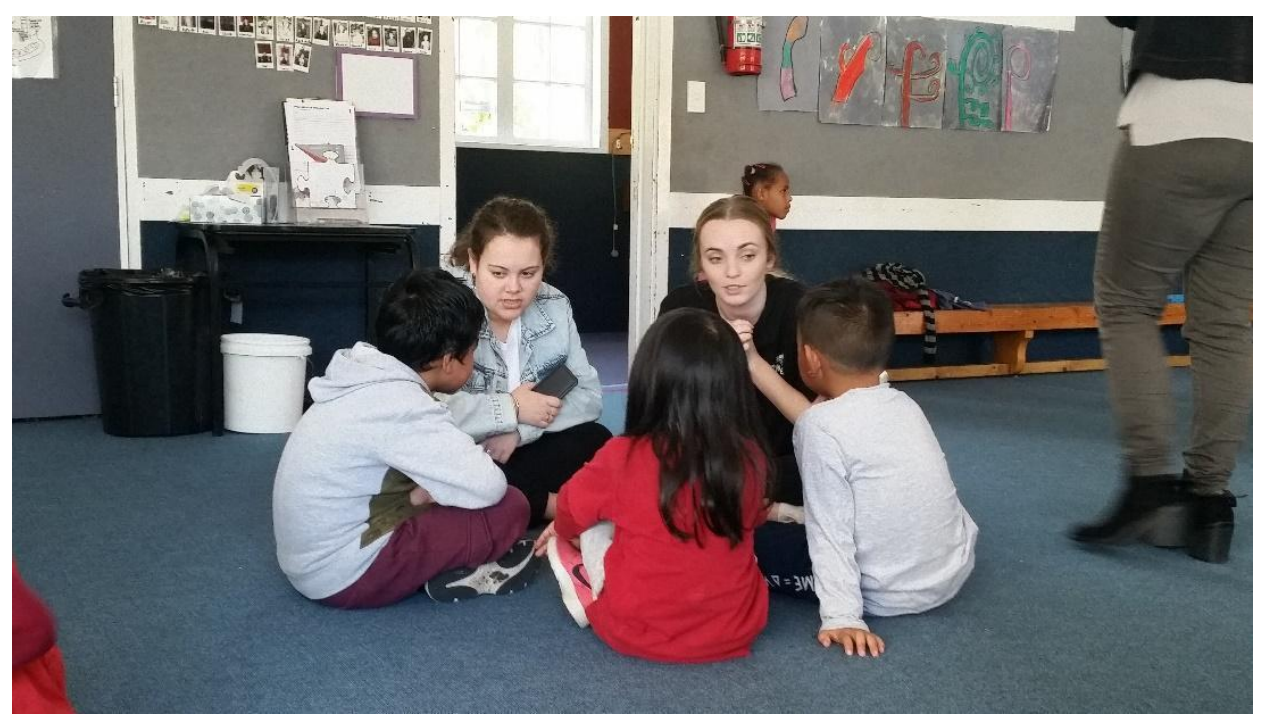

Figure 44: Janaye and Nat listen and share ideas. 


\section{Let Your Imagination Lead the Way}

The Creation and Presentation of Moonlight

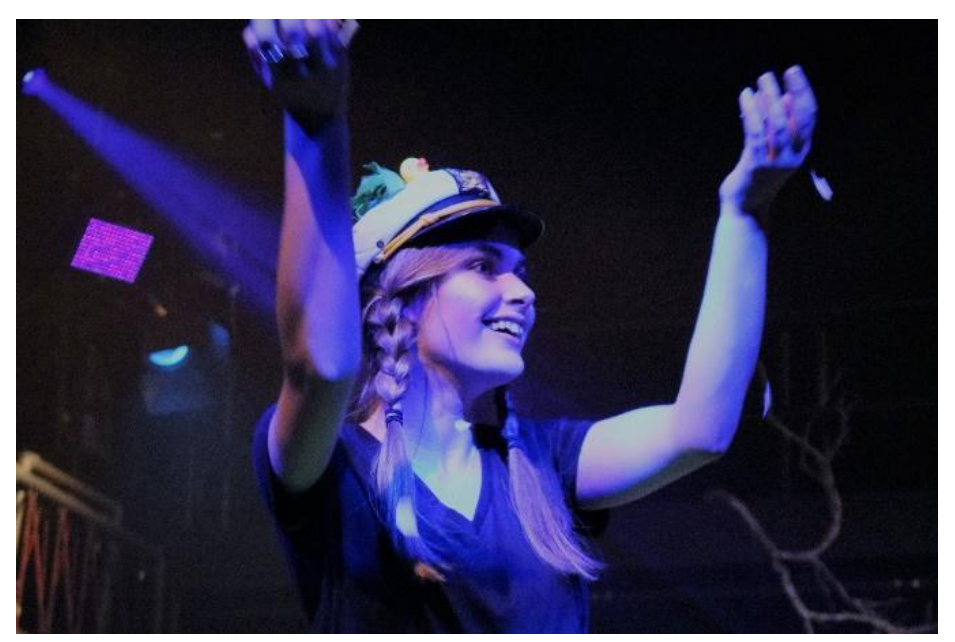

Figure 45: Dara in Moonlight.

\subsection{Introduction}

Interaction with the school children had given the students a solid understanding of who they were creating the plays for. The unique nature of the creative environment is worth reiterating: the students were not professional actors, but undergraduate theatre students. The children referred to in this chapter were a class of five and six-year-olds at Te Aro, a multi-cultural, inner-city Wellington School. One of my key research enquiries was to identify strategies for engaging a young audience in the process of making theatre aimed at their demographic. I was testing ways of building an intergenerational, collaborative model of devising theatre that would encourage agency and empowerment for all the young people involved in the process.

What follows is a critical analysis, with the hindsight of two years from the completion of the project, of parts of the process that directly relate to my research 
inquiries. In particular it explores: practical strategies that were employed to empower the students and the children; an exploration of methods that put the children at the centre of the work being made for them; and directorial choices and approaches that relate to the devising ensemble. It also includes some of the critical reviews, both published and unpublished.

\subsection{Character-Based Text Driven Narrative vs. Image-Based Narrative}

"Image creation actually promotes the artistic impulses in a child_because the young person is doing the art-making by conceiving the image." (Pope 7)

One of the key elements of the PaperBoats project is that the works produced for younger children are image-based and language-lean. Key PaperBoats collaborators Pope and Brown believe that creating image-based theatre for younger children has the potential to resonate more deeply and engage more thoroughly with its audience (Pope 7). The underpinning philosophy is that creating largely image-based modules, leaves the audience open to interpret them in their unique way:

What I find is that because the modules are largely imaged based, that the rendering of the narrative is generally more poetic and open ... Even though as a maker I know exactly and specifically what "my" narrative is for the work and the decisions and nuances of the work are dictated by this narrative-- the audience may not "read" the narrative in " $\mathrm{m}$ " " way because it is a set of images ...the meaning is not literal ... (Brown qtd. in Palmer, "Thea 311.34")

Brown's theory resonated with me. Instead of utilising a character-based text-driven narrative, which perhaps relied more on the audience understanding the literary form, Brown was proposing creating space for children to make their own meaning from 
poetic images. This suggested a more child-centred way of empowering children in their reception of TYA. I was interested in exploring this theory; however, I did not have much experience working solely in a language-lean and image-based way. I was also curious to see if it was necessary to utilise one form at the expense of the other. Would an image-based narrative detract from the viewing experience for those who enjoyed a character-based, text-driven narrative?

Most of the THEA 311 students had experienced an introduction to image-based theatre in an earlier undergraduate devising course, THEA 203 Space, Light and Bodies, which was underpinned by Augusto Boal's teachings and definition of image theatre: "Image Theatre is a series of exercises and games designed to uncover essential truths about societies and cultures without resort, in the first instance, to spoken language" (Boal xix). Much of their work in other courses had, however, been with text-based drama.

We discovered that the image-based provocations worked well in the initial devising stage of the process. In particular, I observed the students found creating work without dialogue simultaneously challenging and liberating: "At first we struggled a lot with using too much dialogue and exposition about what we were doing. Once we stripped back dialogue to bare minimum and focussed on the action we got into a much better flow" (Cruz). The added challenge of getting the students to create without using dialogue was also effective:

[t]he exercises of not being allowed to talk about the different images we were making was very liberating, as discussing things to death, seems to be a big issue when working with devising ... Not only did we not really have time to overthink it, 
but [as] we weren't allowed to discuss it, we had to just go with whatever ideas came up, which I think opened up the creativity. (Himmelmoe)

Once we divided into two groups and began to focus on the final plays, the urge to use dialogue to explain things became stronger. I noted that I was often encouraging the students to adhere to Brown's ideal of poetic image-based, language-lean modules, while simultaneously wanting to resort to my familiar style of using dialogue and character to tell the story. In conjunction, there was also a desire from the students to create a complete narrative, as opposed to a series of modules presented by the other two university groups working on the PaperBoats project.

One activity which helped navigate this form of image-based narrative was introduced on Day $13^{69}$ when I brought along a selection of children's storybooks as a provocation. The students chose the two that resonated most with them: How to Catch $A$ Star by Oliver Jeffers and How to Heal a Broken Wing by Bob Graham.

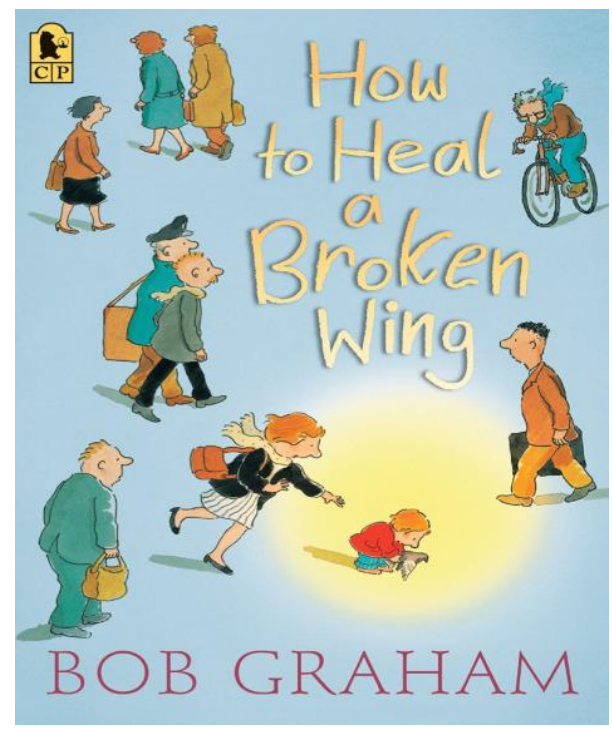

Figure 46: (c) 2008 Blackbird Design Pty Limited Reproduced by permission of Walker Books Australia

\footnotetext{
${ }^{69}$ This was after the visit to Te Aro School where the students had observed how much the children enjoyed reading picture books
} 
Both had very provocative pictures and were relatively language lean. The students were given a composition task:

1. Make a series of 5 frozen tableaux that tell the story of the book.

2. Make a short piece of music that sums up the essence of the book.

3. Combine the tableaux and the music.

The resulting work was some of the most whimsical and beautiful work to date. Even though the rehearsal was late at night, the students were fully committed and engaged. They created images that were a response to Graham's book. Figure 48 is a tableau of the student's interpretation of the family 'freeing the bird' while the rest of the world continues on obliviously.

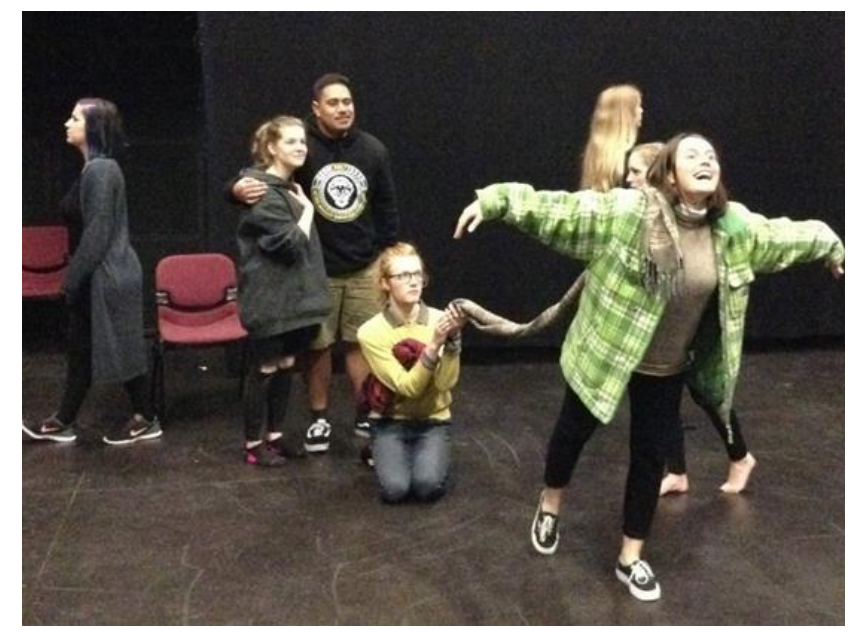

Figure 47: The students in the final tableaux from 'How to Heal a Broken Wing'.

The images were simple and strong, and the audience were able to interpret the story in their own way. Even if the audience were not familiar with the book, the essence and the underlying emotions of the story were made clear through the tableaux the students created. These emotions became even clearer when music was added. I felt that this was 
a turning point in the overall devising process. By using clear imagery and music, the students discovered that they were able to tell the full narrative in a way that was poetic and imaginative and did not rely on words. Reflecting on this work, Dave Brown noted: "There seems to have been a transformation in performance awareness-- a much greater quality of clarity and simplicity in these pieces (Palmer "Thea 311.34"). My intention with this workshop was that the students would get a sense of how text isn't always necessary to convey narrative and that by using clear poetic imagery, audiences are able to interpret a piece themselves.

Even though this was a highly successful workshop, at the next rehearsal I noted that the students added words to explain the images, which led to overexplaining the story. This suggested that while we were becoming more skilled at creating in a language-lean, visual way, and were aware of the potential for empowerment for children, we were still drawn to using the familiar approach of a dialogue-based form. However, an amalgamation of both character-based text-driven narrative and imagebased narrative began to emerge.

\subsection{Paper Bag Productions}

The students' visit to Te Aro School had allowed them to discover the children's likes, dislikes, and interests by sitting alongside them and genuinely engaging with them.

When it came time for group B (Paper Bag Productions) to begin their specific devising process for their play, they returned to the key findings from their visit to Ruma Ti: the children's love of stories; the sense of danger in breaking rules and testing boundaries; free-thinking; playfulness; and imagination. They were also reminded of the children's desire to be surprised, heard, and paid attention to. 
I introduced the students to an exercise where they brainstormed ideas of what content they wanted in their play and the theatrical forms they intended to use. Bert Van Dijk suggests a rudimentary definition of both: "[f]orm relates to the totality of physical and vocal actions: it includes the actors' movements, gestures, interactions, sounds and words" (Van Dijk 56), while "[c]ontent is the totality of intentions, feelings and images that performers use to give quality to their actions." (Van Dijk 57) During my previous devising practice, I have observed that student devisors often favour either form or content in their initial decisions. If the balance of the two is not considered early enough in the process, a devised piece can end up lacking in one area. This can result in a play that is magical, theatrical and impressive in its form, but with no engaging content; or a content-driven piece that lacks any real theatricality in its form. Within a university setting, I have often noted that student devisors will initially be clear in the form they want their production to take yet are unable to easily articulate the content. In this instance, I ensured that the students were aware of the differences and the importance of articulating both, and encouraged them to brainstorm separate lists for content and form.

Form: Group B's initial ideas around form encompassed theatrical elements which the students were interested in using. These included: music, the manipulation of props, light as a storytelling tool, puppetry, a steampunk aesthetic; and the use of fundamental dramatic elements in form such as magic realism, physical theatre and magic.

Content: The group's content was largely controlled by the introduction of the PaperBoats germinal idea of 'Twoness', so the brainstorm unsurprisingly included elements related to this concept. This included ideas around discovering two paths, chance, destiny, fate and choosing your own adventure. The list also included binaries such as good and bad, and danger and safety. Finally, there were ideas about characters, such as a bumbling character, a misunderstood character, and a dark 
protagonist. These ideas predominantly came from the student's interactions with the children.

Group B was encouraged to name their group as if they were a professional production company to inspire a greater sense of group unity and for marketing purposes. "Paper Bag Productions" emerged as a reference to some early provocations and experiments with paper. The company was made up of nine students: Finn, Kevin, Dara, Alex, Pelle, Emma, Georgia B, Nicole, and Yasmin. All had different reasons for gravitating towards the younger age group. Pelle reflected that he was attracted by the openness, and "eager lack of filter" of the younger children, as opposed to the more reserved nature of the older children (Himmelmoe). Some students felt more comfortable working with the younger children. Several who had initially felt nervous before meeting the Te Aro Children, had been reassured by their positive interactions at the school visit.

\subsection{Generating Scenes from Golden Moments}

Following the initial three weeks of play and generating material with the whole class, the two devising groups were ready to begin the 'Exploration' stage. This third stage in Swale's devising process is where the most inspiring/resonant/interesting material from Stage Two-- 'Generation'-- are selected and investigated further. Swale clarifies that this stage is still generative; ideas continue to be generated, but parameters begin to be set, and narrative, characters and scenes emerge (xxx). We began by reviewing video of the work we had already created to identify golden moments from the early group provocations which could be developed further into more detailed scenes.

An early improvisation was provoked by the reading of the Robert Frost poem, The Road Not Taken. This evolved into a larger scene based around the concept of a talking signpost. 


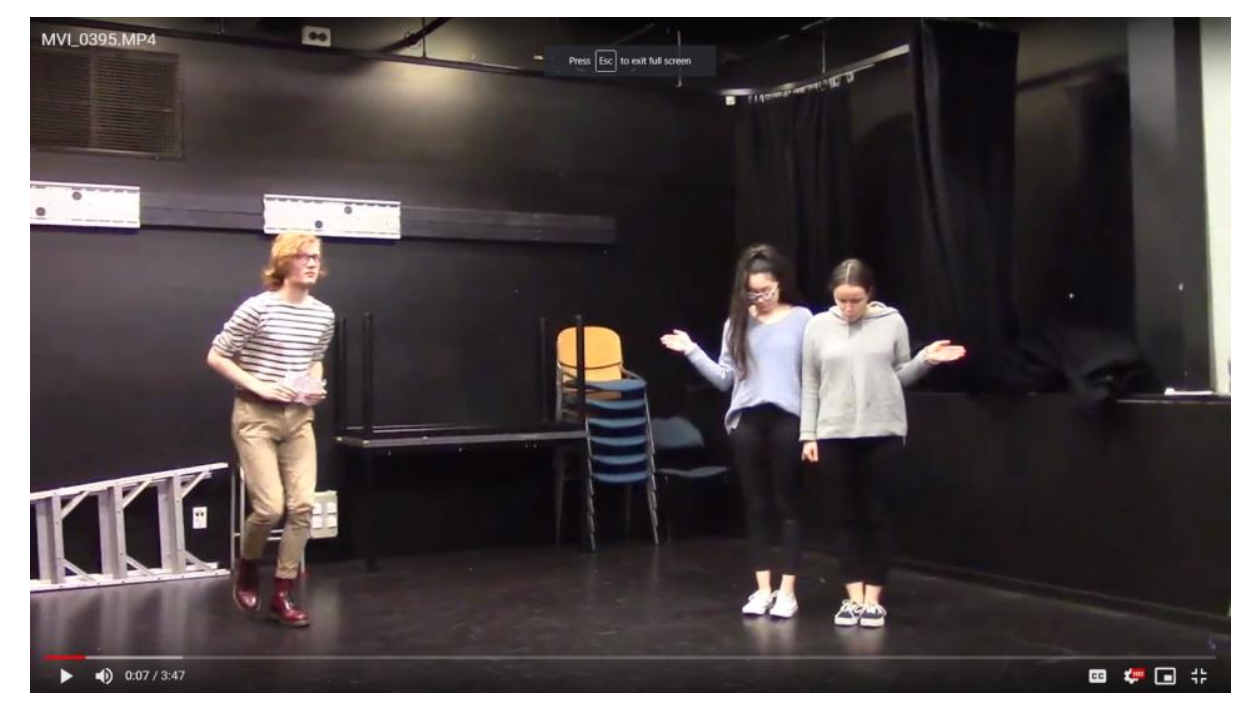

Figure 48: Screenshot. Exploring the provocation-poem, 'The Road Not Taken'.

Finn, Cassidy, and Gemma created a scene where a traveller meets a two-headed signpost. Both heads of the signpost attempt to lure him to follow their path, creating confusion and uncertainty. Eventually, the traveller chooses a direction and carries on that path, where he comes across two 'Tea Witches' singing Tea-For-Two. By exploring the scene in greater depth, the group were able to begin to develop a narrative and create solid characters. In this instance, what resulted was four key characters-- the two heads of the signpost and the two tea witches - who eventually became pivotal characters in the final play. This example demonstrates how the devising methodology specific to this project developed. The students began with the germinating concept of twoness, explored ideas, reviewed them and explored them further until they became fully realised scenes in the final play. The students were developing their own method of creating material while also putting the children's ideas (for example, 'bumbling characters') at the centre of the work. 


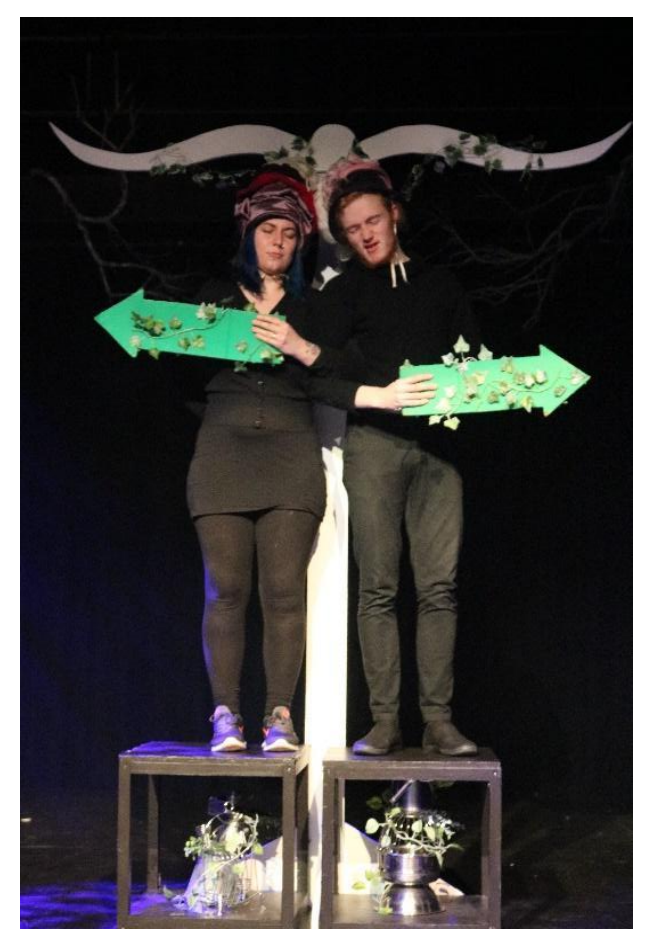

Figure 49: The final Two-headed-Signpost scene

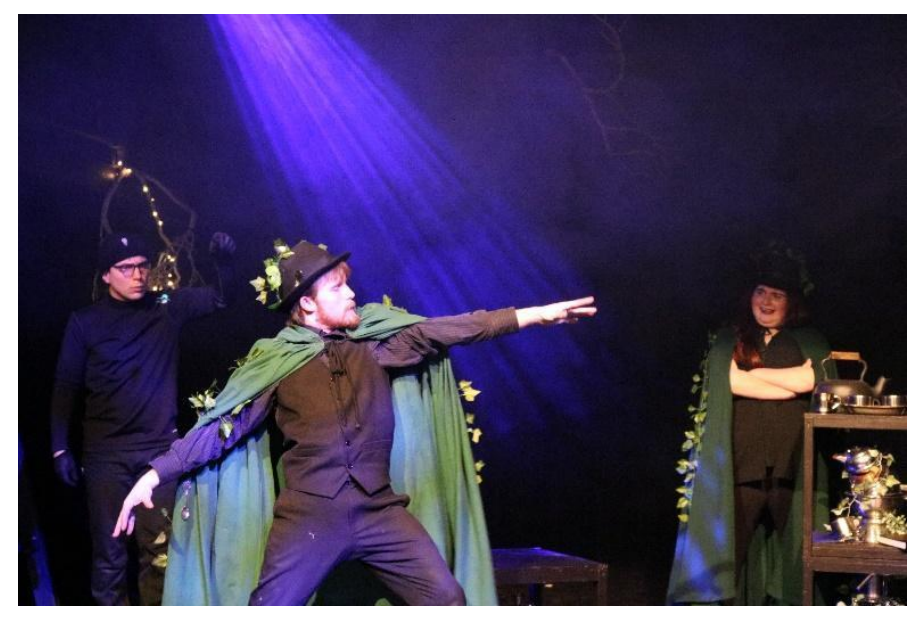

Figure 50: The final Tea Witches scene.

By the end of week six, the Paper Bag Productions group had created a series of imagebased modules. Several scenes were using an umbrella as a key prop. There was a strong child protagonist called Luna, and scenes where sheets were manipulated by actors to create storms and a river. There was also a core theme involving the moon, 
which evolved from the ensemble telling autobiographical stories about not wanting to go to bed as a child.

I next tasked the students to write down twelve moments that could link the modules and uncover a logical narrative for the piece. The students very quickly came up with a linking narrative for the story. There were obvious plot-holes, but the students felt it had the potential to evolve into an engaging 40-minute piece of theatre. Importantly, it also gave them the sense that they were moving towards their end goal. Defining these twelve moments gave us a skeleton framework to work within and we then felt comfortable to return to creating visual/poetic images of each moment.

This amalgamation of methods also supported the way the students were working. Focussing on the text-based narrative-driven form often led us to sit around and talk too much as the students would become too caught up in problem-solving plot-holes. When I encouraged them to get onto their feet and create visual images without talking, this helped them to reconnect with the freedom and sense of play from our very early stages of devising. I learnt that pushing the group to explore ideas on their feet encouraged them to work in an image-based playful way, and was also successful in enhancing the energy in the room. This was often reflected in the checkout sessions when students would relate that they felt much more energised and happier at the end of a rehearsal than they did at the beginning.

Oddey describes this process of 'working on the floor' or 'thinking on your feet' as a way for some companies to overcome blocks in the development of a piece by responding to new ideas and thoughts spontaneously. She notes that this way of working often produces unknown or unseen fresh material (155). However, I was also finding that too much of this image-based free play was still producing anxiety for 
some around the piece as a whole: Would the children understand it? Would we be ready? How were we going to create a 40-minute piece in three weeks? What is this piece even about?

\subsection{Finding Autonomy}

At the mid-point in our process -week seven, and the university mid-term break- Dave Brown from PaperBoats joined our rehearsals. Over the next fortnight each devising group-- Paper Bag Productions and Illuminations-- worked for six full days with Dave and I. The aim was that by the end of the six days each group would have a basic outline of their play. Oddey considers an outside eye as another tool in the toolbox of the devising director: “Sometimes when a group is 'blocked' in the devising process it just requires someone external to the company to look at the work as an 'outside eye'. Fresh eyes, advice, criticism or comments can trigger off a new momentum for the group concerned" (199). As we had been so focussed on the making process, we needed outside help to assess the overall dramaturgy of the piece. Therefore, Dave's feedback at this stage was useful because he could question us about our intentions and evaluate if these intentions were being conveyed clearly enough.

The students presented their ideas and the scenes we had created to Dave. As a group we discussed ways to develop the work further and decided on three ways to explore and advance it:

Our theatre technician, Anna, gave the class a lighting tutorial which demonstrated how the group could begin using light to help tell the story. This visual element became integral to both the underlying narrative of Luna's quest journey in search of moondust, as well as the visual form we used to tell it. 
Dave introduced Joseph Campbell's narrative model of The Hero's Journey. Although this narrative structure could be seen as a divergence from the PaperBoats' image-based methodology, I saw it as recognition by Dave of the student's desire to create a strong narrative. The Hero's Journey is "a pattern of narrative that appears in drama, storytelling, myth...[and] describes the typical adventure of the archetype known as The Hero." ("The Hero's Journey") As a structural underpinning to Disney movies and children's stories, The Hero's Journey is a dramaturgy that children are familiar with; and as children's literature scholar Tim Wadham suggests, it can be beneficial to children. "The importance of children's literature, especially that containing elements of the hero-journey, is found in its ability to provide a sense of completeness and its ability to provide vicariously the contrasts children may lack in real life" (Wadham 3). The students were drawn to the Hero's Journey template to help them link their imagebased modules with a strong narrative.

Dave also presented a selection of Pamela Allen's Mr McGee series. These simple and yet deeply thoughtful children's books re-introduced the group to the sophistication that can come with simple and clear storytelling "Some of the best children's stories have this structure-- even when they appear simple ... they are often deep and symbolic... I call that "simplicity on the other side of complexity" elegant simplicity" (Brown qtd. in Palmer "THEA 311.47"). The use of picture books linked back to the session at Te Aro school - explored in Chapter Seven- where the children shared their love of reading and picture books with the students, as well as our successful session with Jeffers' and Graham's picture books as discussed earlier in this chapter.

We also changed our method of devising. Dave observed that we had fallen into a pattern of using the same actors in reoccurring roles during the improvisations. He 
encouraged us to work in smaller groups and give everyone the same scene to improvise. This provided a variety of interpretations, and was a return to the method of working we had used in the early sessions, with the whole class being given the same composition task. By suggesting students play the same role in each improvisation, I realised I had been loosely casting the group as we worked. Instead of making the group feel more secure, this seemed to remove some of their ability to play and create freely, and increased their anxiety around the work. Shifting this method of working gave the actors greater creative freedom and helped the group return to the playful creative environment they had experienced in the first weeks of class.

Dave also guided the group back to some of the core PaperBoats principles-- in particular Principle 2 "Limiting the Palette". They were given a limited palette of props and the instruction to create, within an hour, a version of the piece as a whole without dialogue. A key moment occurred ten minutes into working, when the actors turned to the three Director-Teachers (James, Dave and me) and asked us to leave the room. This was a pivotal moment for the students in taking ownership of their work. Up until this point, a lot of the work had been created with the director/teachers in the room and ultimately shaped and provoked by us. This was also a fundamental moment in my learning as a devising-director of young people. Anne Bogart suggests that in a devising room, "you cannot create results; you can only create the conditions in which something might happen" (Bogart and Landau, 124). As directors we had set up conditions that allowed the students to create and by asking us to leave, they were demonstrating agency within the project. They later articulated that having the directors in the room adds to the pressure to 'get it right' and can make them less open to experiment freely and fail openly. The fact that they were able to express this to us, in front of our 'expert' Dave, showed us that they felt significant agency in the process. 
This was a turning point in their own journey towards becoming devisors in their own right. We returned to the room an hour later and the actors presented their scene. Some students had found this particular task challenging while others found it a useful activity for getting a sense of the entire arc of the piece. We observed that although the group were beginning to find autonomy in their method of working, they still needed our 'expert' opinion and reassurance. In particular, they needed positive affirmation that they were 'on the right track'.

Eventually, through trialling a variety of methods of working, the play began to emerge. The original name and central concept of 'Moondust' evolved into Moonlight, which told the story of a young girl, Luna, who after her nightlight goes out, begins a journey through a stormy forest to conquer her fear of the dark. Along the way she meets a variety of quirky characters: Mr Watt, a two-headed talking signpost, the Tea Witches, and a pair of confused twins. A firefly, in the form of a puppet manipulated by an actor, helps Luna to see in the dark of the forest. During her journey, Luna discovers that the forest is dying because the moonlight is trapped. When she eventually finds the moonlight, she has to decide whether to give it to Mr Watt to fix her nightlight, or give it back to the forest so its creatures can flourish. The students came up with a central idea that Luna's journey throughout 'the forest' was in fact through her own house to her parents' room, so the twin characters were situated in her bathroom, the Tea Witches in the kitchen, and the signposts in the hallway. This led to some scenographic ideas; for example, the twins were positioned in a bath and the Tea Witches had cutlery hanging from their costumes. The other key concept that came from these intensive workshops was a governing idea or metaphor for the show: Mr Watt the nightlight seller represented the corporate world and its underlying greed in making a profit at the expense of the environment. Therefore, Luna has to overcome her fear for the 
greater good of the world. Moonlight was becoming a complex, character-driven adventure story.

Paper Bag Productions were working collaboratively, calmly, and methodically with little conflict. They were focussed on the work and were discovering methods of working that relied less on 'expert' opinion and more on a model of collaborative problem-solving. They were still very married to the visual imagery they had discovered early on in their rehearsals, in particular: the scenography of the sheets, Luna's umbrella, the Tea Witches' magic and the two-headed signpost. But they were also driving ahead with a collective vision of the play that had a metaphorical governing idea.

\subsection{The Trial Showing}

By Week Eleven of the process, Paper Bag Productions had created a rough draft of a fairly cohesive narrative. Each actor had developed a solid character, and we had a series of images, songs, and vignettes. As discussed in Chapter Seven, because of the dark nature of the narrative and the literal darkness of the staging, some devisors were concerned it would be too scary. Notably, after weeks of intensively working as an ensemble on the piece, the concept of the audience had become dimmer. The group were playing more and more to themselves. A void had opened up in the space between the audience and the performers and the children's theatre cliché of exaggerated facial expressions to portray emotion was beginning to slip into their performance. It was a good time to invite Ruma Ti to the university to get their feedback on the work in progress. This represented the beginning of the Distillation stage of Swale's process, where devisors, "selectively develop and hone ideas and watch the play begin to emerge." (Swale xxx-xxxi). 
Trialling with an audience allows young theatre-makers to determine what engages a specific age-group. Young audiences are often, by nature, brutally honest:

Children rarely grant you the right to fail. They react rather more like the adult audiences of Shakespeare's day. If they are bored, they won't keep the fact to themselves. They will probably start talking. They will take their eyes off the stage and look around for something more interesting. They will get fed up with sitting and stand, walk around or see what it's like to hide under the seat. (Wood and Grant, 19)

Nevertheless, audiences of any age group may be reluctant to share their ideas and true feelings on a piece if the environment is not set up to make them comfortable to share them. We wanted to receive genuine and constructive feedback, so we needed to foster an environment that meant the children would feel comfortable being critical about the work, as well as discussing what worked for them. Because of our previous interaction with the children and the relationships formed we hoped that, even though the children were coming into our space, we would again be meeting on a level playing field.

We invited Ruma Ti to the university to see a run-through of Moonlight on 25 September 2017. Understandably, the students were anxious about showing the work. However, as soon as the children recognised students they had previously connected with, many called out to them and this seemed to help both groups relax. Throughout the showing, giggles and engaged chatter from the children told the actors what was working, and what needed greater clarity. The children were comfortable with commenting on the action and discussed freely what was happening around them. Thanks to their previous experiences with the children, the students had learned how to interpret this kind of feedback. The chatting was directly linked to the show; the 
children were talking about and connecting with the characters in the show, and showing engagement, not boredom or rudeness. One of the first moments where the students felt that the audience was engaged was right at the beginning. In the opening scene, Luna goes to turn on her night light, played by an actor. A game ensues with the nightlight turning off and on in a playful way, much to Luna's frustration. This introduced the nightlight as a delightful and cheeky character. There were many giggles of laughter from the audience throughout this initial scene. In having a real, live audience, I noticed that the students were physically opening up to the audience, reacting and talking to them.

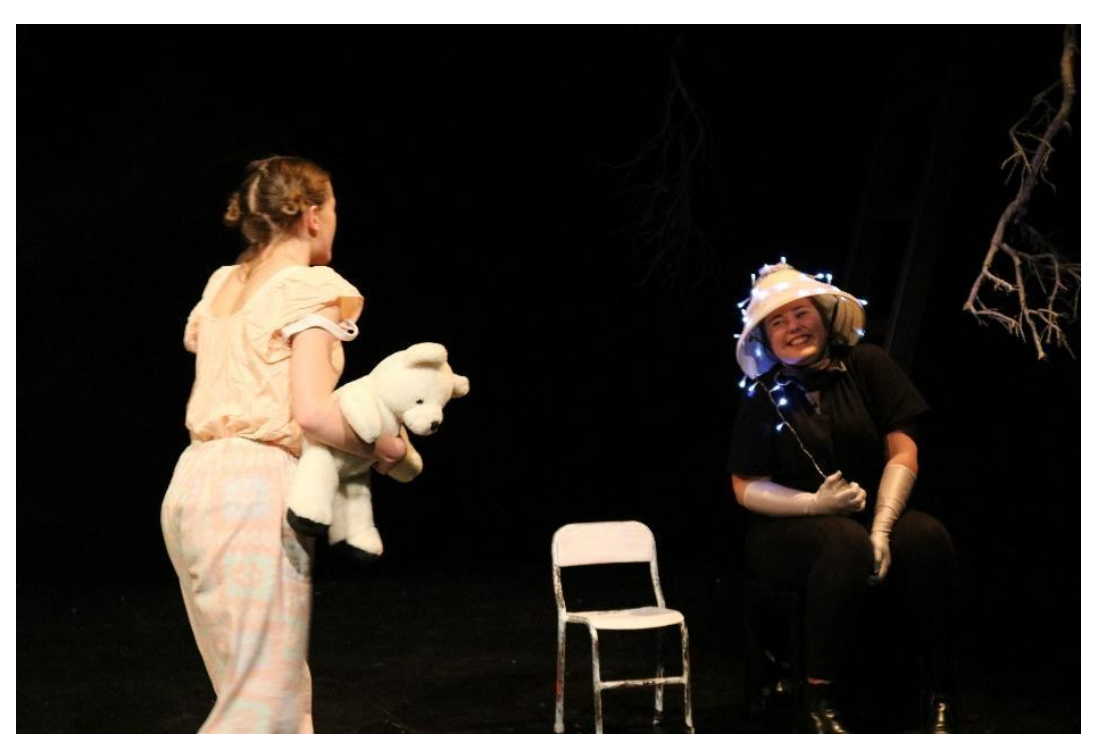

Figure 51: Luna and The Nightlight.

Even though, for me, the piece felt dramaturgically quite messy-in particular the transitions and the linking together of the narrative as a complete arc - it was heartening to observe that the children were engaged for the full 30 minutes. We finished the showing just before what would be the final ending, where Mr Watt and Luna fight over the moonlight and it spills out of the umbrella. As soon as the show finished one of the children blurted out "It was VERY funny!!” (Ti). 
We sought feedback in different stages from the children. Taking into account Reason's ideologies on children talking about theatre (The Young Audience 155-166), we initially gave the children a few minutes to share their thoughts of the show with their neighbours. We came back together as a group and the children shared their responses to the play:

"It was funny"

"I liked the map bit- where there was nothing there."

"The light turning on and off."

"I liked the singing."

"I liked it when the witches gave Luna the tea" (Ti).

I attempted to guide the children to be more specific in order to reach a deeper level of feedback. We ascertained that there were many moments in the show that the children 'liked.' Moreover, many children understood the overall narrative of the piece and the metaphor that underpinned the show: of individual happiness and fulfilment versus collective responsibility for the good of a group. They were able to answer all of my plot-driven questions clearly and articulately, for example:

KP: Why were the creatures in the forest dying? -

"They didn't have any moonlight to guide them.?"

KP: Why did Luna want to share the moonlight?

"Luna wanted to help all of the forest." (Ti)

We questioned the children about the sheets, which some interpreted as "the clouds and the sea" (Ti). This gave us confidence that our concept of using the sheets to create 
scenographic moments was successful. When asked what they felt should happen next, some answered, "They should share the moonlight, 'coz there's a lot" and "Without the moonlight, everything in the forest will die" (Ti). What was clear from this initial response was that many of our conceptual ideas were being interpreted clearly by our audience. This indicated that our strategies of engaging our audience were working. One child noted, "It was a little bit scary at the end" (Ti), but what we had observed was that this seemed to be a good type of scary-- it built tension but didn't terrify the children. TYA Director Janet Stanford considers how 'Scary' at the theatre can be empowering for children. "Some parts of the story might be scary, but it's normal to have fears. It is excellent preparation for life if children can experience something that's a little scary in a story, observe how the characters confront what scares them, and then solve their problems and overcome their fears" (Friedman 37). We observed that Luna, overcoming her fears, seemed to balance the 'scariness' of the story, which made it a good type of scary. After leaving the university and returning to Te Aro School, Ruma Ti teacher, Nicole sent us an email: "That was amazing! My class cannot stop talking about it!" (Head).

When the children returned from seeing the play, they were encouraged by Nicole to draw a picture and write a story about what they had seen, which she shared with us. Most of the choices the children made in these initial drawings and stories, involved the fact that they went to a play called Moonlight, and an opinion that it was "Cool and Funny":

"We went to yuonuvosatey [university] thay did a play for us. We loved it. It was Koll [cool]. I loved it."

"The Play was cool and it was funny. Becos [because] mrs wot was really funny!" 
“The play was cool. But it was a little scaery! [scary] Tere [there]was a girl called Lana. She was the main caricter [character] of the play." (Ti)

Some children described specific moments they enjoyed:

“We went to a play. In the morning the play was funny. The fun part was when the nightlight went off"

“Today we went to a play! I liked it when the tiwns [twins]came on and scraeb ech oathre.[scared each other]"

"It was cool. I liked wen the twins cam out. It was fune, Mr Whatt was fuane.[funny]

I liked when Lona found the moonlit.

"In the trees there was moonlight." (Ti)

This exercise with the children demonstrated how asking young children to write their responses can result in generalised, not very useful feedback. Presumably, this was because of their limited skill in writing. Also, worth noting was that the pictures the children drew were quite minimal, perhaps because they had spent the time focussing on the writing. Because we wanted to gain more specific feedback from the children to guide us further, we arranged another, more detailed feedback session. 


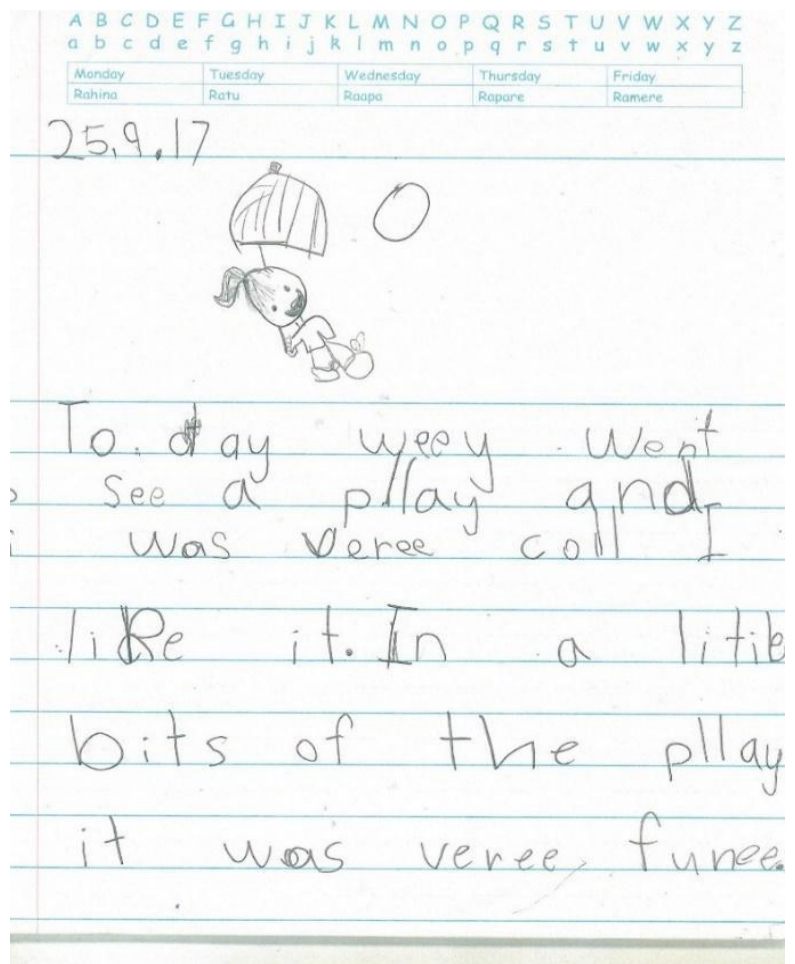

Figure 52: Ruma Ti Drawing (Ti)

Reason maintains that asking young children's opinions directly after the show is finished and getting them to use words to do so are both problematic methods of gathering genuine feedback. Reason's philosophy is that certain things that we feel cannot be put into words and in particular this may be the case for younger children whose speech may not yet be able to keep up with their thoughts (The Young Audience 137). He asserts that:

One of the challenges for teachers, artists and other cultural workers is to find ways of actively engaging children with the arts in a manner that does not educationalise perceptions on the art form but instead allows children to engage more deeply on critical and creative levels. Structured investigation through drawing is one possible approach (Reason, The Young Audience 119). 
Reason has developed a method of engaging children in discussing a theatre work through drawing, as a way of looking at, learning and interpreting the theatre experience (122). He maintains that "increased knowledge increases engagement and intensifies the pleasures and satisfactions associated with engagement in the arts...it enables them to see and remember more; it makes the experience mean more to them" (The Young Audience 139).

Three days after the showing we returned to Ruma Ti and the students encouraged the children to draw then discuss pictures of the play. We adapted Reason's methodology to make the most of the limited time we had with the children. Our primary focus in using Reason's drawing method was to gain insight into what the children had understood from the play. By casting the children as experts in their own creation, the drawing, and by discussing their experiences of watching the play, we were aiming to gather information that would assist us in further rehearsals to better tailor the final product to the audience.

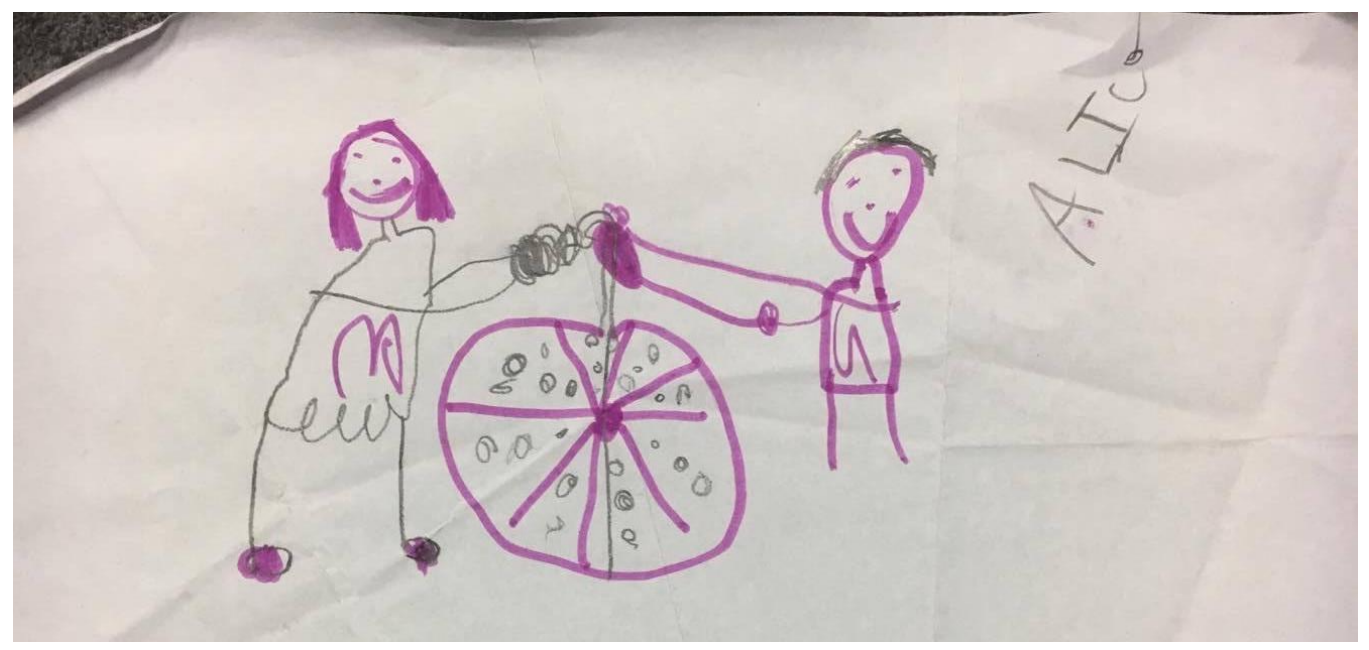

Figure 53: Drawing the play. 
The questions based on Reason's 'Talking about Theatre' model, were divided into four main areas: First Impressions, Descriptions, Analysis and Interpretation (The Young Audience 155-166). I briefed the students in ways of asking open questions and encouraging the children to talk. Each student was assigned three or four children. The children had time to develop their drawings and appeared to greatly enjoy talking to the students. This method seemed to produce more detailed drawings than the earlier activity set by their teacher, and many of the children gave detailed descriptions of what had resonated with them as they talked with the students. Initially, there were lots of positive, non-specific comments from the children: e.g., "I liked everything" (Ti). But eventually, some detailed answers to the students' questions began to emerge:

\footnotetext{
"I loved the nightlight, when Luna walked away and it went on and off and off on and off. It made clicking noises."

"The Twins died because they lost each other because there was no moonlight." "Luna gave the moonlight to all of the animals, then someone stole it. And Luna wanted to share it, I thought she was very nice, but the man wanted all of it, he was afraid of the dark." (Ti)
}

Some expressed moments they didn't understand: “I didn't understand the little songs"; "Why did the lights work if he was afraid of the dark?" (Ti). Georgia spent time with a child called River who executed two detailed drawings while discussing the play. His responses demonstrated a solid understanding of the basic plot, but with his own added interpretations. 


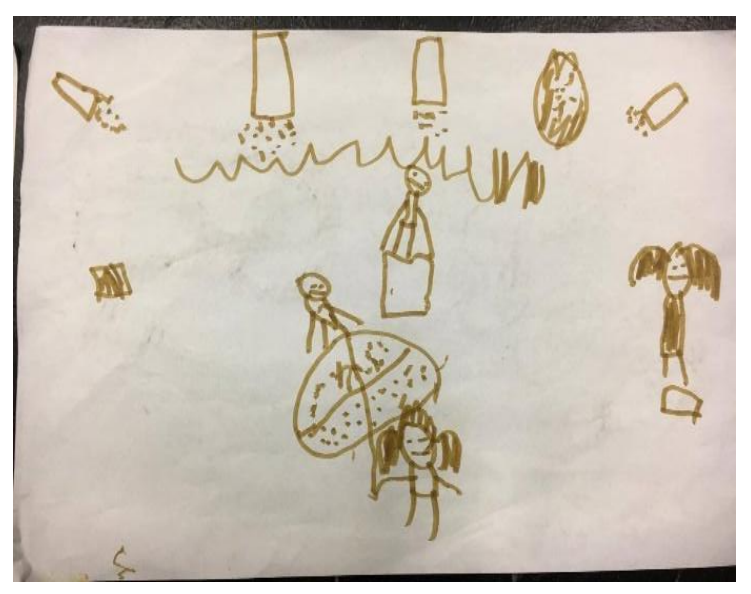

Figure 54: Drawing the ending.

Georgia: "Tell me about your picture, River?"

River: "They were fighting over the moonlight and then he [Mr Watt] gets stuck in the target. Because Luna throwed him in but he comes back out and keeps fighting. Because he wanted the moonlight all to himself but Luna wanted to give it to the jungle."

Georgia: "What do you think should happen at the end of the play?"

River: "The snake pulled a part off the umbrella. He [Mr Watt] jumped in the bullseye then he gets through and he is dead."

Georgia: "Why did they need moonlight?"

River: "Because if she couldn't find it they would be dead"

Georgia: "Why would they be dead?"

River: "Because something was wrong with it [moonlight]."

Georgia: "What about the storm?"

River: "It made it not work and if it didn't work, they'd be dead" (Ti)

Reason describes this type of response, where there are lots of details in the drawings and the child's observation links meaning to detail, as fairly typical (The Young Audience 91). He sees this as an illustration of understanding the theatrical presentation but also 
an ability to reflect on the understanding of the fictional world (The Young Audience 92). Later in the conversation, River included his own ending to the play by adding a snake and killing off Mr Watt.

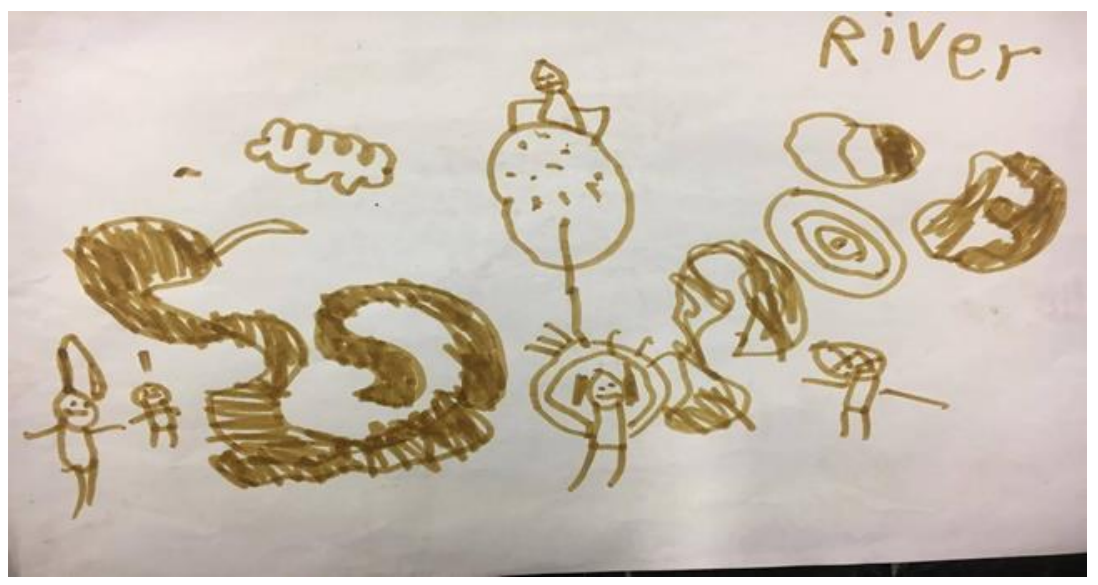

Figure 55. River's Drawing of the ending, the snake, Mr Watt and the target.

This could be interpreted as a part of the story being realised in River's imagination. Reason calls this depiction of something that never appeared on stage but that is alluded to as 'evoked experience' (The Young Audience 61). He says that responses such as these are compelling as they show us that the "children engaged with the production in a manner that allowed them to complete the gaps in their imagination" (The Young Audience 63). River's imagination of the ending also supports Dave Brown's philosophy that language-lean work leaves the audience open to interpret it in their own way and that creating an environment for open-interpretation, allows children to be an active rather than a passive audience (Brown qtd. in Palmer, "THEA 311.34").

The two most popular scenes that the majority of Ruma Ti drew pictures of, were the umbrella-struggle for the moonlight between Luna and Mr Watt, and the twoheaded signpost scene. 


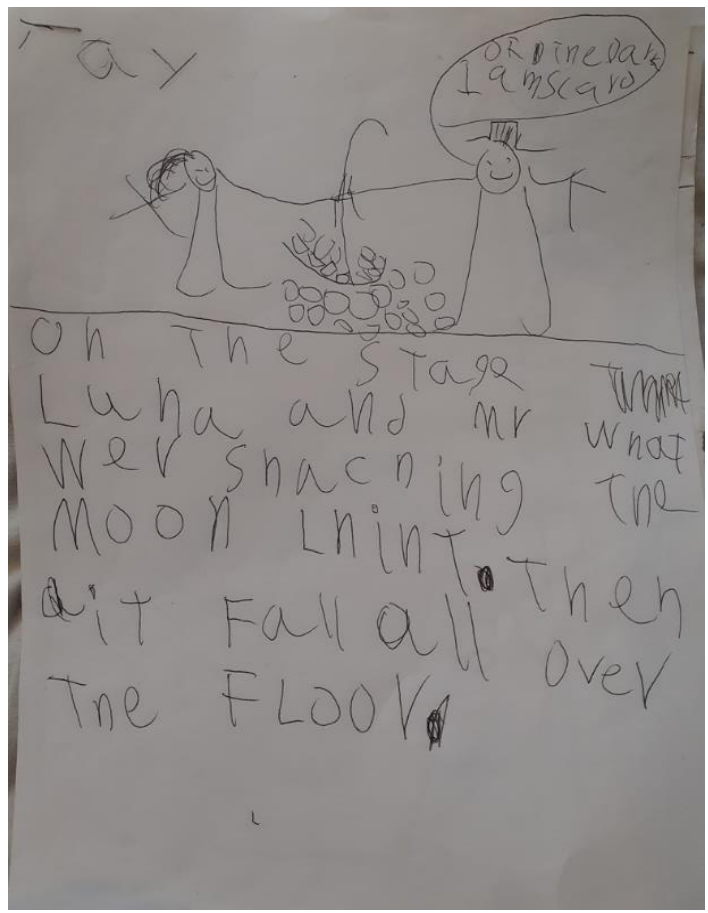

Figure 56: The umbrella-struggle (Ti)

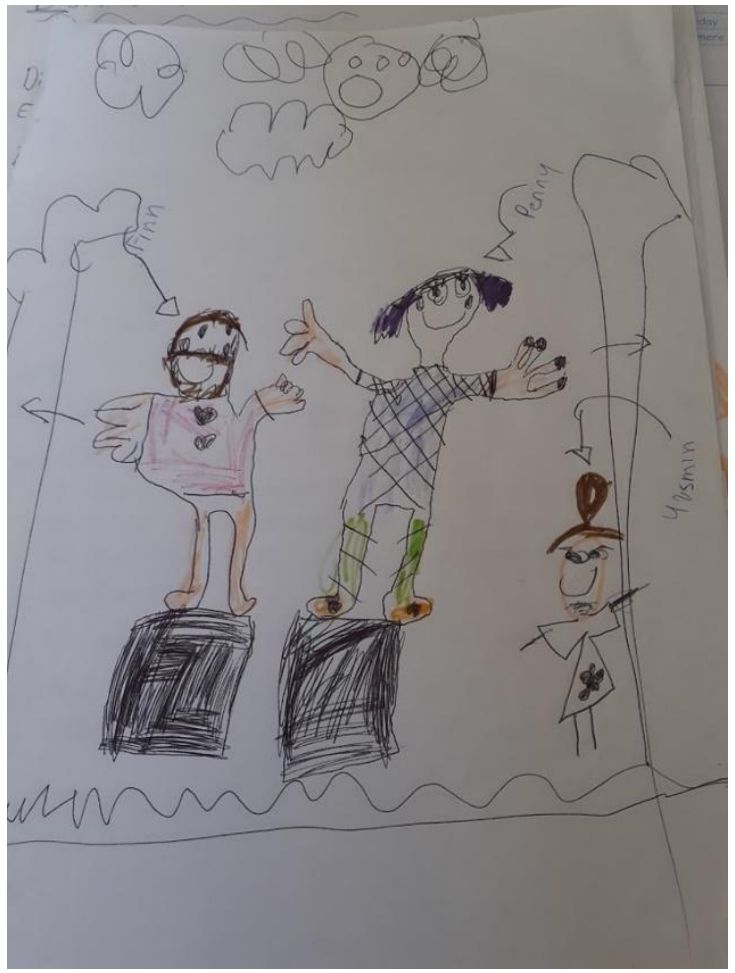

Figure 57: A Te Aro child's drawing of the signpost scene (Ti) 
A particularly memorable moment from the session was a re-enactment by children of a comic scene in which Luna finds herself interacting with a two-headed signpost, played by students Pelle and Finn. Luna, lost in the forest, asks the signpost for navigational assistance, only to discover that the signpost is, if anything, more disoriented than she is. When two of the Ruma Ti children saw Pelle and Finn during the feedback session, they immediately re-enacted the entire scene. First, they performed it spontaneously, and then they wrote the script down with Pelle and performed it again, with more children. They checked with the actors as they performed, asking, "Is this right?", which demonstrated their desire to accurately recreate the scene. They loved the wordplay and the characters' goofy voices and were delighted to keep playing this scene over and over with the students.

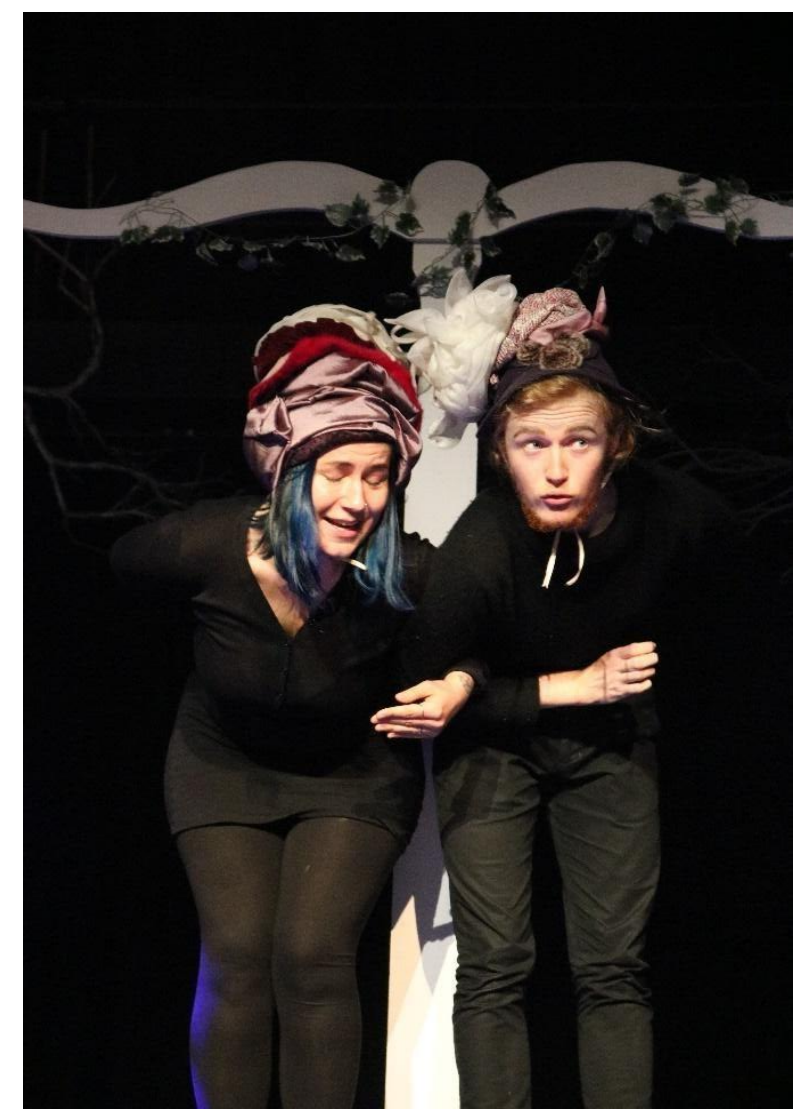

Figure 58: The Signposts. 


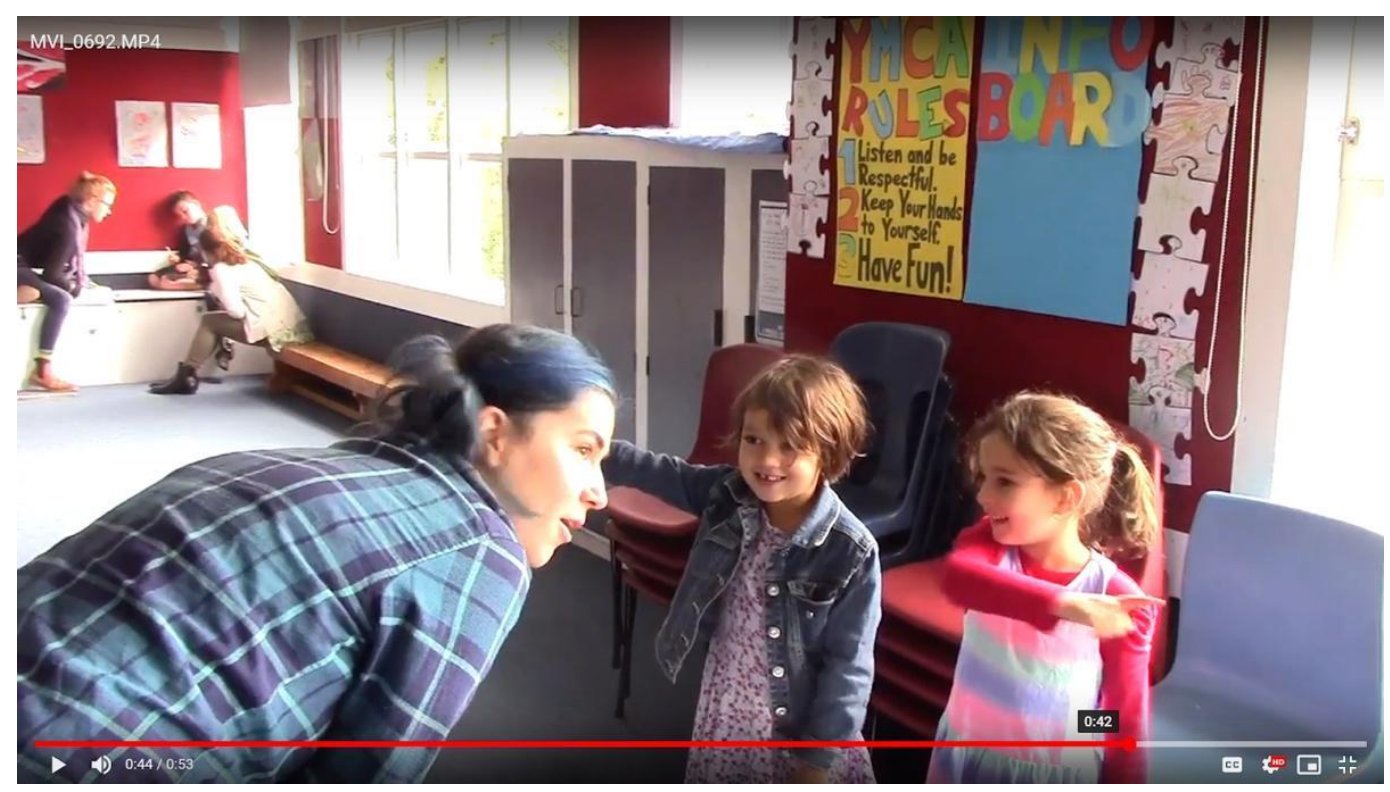

Figure 59: Screenshot. The children acting out The Signpost scene with Pelle.

The chance to meet in the children's environment, in an informal way, where the children felt confident speaking in small groups, revealed several key points that resonated with myself and the students. The governing ideas and the main plot of the story were clear. The children particularly enjoyed the characters and were able to describe, in detail, most of the characters' personality traits. Many loved the wordplay, especially the signpost's dialogue and the phrase 'Luna? Like the Moon?' which was repeated three times in the play. They found the play funny. Some found 'it a bit scary but, not in a bad way' (Ti). Some loved the singing, while others didn't understand the purpose of the songs. Some found it confusing when people and characters 'came from off the side of the stage,' which we presumed referred to the moments where people moved the set around. Some children were inspired to re-stage and present parts of the show that they loved and go over and over the word-play with each other.

Interestingly, this particular group of children were responding very strongly to the characters and the text; however, they also appeared to have space to interpret the 
scenes in different ways. This indicated that even though we had not presented a fully image-based poetic piece, we had still created a piece that encouraged creative problemsolving and left room for children to make their own interpretations of the narrative. Importantly, the children - and the students - seemed to relish having time to discuss the play in depth. They showed us that they cherished being an important part of the process by the enthusiastic way they responded to the students. This positive interaction was a clear indicator that our methods were effective in engaging the children as co-creators of the work.

This feedback from the children became a scaffold for further creative work over the remaining three weeks of rehearsal. The devisors would frequently return to the comments and suggestions that the children had made, to help them shape the final show. The children's response to Moonlight reassured the group that the play was not too scary, and the absence of a fully coherent plot did not prevent the audience from engaging in the performance and being able to create their own meaning. This signalled to us that the combination of methods - our character-driven narrative and Brown's image-based narrative - was not as muddy as we had feared. In fact, the combination seemed to appeal in different ways to different children, serving those who preferred a character-driven narrative and those who preferred a more abstract presentation.

\subsection{Distillation and Presentation}

The three weeks in the lead up to the opening of the show saw an amalgamation of Swale's stages Four and Five "Distillation" and "Presentation", in which we move from the rehearsal room to the wings" (Swale xxx-xxxi). Swale describes The Distillation Stage as "the most challenging as it involves throwing away ideas that actors will inevitably have become attached to" (81). I have observed that this penultimate stage is one that is often left out or rushed in the devising process. This is the point at which 
devisors have to make tough decisions about what material stays and what goes. This is the time to reorder, rework and develop the narrative, flesh out character and experiment with structure. It is also the stage where things can change dramatically and quickly, which can be particularly unnerving for a student ensemble. Much of this stage is about shaping and editing. Moonlight still felt like a series of small sketches. But because the children had revealed how much they enjoyed the characters and the story; we chose to spend much of the distillation period solidifying the narrative arc and ironing out the plot holes. Because of the strong positive response from the children, we clarified and tightened the moments that the children had enjoyed, such as the wordplay moments and the quirky characters, but ultimately didn't change these scenes. In particular, Mr Watt's entrance and The Two-headed signpost scene changed little by the final performances.

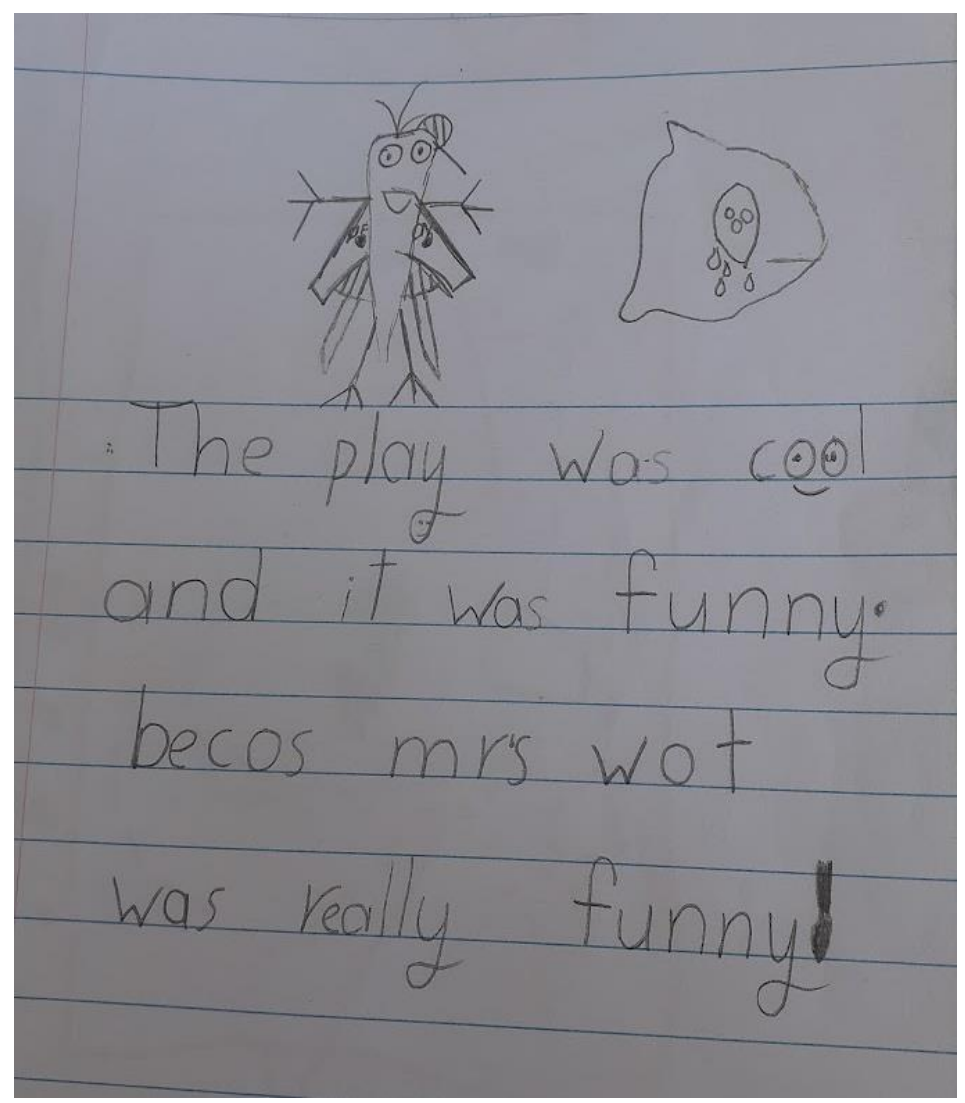

Figure 60: Te Aro Child's Initial response to the play. (Ti) 
Something else that we didn't change was the casting of the actors. We had noted that the children had responded well to Yasmin playing the protagonist, Luna. Yasmin is small and has a childlike quality in her natural performance, evoking a young child without resorting to a patronising portrayal. We had noted in our early session with the Te Aro children, that many had gravitated towards Yasmin, presumably because of her small stature and quietness. This led to a unanimous decision by the group to cast her as the protagonist. We were also very keen to have a child as the main protagonist, observing Davis and Behm's belief that an active protagonist makes things happen, and "when this is a child, then it is this that is empowering for a child audience" (XXV11, 1). The children's positive response to Yasmin was indicative of how they related to her. As evidence of the children's positive response to Yasmin, at the Te Aro debrief session she had a meaningful interaction with two of the children that led to a change in the final script:

I had kids performing scenes to me and talking about their favourite characters. I sat down with Elani and Lexi to do some drawings with them and was delightfully surprised by how much they remembered from our showing. It was very difficult to get them to express what they would like to add as they kept stating what was already in the show. One thing which Elani did mention was knowing more about why Mr. Watt was scared of the dark. This was something we did change or show more in our ending. (Golding)

As mentioned above, some of our Te Aro children reported being confused about people coming on and off the stage. I surmised that this was an indication of children being used to scenes in TV and Film changing seamlessly from one to the next. A key element in TYA practice is making sure audiences can understand stories by interpreting the theatrical signs used on stage. It can be related to Wood's idea that all 
children cannot be expected to understand the theatrical conventions of a play (Wood and Grant 20). Also relevant are Reason's extensive discussions around the cultural rights of children: "theatregoing is a learned activity, governed by a complex set of cultural values and implied social codes, which individuals need to adopt for themselves if they are to internalise a sense of entitlement, ownership and legitimacy as members of the audience" (The Young Audience 29). Therefore, by introducing the theatrical element of actors moving set pieces and coming on and off the stage, rather than appearing seamlessly in front of the children, we were, for some children, introducing new specifically theatrical practices. We decided to keep these visible set changes in and made them a part of the show to emphasise this was theatre, not TV. However, we made them even more theatrical; the actors changed the set incharacter and they were almost dance-like in their presentation. We also created moments of diversion, to 'pull focus'. ${ }^{70}$ For example, as Luna and the firefly set off on their journey, they used the upper level of the theatre and moved along the balconies and behind the audience, with the lights were focussed on them while the other actors changed the set. This gave the children an option of what to watch. They could watch the action of Luna and the Firefly, staying in the narrative of the story, or they could watch the actors changing the scene and viewing the operation of the illusion. By presenting these options and discussing them with the Te Aro children, we were able to effectively introduce a new set of ideas and practices that the children could adopt for themselves during future theatrical experiences, as well as giving them some autonomy over where they chose to direct their attention.

The final week before the show opened was a blur of long days and nights in the theatre, with two shows being worked on simultaneously. Fortunately, in addition to

\footnotetext{
${ }^{70}$ To 'pull focus' is to create a distraction on one part of the stage so that the audience is compelled to look there.
} 
the stress, I observed a sense of community and ensemble developing as the students pulled together to support one another in creating their final piece of theatre. The fact that they had formed a relationship with their audience seemed to make them more determined to produce high-quality work. Yasmin commented: "When we went back to Te Aro School, the reaction from the kids was quite surprising and gave us the encouragement we needed to really polish our show" (Golding). This connection, their discussions, and reflecting back of their work from the children, all helped them to make a play that was accessible and entertaining for their audience. Simultaneously, the students were discovering their own creative agency in the making of the work. They were consistently reflecting on and developing their own methodology in making quality TYA.

\subsection{Moonlight- The Final Performances}

This section critically examines moments in the play that relate to the research enquiries, in particular: the identification of practical strategies for engaging a young audience and the methods we used to encourage agency and empowerment. The full version of the play is on the accompanying USB.

Billed as a visual spectacle aimed at four to eight-year-olds, Paper Bag Productions publicly presented Moonlight at Studio 77, Wellington from the $11^{\text {in }}$ to the 14 $4^{\text {th }}$ of October 2017. Audiences of both children and adults gave us mostly positive feedback in the form of written and verbal reviews. The Te Aro children that came to the final iteration of the show were enthusiastic to share with their families the production that they had helped to create. It was inspiring to see them explaining and discussing moments of the play, in particular their 'expert' narration and opinion of what was happening or about to happen next. This was an empowering position to have, in particular over the adults who had accompanied them. 
The five public performances of Moonlight were a mixture of 10 am shows aimed at young children and their families, and evening shows for the students' friends and families to attend. Children in the audience were encouraged to sit on the floor. There were seats for adults behind them, and a line of lights in paper bags tied together with ropes in front which delineated the stage space. Because the children were on the same level as the actors and were physically close to them, this 'barrier' was remarkably effective for keeping the children engaged in the action and yet out of the way of the actors. Most of the first sequence of the play was nonverbal. This is indicative of how, early on in our process, we adopted Dave Brown's method of non-verbal dramaturgy. I believe that this non-verbal opening sequence of Moonlight was a successful way to begin the show. It demonstrated a playfulness and quirkiness we thought would best engage the children and created a magical and whimsical environment that set up the world of the play. The positive way that the children responded to this opening sequence, and the post-show discussions at our trial, suggested immediate engagement. In addition, by not presenting them with lots of dialogue, we achieved our goal of opening space for them to create their own meaning from what they were viewing. 


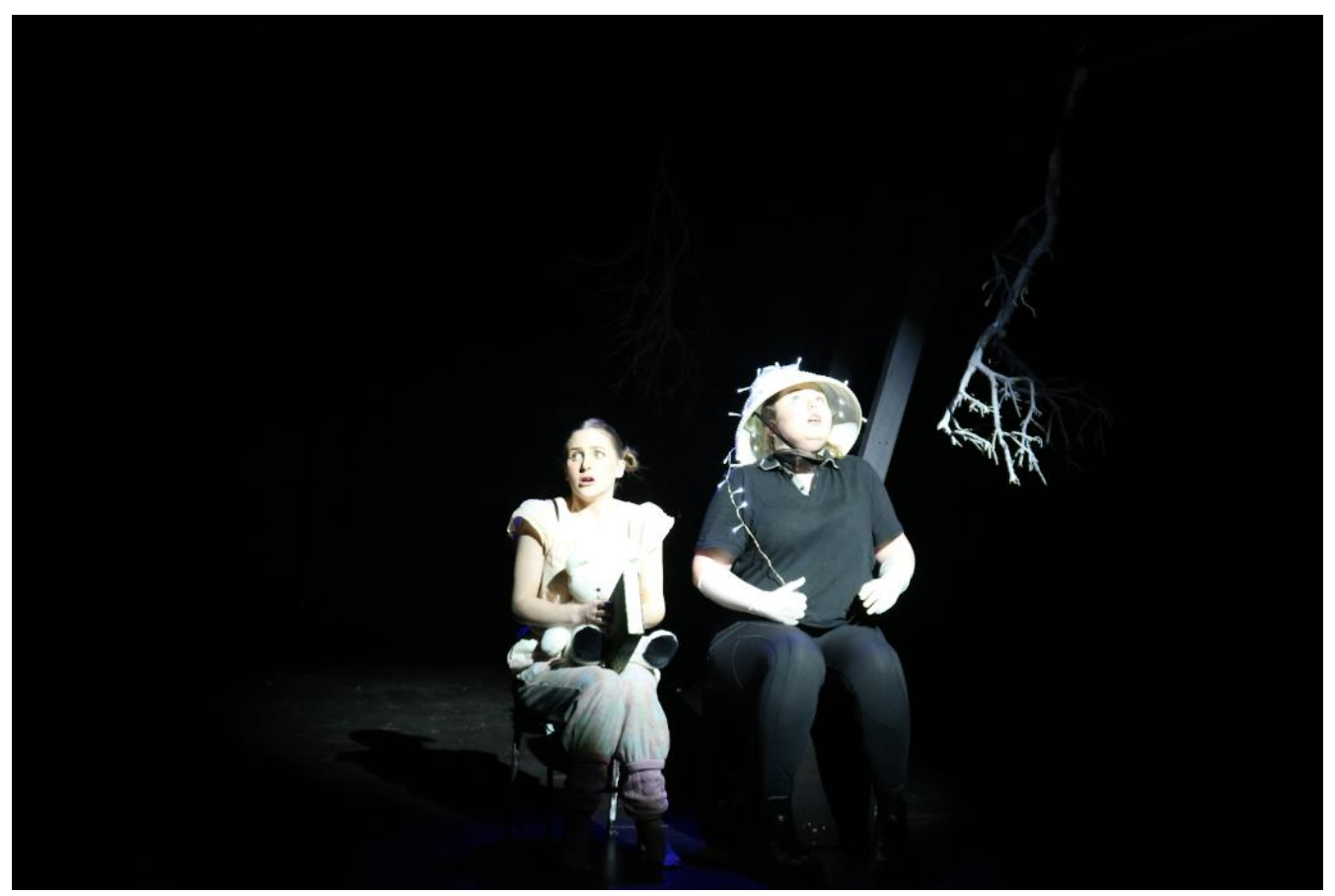

Figure 61: The non-verbal beginning to the play.

We used song as a dramaturgical device to advance the story. This was influenced by my work at Capital E National Theatre for Children, where song was used frequently to move a narrative forward in a way that is easily accessible and memorable to children; for example in Around The World and Buck Again (Patrick) and Seasons (P. Wilson). 

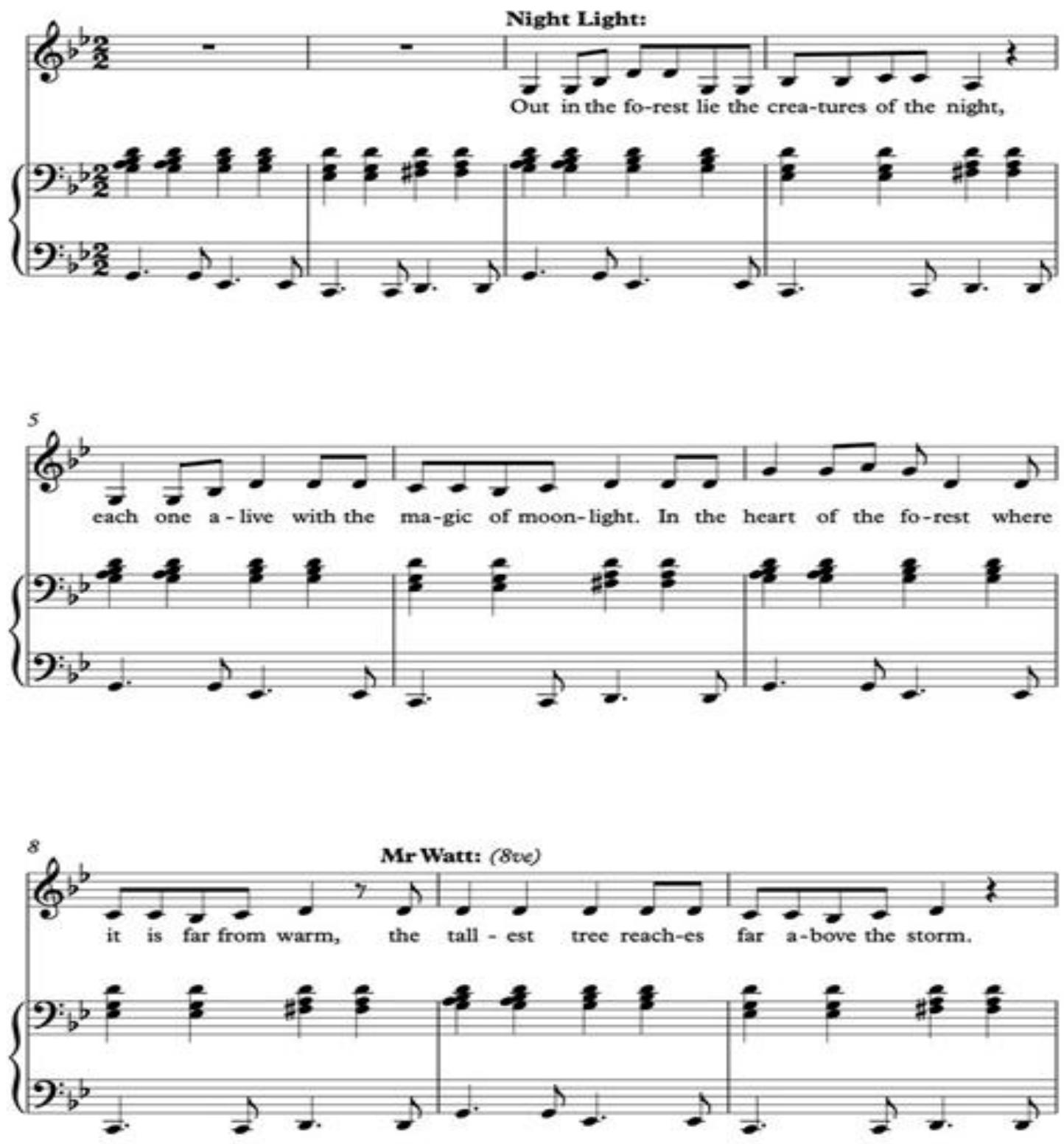

Figure 62. Musical Score of The Nightlight song, by Joel Rudolph.(Rudolph)

Musician and composer Joel Rudolph was a key collaborator on both Moonlight and In The Attic, and was in the rehearsal room for much of the devising process. In 
developing the musical score in Moonlight, he composed several of the songs alongside the other students and provided a soundscape of classical music behind much of the show. Joel's involvement as musical director in the devising process is explored in more depth in the following chapter.

Also utilised were several segments of word-play to further engage the audience. Phrases such as "Luna like the moooooon" and "Luna more like Ruuuuude$\mathrm{a}, "$ that resonated with several children and were repeated after the show.

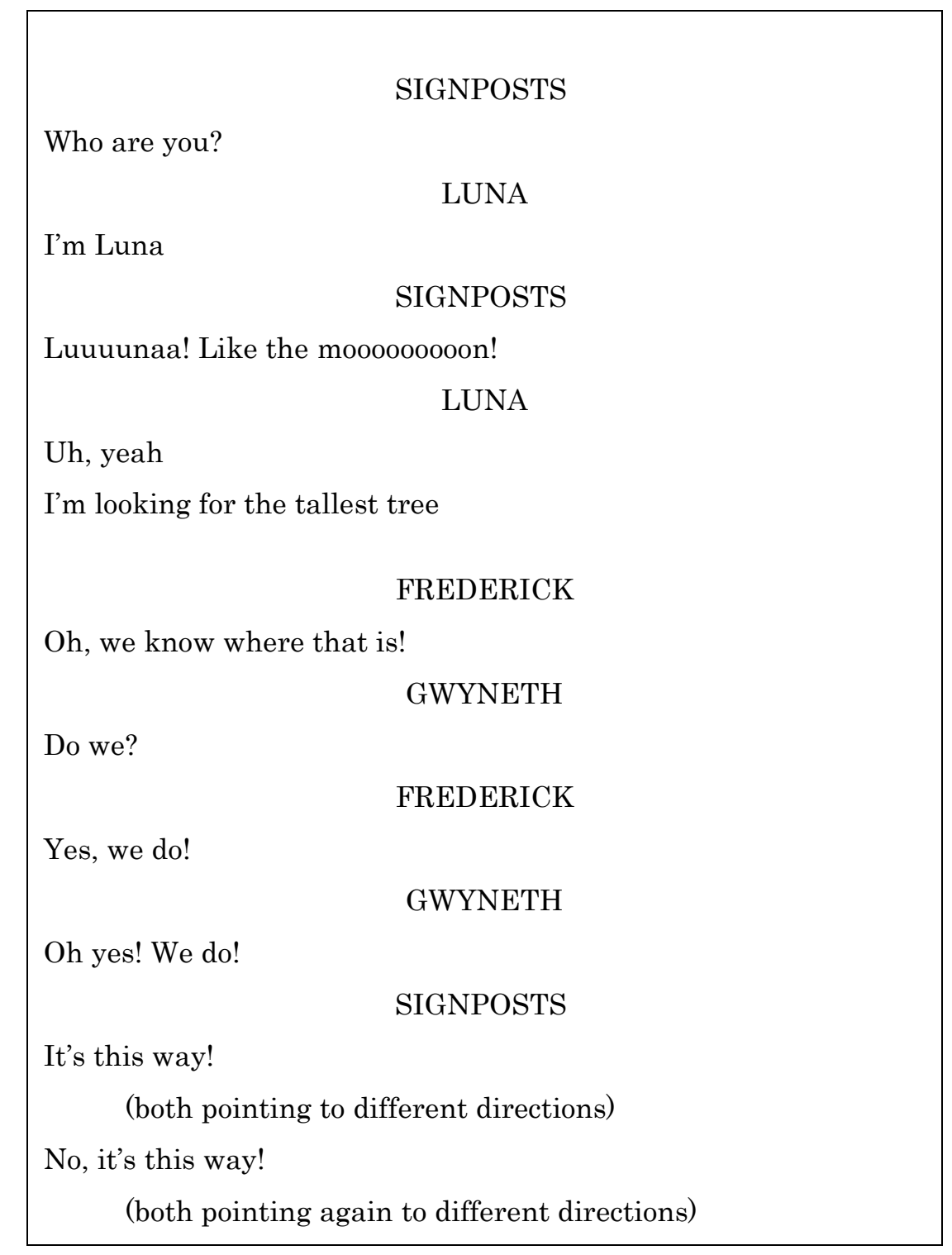




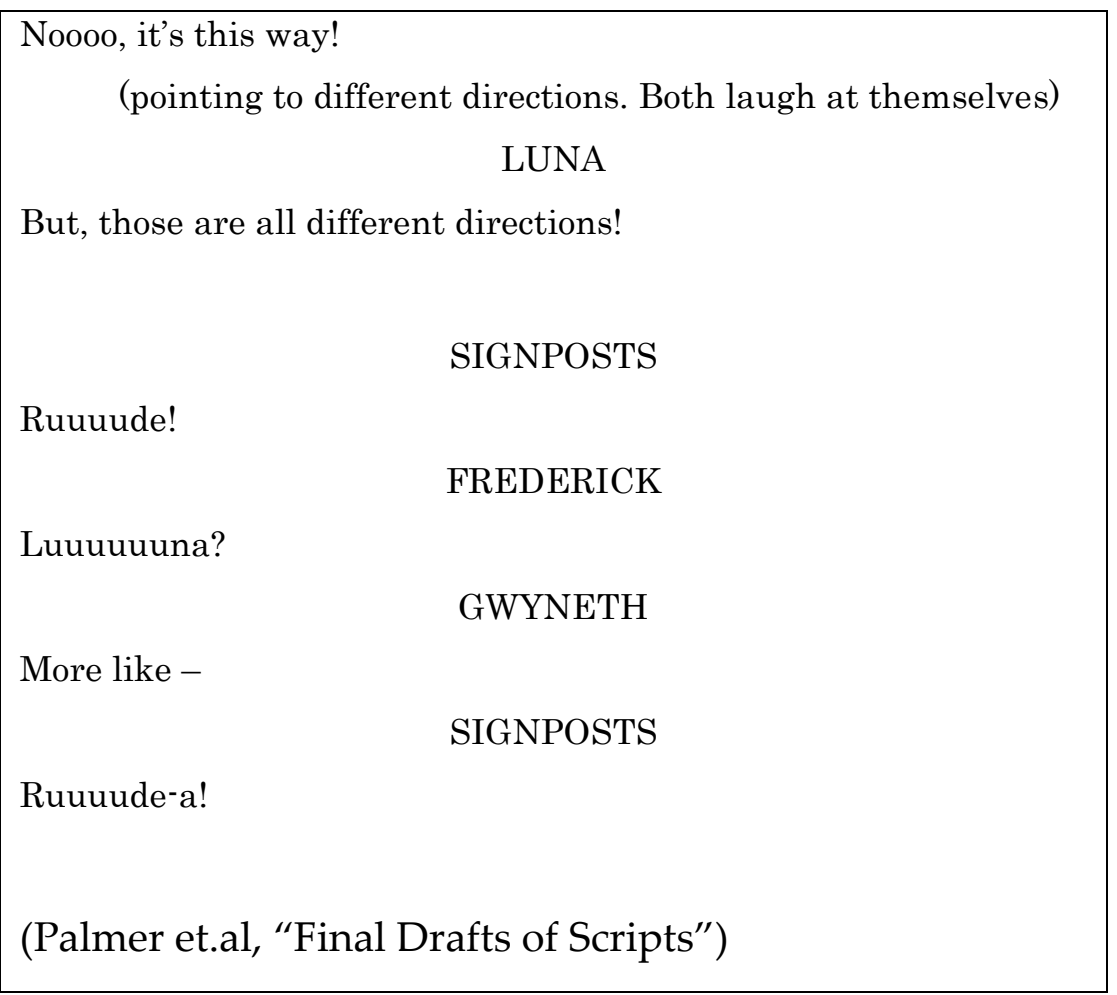

Other theatrical elements employed throughout the play included: the magical manipulation of objects flying through the air; people moving through space; and invisible elements such as 'drawing' on a map, but leaving it for the audience to imagine. This was a chance for the actors to experiment with what the children were willing to believe, and can be linked back to Shifra Schonman's research in children's understanding of aesthetic distance. "Aesthetic distance is a kind of detachment on the part of the spectator, a gap between the work of art and its audience" (Schonman 84). Also relevant is Coleridge's theory of the willing suspension of disbelief. "In a nutshell, the willing suspension of disbelief means the people in the audience know that what they are seeing on stage or screen is a pretend reality, but they are pretending that they do not know that" (Hooks). In the Tea Witches scene for example, the witch lifted his hand and the tea caddy was raised into the air by another actor, dressed in black, indicating that the witch was magically manipulating the tea caddy. 


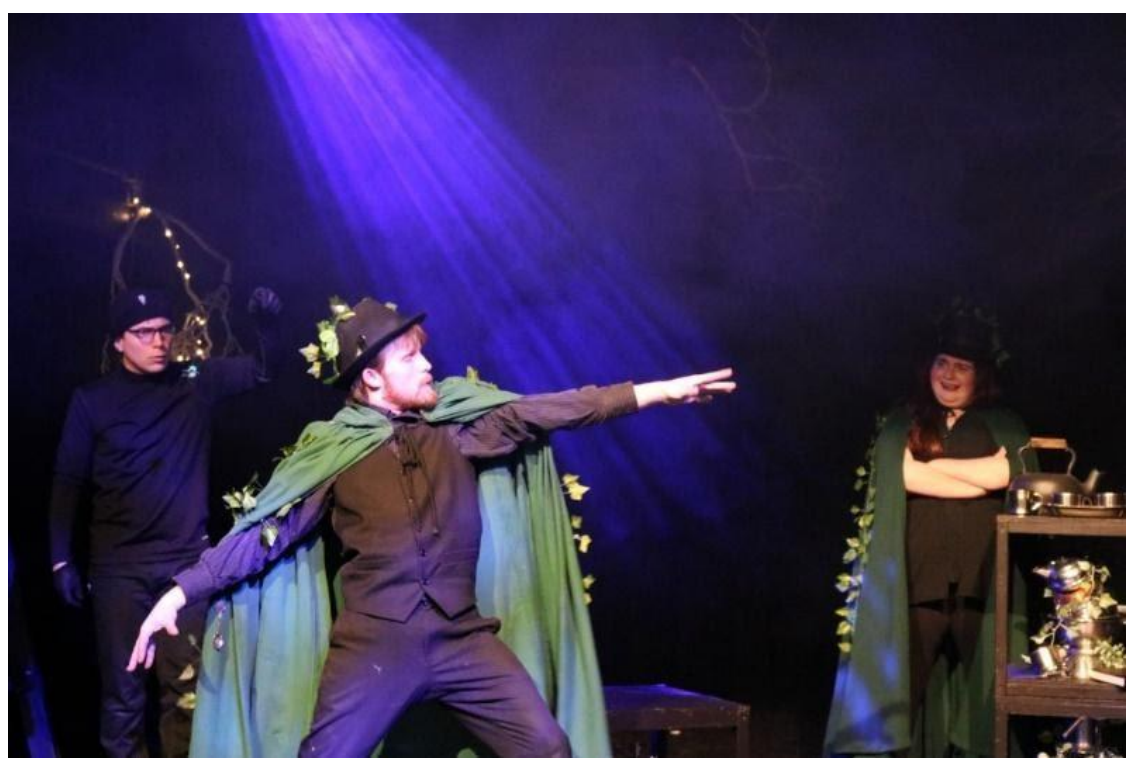

Figure 63: The Tea Witch 'moves' the tea caddy.

Reason notes that children's ability to watch the construction of the 'theatre magic' while simultaneously believing in the magic is an example of an "immensely complicated and immensely rewarding piece of mental self-trickery-simultaneous belief and disbelief" ("Did You Watch the Man or Did You Watch the Goose?" 353). This can also be connected with Schechner's theory of play being an intrinsic part of performing, because it embodies the "as if", the make-believe (89). Reason suggests that "assertions about protecting the magic of theatre for children by not destroying the illusion are in effect disempowering actions that use adult authority to underestimate and patronise children" (The Young Audience 83). He asserts that for children seeing the illusion and the operation of the illusion allows a dual-reading of a scene - oscillating between the real and imagined. He suggests that engagement with the real enhances the imagined (The Young Audience 83). By showing the children the method of creating the illusion of flying objects, we were honouring the complexity of their perception. In doing so we were giving them power and ownership of their reading of both the reality and the illusion.

This is a key idea in the presentation of TYA. I have directed several shows that have extensively presented theatre magic. The illusion has been created by employing 
methods such as actors dressed in full blacks, lighting effects, UV light, and complicated set tricks. What I regularly noted in post-show feedback sessions, was that children often asked 'how did you do that?' There was a choice here to protect the theatrical illusion by not revealing the trick, or demonstrating how these tricks worked to the children who were fascinated by the mechanics of the illusion. I believe that in Moonlight, by actively demonstrating the creation of the illusions to the children, we were honouring their ability to see that it was an illusion while still supporting their ability to accept the fictional narrative. This empowered them as audience members. They could choose how to read the scene, and they were being complicit with the devisors by accepting the illusion while simultaneously accepting the reality.

Another recurring motif we adopted to engage imagination, was the use of sheets to indicate or represent a storm, a map, and a river. For example, in the opening scene, a sheet dance conveyed Luna playfully not wanting to go to bed, and was presented with light music and movement. Later when Luna found herself in the eye of the storm, she was entrapped by another 'sheet dance,' this time dark and menacing.

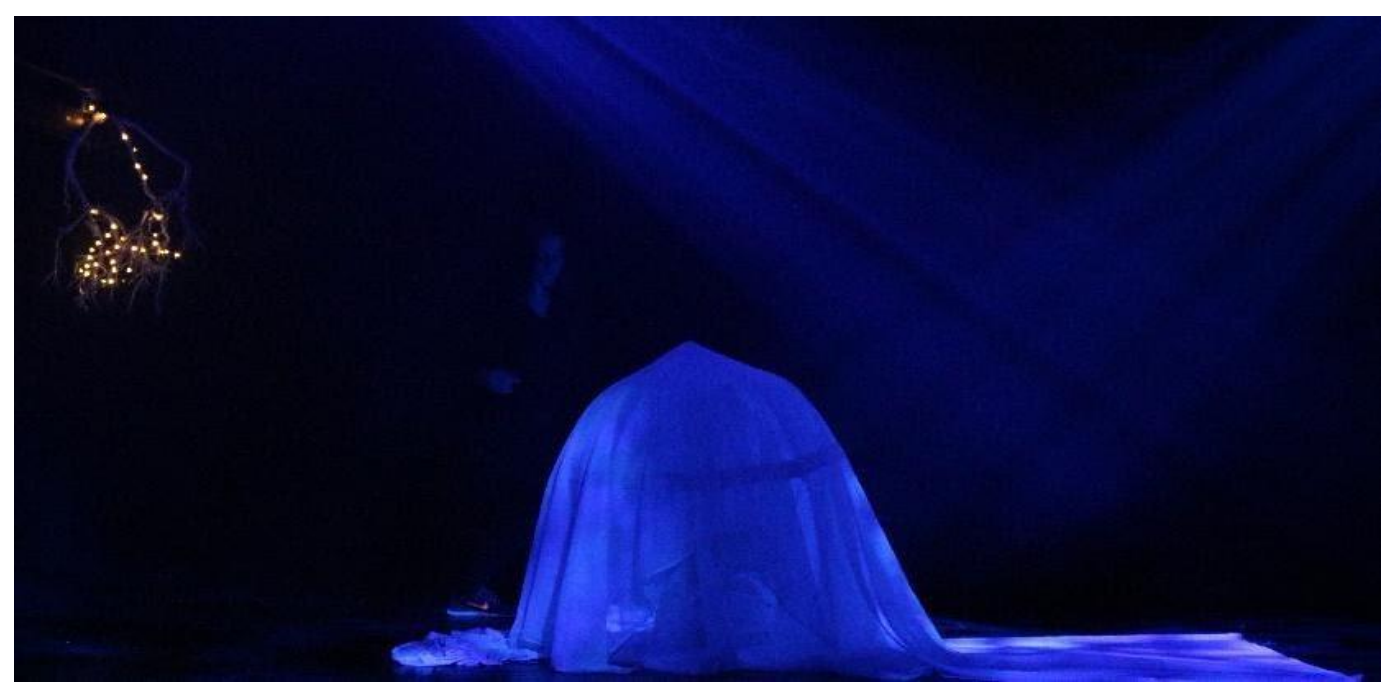

Figure 64: Luna shelters under her umbrella 
The audience was encouraged once again to engage both layers of meaning: sheets manipulated by the actors and a fictional world in which a dangerous storm threatened Luna. In the initial feedback sessions, one of the children commented that she "thought the storm was the sea". This interpretation of the visual imagery reinforced how the image-based narrative gives children agency to make their own meaning from poetic images and emphasised Brown's philosophy of how creating "image-based modules, leaves the audience open to interpret them in their unique way" (Brown qtd. in Palmer, “Thea 311.34").

Another memorable moment for our audience in the play was the final moment when, after Luna has freed the moonlight, Mr Watt returns to fight with Luna over the umbrella filled with moonlight. To represent the moonlight, we used confetti made

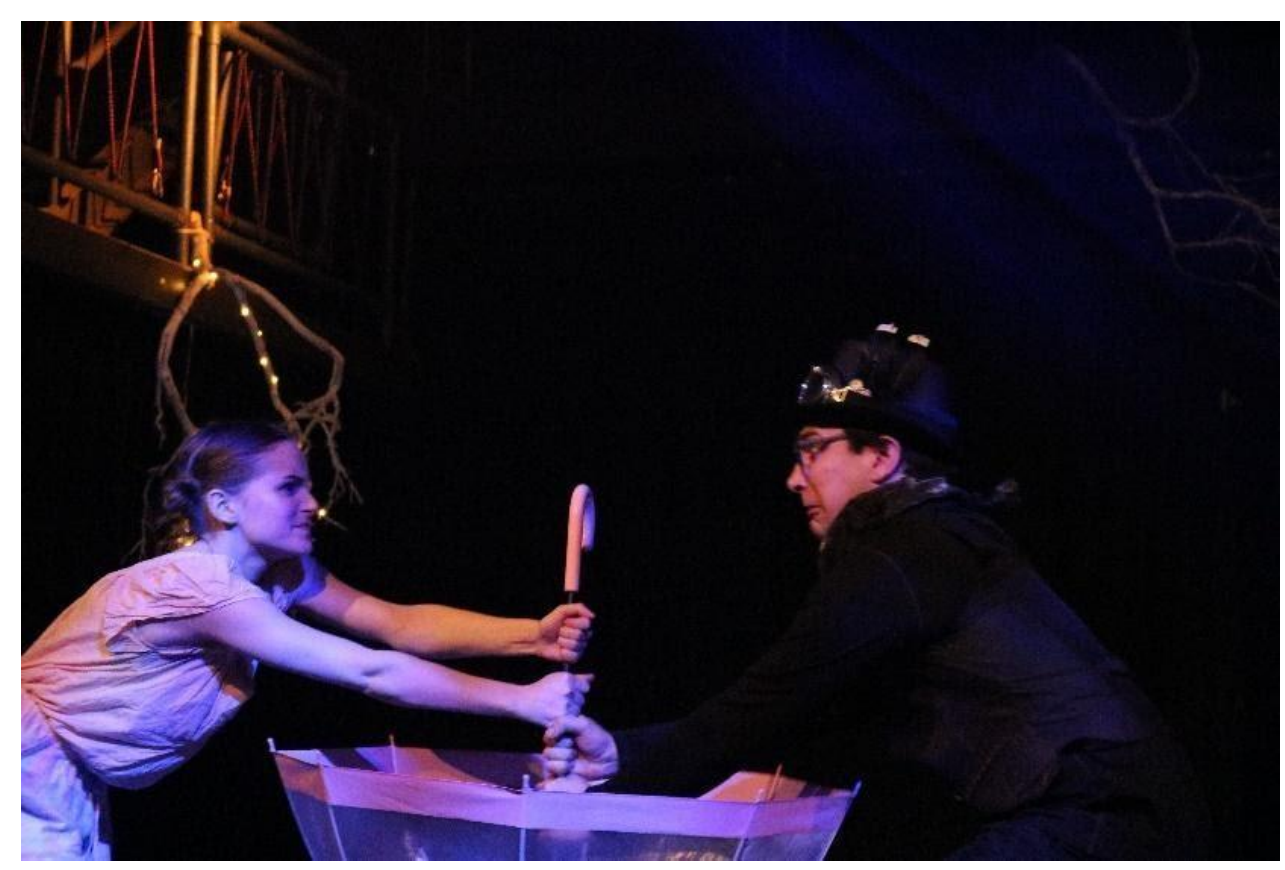

Figure 65: Luna and Mr Watt Fight for the Moonlight.

from small pieces of tissue, which created a beautiful visual effect while falling through the air. As Luna and Mr Watt fought, the moonlight spilt all over the stage, falling from the ceiling of the theatre to the audible delight of the children. Many of the children in 
the audience scooped up handfuls of the 'moonlight' and played with it. Some even gathered handfuls in their pockets to 'take home some moonlight.' There was a palpable delight in being able to touch and keep something 'magical', indicating again how the children were able to endow an ordinary piece of paper with a magical quality.

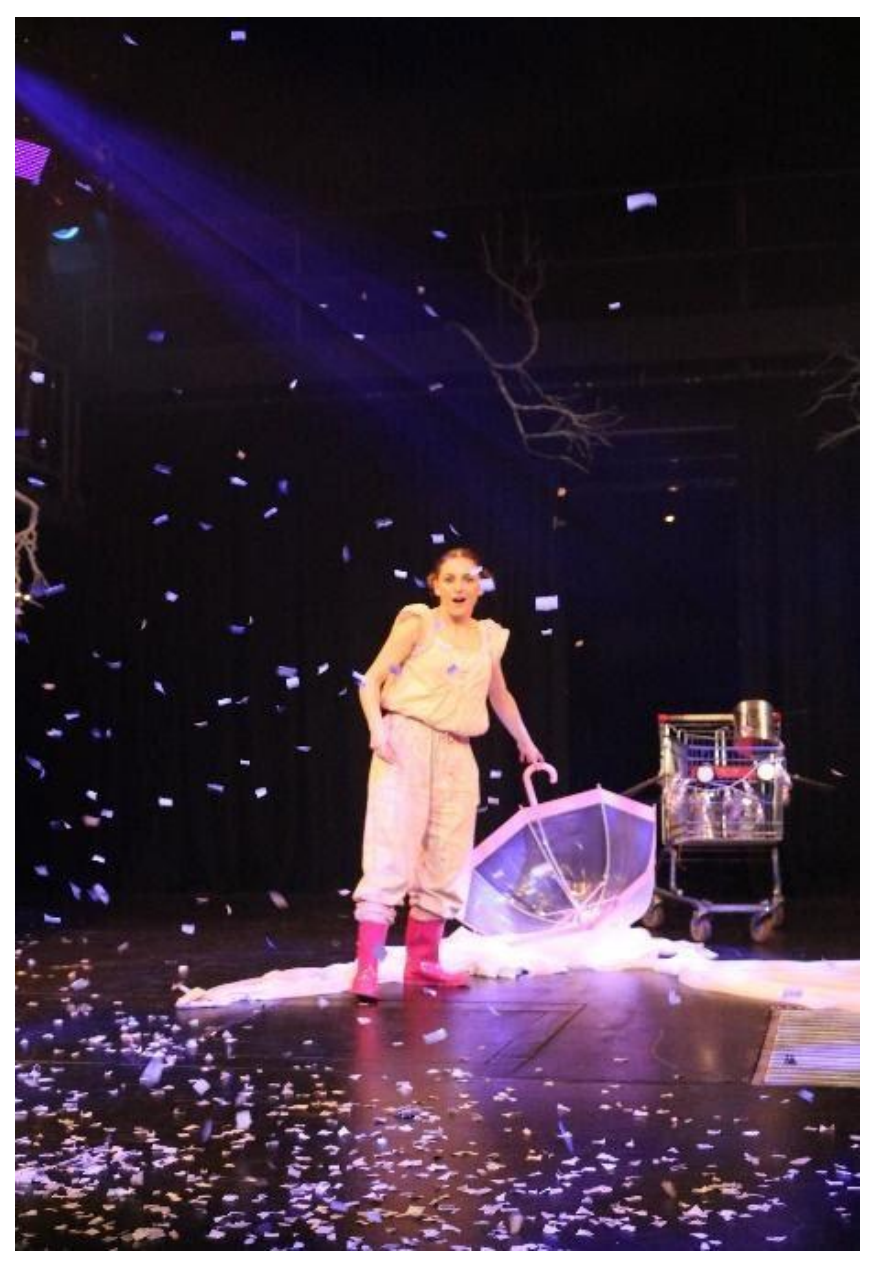

Figure 66: The Moonlight Falls.

\subsection{Summary}

Moonlight was created by the students of THEA311 with the guidance of a class of five and six-year-old children at Te Aro School. We used interactions with the children at three different times, to shape both the content and form of the play. We 
trialled the show with the class, using their feedback to test the work, before performing it for a paid audience. We consistently reminded ourselves of the audience we were making the play for. Our interaction and engagement with the children meant that the process demonstrated agency and empowerment for both the students and the children.

Several adults reviewed the play, and analysing some of their comments helps understand how the piece was seen through the eyes of theatre professionals, which is useful to the debate about quality TYA. Moments of artistic excellence were highlighted, such as the use of music performed and partially composed by student Joel Rudolph

Joel Rudolph's live music (also present for In the Attic) is what truly helps bring the magic of Moonlight to the forefront. He matches the tune perfectly with the tone each scene is going for; when Luna's starting her journey or toying with her Nightlight, the tune is whimsical, happy-go-lucky, soft, and uplifting. When Luna is in more dire situations, like her travel through the storm, the keyboard plays sharper notes, becoming deep, booming, and final. It's the perfect accompaniment for the show's nonverbal segments, which place a greater emphasis on showing the narrative through action rather than speech. (Art Murmurs Review, Spence)

Theatreview reviewer Jo Hodgson commented on the overall setting of the play and the creation of ambience in the theatre as a whole:

The calm and peacefulness of the Studio 77 theatre as we enter the space is transforming: the audience joins the reverence of the night scene that is waiting 
for us. Tranquil music and shards of light filter down as if through trees or a not fully closed curtain. From the moment we set foot in the creative space we are alert and waiting for what is to come. With a background of beautifully evocative lighting, a soundscape of original and classical compositions, creative use of space and levels, humour and quiet wonder, Luna tells us her story of learning to see her fears through different eyes while pushing through challenges and to look inward rather than always expecting help from external sources. (Theatreview published review, Hodgson)

She also noted our attempts to work against the usual tropes of TYA as well as the success of inviting the audience to collectively suspend their disbelief:

Palmer challenges her third-year Collaborative Production course students to devise a piece of theatre for children. Not just to create a formulaic 'let's have a jolly ol' time and have a few laughs' type piece, but something that is truly inspiring and respectful to the intellect of children that might otherwise be forgotten when trying to 'entertain' them...I like that this production doesn't call for the panto style interactions and allows the observer to journey along as if they are Luna in the adventure...As much as theatre-makers need to create something to inspire the child, the piece also needs to capture the imagination of the adults who attend with their children. This is often done with 'over their heads' humour or subtle adult references but in Moonlight we are given an invitation to suspend our disbelief and to travel this journey with our children and find the child within. The messages resonate for us too. (Hodgson) 


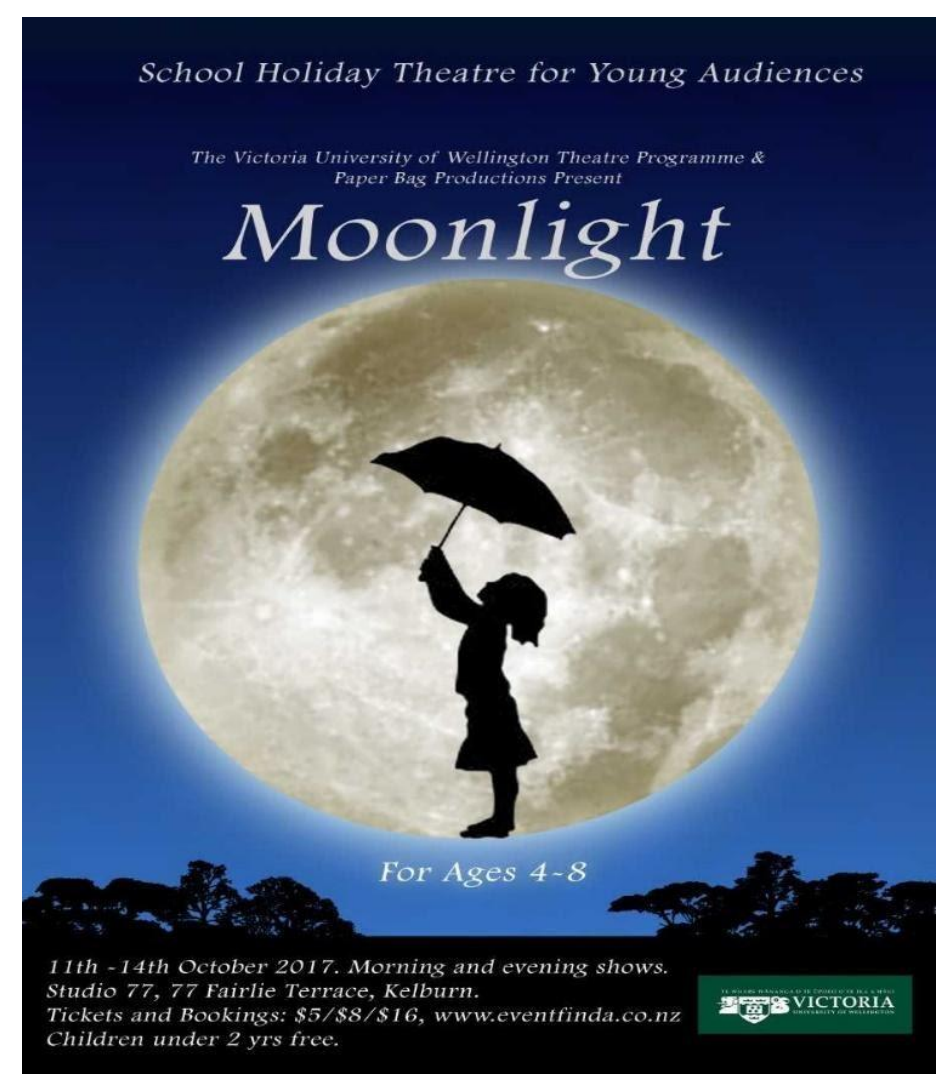

Figure 67: Poster for Moonlight, THEA 311 Production.

Victoria University Professor of Theatre and theatre director, David O'Donnell commented: "I think you've truly achieved many of the aims you set out to achieve in relation to children's theatre with great integrity and artistic excellence. You also showed that great children's theatre is also great theatre for adults" (O Donnell). It was affirming to get this acknowledgement from theatre professionals about the artistic integrity and quality of the production.

Most rewarding for us, however, were the positive responses from the children, their enhanced engagement, the relationships formed, and their post-show recollections of moments in the play, in particular re-creation of scenes. Also, it was evident that the children were excited to help us to create a show for them, and to a degree were invested in the process. Through our close interactions with the Te Aro children, we 
were able to identify several strategies that helped to keep them engaged throughout the viewing of the play. We discovered that by amalgamating both character-based textdriven narrative and image-based narrative we could appeal both to children who preferred a character-driven narrative and those who preferred a more abstract presentation. Our mixed approach gave space for whimsical interpretation by some children of image-only moments and a relishing of word-play and strong characters by others. By showing children the method of creating illusion - both in the set changes and in the magical elements of the show - we were giving them ownership of their own reading of the show. Crucially, we discovered engagement with the children in the making of the work- even if only for three sessions- was beneficial in giving them a sense of ownership and pride in the final piece. This engagement positioned them as 'experts' and co-collaborators in the play which appeared to make them feel more empowered.

As a director I realised that the more I gave ownership to the students the more they owned the work. This concept of empowering the young ensemble is examined further in the following chapter where the work of the second THEA 311 group is examined. 


\section{Exploring the World of OWT}

\section{The Creation and Presentation of In The Attic}

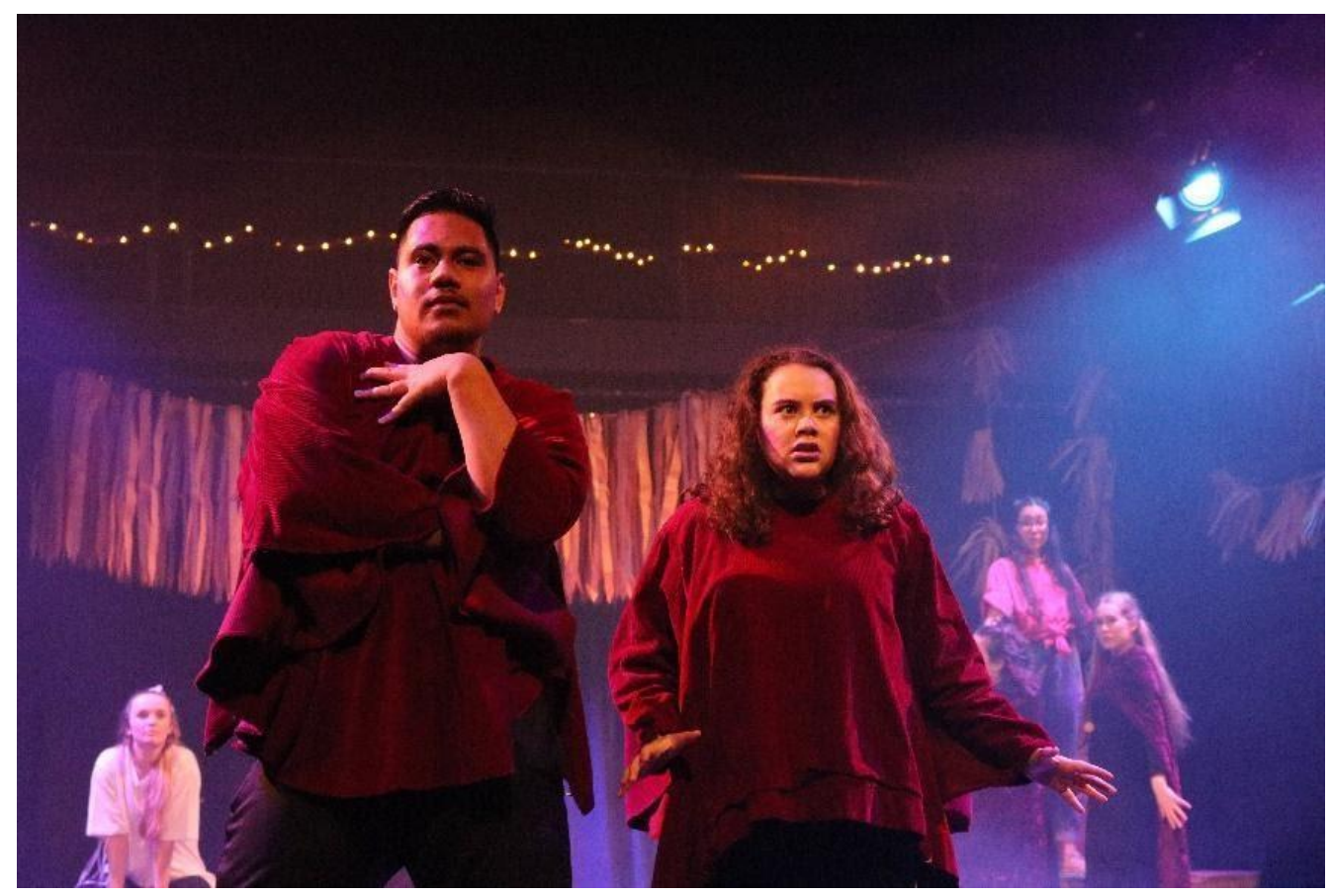

Figure 68: In The Attic.

\subsection{Introduction}

Through their visit to Tawa School, the THEA 311 students created an important intergenerational relationship with the children of Room Four. They made some surprising discoveries around the maturity and hobbies of the children, which they were enthusiastic to explore further in the rehearsal room. This chapter discusses the work that was created from the interactions between the two groups of young people. It begins with a brief discussion of the preadolescent period of development, to contextualise the group of children in Room Four. A critical analysis follows of 
moments in the play and in the process of making the play that directly relate to my research inquiries. I focus on the practical strategies we employed to engage the older children in the making of In The Attic. In particular, the way the students used the children's ideas to guide their devising process, and the children's visit to the university, which resulted in the students integrating the children's ideas into the play. Furthermore, I examine my role as director and the identification of methods that created empowerment and agency within the devising ensemble.

\subsection{Youth, Young People and the Preadolescent Theatre Experience}

CNZ describes Young people as "those aged up to 18 years and Youth as those aged between 18 and 25," (" Glossary"). The Ministry of Youth development states: "In New Zealand, 12 to 24 years is the generally accepted age range for defining "youth" or "young people""'. ("Policy-and-Research/Policy-Document" 6) The discrepancy of age range demonstrates the challenge of defining young people and youth, even within our government, and highlights the fluidity of the definition of youth and young people. In his research, sociologist William Corsaro asks the question: when does childhood end? (217). He affirms that defining the boundaries of childhood is a difficult task considering that childhood is a social construction that is related to, but not determined by, factors such as, "physical maturation, cultural beliefs about age and institutional age grading" (217). The age group that we were working with at Tawa School was 10-12 years which can be defined as the preadolescence period. ("Preadolescence")

Teacher and author Lou Harvey-Zahra writes that the five years before the age of thirteen are a huge transformational time for children: "Ages 7 to 12 represent a very important time of child development... Between the ages of 7 and 12, major changes occur in children's sense of self, their relationship to others, and their grasp of the world around them" (Harvey-Zahra 11). Harvey-Zahra suggests that children transform on all 
levels in this time, specifically in physical dexterity, intellectual development, and emotional awareness, and it is a time where their social and friendship connections will become more complex (241). The shift from early to middle childhood happens between the ages of $8 \frac{1}{2}$ and 10 (32). A young person turning 12-years old, however, signals the end of middle childhood and sees the beginning of their growing separation from their parents. Children begin to see themselves as unique and different from other people at this age (241). The difference between children feeling alone in the world and identifying individuality suggests large emotional differences which are worth considering when making work for this age group. However, all children are naturally different and reach different stages at different times. As with our visits to Te Aro School, we hoped that our interaction with the children at Tawa School would help us to understand the range of emotional differences and changes that might influence the way the children would respond to a theatre show.

\subsection{Group A - Illuminations}

The THEA 311 students creating the play for the Tawa School children chose the group name 'Illuminations', and was comprised of ten students: Cassidy, Corey, Gemma, Georgia M, Janaye, Nat, Peter, Saffron, Daz, and Terri. The children in Room Four-our preadolescents, aged 10-12-, were only 9-12 years younger than the 19-24-year-old students -in late/adolescence/young adulthood (Teipel). A significant discovery made during the first visit to Tawa School was that many of the children were fascinated with the same books, video games, and stories that also captivated the students, not just when they were children, but as a continuing interest in their present lives. Both groups shared a particular interest in stories and games that transported the protagonist, reader, or player to another world, such as Harry Potter, or Dr Who. When questioned, one child explained that, in these exciting worlds 'everything has potential, it is a better place.' Many of the children were drawn to the idea of a completely new world. As 
explored in Chapter Six, this led to a discussion of video games. The children articulated that the appeal of many video games was also the creation and exploration of a new world. There was some discussion of how in this 'new world' the rules of the world were clearer than the rules in real life.

The reasons why children might be drawn to fantasy are explored in several academic fields. Senior lecturer in Children's Literature Victoria Flanagan asserts:

One of the most obvious benefits of fantasy is that it allows readers to experiment with different ways of seeing the world. It takes a hypothetical situation and invites readers to make connections between this fictive scenario and their own social reality. (Flanagan)

Professor of Psychology Alison Gopnik writes:

Cognitive science suggests that children may love fantasy not because they can't appreciate the truth or because their lives are difficult, but for precisely the opposite reason. Children may have such an affinity for the imaginary just because they are so single-mindedly devoted to finding the truth, and because their lives are protected in order to allow them to do so. (Gopnik 2005)

This suggests that there are many complex reasons that children might engage in fantasy, and create and play in fantasy worlds. Discovering that this was an area of interest for the Tawa School children became significant for the Illuminations group when considering the content of the play. 
During the Tawa School visit, there also emerged a fascination by many children with watching 'real-life' videos on YouTube. The Common-Sense Media Blog suggests one possible reason for this:

YouTube's unscripted, anything-goes quality is super appealing to kids. Maybe kids need a break from the world of school, rules, and chores. Maybe they're looking for others who validate their own thoughts and feelings, and these hosts can serve that purpose...Kids become attached to YouTube hosts in part because of their honesty and relatability. There's an intimacy that some YouTube hosts develop with their followers that isn't available on traditional media such as TV. (Commonsense Media)

This idea of intimacy, relatability and the creation of relationships resonated with the students. Similar desires for connection were also reinforced when they went to visit the younger children, prompting both devising groups, to consider the question: how do we make every child in the audience feel as if we are performing this show just for them? The practice of interacting with the children in their own environment was key to making them feel they were part of the show. It encouraged the students to not make assumptions, but instead to learn from the children about their unique cultural knowledge and beliefs (Nolan and Raban-Bisby 10). Situating the children as active participants in the devising process and adopting a reciprocal learning model (Tempest 190) encouraged the students to view the children as individual participants and audience members - as opposed to a homogenous group.

During our first visit to the school on $24^{\text {th }}$ July 2017, a key discovery for the students was that some children revealed that they did not want to see stories with happy, predictable endings. They did however want hope for the characters beyond the 
ending, and the sense that everything would eventually be okay. This was strongly articulated by a 12-year-old girl who had recently lost her father, and resonated greatly with one of the students as expressed in his journal:

M's suggestion of a story that doesn't have a happy ending rang quite true to me, as when I was younger, I'd often feel quite cheated by stories where characters would magically heal or return to life. I enjoyed the escapism of such stories, but they also made returning to reality that much harder afterwards. A lot of kids are exposed to death and loss from quite a young age, and I think there's a lot of room to explore this within storytelling and especially within Theatre for Young Audiences. (Nacey)

The students realised that a Disney-type ending, such as the one the younger children loved and responded to in Moonlight, could be viewed as too predictable and cliched for this older age group. There was also a sense that the children were drawn towards the unfamiliar, and they wanted to be surprised. The articulation that they wanted something challenging, darker and more surprising, had a strong impact on the making of the group's play.

How families influenced the children's lives and futures was also a significant topic of conversation with the children in Room Four. Many children spoke affectionately of their family members and how they wanted to emulate them and choose similar occupations. The children said they would be willing to share 'a secret for a secret', and that if the students told them something about themselves, then they would be more willing to open up and share something. It was noted that the older the children, the less inclined to share freely they were. The students also observed that the younger the 
children, the more easily they talked to the students. The older children in the group were less inclined to speak out first, often standing back to allow the younger ones to speak. At our debrief, the students questioned how many of the children's ideas may have been influenced by their peers and their parents' own ideologies and beliefs. We concluded that one session with a group of children was not enough time to thoroughly investigate this. This was critical for me to note in terms of future work of this nature. However, the students felt that even after this one session they had a better understanding of what this particular age group would respond to. They had also formed greater respect for the children, which challenged their preconceived ideas about what theatre for this age group would involve. One of the students reflecting on this part of the process stated: "Knowing how mature some of them were really emphasised to me the need to make them theatre, not kids theatre, but theatre, enjoyable for everyone" (May).

The interaction with Room Four led to a detailed brainstorm by the students around both form and content. Ideas around form consisted of experimentation with light, such as candles, dark, projection, shadows and UV Lighting. The students were eager to use a scenographic palette and aesthetic of boxes, paper bags, crates, potato sacks. They articulated that music would be an important component, in response to an identification of their groups set of musical skills, and ideas on content, as shown in fig 71, were a recognition of their shared love of fantasy. Illuminations identified potential content areas as different fantasy worlds, family, magic, time travel, darkness, politics, YouTube, and unhappy endings. 


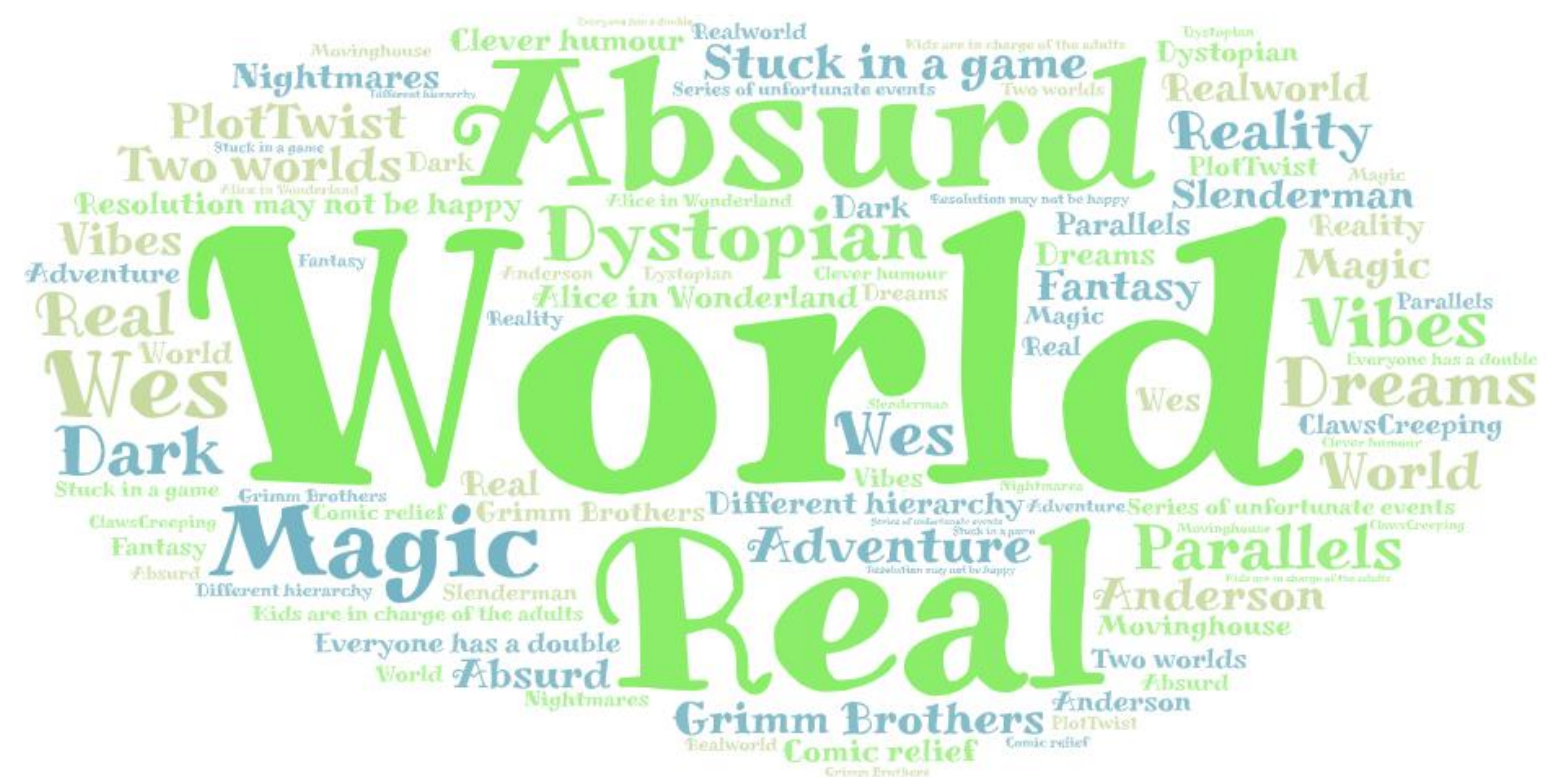

Figure 69: Illuminations Content Brainstorm Thea 311.31 Group A's Initial Concept Brainstorm (Age 10-

\subsection{Twoness to Twinness}

While revisiting ideas for subject matter that the Tawa School children had expressed in week two, the group realised that they needed a starting point to begin to explore these ideas, and returned to their earlier devising work. As outlined in Chapter Five, THEA 311 used the developmental idea of twoness as a 'seed' for the devising of their plays. Paper-Bag Productions (Moonlight), responded to Twoness by creating pairs of characters, like the Two-headed Signposts and the Tea Witches, and investigating 'journey' through the initial concept of two roads in a wood. One of the concepts that had developed from the very first brainstorm was twins: "Always being mistaken as twins with my older sister, Twin Siblings, Matchy, Matchy: Double Trouble, TwinsTweedle Dum and Tweedle Dee, Siblings, Twins, Best Friends, Wanting to have a Twin" (Palmer "THEA 311.13"). Peter offered direct insight into being a twin, a relationship that was fascinating and enigmatic to the many non-twins in the class. We had explored the idea of twins early in the term when the group were working as one, 
in a shared group activity where pairs of students dressed as, and improvised being, twins.

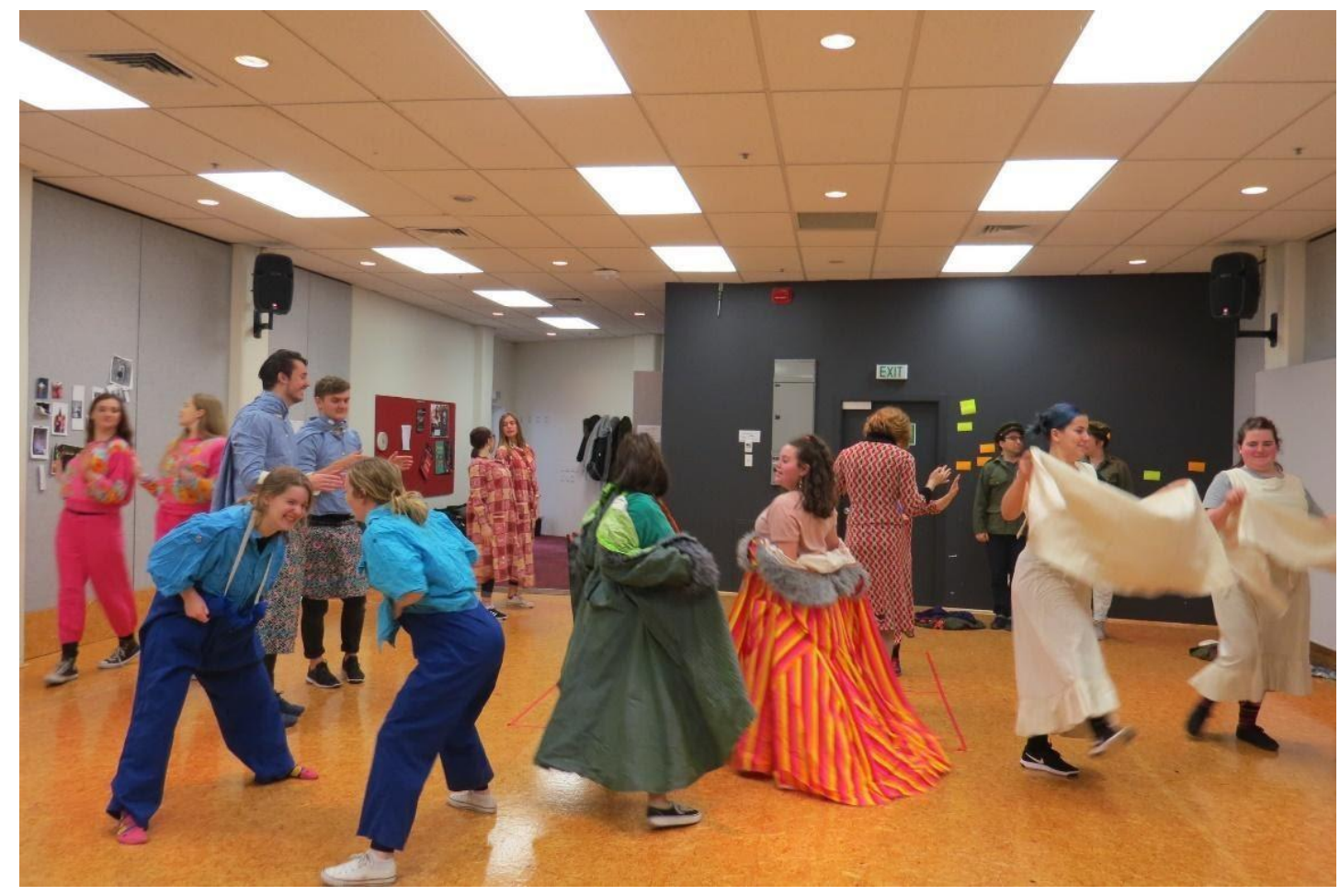

Figure 70: THEA 311 Exploring Twinness.

Peter had brought a creative writing piece to the class in which he reflected on his own experience of being a twin:

Being a twin is knowing that it doesn't matter which path you take because there will be someone walking beside you. Having a twin is the freedom of knowing that there is someone out there that is always in your corner. It's an indescribable force like knowing you can try anything, do anything, and failure doesn't matter because you could never be a failure to them. A twin is a best friend, not in the flimsy way people use the term 'best friend' now, but a lifetime connection, it's deeper than brothers, sisters and family. It's a collaboration of life and spirits that bind you together, regardless of sin or frailness, you are twins, two, forever. 


\section{(Palmer "Thea 311.26 Twin Writing, Peter")}

He was eager to share his personal experience with the group and they were able to question him about being a fraternal twin. The group also watched the videos of the twin scenes they had created previously. In particular, we noted the great moments of connection between Corey and Peter. The sense of play and friendship that developed from this early improvisation work served to create a symbiotic, playful relationship between them, which evolved into the creation of core characters Sam and Alex.

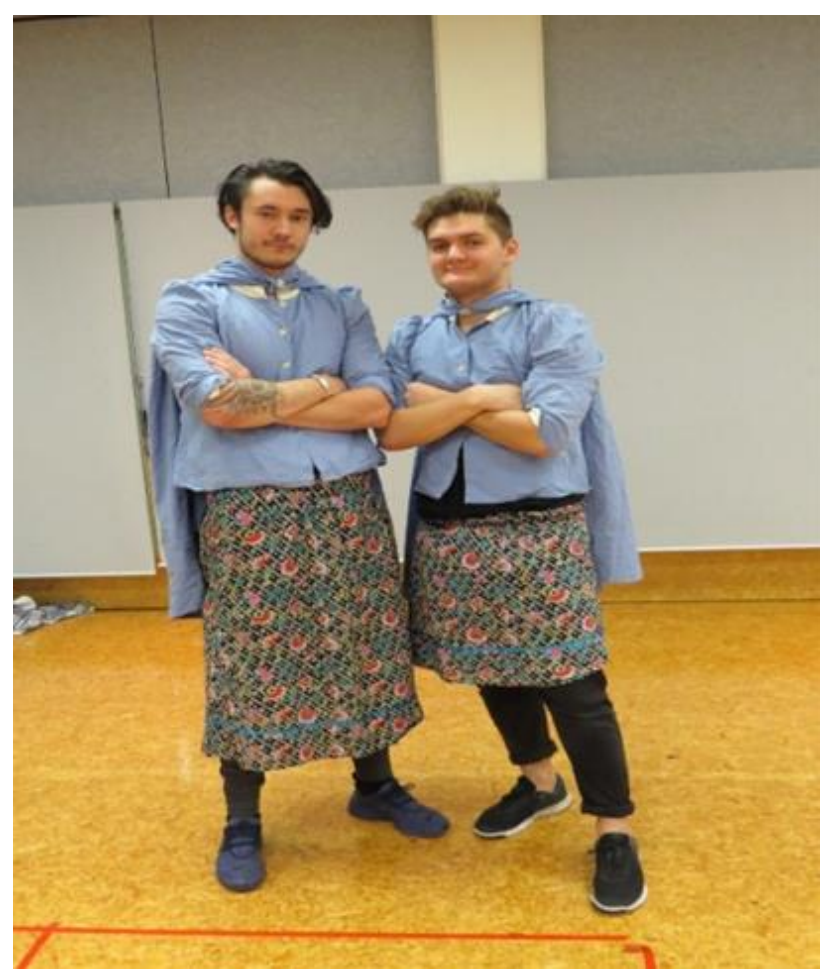

Figure 71: Corey and Peter's initial twin characters. 


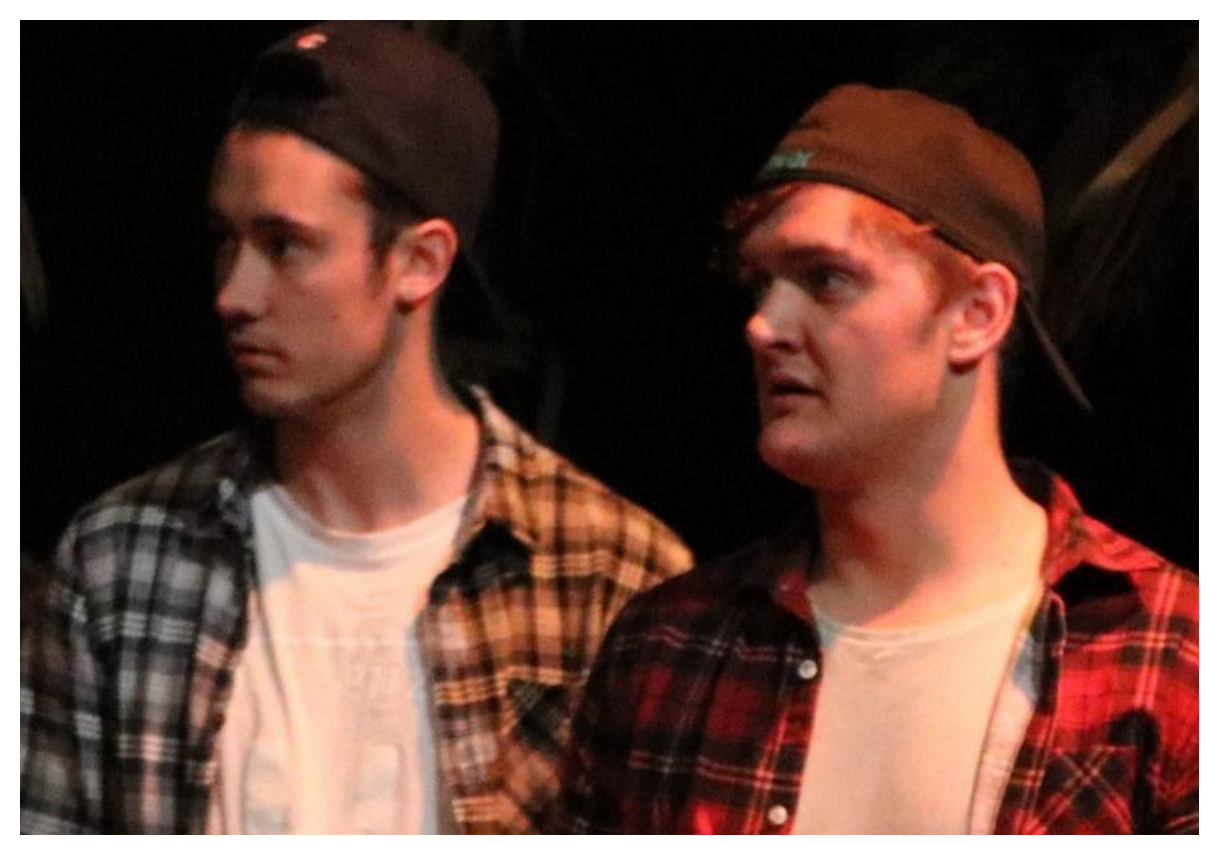

Figure 72: Corey and Peter as Sam and Alex- In the Attic

In this initial provocation task, and in contrast to most of the class, who used the costumes to directly inform the type of twins they created, Peter and Corey demonstrated an ability to think outside the square. Their improvisations demonstrated elements of surprise and they created a unique brand of twins. Through the way they used the costumes, by turning skirts into capes, for example, they were able to evoke a real sense of being young boys, exploring their gender fluidity, and experiencing the world through fresh eyes. Brown reflected on these twin improvisations;

[I] really loved the sense of "ease"; the authenticity ... the presence of the performers ... the "in the momentness" of play ... even though a lot of it was BIG ... in physicality, it wasn't contrived ... it felt authentically playful.... so that says something "good" about their training and about your lead-up to these activities. (Palmer "THEA 311.14") 
While reflecting on their interactions with Room Four, the Illumination's group decided that an exploration of family dynamics and specifically twins and friendship might work as a framework for the play. The successful session in exploring twins led to further examination of this concept and twinness became a governing idea, and a catalyst for creating many of the play's characters.

By using the PaperBoats Principles for our 10-12-year-olds, we were expanding Brown's tools and methods to suit the older age group. Because of their interactions with Room Four, the group were strongly drawn to creating an alternative-reality world, somewhere where there was conflict and that had the potential for an unhappy, surprising and 'non-Disney' ending. The students also began to experiment with ways to tell the story that would appeal to their sophisticated audience. This saw an introduction of rap music and hip-hop-style dance, examined later in this chapter. Even though the group found themselves veering away from The PaperBoats' concept of image-based modules with a poetic and open narrative, they were hopeful that the complex character-based narrative would still be able to engage their young audience and leave space for discussion and debate amongst them. The Illuminations group were also strongly aware of their responsibility in creating truthful and authentic characters. As discussed in Chapter Three a major challenge of TYA lies in being playful and entertaining while still respecting a young audience's intelligence. Having been made aware of the many similarities they had with their trial audience group, they were determined to act in a way that was non-patronising to their audience and this became a key focus to their work. They employed several of the techniques discussed earlier by Jenner, Wood and Wake, which included: treating the audience with respect by avoiding clichés of TYA acting such as sing-song vocal delivery, developing fullyrounded and complex characters and remaining authentic and responsive to the audience. 
At this stage of the process, as director, I was trying to stay open to the range of possibilities that were being explored in class. I was encouraging the students to consistently remember their audience and consider strategies that would best keep them engaged. The rehearsals were still structured in the way that we began, with a check-in and a warm-up and finished with a checkout, but I was also supporting the students to work independently by giving them provocations to create raw material in small groups.

In comparison with the Paper Bag group, Illuminations didn't initially create a list of 10-12 narrative moments, but instead used the three weeks before Dave Brown arrived to experiment with ideas, feelings, and thoughts around the concept of twins and creating an alternative world. These loose ideas created space for further whimsical play and exploration and were in line with the PaperBoats concept of not pushing for a predetermined outcome. In his analysis of Brown's principles, Pope suggests that whimsy describes "activity that mimics the creative play of children" (Pope 14) and that the key to using this principle in the creative process is to:

Avoid a predetermined outcome or to attempt to make the play sessions serve a goal, idea, or plan...The group devises in a childlike, whimsical way with the materials provided and engages in games, tasks, improvisations and silliness. There is a tremendous feeling of liberation for the creative team. (Pope 14)

The Illuminations group were working together to explore new ideas around Twoness and Twinness and engaging in flights of whimsy that contributed to the accumulation of lots of raw material. As the director in the room, my role at this stage was not just to encourage the creation of raw material, but to also act as a dramaturg and simultaneously begin to piece this material together. As Pope states, "the director obviously has the understanding that a theatrical performance will be the end result of 
all this creative play" (16). This meant that while guiding the group to generate whimsical material, I had to be mindful that it would eventually need to be ordered logically into a performance piece. This was also the period, as examined in Chapter Five, where the group was becoming more product-focused than process-driven and the anxiety around the final product was increasing. Consequently, as well as directing the action in the room and thinking ahead to the performance piece, I was also managing the anxiety of the students.

It was here that I began to examine my role as a director of young people more closely. Fundamentally, I wanted the students to feel a sense of agency and empowerment within the process. Watkins suggests a way of doing this is by inviting the students to claim ownership of a devising project through their invention and problem-solving (169-170). However, I also wanted them to feel safe and supported in the process and not become overwhelmed by the amount of work that needed to be done. This was a lot to balance and the other group were at a similar stage. Bearing in mind that the developmental stage of the students indicated that they were able to develop and apply abstract thinking and meet demands of roles and responsibilities (Teipel 1-2), I began to encourage them to manage their anxiety around the final product, to find solutions to conflicts that were happening within the group, and to start thinking ahead to how the material might be ordered. Instead of relying on me to solve the problems, I encouraged them to ask: What is best for the work? as a way to focus the group on the collective work rather than on their individual egos. However, I believe I didn't go far enough at this stage in giving the students autonomy over the process, which resulted in them still looking to me to solve problems. I think that I felt an overwhelming duty to hold the piece and the process together and perhaps did not trust the group enough to be able to do it without my guidance. Nonetheless, I began to 
recognise that an important part of the young people having ownership of the product and the process, was for me to step back more and let them find their way.

\subsection{Creating the Narrative and the World of the Play}

When Dave Brown arrived in mid-trimester break the group had made decisions around several key elements. It would be centred around twins, there would be an alternative reality/world, where being a twin was a basic tenet of the world. The world would be called, Owt - 'two' spelt backwards - and the adventures in the world would involve conflict and some sort of sacrifice that would lead to an unhappy ending. The actors were also determined to work hard to portray their characters authentically and in a non-patronising way.

To explore the alternative/fantasy reality that we had identified would best engage our audience, we felt that it was important to first show the 'normal' world. Corey and Peter were encouraged to continue being twins and became the characters, Sam and Alex. In early sessions we had also experimented with mixed-gender friendships. There had been much discussion and reminiscence of the groups own mixed-gender childhood friendships, as well as what happens when a third person is added to a friendship of two, and we created the character of Bea - a best friend to both of the boys. After brainstorming around how one would find an alternative world, and researching how children's fantasy authors JK Rowling and Phillip Pullman do this, the group decided that the protagonists would need to discover a portal. The ensemble liked the idea of Alex, Sam and Bea tumbling through a portal into this new world. It was this concept of space and falling that led to the idea of an attic:

We had a great time playing with this scene. The first thing we did was to grab a prop each- that one might find in an Attic. We set them up and the props included a large tin box, several cardboard boxes, a parasol, a baby carriage, a 
lampshade, a helmet, a picture of Jesus and some sheets. (Palmer "THEA $\left.311.39^{\prime \prime}\right)$

The whole group contributed to establishing the basic shape of the scene, and when Dave Brown arrived, we had just begun to add music, sound effects, and to create moments of action. Dave embraced the fundamental concept of the world of the play; however, his initial assessment of the attic scene was that the students were overcomplicating each moment of action and clouding it by 'over-explaining'. He observed their habit of frequently performing an action and then explaining it verbally. He encouraged the students to break each moment of action into clear steps, to simplify the moments of action and non-action and to use less dialogue as a way to tell the story more clearly.

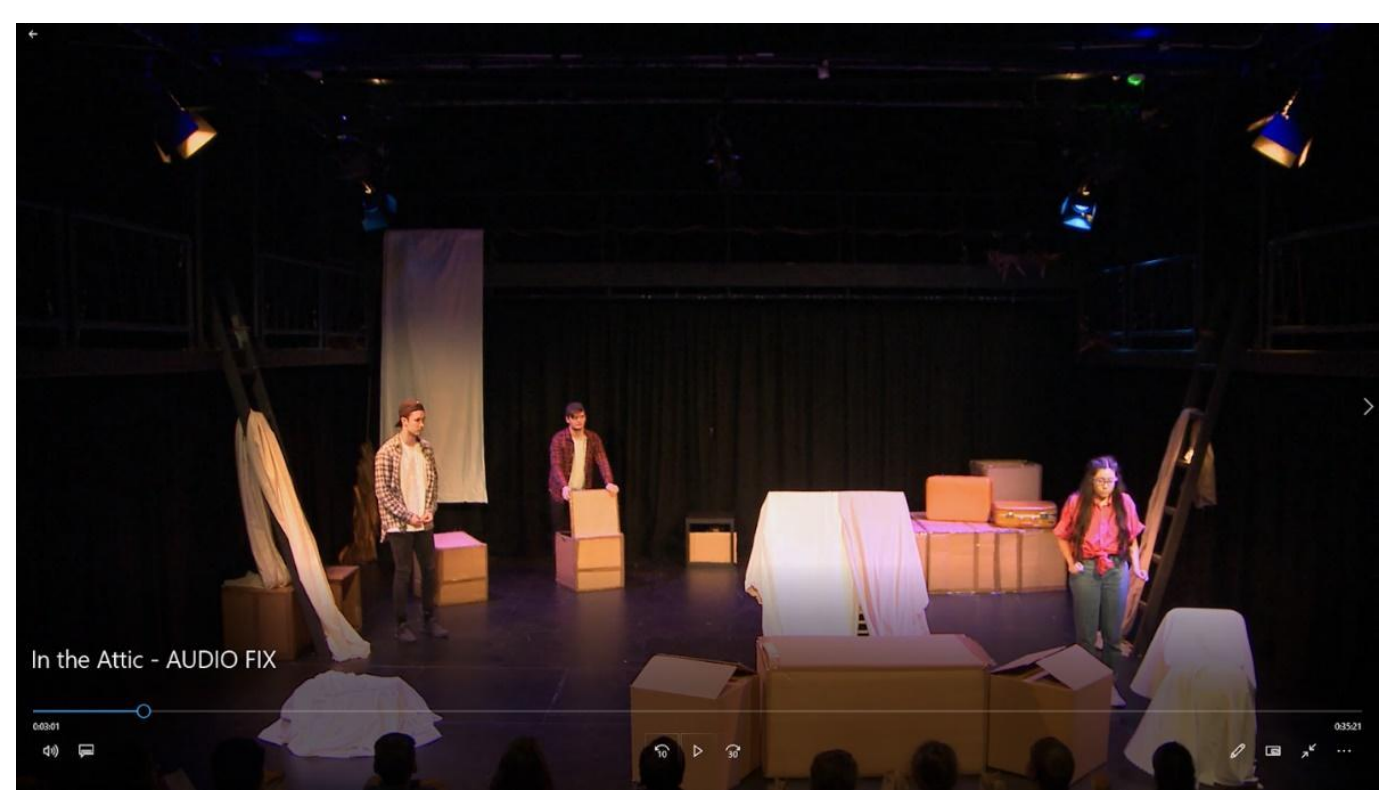

Figure 73: Screenshot. Exploring the Attic.

"When I turn the sound off it becomes magical and compelling ... there's not one word of dialogue that serves any function other than to explain what is going on and that (for me) makes the potentially magical become banal" (Brown qtd. in Palmer "THEA 
311.37"). Dave was leading the students back to his PaperBoats model of language-lean, image-based modules. However, it felt like a departure from some of the ideas the students had identified as being important to the older age group, such as un-happy endings and sophisticated stories. This was a key moment in the intersect between The PaperBoats model - fundamentally aimed at a younger age group - and the way the Illuminations group were experimenting with engaging their audience. Since the group were open to experimenting with different methods at this point, and their instinct and mine - was to follow Dave's guidance, the first scene became mostly non-verbal action, accompanied by music.

Once we had decided on the basic shape of the opening scene, we moved on to creating the alternative reality: the central world of the play. We revisited the worlds that Room Four had identified as being their favourite fantasy worlds, such as Hogwarts, and the worlds of Dr Who, and returned to some early play that had been done with the whole class. One of the most resonant improvisations from that stage was 'The Hands-Eyes and Foot Stomp.' In this provocation, the group experimented with how the ordinary could be affected by the bizarre. The students were encouraged to explore the room as if it were a brand-new world. Returning to this 'strange new world' led to the creation of Illumination's fantasy world Owt. In this alternative world, many things were 'not natural', the bizarre was normal and the doctrine of 'two is better than one' became the ruling policy and was utilised as the main conflict. 


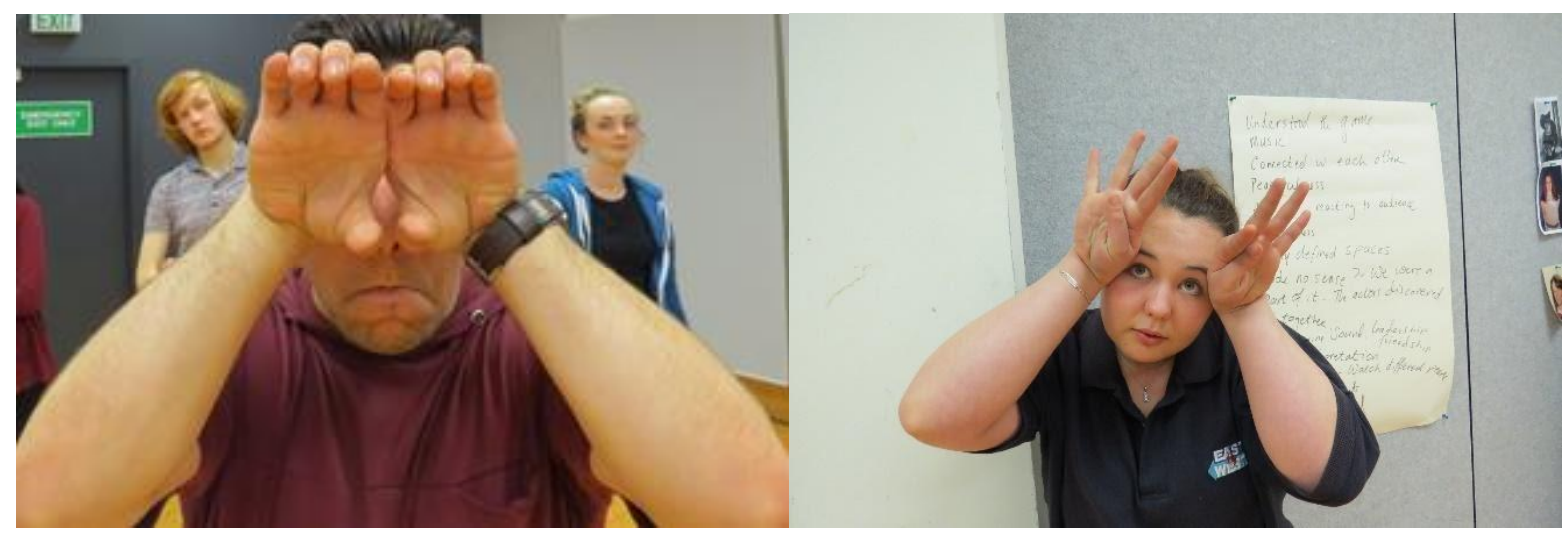

Figure 74: Early provocation work-The Hands-Eyes and Foot Creatures.

There were many ideas within the group about what Owt could look, feel, sound and smell like. The students were given free improvisation time, to explore the space to music and to spend time with Dave and I exploring ideas, through a combination of improvisation and discussion. Owt evolved into a world where all the creatures were in pairs. Each pair was different and employed many of the creative and playful qualities that had been discovered in the early weeks of devising.

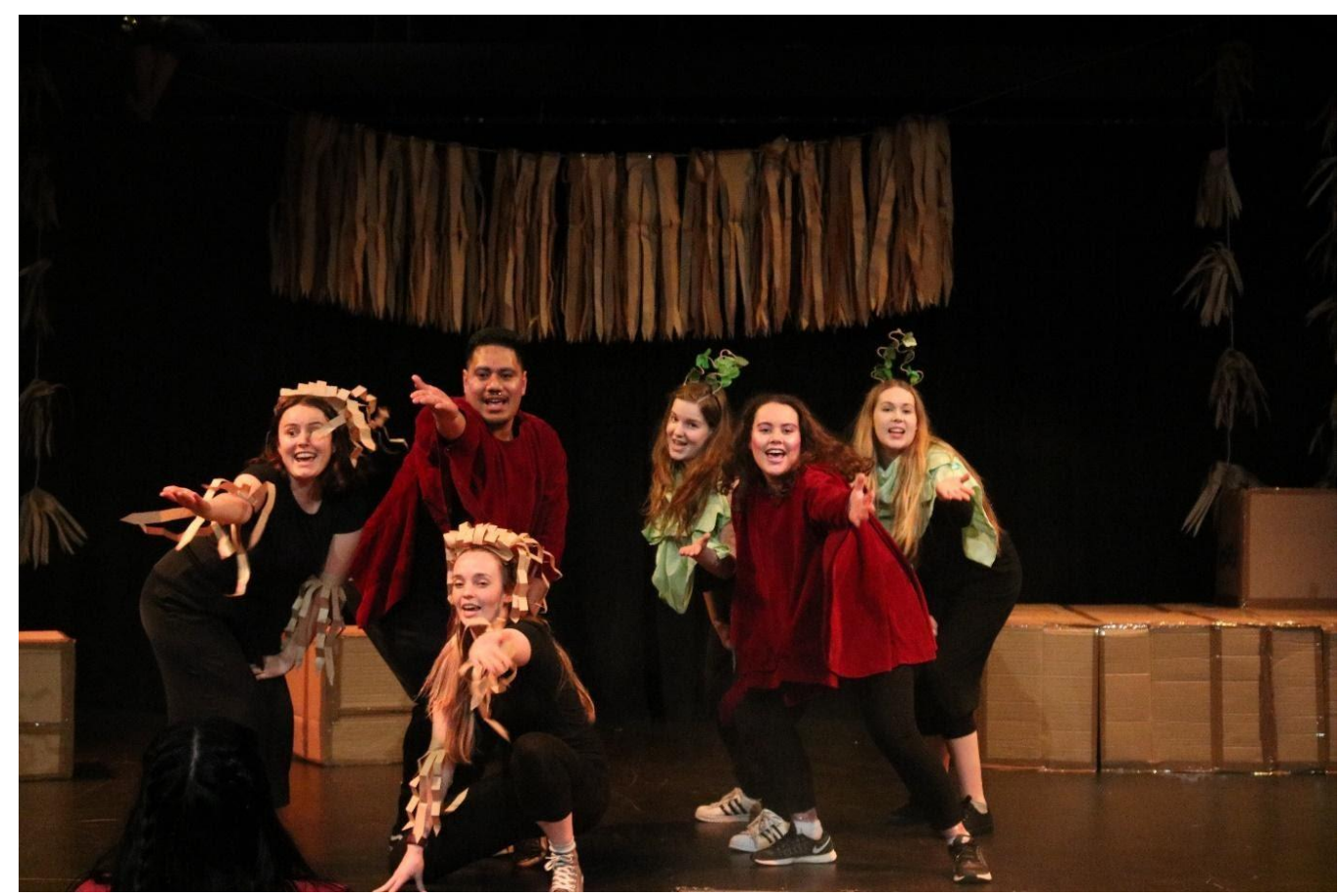

Figure 75: The World of Owt. 


\subsection{Casting}

By this stage students were demonstrating key attributes linked to their developmental stage such as: developing and applying abstract thinking skills, developing stable and productive peer relationships and meeting demands of increasing mature roles and responsibilities (Teipei 1-2). However, some were still displaying levels of anxiety in the process, in particular several students were still very concerned that we had not cast the play yet. I acknowledged the anxiety within the group and tried to encourage them to wait a bit longer and to keep exploring the world of the play. I explained that my instinct was to try this way of working in the hope that the casting would evolve organically. However, Dave and I noted that this anxiety was, for some, hindering the devising process and it became clear that it had to be addressed. I articulated the challenge in my daily blog:

There comes a time in a devising process when a director has to begin making decisions and driving the process forward. In a learning environment, I am hesitant to do this too early. Why? I want the students to have as much ownership of the process as possible. I want them to engage as much with the making process as possible. I want them to learn how it is to lead a devising process of their own, and this is not always best done by following someone else's directions, but by them experiencing what it is like to be the person who makes decisions and how the decisions are made. The hard thing is to get the process as democratic as possible, but without letting it go on too long. (Palmer “THEA 311.49 Day 25 Blog. Casting and all them dramas")

I was hesitant to make the casting decisions myself, believing that the students would feel more empowered by a democratic decision that was not teacher-led. However, the majority of the students articulated a preference that I cast the play. Responding to this, 
I assigned roles, which immediately led to some relief, but also conflict and hard discussions. This process is typical of collaborative devising: decisions can be made to move a process forward, however, these may not be as organic or as 'fair' as when more time is taken to arrive at consensus. I was again confronted with the balance of directorial pressure I was applying, and because I wanted the students to feel more autonomy and look less to me to solve problems, I introduced a key philosophy that I have developed and used before in devising ensembles. I encouraged the group to take agency over their individual roles and the final product by empowering them to change things they weren't happy with. I reminded them that this was a devised piece that was still being created and if they were not 'happy' with their role, then they could change it - by adding more lines, creating a new character or enhancing the scene. This philosophy seemed to alleviate some of the frustration around roles and it was an example of me stepping back and handing control and ownership to the students. Essentially, they had given control to the director/teacher by insisting I cast the roles, and now I was handing it back to them. This sense of control residing in the group relates strongly to my research enquiry of encouraging agency and empowerment for all those involved in the making of the work.

Once the casting had been agreed on, we returned to clarifying the overall arc of the play. We spent two full days on this and succeeded in loosely blocking out the entire narrative of In The Attic. This saw the group starting to work more coherently as an ensemble. By responding to their anxiety around casting, I had freed them up to return to being creative and playful. Having surety of what roles they would be playing, and encouraging ownership in the creation of the characters and material, seemed to give them confidence and reassurance. This led to a productive calm and creative period, which felt like an acknowledgement that I had achieved a useful balance of directorial pressure and creative freedom. 


\subsection{The Trial Showing}

Illuminations had been working towards a week nine showing of their play. It was timely, as they had reached a point - similar to Paper Bag Productions - where they needed to be reminded whom they were creating their play for. They wanted to test if the work would engage the Room Four children and crucially, they could not decide how to end it and wanted to ask the children for their opinions. Room Four came to the showing at the university theatre studio. I opened the showing with an introduction that informed the children what we had been doing since we last saw them, and what we were expecting from them.

As soon as Cassidy, playing Bea, put her head through the curtain into the attic, there were giggles from the audience and the play began. The showing was 28 minutes long and at a moment of climax after the twins had been separated and Bea was about to undergo a mysterious "binding," we stopped the showing. Following a similar feedback protocol to the one used with the Te Aro children, the audience was given a few minutes to share their thoughts with their neighbours, and then I facilitated a feedback session. This began with a general discussion of what they had been discussing with their neighbour. Instead of asking: did you like it? I asked them to specify aspects of the play they liked or didn't like and things that didn't make sense. The session was informal but guided by questions and it generated a free exchange of ideas and comments between the students and the children. The students were genuinely engaged and interested in the children's feedback and responded positively to their ideas. This acknowledgement seemed to give the children the confidence to speak, to make suggestions and to question. I noted that a wide range of children spoke, not just the outwardly confident ones. The students showed they were comfortable with the process in the way that they were open to asking the children for further clarification and encouraged them to share their ideas. 


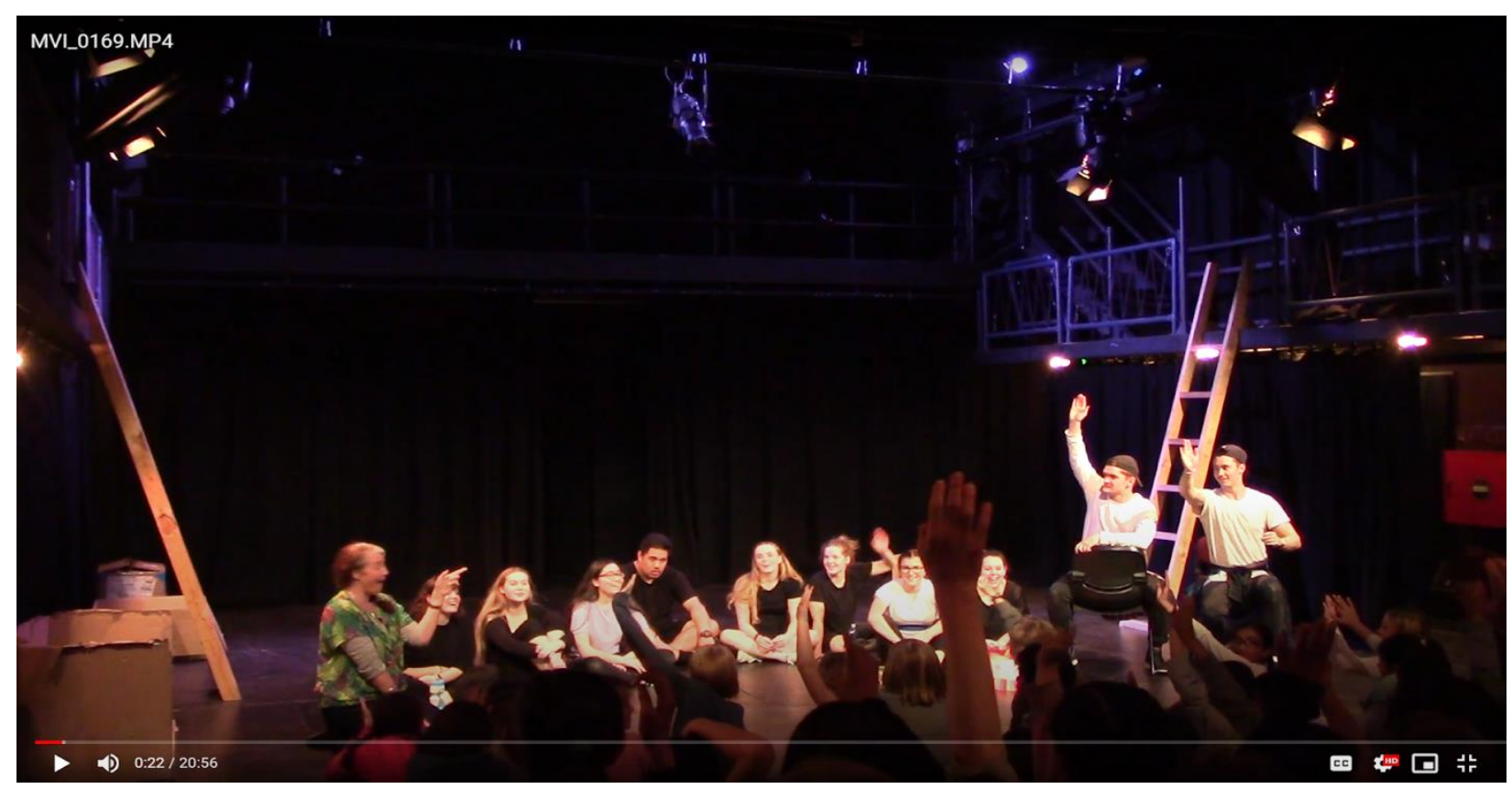

Figure 76: Screenshot of the Feedback session with the trial audience.

A particularly useful method in this session was physically reminding the audience of each scene. The actors formed a frozen tableau of a particular moment in each scene and I asked the children to discuss with each other what was happening in the scene. This was especially useful in ascertaining the clarity of scenes and characters, as well as gathering information about what the children thought should change or remain the same. Because of the older age of these children, we were also able to introduce a written set of questions for them to answer back at school (See Appendix C). A week after the showing, we had a further feedback session at Tawa School. Due to outside commitments, only half of the Illuminations group returned to the school. The method we used at this session was to break the class into small focus groups and assign a student to each group. We used the children's written feedback as a starting point of discussion. A key discovery was that the feedback session directly after the showing was more useful for us with this age group of children than the younger ones. In particular, the physicalising of scenes and the facilitation of feedback relating to each 
scene seemed to engage the children as they were talkative, and brimming with ideas. However, during the post-showing school visit, it felt like they did not have much more to add to what had already been said or written about in the feedback form. This was in contrast to the engaging post-showing session that we had at Te Aro school. The following is an analysis of some of the key moments that the children engaged with, and how the students responded to their feedback.

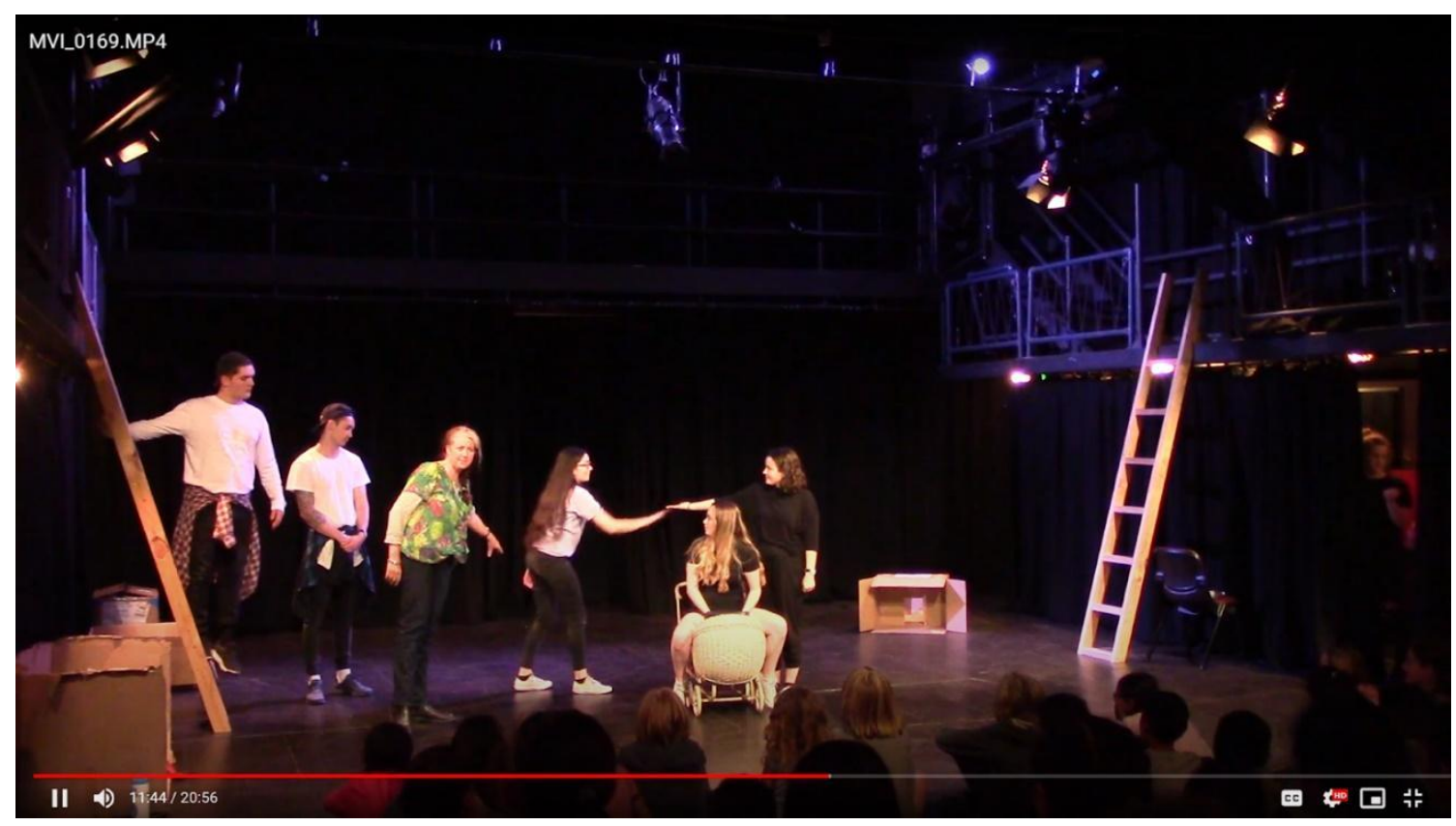

Figure 77: Screenshot of physicalising each scene and facilitating feedback with Room Four

\subsubsection{Discovering the Portal}

Illuminations, following the guidance of Dave Brown, had created a language-lean, image-rich opening to the play. Set in a mysterious attic in the 'real world', the performers were able to establish important information about the three main characters. Specifically, that Bea was the leader and that one of the twins, Alex, was braver than the other. Musician Joel had added eerie piano music that enhanced the risky and forbidden atmosphere of the attic. I thought that we had created a delightful 
way to begin the play. However, after the trial showing to our test audience, this was the scene that many of our Tawa kids commented that they didn't understand or like:

I got a tiny bit bored when they didn't talk for ages at the start.

The scene in The Attic needs more words.

The start was all over the place.

The start was a bit boring because I didn't know what was going on.

The start because nothing was happening because the actors kept falling over (Tawa School Feedback. 29 Sept.2017).

The fact that nearly a quarter of the Tawa School children had found this first scene the most boring or least interesting, raised lots of questions for us. Was a language-lean approach not the right mode to be used with this age group? Was it something that perhaps worked better with a younger age group and an older age group may respond better to more dialogue? Was this a question of the staging of the scene and the fact that it was very slow and tentative in the quite dim light that was making it boring? Did it matter that a quarter of the group had found it boring, or was it the fact that we had asked them specifically to pinpoint a boring moment that made them feel they had to do so and therefore chose the least action-filled one? Or was it the fact that we had yet to add the special effects that would enhance the scene, such as costumes, better lighting, smoke and a trapdoor that would allow actors to magically disappear? 


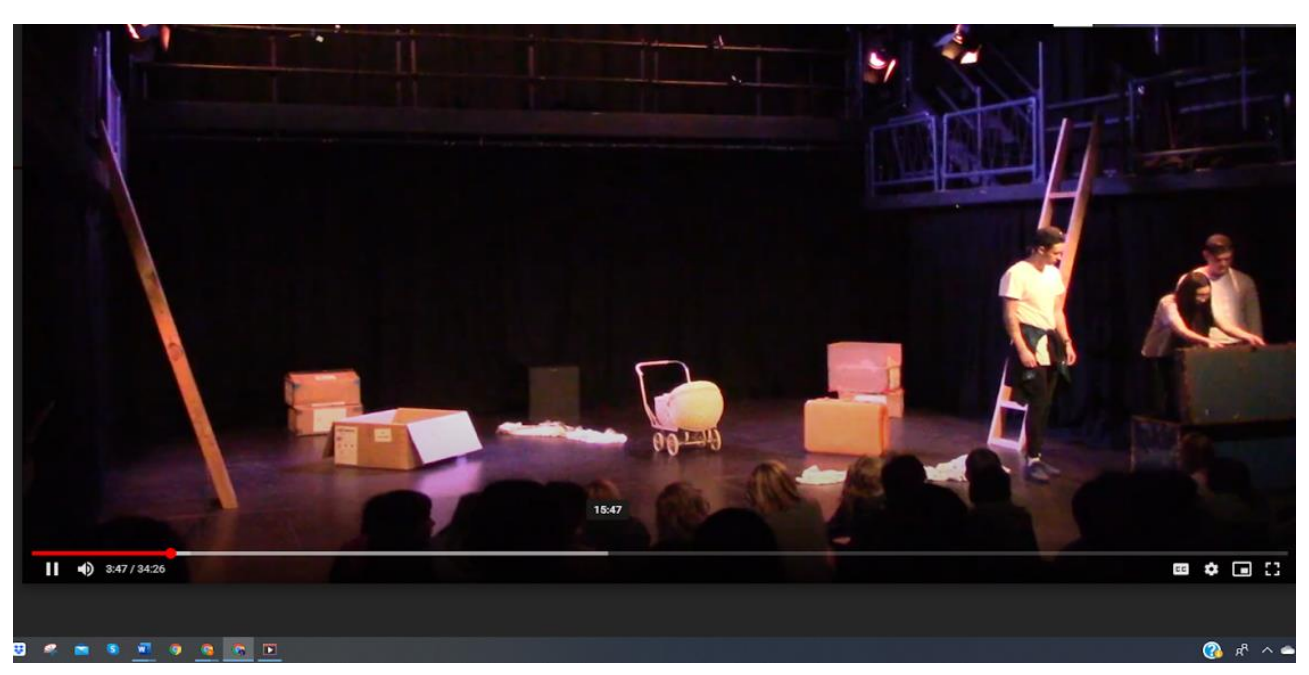

Figure 78: Alex, Sam and Bea find the portal- Trial Showing

We also noted that some of the children did like the Attic scene and in particular the way the characters were introduced subtly in a comedic way. There had also been a feeling, by myself and the cast, of the children being engaged in the scene, as demonstrated by their giggles and active listening. After much experimentation and consideration, we decided to stick with the essence of the original scene, predominantly because we felt the scene worked well to set up the alternative-reality world of Owt and was able to introduce Bea, Alex, and Sam in a non-expositional way. In order to respond to feedback from our intended audience, however, we focussed our efforts on enhancing the visual effects in the scene including the lighting, smoke effects and in particular the trapdoor illusion. 


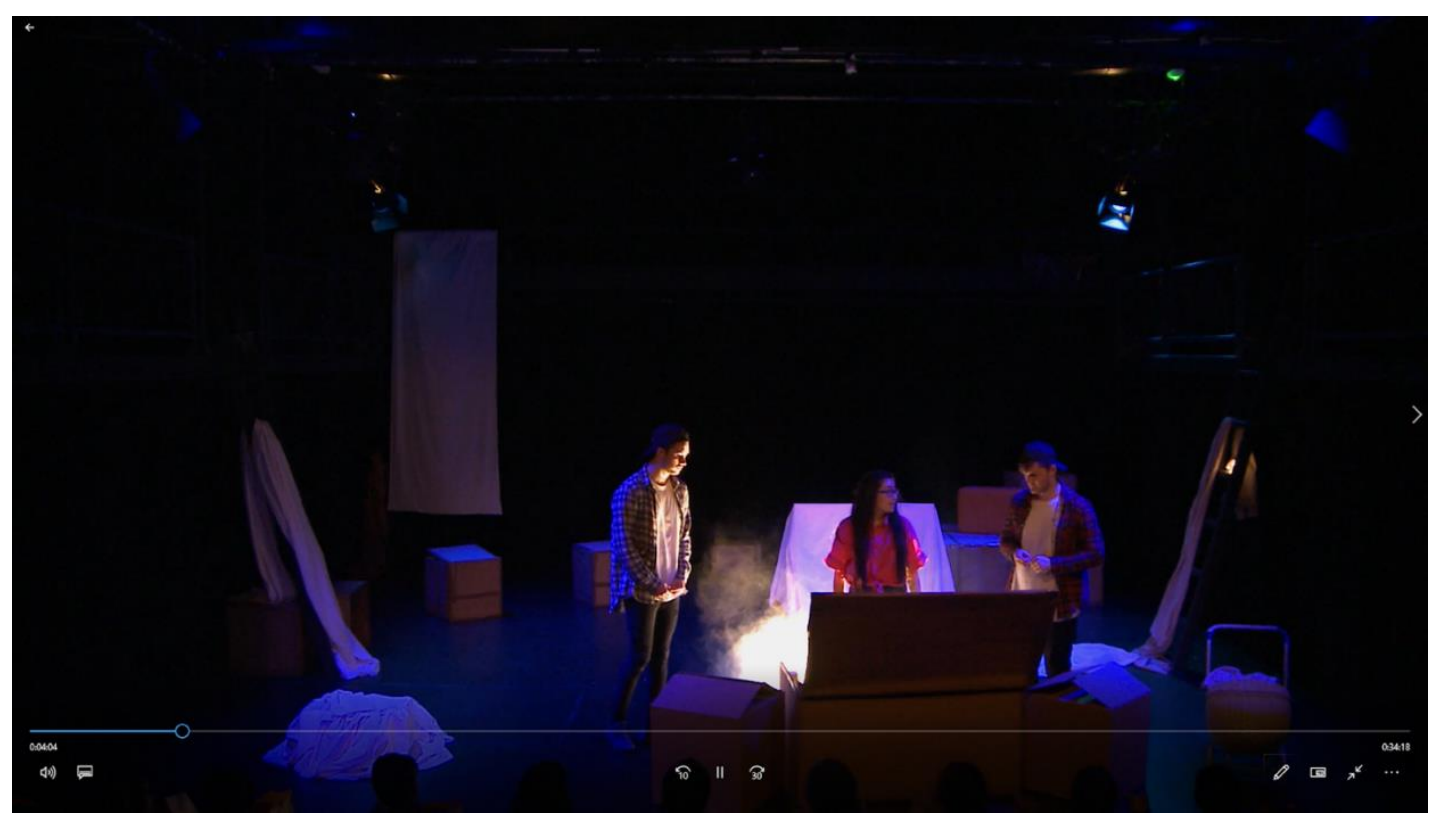

Figure 79: Alex, Sam and Bea find the portal- Final Performance.

Two key discoveries emerged from this part of the feedback sessions with the Tawa School children. Firstly, the students had initially steered away from creating a language-lean opening as they felt that the older age group would not respond well to it. They were then encouraged by Dave to experiment with this mode, and subsequently discovered that it was not universally engaging to the Tawa children. This showed an important moment in the process, where the directors, Dave and myself, did not follow the suggestions of the students when maybe we should have. Because of our previous experience we had assumed that this slow start to the play would resonate with our audience, instead of listening to the students who were responding to their interactions with the Tawa School children.

Secondly, even though I had verbally signalled before the showing that the special effects were not yet present, it seemed that the children needed to actually experience these to get the full effect of the scene. This could be linked back to the idea explored in Chapter Two that children only know what they have experienced before. 
Having not seen special effects live before, perhaps they could not imagine what we were describing. Critically, this feedback from the children made us consider the scene in great depth and experiment with ways of making it more engaging. Furthermore, I began to question the way that I was guiding the students. They had demonstrated that they had good instincts when it came to anticipating what engaged the 10-12-year-olds. Even though Dave and I were 'experts' in the room in terms of theatre-making, we needed to trust the young people more, in particular as their interactions with the children had resulted in strong relationships between the two groups.

\subsubsection{The World of Owt}

The feedback session with the children also revealed their appreciation of the fantasy world of Owt. Tawa School children described Owt as: 'Another world', 'A magical place', 'Very Phantom-Toll-Boothish', and 'Another Dimension.' (Tawa School Feedback 29 Sept.2017). The characters Bea, Alex, and Sam were introduced to the world and creatures of Owt through a song and dance number called 'Welcome to Our World.' This scene introduced two major dramatic problems. Firstly, Bea is singled out as an ENO (One backwards), which is an anomaly in the world. Secondly, while the audience was focussed on the singing and dancing, the box through which the children had accessed the magic portal, and which was their likely route home, had disappeared. The following scenes, similar to Moonlight, were loosely structured on Campbell's narrative template "The Hero's Journey": the three children embark on an adventure, experience a series of obstacles, challenges and characters in the world of Owt, before finding a way home. Partway through the journey, Bea is kidnapped because she is an 'ENO 'and a ritual is prepared to bind her to Owt's only other 'ENO'-Yek. During the trial showing at the point of climax where Bea and Yek are about to be bound together, we stopped the showing and began the feedback session. 
" I don't want to leave- I want to know what happens next." (Tawa School Feedback. 20 Sept.2017)

Several children said straight away that they liked "EVERYTHING!" about the show and the majority indicated that they wanted to come back and see it when it was finished. A number commented how much they had enjoyed the twins, Alex and Sam, saying "they were funny" and "acted like twins actually do", in particular noting their rivalry and friendship (Tawa School Feedback. 20 Sept.2017). In the written feedback some mentioned that the twins would be the character they would most like to play, because they were funny, disagreed a lot, and because, "I've always wanted a twin brother" (Tawa School Feedback. 29 Sept.2017). We were particularly interested in seeing how the children responded to the only other non-twin or ENO in the world, Yek. The intent of introducing a single character in a world that celebrated Twos was to provide a subtheme of: 'It's ok to be by yourself' and 'It is ok to be different from the crowd.' We were unsure if this theme was clear. However, at the trial showing, one of the Tawa children approached Terri, the actor playing Yek, after the show to specifically tell her how much she had loved watching her character being so happy on her own, confiding that she also loved to be on her own. This interaction indicated that the character" relatable and that one of our underlying concepts, challenging ideas about 'fitting in' and 'following the group', was resonating with some audience members. Several of the older girls in the group reported also really enjoying Yek's attraction and subsequent flirting with one of the twins. "The [most interesting] moment was when [Yek] was flirting with Korey!!" (Tawa School Feedback. 29 Sept. 2017) In discussions after the trial showing, they indicated that the low-level flirting was something they loved, found funny and wanted more of. This interaction compelled us to consider ways we could add more charged and nuanced subtext to our work, that more sophisticated young people could engage with. 


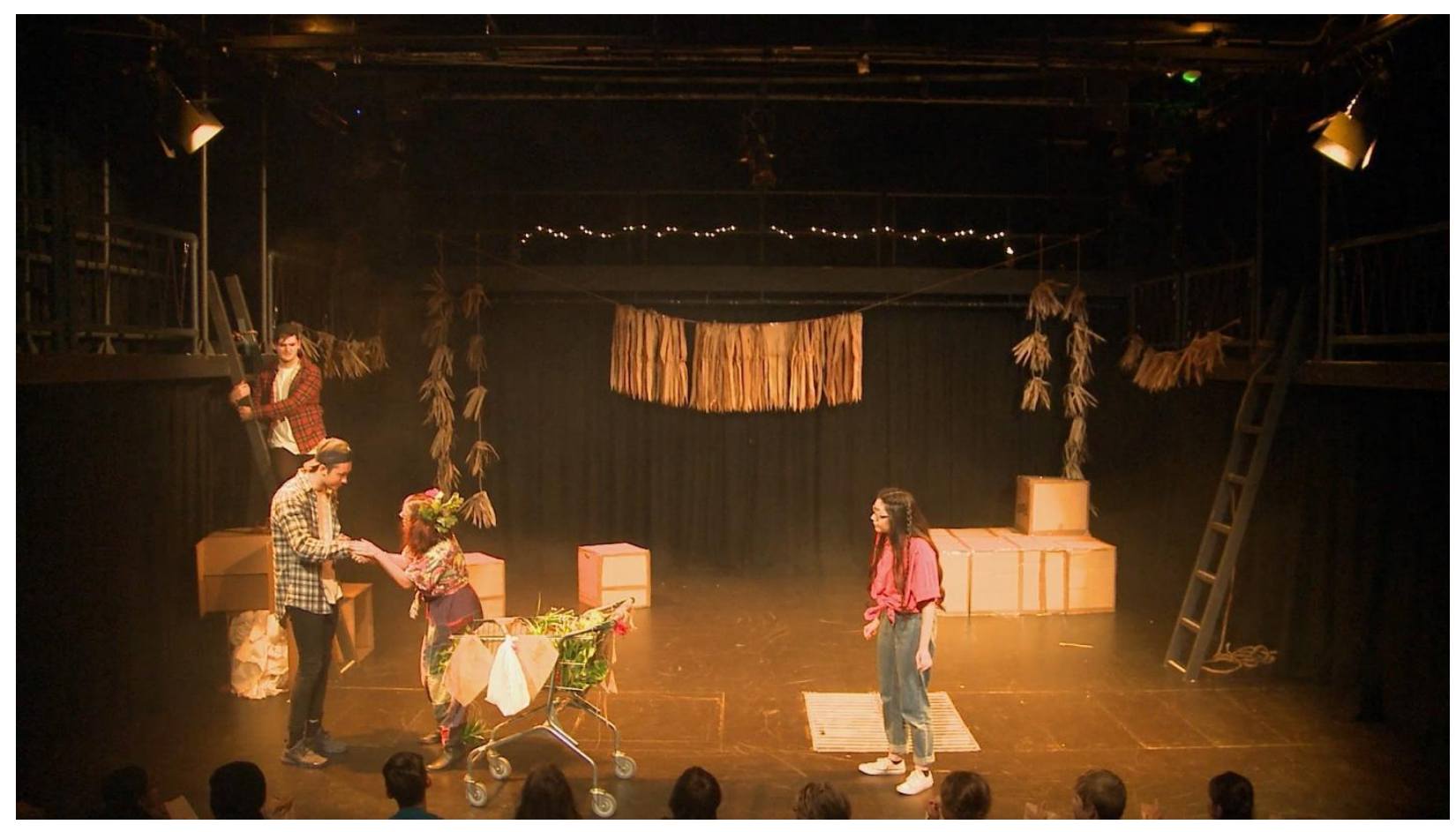

Figure 80: Screenshot. Yek Flirts with Alex.

One of the questions on the feedback form was, "What was the most interesting part of the play?" There were a variety of responses but the most common include: The Binders, The Police People, and The Guides. The Police People, played by Gemma and Natalie, were one of the most entertaining and memorable sets of twins. Using sounds and clown-like exaggerated movement, they created a dynamic and amusing nonverbal scene in which they interacted with the audience by taking photographs of potential sets of twins, choosing audience members that looked vaguely alike. When they turned to Bea, Alex, and Sam and tried to photograph them, they suddenly expressed great concern at there being an 'ENO' in the group, reiterating the basic tenet of OWT that two is better than one. This whimsical and vaudeville-like scene appealed to children and adults alike:

"The most interesting part is the people who ride on a pram and say cheese." 
"The (most interesting) part when two people came in and took a picture of Lochie and Mia because they looked similar... I thought this part reminded me of myself because they were very weird." (Tawa School Feedback. 29 Sept. 2017)

The Pan's Labyrinth's Pale Man creatures, as well as the hilarious French police clowning duo, were my favourites, succeeding in their task of both scaring me and making me laugh. (Salient reviewer- Emilie Hope)

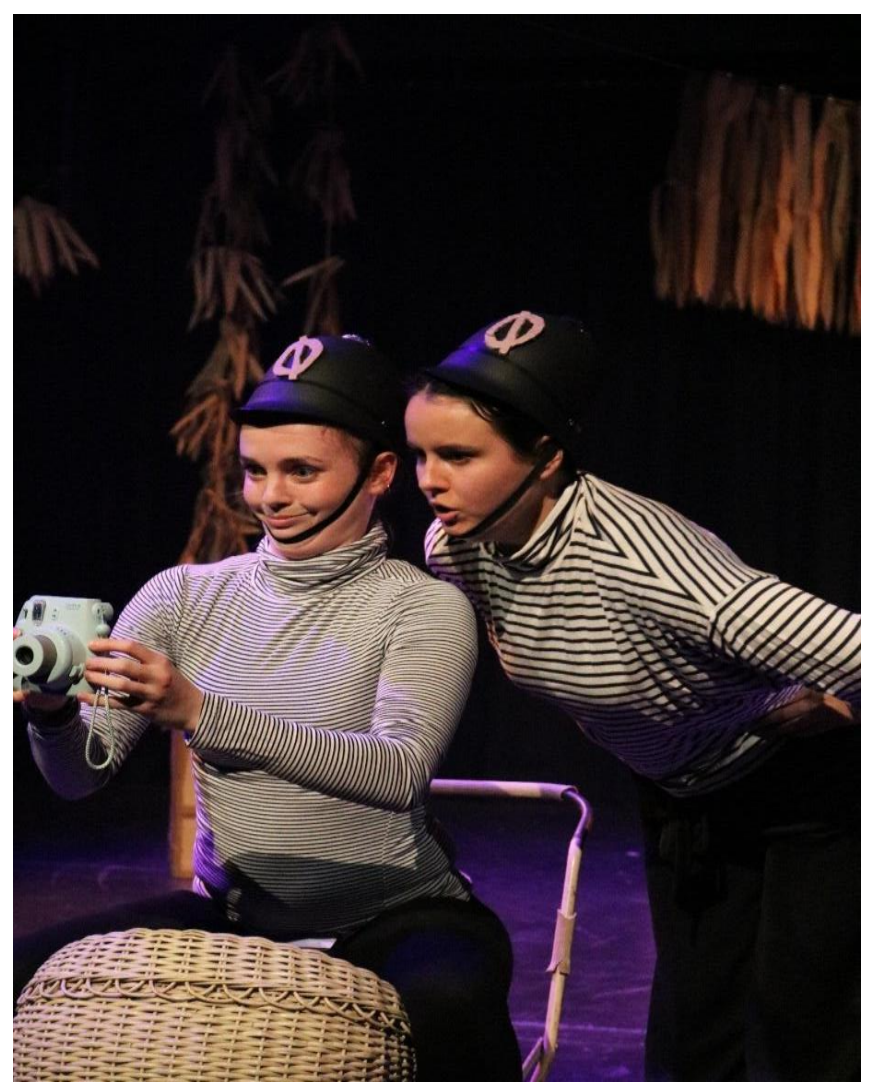

Figure 81: The Police People

The Police People evolved directly from our early devising work, where I had noted the group as a whole to be the most open and creative, working generously and playfully. Similar to the Te Aro children imitating the talking signposts in Moonlight, 
several of the Tawa School children repeated the Police duo's wordplay and mimicked their sounds and gestures in the feedback sessions.

Another very popular pair were The Binders, created by Gemma and Saffron. The Binders drew on the early idea of 'witch-like' object manipulation and were able to control objects and characters with their telekinetic spells.

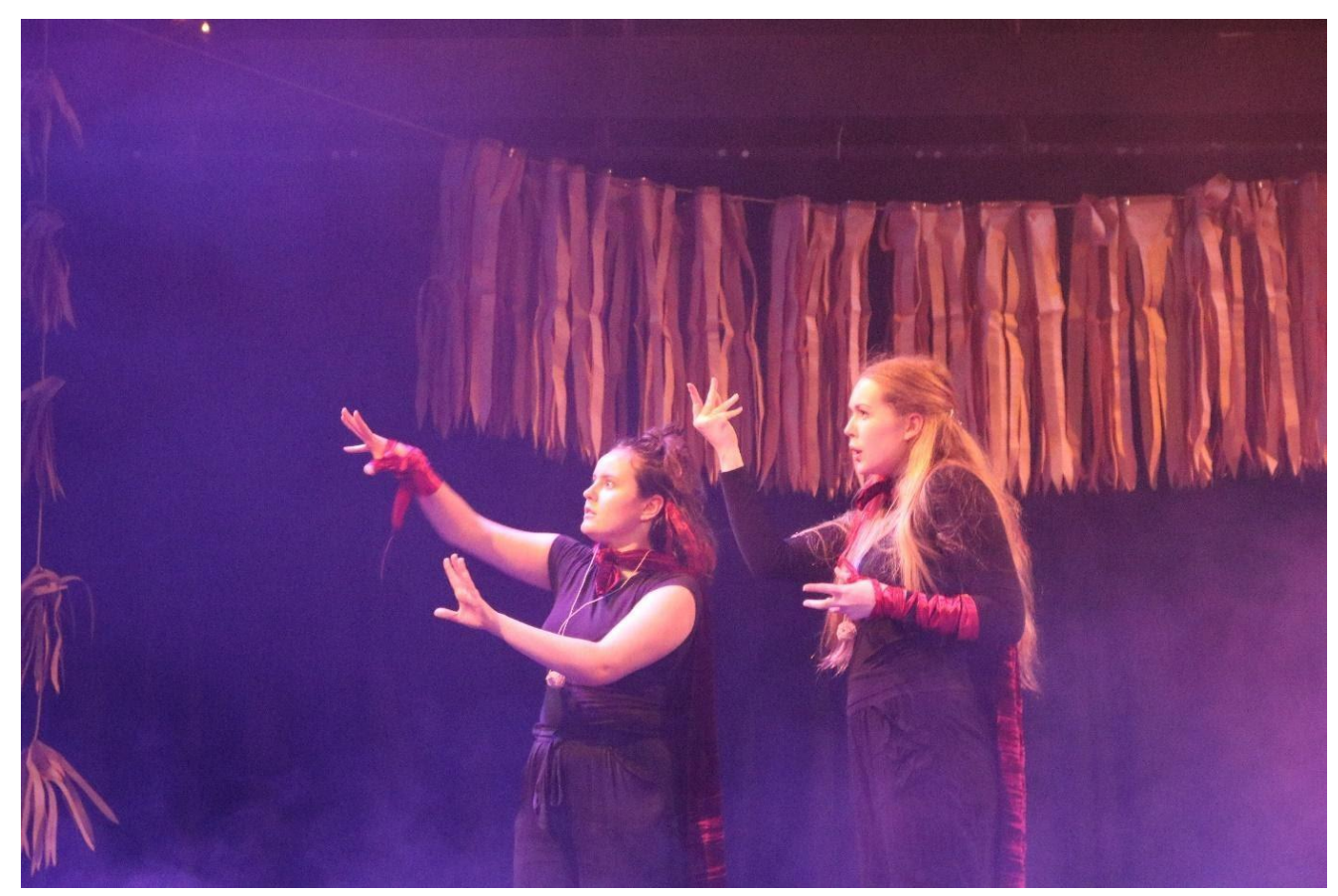

Figure 82: The Binders.

This also seemed to appeal to many of our audience:

I liked it when The Binder people could control people, it looked pretty real/ The moments I liked the most were when they sang around the cauldron and chucked things in and then Bea came out like a puppet/

I would be one of The Binder's because they were interactive and funny. (Tawa School Feedback. 29 Sept. 2017) 
An adult reviewer commented: "I left the show humming The Binders' song, haunting and inviting at the same time" (Hope). At least one parent remarked to me that their children were still humming the Binders song a week or so after they had seen the show.

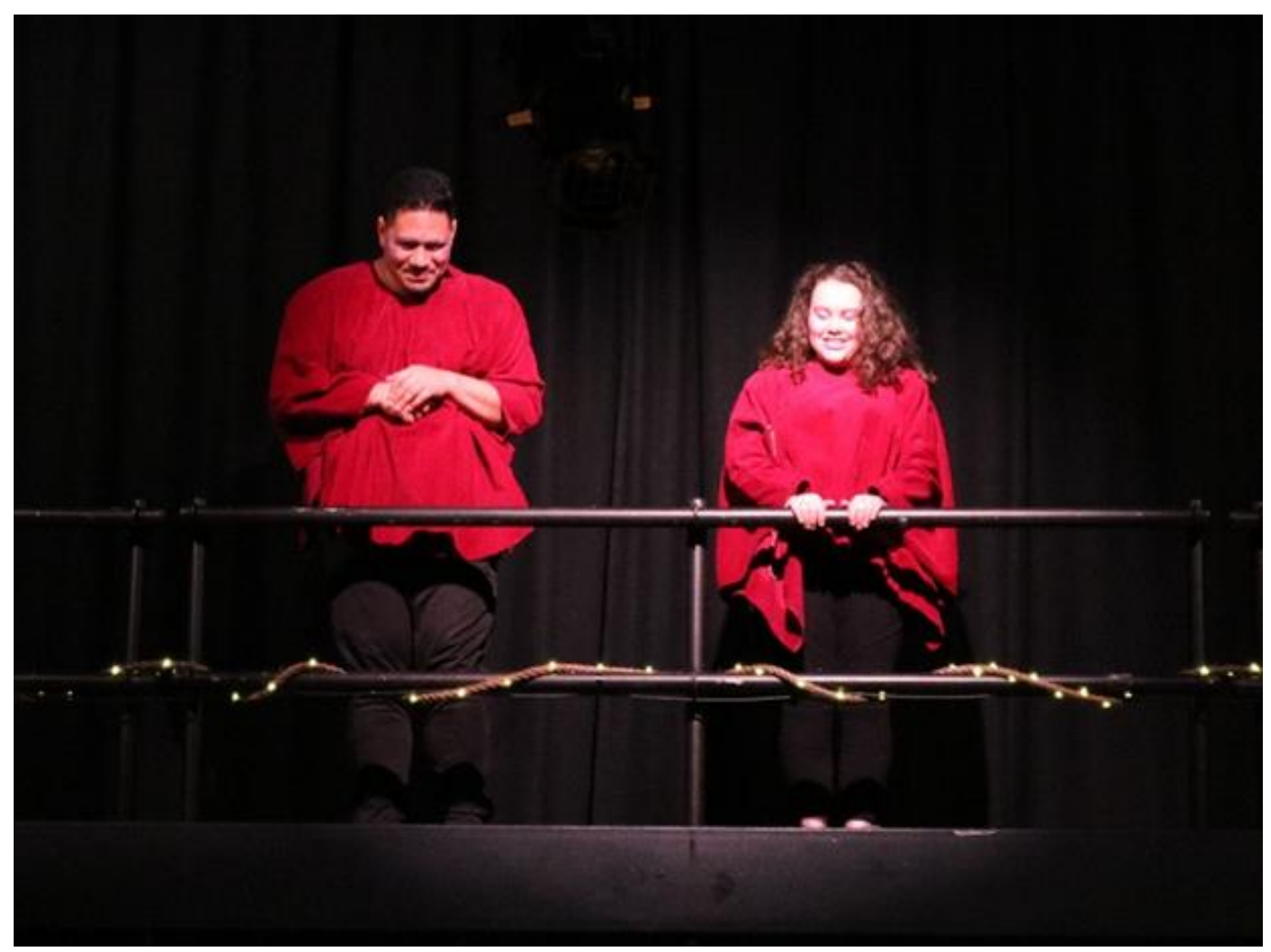

Figure 83: The Guides.

The Guides were also popular characters in the play. The children referred to them as "The Big Bosses" and "The King and Queen of Owt". (Tawa School Feedback. 29 Sept. 2017) Illuminations had decided early on that there needed to be some sort of powerful figures in the world of Owt that would challenge Bea, Alex, and Sam. These characters evolved slowly at first and several ensemble members made offers of what type of characters these powerful figures might be. In one rehearsal Janaye and Daz improvised the characters by utilising their performance strengths of rapping and hiphop dance. The characters suddenly felt very alive and the class responded 
enthusiastically to Janaye and Daz's interpretations. I was excited by the characters that they created. It was only later that I considered the politics of casting Janaye, who is Māori, and Daz, who is a Samoan New Zealander, in such distinctive roles from the other actors. Specifically, how this casting had the potential to reinforce problematic ideas about the representation of cultural difference. Janaye had been consistently articulate about her identity and ethnicity throughout the devising process and in her post-show reflection she vented some of her frustrations:

I talked a lot about diversity while we were devising and I know some of my classmates found it laborious and unnecessary, and I do accept that it's on the forefront of my mind almost all the time in a theatre space and I unnecessarily sometimes burden myself with how I'm being perceived and what we're representing and the wider implications - and I fully accept that most audiences watching don't really care or think about it half as much as me - it's a pressure I load on myself (Henry).

This caused me, a Pākehā New Zealander, to reflect on whether I had sufficiently supported Janaye in the devising process. The Illuminations group were predominantly Pākehā New Zealanders, three identified as New Zealand Māori (Janaye, Corey and musician Joel), one as Samoan-New Zealander (Daz) and one as Filipino (Cassidy).

Ethnicity and identity politics are a prevalent social discourse in New Zealand. The representation and marginalisation of our indigenous people continues to be confronted in the New Zealand theatre industry. However, there is still a long way to go. As Tainui Tukiwaho asserts in his 2020 article "Fight Against Systemic Racism Not Over": 
although things are working in [our] favour right now, it doesn't mean there isn't still work to do when it comes to systemic racism within the current arts funding system...You know, a kaupapa Māori theatre is thriving in our current climate but in saying that (we don't get) as much money as Pākeha companies who have less responsibility than we do. (Tukiwaho)

It is a contentious and at times deeply uncomfortable discourse, not just in New Zealand; the 2020 "We See You White American Theater "movement in the USA also recognises similar challenges (“We See You W.A.T.”).

New Zealand institutions, including Victoria University of Wellington, are required to abide by New Zealand's founding document, The Treaty of Waitangi or Te Tiriti o Waitangi ('The Treaty in brief'). The University's relevant statute requires adherence to the principles, of Kāwanatanga (governance), Rangatiratanga (Māori autonomy and self-determination), Kōwhiringa (options), Mahi tahi (partnership), Kaitiakitanga (protection), Whai wāhi (participation), Rite tahi (equality) and Whakaoranga (redress) (Te Tiriti O Waitangi Statute 1). Victoria University's Theatre Programme Director Nicola Hyland explains how these principles are integrated into the programme:

The VUW Theatre programme are committed to the Treaty's guiding principles of participation, protection and partnership; striving for autonomy, selfdetermination and inclusivity for students in all practical work. We aim to create work which supports the realities of Māori students and encourage all students to draw on their own worldviews in original practice-led projects. Māori students are invited to participate but not to "represent" all Te Ao Māori and our 
inclusive focus means that students should never feel compelled to explain or stand in for their cultural communities. (Hyland)

Reflecting on Janaye's experiences of feeling that the class found her discussions about diversity "laborious and unnecessary" (Henry), I realise that often I chose to ignore the identity politics that appeared in the group. This perhaps saw the Māori and Pacific students being alienated by this production. This alienation is something that I became aware of retrospectively and I acknowledge that in this instance I was not following best practice. The experience, however, has made me consider new ways of working, to embrace principles of Mahi Tahi (partnership) and Rite Tahi (equality) such as getting a cultural consultant or working with a kaumatua to have open discussions about representation during rehearsal. In the student production I directed following THEA311 (Black November 2018) for example, I employed a Māori practitioner to work as a dramaturg and to specifically research and identify Māori politics relating to the process and the play.

Although I was not following best practice in this instance, I was, however, aware that the casting of Janaye and Daz as antagonist characters in In The Attic may have political implications. Janaye reflected on this:

I don't know if you remembered but originally I wasn't a guide, the guides were the part that interested me the most from an acting perspective because I love playing characters that have a lot of subtext AND because I was aware that maybe University was perhaps the only space ever where two not white people could play the villains and not be absolutely ripped to shreds for it - I mean there were other not white people in our show but when you put two not white people as villains it kind of innately becomes political and when getting cast I think about these kinds of things as well but I thought uni was the perfect space to 
explore and try not to worry too much about that aspect because I have the rest of my theatre career to worry about that. (Henry)

Janaye's understanding that The Guides were the characters that were the most "interesting" to play, full of "subtext" and "depth" relates to ideas of Tino Rangatiratanga - Māori autonomy and self-determination - (Te Tiriti O Waitangi Statute 1) that she demonstrated by taking on this role, regardless of the potential political implications. Furthermore, I observed that the more Janaye and Daz developed the characters, the less 'villainous' they became. Instead, The Guides became the most powerful and most high status characters, and the smartest people in the room. Despite my lack of recognition of the identity politics at play in the group, the way that Janaye and Daz determined to play the roles and then created the characters to be powerful and smart demonstrated a level of self-empowerment in the process. The committed and energetic way that they played The Guides, made them popular with the children as indicated in the verbal and written feedback after the trial Showing. " $"$ " [I wanted to play] The King- because he was funny and cool." "I found the rapping parts really cool and exciting."'" (Tawa School Feedback. 29 Sept. 2017)

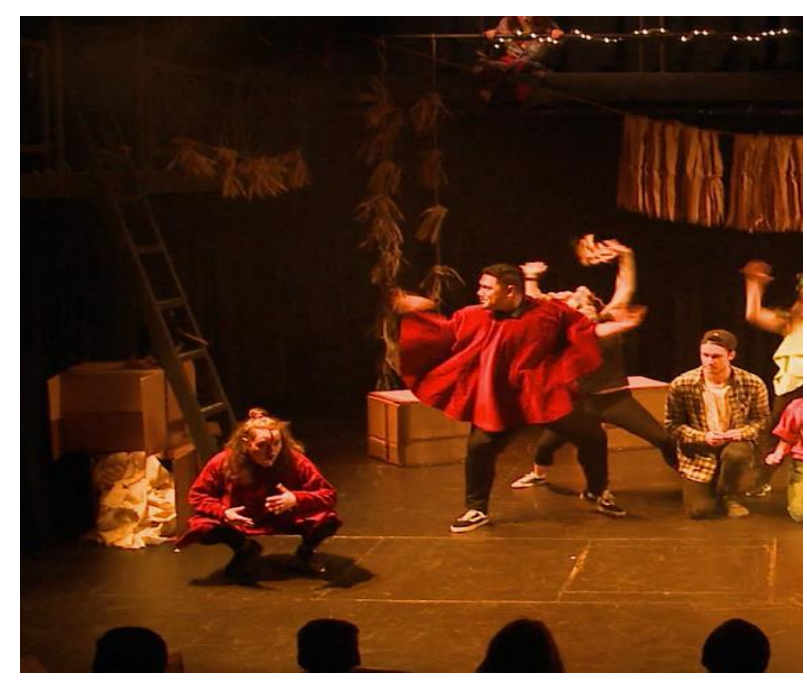

Figure 84: Janaye and Daz 


\subsubsection{The Music}

In the Attic integrated a variety of music styles, composed and directed by MFA Student Joel with the support of Corey. Styles such as rap, hip hop, musical theatre, and classical piano were all utilised throughout the play and were successful in engaging the Tawa School children, "[my favourite part was...] When the King and Queen started rapping." "When they were rhyming." "I loved the singing and dancing." "[They were] Good Rappers" (Tawa School Feedback. 29 Sept. 2017).

I consistently use music as a key element in my productions. As much as possible I will use live music so that the musicians and the actors can work in a symbiotic way. This is particularly useful in devising work, as the actors and the musicians both can lead the process, make offers and present different ways of storytelling. Music, as Pope states, can be another method of non-verbal storytelling:

Having musicians as part of the creative process incorporates a non-verbal layer that is inherently whimsical and incredibly powerful in evoking responses from the performers who are "in conversation" with the music throughout their actions. In turn, the playing by the creative team also impacts the musicians and a dialogue of call and response is often the result. The music has a powerful ability to promote creative play and dramatic ideas often emerge as the musicians become active participants in the whimsical playing. Again, the musicians do not enter the devising process with "things" they have prepared to play, rather, they respond musically to the activity of the makers and then become generative themselves as they introduce new ideas into the play (Pope 15).

Renowned Wellington composer Tane Upjohn Beatson, my collaborator on the 2015 production of Kiwi Moon for Capital E, advocates music as a powerful storytelling tool 
that creates emotional connections and paints mental pictures: "I love writing music for stories because it requires you to dream outside the realm of the known, to immerse yourself fully in a moment or a character, and seek out a story's beating heart, that unique thing that makes it important to tell" (Upjohn-Beatson).

Music adds another dimension to the storytelling and often evokes emotions and feelings in an audience in a way that words can't. It is for this reason that I regularly use music as a key component in my work, in particular in TYA work. In the Attic was no exception and Joel provided a variety of tunes during the exploration and generation phases for the actors to experiment with. As we began to distil and streamline the action, he created a soundtrack that went throughout the show. Joel's musical contributions at times followed, and at other times led, the devising work. His music also helped define the characters. As Daz articulates, it became another beneficial devising tool:

Something I've really enjoyed about this devising process so far, is Joel just playing around on the piano! It actually makes a difference having him play music because not only does it set the mood, but I even feel that it helps me (and the other actors) create and play; because he's given us something to work with (Gagau).

An example of this symbiosis was in the creation of The Police People. Serendipitously, Gemma and Natalie arrived one day at rehearsal both wearing striped shirts. This sparked an idea from Joel that they might be French. He played a quirky FrenchCabaret style of music that inspired the two actors, who had not originally conceived the policeman as French, to adopt French accents and create exaggerated walks. 
Sometimes Joel's music was in the background, used to enhance and create the atmosphere of a scene; at other times, it was at the forefront of the scene, used to help tell the story. For example, when Natalie and Georgia M wanted to create a pair of mysterious and eerie 'Light Creatures' that spirited away the children's light, they worked intensively with Joel to create the scene. Sometimes their choreography would inform the music and at other times the music would inform the choreography, demonstrating a symbiotic process that resulted in a sinister and mysterious scene, that some of the Tawa children described as, "cool and interesting" (Tawa School Feedback. 20 Sept. 2017).

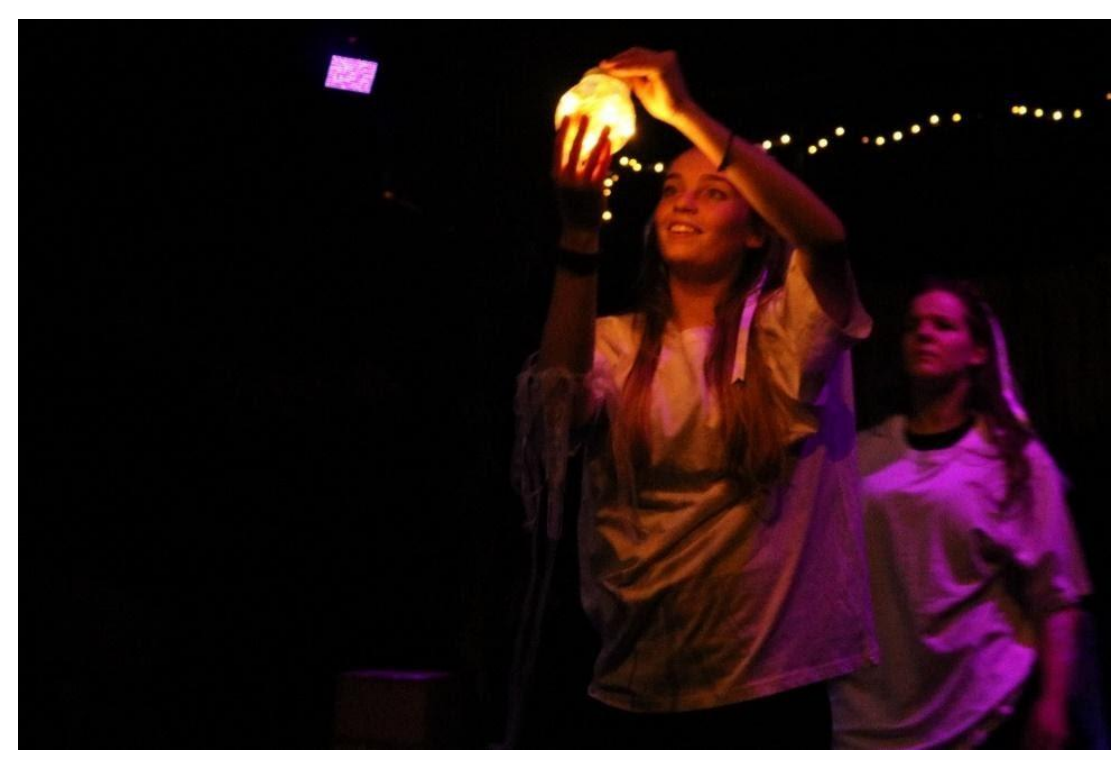

Figure 85: The Light Creatures.

In feedback received after the showing one of the children suggested that the play should have, "less music, more talking-because in some scenes you didn't know what they're doing." Another suggested we "take out the rapping" (Tawa School Feedback. 20 Sept. 2017). However, the majority of the children commented positively on the integration of music throughout: 
The strongest act ... were the songs and the most interesting was The Binders one.

I liked the songs.

I enjoyed the Big Bosses because they were good rappers.

The rapping part [was] the strongest. (Tawa School Feedback. 20 Sept. 2017)

The songs were mostly used as a dramaturgical device to clarify or move the story along without directly telling the audience through dialogue. The clearest example of this was in the first song, "Welcome to Our World." When Alex asks "Ah where are we?" The Owt creatures break into a song that explains where they have landed, as well as the ideology of the world:

\section{Verse 1}

Welcome to our world

Please come and step this way

We hope that you will like it here

(we hope that they will stay)

Welcome to our world

The locals call it OWT

O DUB TEE come follow me

You'll love it here no doubt

\section{Chorus}

Welcome to our world

Step inside and play

Something's really happening

We think that you should stay

(repeat chorus) 


\section{Verse 2}

There's no need to be afraid

There's no need to fear

It may seem a little strange

But we all have a pair

We find the best things come in twos

Why would you be one?

When you have someone by your side it's always much more fun.

\section{Chorus (Repeat)}

\section{Rap (By Guides)}

I'm from the Oh Dub Tee

You don't do it like we

We sing and dance and wake up again just to do it again

If you're lost in the woods and you need a hand

If you want people to come together for a band

Like a collection, or we're a group of creatures

Coming together, we've got something to teach ya

Yo, we got mad power

Yo we make the regulars cower

Yo, join us and be a two

Together I know we'll come through

\section{All}

Welcome to our world

Step inside and play

Something's really happening

We think that you should stay

Welcome to our world 
Come see what we're about

Our strange and weird collective

Together we are OWT

(Palmer, and Class of THEA 311.)

This song, with its rap and hip-hop influence, was effective in not only engaging the younger members of the audience but also in setting the world of the play and providing key exposition by explaining the world to the three main characters. An observation from Daz's final workbook discussed how the character he was creating had similarities to himself and how empowering he found this as a performer:

It was real fun, and kinda made me feel like this character isn't too far off from who I am. Or at least, it has a really fun and "hype-man" aspect that I love being as well!... a lot of the stuff I suggest are said in jest - but they end up making it on there and it ends up being really cool. I really like that! I'm starting to appreciate what I have and what I can offer... this entire devising process has really had me thinking, that I really tend to hold my tongue when I have ideas or suggestions... mostly because I'm scared of being rejected. But it's been refreshing realising that what I have to offer, is special; that what I think could be really stupid, other people actually find funny or cool. I love it! (Gagau)

Janaye noted how she was a freestyle rapper and that "it felt quite natural that rap was built into whatever character I played because it was integral to my devising process, as well as the fact that Daz was an excellent hip hop dancer which made the transition logical" (Henry). The rapping and dancing perhaps, as one reviewer noted "added a sense of modernity to the show" (Hope), and was particularly appealing to many of the 
children. "The best moment of that show was when the King and Queen did a rap at the end ...I am a big fan of rap songs" (Tawa School Feedback. 20 Sept. 2017).

\subsubsection{The End}

I think the play was absolutely amazing, the ending had me biting my nails. I needed more. I can't wait to see the end product (Tawa School Feedback. 20 Sept. 2017).

As outlined earlier, in rehearsal the group could not agree on how to end the play, so decided to turn to their test audience for inspiration. At the trial showing, we stopped the performance at a moment of climax and asked the children how they thought we should finish the play. We received a variety of responses, such as:

Flying in the briefly mentioned and unseen Swimmy the goldfish to save the day;

Yek escaping Owt with them;

Yek's twin arriving;

Alex and Sam taking over Owt;

Bea having to choose to save one twin;

The characters waking up and thinking it was a dream, but it wasn't.

(Tawa School Feedback. 20 Sept. 2017)

The majority of the class, however, expressed a desire to see an 'epic battle' scene in which Bea and Yek are freed. We then mooted the idea of an unhappy or uncomfortable ending, as had been suggested by some children when we first visited Tawa School. The children reiterated that they would still like this to happen, so we opened up a discussion about one of the three children characters remaining in Owt. The bulk of the children approved, however since they held differing opinions on if this should be Bea 
or one of the Twins, we decided to get them to vote. The majority of the Room Four children voted to leave one of the twins in Owt. However, we chose to leave the decision about which twin would remain until we were back in the rehearsal room, preserving the element of surprise for Room Four children that attended the final production. Subsequently, In The Attic got the dark and surprising conclusion we thought its audience wanted: only Sam and Bea return from OWT, while Alex's fate is left unknown.

Fascinatingly, when some of the Tawa children returned to see the final version performed for public audiences, they were surprised by this ending, and not all were satisfied. Some demanded a sequel and stated that it wasn't 'fair' to leave the play openended. These children's reactions revealed that perhaps they thought they wanted an unhappy ending, but in reality this was disturbing to them. Further consideration revealed that by ending the play on a moment of tension and unhappy uncertainty we had only fulfilled part of what the Tawa children had articulated. We had given them an unhappy and unresolved ending, but had not given them hope for the characters beyond the ending and the reassurance that everything would be okay in the end. Significantly though, after observing several impassioned demands for a sequel and fielding 'what happens next?' questions, I realised that although the open-ending in In The Attic was challenging, it created space for extensive audience discussion. Specifically of what had happened to the twin that was left behind, what would happen next and what would a sequel look like. This reiterated to me the importance of giving a pre-teen audience agency to make their own meaning from what was being presented, as opposed to spoon-feeding them a pre-determined conclusion. This reinforced the discoveries in Moonlight where the image-based narrative gave children agency to make their own meaning from the poetic images. 
Significant to note was that, in contrast to the language-lean, openly poetic module structure advocated by Brown for performances aimed at younger children, a pre-teen audience were able to create their own meaning-making within a complex character-driven narrative. This discovery suggests that children of different ages feel more agency viewing a theatre work when there is space left for their own interpretations and reading of the work, and the method of achieving this space can be tailored to suit specific aged children.

\subsection{But What Does It Mean?}

From our trial showing and discussions with the Tawa School children, it became obvious that we were engaging our young audience in a variety of ways. The university students were able to take the children's feedback and return to the rehearsal room to finish creating the play. They were more confident with what would engage the audience, had solid ideas on how to end the play, and were happy that their test audience had responded positively and enthusiastically to their work. It was therefore interesting to note after the public performance of the play, industry reviewer John Smythe questioning the underlying 'purpose' of the play with his review titled: But What Does It Mean? Smythe gave some personal interpretations of his own about the 'purpose' of the play: “Never explore anywhere alone (including your own imagination)? Two is good but three is not? Obey the rules imposed by strangers but at the same time trust no-one?" (Smythe). To me, this indicates Smythe's preconceived notion that all TYA needs to be educative or at least have a moral message. Another reviewer interpreted the play as: "being brave and doing the right thing when need be; it's about individuality and standing out from the crowd; and it is a challenging story for young audiences, as not all will end happily" (Spence). I decided to return to what the children thought after the trial showing. Notably, they had not seen the entire play 
at this point but were still able to articulate a variety of interpretations of what they had experienced:
A box that teleports to a new world;
Getting back home;
Two is better than one;
Teamwork and how everyone should have a friend;
[They] find themselves in another world full of evil and good;
Having an adventure;
Twins/ [It's] about having a twin;
Travelling to a different land and learning about their world;

Never being alone. (Tawa School Feedback. 29 Sept. 2017)

The majority of the children answered the question "What do you think the story was about?" with an arguably literal understanding of the play which could be summed up as: The children were trapped in a strange world; they had an adventure and they needed to get home. Another key observation in the feedback session after the first showing was that not all the children understood everything. It was a joy to see the children debate different things that happened and fill each other in on moments they may not have immediately understood. For example, some children immediately understood that the Police People were taking photos of audience members that looked similar because they were looking for twins, however this was a revelation to others. Similarly, some quickly realised that Owt spelt backwards was Two, while others needed an explanation from their peers. There were several exclamations of understanding in the post-show discussion where children debated different interpretations of the show. To me, this demonstrated one of the strengths of the show. 
The group had not spoon-fed a didactic or patronising message for the children to take away. Instead, they had provided an ambiguous and complex puzzle that engaged the children in heated and excited discussions. This is the territory that Brown is aiming for with his work; even though the maker understands what the narrative is, the audience interprets it in their own unique way (Brown in Palmer, "Thea 311.34"). It was liberating to note that even though one of our adult reviewers seemed bothered by the lack of a clear moral message, this was not something that concerned the children, either at the trial showing or after the full performance. In contrast, many seemed to relish the opportunity to debate, to construct meaning, and to create a further narrative from what they had experienced. Many children, for example, got caught up with the fate of the twin's pet, Swimmy the goldfish. They loved the idea that Swimmy could become a three-dimensional character that would come and save the three friends. This demonstrated the way that even a briefly mentioned character can stick in the minds and imaginations of children and from there they can weave a complex and imaginative narrative of their own - similar to River's imagining of the end of Moonlight as discussed in Chapter Eight. One student suggested that "Swimmy should become a robot and then come back to Owt and save them." Perhaps this was also a further demonstration of the children wanting to have some 'power' over the ending. We considered adding Swimmy into the play, but feeling pressured by time eventually rejected the idea. In retrospect, it would have been interesting to note how the children responded if we had taken them up on this offer. Such creative responses from the children did, however, lead me to disagree with Smythe's sentiments that "responsibility needs to be taken for what the audience might make it all mean" (Smythe). Very few of the children we interviewed after the trial showing and after the final performance articulated being concerned by a lack of clarity, or confused by the complex underlying themes of the play. On the contrary, they seemed to revel in meaning-making and openly discussing their different points of views. 


\subsection{Summary}

The Tawa School children were an important part of the creation process of In The Attic. The initial session gave the students clarity of form and content that would engage their audience. The realisation that their audience was not that much younger than they were assured them that there was no need to simplify the work. The trial showing was hugely beneficial both for ascertaining what was working, and also for determining what Illuminations needed to spend the next few weeks on in revising and refining. It was reaffirming for the students to hear from their audience that the piece was engaging and entertaining and that most wanted to return to see the final version. This was ultimately more important and useful than being reassured by me. Aside from the first scene, In the Attic departed from The PaperBoats' model of image-based modules with a poetic and open narrative. However, the group discovered that the complex character-based narrative they had created was able to engage their young audience and leave space for discussion and debate:

I did not feel bored at any moment through the show. I was way too excited and slightly confused by it all to be bored. (Tawa School, 20 Sept. 2017)

After the university term concluded, and two weeks after the children had seen the show, I decided to make one final trip to Tawa School by myself. Using the same written template and discussion methods we had used in the feedback session at the trial showing with Room Four, I re-interviewed a small group of Room Four children and interviewed a group of children who had not been part of the making process and had seen the show solely as a public performance. I made yet another crucial observation. The children that had seen the play but had not been involved in the making process appeared not to be as engaged or excited by the play as the students that had been part of the project. The children outside of Room Four found the play 
entertaining and enjoyable, but the experience didn't seem to elicit the number of superlatives and positive feedback we received from the Room Four children, who were still excited about the play two weeks later. What this suggests to me is that by engaging the children in the creation process, they were ultimately more engaged and excited about the play. They related to the characters more, were highly engrossed in the story, and were freely able to discuss alternative endings and sequels. Overall, they gave the impression that they felt some ownership of the play, and relished not only their part in making it but also the relationships they had formed with the students and the insight they had obtained about working on a play. Furthermore, the process of making In The Attic emphasised methods in the devising room that were useful in creating an empowered young ensemble. These included using autobiographical story, allowing them to discover narrative and characters through play and improvisation, and encouraging them to problem solve and work through their own insecurities and anxieties.

The process was by no means easy and without conflict. The challenges we experienced around casting, identity politics, and general anxiety all contributed to moments of disagreement and tension. I found that the Illuminations group were, on the whole, the more challenging group to work with. I believe this was because of the specific make-up of the group. Many of the students were extroverted, opinionated, and not afraid to articulate their thoughts, while others were quiet and reluctant to share their ideas or disagree with their louder collaborators. Often this left me, and my instincts for peace-making-feeling anxious that the students, in particular the quieter ones, were not happy. As a result, I, at times, steered the group away from conflict and hard discussions that may have been beneficial to have confronted, such as identity politics. As discussed earlier in this chapter, I also didn't always give the students enough autonomy in the process, resulting in them looking to me to solve problems. 
However, my approach as peacemaker, encouragement of the students to articulate their anxieties and to find agency within the process were intended to create a warm productive devising environment, one where different approaches could be tested, discussed and where the students could analyse their own process:

It is extremely clear to me what I struggled with. I had a hard time shifting from the play side of things into the work side of things. I assumed decisions had to be made as soon as possible in order to make progress... These struggles also turned into the most rewarding part of the process. I learnt how to let things happen in a performance, how to step back from analysing and how to stop criticising my own performance abilities and focus on using the abilities I have to help create a stronger ensemble. (May "Final Report")

The analysis of this process has led me to become more aware of how I respond to challenges in a group, and has encouraged me to make changes in my practice. The successes and challenges of the making of both Moonlight and In The Attic have led to the creation of a unique intergenerational, collaborative devising model that encourages agency and empowerment for all those involved in the making, this model is discussed in more detail in Chapter Ten. 


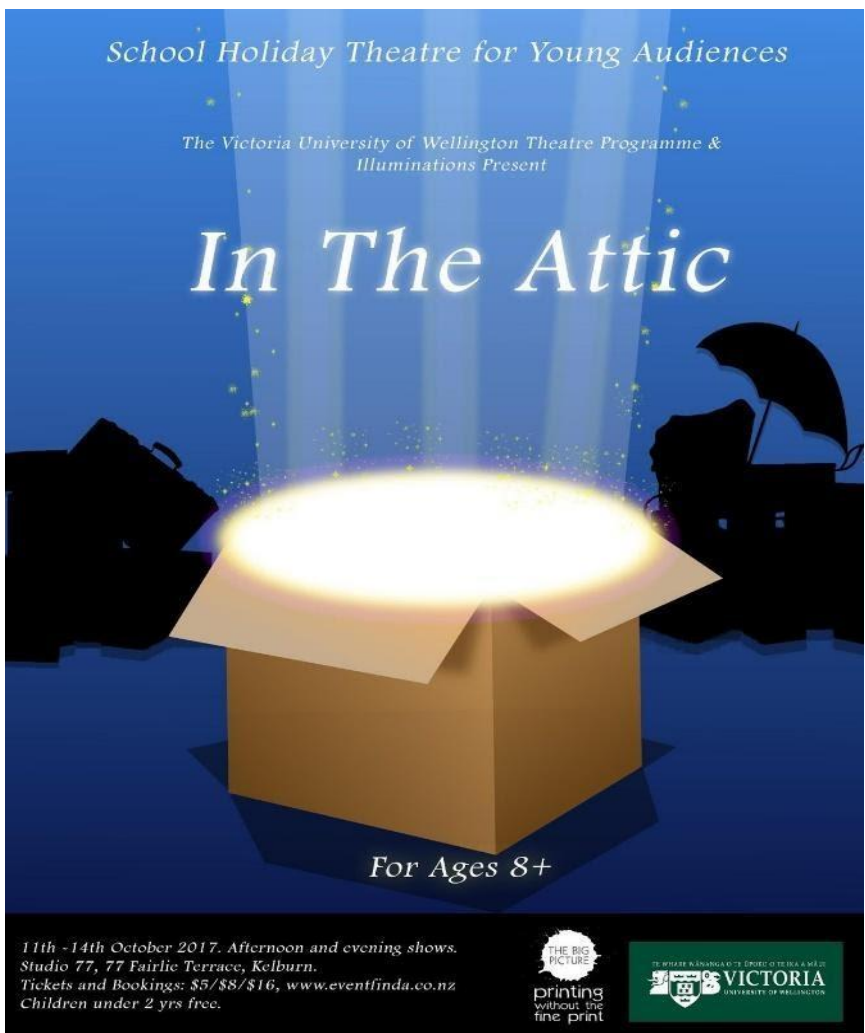

Figure 86: Poster for In The Attic, THEA 311 Production 


\section{Conclusion}

\section{Activating Change- Key Findings, Contributions to Knowledge and Recommendations}

This research evolved from a place of frustration, specifically with the ingrained undervaluing and underfunding of TYA in New Zealand. Early drafts of this thesis were filled with rage against this perceived marginalisation of children, young people, and practitioners within the sector. Embarking on a $\mathrm{PhD}$ gave me the time and resources to investigate the field; a chance to identify ongoing challenges and make recommendations for strengthening the sector. I investigated literature related to TYA and conducted a deeper analysis of the genre and mapping of the scope of TYA work happening nationwide. The second phase of this $\mathrm{PhD}$ was an arts research project, an investigation into ways that devised theatre can increase agency in children and young people so that they feel more empowered and can claim ownership of the work. I utilised the arts research paradigm in both my theory and methodological approach of the project.

This chapter examines the four specific research enquiries I articulated at the beginning of the thesis. It draws on the outcomes of my research to outline key findings, convey the contribution to new knowledge and to make recommendations.

\subsection{Key Findings}

10.1.1 The current practices of practitioners involved in making theatre by/with/for young people in Aotearoa/ New Zealand. 
The 2019 Survey on Theatre for/by/with Young Audiences identified, categorised, and mapped the predominant TYA companies - those that employ paid creatives and create theatre for/by/with young people - in Aotearoa/New Zealand. The majority of the thirty -seven professional companies identified, produce theatre for and with young audiences. This is opposed to theatre work by young audiences, which is the domain of youth theatre companies, of which eight were identified in this survey, and after-school drama classes, schools, and educationally-based projects. There was a response rate of $73 \%$ of participants. I acknowledge that this is an evolving and changing list, with companies emerging and folding regularly. The TYA companies are spread geographically throughout New Zealand with the majority situated in the main centres: Wellington, Auckland and Christchurch. Many of New Zealand's smaller regions benefit from touring companies based in these main centres.

A closer investigation of the TYA field revealed a diversity of work. Some companies create shows based on fairy tales or children's books, and others create original material. There are a range of methods employed in the creation of TYA works, such as: devised, scripted, working with young people in the room, and rehearsing in schools. However, there are still widely held but ill-informed assumptions about what constitutes 'good' children's theatre, by practitioners and also the wider public. This can lead to stereotypes and clichéd tropes being employed in both the programming and presentation of TYA.

The road to the validation of TYA as a vital part of the theatre industry, has been long and frustrating. Some of the recurring challenges recognised are that TYA is often not given the same status as adult theatre, the programming and performing of some TYA suggests a marginalisation of child audiences, and TYA is regularly viewed as a job for emerging, rather than established, theatre practitioners. An investigation into 
international literature showed that these are global challenges for TYA practitioners. However, because of the lack of academic discourse, analysis of practice and quality control measures in New Zealand, TYA practitioners articulate feeling consistently isolated and undervalued. They desire a greater sense of community and connection with other TYA practitioners, more sustainable career paths, safer working conditions, better remuneration and greater validation from the theatre industry and the wider New Zealand Community (Palmer).

An examination of the way TYA is currently funded in New Zealand revealed that the infrastructure and funding models do not support the creation of TYA to a sustainable level. I acknowledge that changes have been implemented in 2020 and recognise that these have recently - as of July 2020 - been changed again as a response to the COVID 19 crisis. However, the lack of funding remains one of the most consistent frustrations by practitioners in the field.

There have been several attempts to establish an advocacy organisation for TYA in New Zealand (Wake, "Text message to author"). Predominantly this has involved Jenny Wake's tireless work in championing the sector, and promoting the advocacy and networking of ASSITEJ international. In 2020 PAYPA (Performing Arts and Young People Aotearoa) formally registered as a trust and advocacy body. The board - Jenny Wake, Marianne Taylor, Lynne Cardy, Tim Bray and myself - are currently creating a strategic plan for strengthening the TYA industry. This research has identified the need for, and desire by TYA practitioners for, such an advocacy board. It has specifically identified areas that need attention, such as funding, validation, pastoral care, and tertiary training. It has identified several commonalities and frustrations between companies and independent practitioners. These key findings present a detailed 
overview of the field that I hope will be useful to PAPYA as well as the predominant funding organisation CNZ.

\subsubsection{An investigation of standards by which quality in theatre by/with/for young people can be recognised, communicated and encouraged.}

I examined New Zealand and international research to situate my study. One of my key findings was the absence of a New Zealand-centric model to measure the quality of TYA work. This deficit makes it challenging to ascertain if TYA work is 'good,' or if it marginalises and patronises a young audience. My experience of attending several TYA shows led me to believe that there are varying standards of TYA in New Zealand. From my experience as a high school Performing Arts teacher, I recognise that teachers can be inundated by a volume of material about theatre shows, with no clear method to ascertain their quality.

Ways that quality in adult theatre can be ascertained -for example through robust discussion, research, and critical reviews - are generally understood in New Zealand. However, a lack of discourse, research, and reviewing in TYA means that quality in TYA is harder to recognise. Relating to this is the reality that adults are generally leading the research and debate where quality and programming of TYA work is concerned. Consequently, the perception of quality is viewed through an adult lens, not through the eyes of the young people it is intended for. Through investigating methods that other countries use to define best practice and quality TYA, I believe one way for New Zealand to increase the value and perception of TYA work is to implement a set of quality control measures. This has the potential to educate adults, teachers, practitioners and children to recognise the difference between quality TYA and TYA that is marginalising, patronising, and relies on tired tropes. 
This thesis recognises that 'quality' is an imprecise and subjective term. I found that interrogating the programming and presentation of TYA was a way to analyse the genre more robustly. I discovered that instead of relying on preconceived assumptions of what constitutes quality TYA - such as fairy tales, audience interaction, and loud, fast-paced action; there are several methods worthwhile considering, such as engaging with some method of quality metrics platform, such as the UK-based 'Culture Counts' (Chapter Four), which demonstrates an awareness of the benefits of measuring quality. The key finding is that it is important to have a method of defining quality, such as a critical response framework that aligns with New Zealand's unique cultural, economic and geographic conditions.

It is worth considering methods that other countries use: for example, the Danish Culture Crew programme, where young people are encouraged to recognise quality, and programme TYA work for their schools. This has the added benefit of empowering young people in selecting, making decisions and recommending work to adults.

An examination of the major tertiary institutes for actor training in New Zealand - Toi Whakaari, Unitec, and The Actors Programme - revealed little institutional training in and recognition of TYA work. All three institutes disclosed that they employ little or no specific training in the field of TYA, or much dedicated exposure to TYA work. I recommend that this is a key issue that is addressed in PAYPA's strategic planning.

Another key finding that developed into a critical research enquiry for the arts research section of this thesis, is that engaging with the demographic or intended audience has the potential to increase the quality of the work. Engaging with children in 
the making of the work is integral to some TYA companies, but others had very little or no engagement with children. This indicates that these companies are creating TYA work based on their own assumptions of what children will respond to and engage with, and would benefit from support and encouragement to interact with children during their making processes. Perhaps through collaborations similar to the one undertaken by THEA 311.

Considering a young audience's extended engagement (Reason, The Young Audience 111-112) with TYA work is another way of enhancing quality. This can be challenging to quantify. However, practitioners are less likely to create a forgettable, insincere work when an enduring, extended and authentic engagement with a young audience is achieved. These findings contribute to an overview of the sector and the identification of some of the main challenges in creating TYA work in New Zealand. My

research project was designed to identify, examine and test strategies that could be used to limit these challenges and to validate and invigorate the TYA sector in New Zealand. By utilising a practice-based research methodology and my own strengths as a teacher and director, it aimed to identify strategies that could guide practitioners to make professional, quality theatre, genuinely accessible for Young People.

\subsubsection{Identifying practical strategies for engaging a young audience in the process of the making of TYA work.}

Through interacting and consulting with the children at Tawa and Te Aro schools two key Childhood Studies theories were applied in this research. By applying a poststructural perspective (Nolan and Raban-Bisby 13), as well as drawing on an element of socio-cultural theory (Nolan and Raban-Bisby 9), the students and I were able to position ourselves as responsive researchers, and view each child involved as an 
individual. This ensured that we regarded every child as being worthy of their own unique opinions and valued what they were experiencing in the here and now. Furthermore, the creative project employed an intergenerational model within the devising process. Two groups of school children (aged 5-12) worked with a group of youth (aged 19-25) to create two original plays. (Moonlight and In the Attic) Through this research, we were able to identify several practical strategies for engaging a young audience.

The school-based interaction between the students and the children meant that the university students were able to gain direct insight into the: opinions, attitudes, views and viewing habits of the specific age-group they were making the work for. They did not work from misguided assumptions about what children were interested in, or wanted to see. Significantly the assumptions that the students had of what constituted 'good 'TYA (Palmer "Preconceptions of Children's Theatre"), were challenged by their interactions with the children. The children's viewing of and feedback on Moonlight and In the Attic, part-way through the devising process, was hugely useful for the students. The key findings most relevant to this enquiry are as follows;

1. A connecting force of 'Play' created a rich environment for the two groups to work together in and enabled a reciprocal-knowledge model. By observing and joining in with the children through a series of drama games, the students began to have their pre-conceptions about children challenged. The children shared their ideas openly and generously, and this engagement early on in the devising process, compelled the students to consider a range of ideas in both form and content when it came time to create their plays.

2. Inviting the children into the university to watch a trial-run of the show was an active way to test different methods the students employed in the devising room. 
They were able to observe the children's responses at each point in the performance and ask them directly for feedback after the show. The students were also able to test the extended engagement of the children, specifically, what continued to resonate with them several days after they had seen the show. The students then considered each moment of the show, by referring to the feedback and their experience of the trial performance. This helped them to shape the plays in ways that engaged their audience.

3. Trialling with a child audience, ensured that the students could test levels of audience participation, 'breaking-the-fourth-wall', voice levels, levels of energy and in particular the engagement of the audience during each moment of the play. By noting the children's response to the showing, they were able to practice responding and adapting to an audience of children. It demonstrated to the students the importance of creating relationships with an audience. They noted how differently the children responded when they had the sense of being listened to and respected. It also raised the stakes for the students, and they were inspired to make quality work for the children, which encouraged them to respond more authentically to a live audience when they were performing. Finally, it allowed the testing of different forms of TYA such as: image-based modules with poetic and open narratives, language-lean and complex characterdriven narratives, which led to a greater consideration by the students of forms that would best engage their specific age group.

One of the key findings to come out of the project was the importance of creating each play for a specific age group. The reason I encouraged THEA 311 to focus on two precise age groups in the research came from my empirical experience of TYA companies defining their audience in a broad range of age groups. For example, Duffy Theatre shows are aimed at 5-12-year-old children. Catering to a broad age range can be 
very challenging. For example: what 5-year-olds might see as hilarious and entertaining may be viewed by a pre-adolescent child as patronising. For the entire THEA 311 class to interact with each different age group, this meant that they were able to experience the differences in maturity and engagement of different aged children. By clearly defining the age-range of our audience before making the plays, we were able to cater to the specific desires, needs and interests of that age group. This engagement led to understanding, and a fuller investigation into the differences in content and form that would appeal to each age group. Both production groups - Illuminations and Paper Bag Productions - were able to adapt the content and form of their pieces to meet the demands of their specific aged children.

The engagement with the classes had some benefits for the ownership by the children of the work. This was demonstrated at the public showings, in the way children from our test classes were keen to introduce their families to us and talk about what they knew was going to happen, or what had happened in the show. Also significant was the discovery that children that had viewed the public showings but had not been part of test class were not as invested in, or as excited about the shows. This led to an awareness that by engaging with the children in the making of the work, even only for three sessions, was beneficial in making them feel ownership and pride of the final piece, as well as facilitating deeper engagement with the work.

\subsubsection{Building a model for intergenerational collaborative devised theatre, that encourages agency and empowerment for all those involved in the making, presenting and viewing of the work.}

Employing an arts research model for the testing of my key research enquiries was beneficial for the development of a devising model that encourages agency and 
empowerment. Trialling in the rehearsal room, writing daily about my practice, and analysing each session meant that I was actively able to test ideas in 'best practice' of creating a devising ensemble. I applied autoethnographic principles such as Interactive Interviews (Ellis et al.6), and Community Autoethnography (Ellis et al.6), to analyse the outcomes of this practice, specifically by in-depth post-course interviewing with the class of THEA 311. This method of analysis elicited comprehensive feedback from the group involved, which was useful in understanding the effectiveness of different methods that were tested. Several key findings arose from this arts research project:

\section{Devising theatre has a multitude of benefits for a youth ensemble.}

I regularly find myself defending a degree in theatre as a valid vocational choice for young people. The skills and learning gained during an arts degree are often overlooked and undervalued. During our THEA 311 production period in 2017, the School of English, Film, Theatre, Media Studies and Art History at Victoria University of Wellington initiated a keynote session as part of their postgraduate day provocatively titled: 'The Humanities are Dead-Long Live the Humanities." I was asked to speak as a representative of the Theatre Programme and the following is an excerpt from my paper:

My students are coming in every day this mid-term break to work for up to 6 hours a day - this is expected - but not compulsory. They are spending the days on their feet away from screens (except for dedicated phone breaks.) They are spending them creating, playing, problem-solving, talking, debating, arguing.

There have been tears, there has been much laughter, there has been singing, tantrums, dancing, joy and at times despair. In other words, they are experiencing life and how to deal with life through being fully involved in the 
creative process. I don't expect that most of these students will go on to be actors, directors or designers. Some will, but more will take the skills they have learnt doing a humanities degree into the big, wide world. They are learning to be present in the world. They are learning the art of dealing with not getting what you want, of how to work collaboratively and willingly beside someone who drives you crazy. They are learning to be generous - when they are feeling tired, hungry and sick. They are learning to give other people credit for something they may have contributed to, to make other people look good, to be confident and make their own voices heard in a group of many voices. (Palmer, "The Humanities Are Dead.)

It was useful to be able to articulate the skills and attributes that a devising project can encourage in a group of young people. I found that by creating appropriate conditions in the devising room, this ensemble-devised project was worthwhile, enjoyable, beneficial, and helped guide the students into future careers. As well as more specific arts-based skills such as acting, set-design and stage-management, the students learnt skills in problem-solving, collaboration, time management, people management, conflict resolution, and project management. They learnt empathy and communication skills, and gained confidence and a sense of what it would be like to work professionally. It was reaffirming and delightful to communicate with the now-former THEA 311 students in May 2020. Two and a half years after the course concluded, most have shared with me their current careers and life paths, and how their theatre degree and THEA 311 shaped their world views and their post-university journeys:

There was a lot that I took away from devising. I learnt so much about myself as a creator and a team member, which has helped me to work on aspects of myself which I was not aware of before this course. I am now able to identify the types 
of people I enjoy working with, and those who I might try to avoid in my future, and having more confidence in having my own back, and not letting negative behaviours affect my view of a project. It taught me professionalism, and that things don't always go the way you might have thought, but that sometimes that's okay, because there are still things to be learnt from that. It taught me to be more open to play, and improvising - there were moments (such as the workshopping of the police characters with music) when the puzzle pieces just fit into place straight away, and that was usually when we just trusted ourselves and our scene partners and went with - usually the most ridiculous - ideas! (Revell)

Even if young people do not aspire to a career in the arts, there are still a multitude of learnings that can be useful through the model of devised theatre: "One thing I think I carry forward from the class, is how people work and act within a devising space. It has allowed me to strongly work with, especially, teenagers when conflict or power inequalities begin to show. "(Wills, "Re: Hello (AGAIN) THEA 311 of 2017")

This valuing of the way a devising process can help young people learn about relationships was important to recognise. As were the discoveries the students made about themselves:

I think THEA 311 was amazing as a platform to learn about myself and the people I was devising within the way we all work. I learnt so much about the things I would do in the future to make theatre and so much about the things that I was terrible at when it came to making theatre and working with people. (Rogers) 
The three months that the THEA 311 students spent together working on a collective goal, provided them with knowledge and skills that have been useful in their journey to adulthood and post-university life.

\section{Devising theatre for and with young people is challenging}

This project was a complex and at times frustrating process. Although much of the postshow feedback from the students was positive, there were many tears and moments of exhaustion. In Chapter's Six, Eight, and Nine I have outlined some of the many challenges in the devising processes that lay alongside the joys and successes. Having the opportunity to deeply analyse my practice has meant that I have been able to identify specific challenges to my directing practice. In particular, articulating that the process will be difficult at the beginning, and that conflict will undoubtedly arise, does not alleviate this happening. A better strategy is to have clear processes for giving and receiving feedback, and not to use these to avoid conflict or hard discussions.

My maternal approach to directing has many advantages, in particular in making a group feel relaxed, supported and able to create freely. However, this also leads an ensemble, in particular a young ensemble, to rely too heavily on the director. The challenge with this leadership model for me was that I tended to guide too much. By solving the students' problems, avoiding conflict, and alleviating their anxiety by reassuring them that 'it would be all right', I was enabling them to rely on me. I later identified this as being less empowering for the students than if I had allowed them to make their own mistakes. 


\section{An intergenerational collaborative model of devising theatre can instil Agency that leads to Empowerment for both groups.}

Developing a sense of agency and increasing empowerment, for the students and the children, in both the process and the product were key aims throughout the project. The challenge lay in how that agency could be achieved.

One challenge I found in THEA 311 was giving agency to the collaborators and simultaneously upholding the sense of order and progress needed for the group to feel safe and supported. One of the key findings has been that the group benefited from having a director. There was value in having me guide them, make hard decisions, encourage them to problem solve, and to uphold a sense of structure. Significantly, I needed to guide the group in an empathetic and non-autocratic way, by employing a process that allowed each ensemble member a chance to contribute, a chance to lead and make decisions. I had to communicate clearly and provide a solid structure and rehearsal environment that left room for authentic contribution from the participants. I utilised a variety of methods to ensure this such as:

Giving all ensemble members a forum to speak;

Writing a collective contract at the beginning of the process.;

Giving the group the autonomy to create their own rules;

Guiding the group to develop a critical response protocol and a method of feedback that ensured a balance of constructive criticism, but upheld their individual self-esteem;

Allowing the group agency over their roles and the final product by empowering them to change things they weren't happy with, and encouraging them to ask: what is best for the work? 
As the students learned to take autonomy over the creation of the work, I discovered that the more agency I gave them, the more ownership of the work they felt. It is gratifying for me to see how many THEA 311 students have continued to devise and have found the skills they learnt in the course invaluable to themselves in their teaching and devising processes. Corey, now a secondary school drama and music teacher, writes:

Looking back now at the paper and show I still have the best memories, as I got to create for such a long amount of time and really pushed myself as a stronger voice in a group, a skill that is so helpful to my career now. Especially after taking a step back and watching my students rehearse and perform [it]has really made me miss the acting and creating, it puts everything into perspective as how much I loved it (and consider children's theatre my speciality)" (Wills).

This project emphasised that in a pedagogical context, students need to be able to feel sufficient agency over a process so that they can employ it after they have left the classroom. However, there is a fine line between constantly reassuring the group and solving their problems, and allowing them to make their own mistakes. For students to transition from students of devising to devisors in their own right, as the director I needed to experiment with levels of support, guidance, and ownership at every stage of the process. The project highlighted the need to generate conditions in the rehearsal room that can allow the work to happen safely. An empathetic style of leadership, where emotion is encouraged and devisors feel they can safely experiment and fail, as well as firm guidance towards the end goal, inspires this delicate balance between process and product. 
As well as giving agency to the young people creating the work, an important part of the research enquiry was to explore ways to give agency to and empower the audience. Matthew Reason's extensive research into the ways that children as spectators can be empowered by their experiences of theatre-going was integral to my research. The initial engagement in the schools, the post-production workshops and feedback sessions were means we discovered that encouraged the audience to feel ownership of the work. We determined that engaging with the audience as part of the devising process ensured greater post-performance engagement and resonance. Reason suggests that:

Too often young people are merely exposed to theatre with little sense of personal investment in the ownership of the culture in question. Instead of being relevant to their lives, or perceived as being theirs, the experience is very much of culture as other-both in terms of content and form - and in this sense, it is worth little to them in their daily or imaginative lives. (Reason, The Young Audience 29)

We discovered that by going into the children's space, talking, playing with, and listening to them, we could more effectively create relevant theatre that they felt invested in. It is here that the value of theatre, that is produced specifically for children and young people, lies. Furthermore, by paying attention to the particular experience of being a specific age, the ability to respect the children's unique outlook on the world and their place in it is heightened. The resulting plays and analysis of the process demonstrated the effectiveness of this process. Even though we concluded that more time interacting with the children could have been beneficial to us, the limited time we spent with them positively impacted their agency and sense of ownership of the work. 
Giving collaborators and audience creative agency instils confidence and ownership of both process and product. It allows collaborators the space to fail, room for their voices to be heard and the confidence to feel they can achieve. By inviting an audience to help with the creative process, they are being employed as active rather than passive subjects. The theatre is not being made just for them but with them. By putting the audience at the centre of the work that we were making, the ensemble was constantly aware of them and the children were integral to the process of making the work.

The process for the young people and the children in my project, was an example of how creating theatre by and with young people can be challenging and empowering. Building this intergenerational collaboration took patience and required time for analysis and reflection. The careful development and nurturing of the intergenerational relationships broke down potential barriers and created a safe space where ideas could be shared reciprocally and respectfully. The collaboration with the children meant that the students kept their audience at the forefront of their minds during the devising process to validate and support the relationships they had formed. Using child-led provocations and gaining genuine feedback from the children about both the content and form of our plays, meant that the students created two new works that engaged, challenged and entertained young audiences. They learnt about the value of creating quality work for a young audience and simultaneously felt empowered by the experience:

I am incredibly proud of what we were able to create in such a short amount of time. The story, the sets, the music. I adore the end results of all our hard work, and it feels very sad to have to let it go. This show was the result of months of playing and creating with people I care for deeply. I will never forget how 
exciting and magical it all felt, even with moments of feeling lost and exhausted. It was all worth it in the end. (Himmelmoe, “Re: Hello (AGAIN) THEA 311 of 2017")

Being in THEA311 definitely impacted where I am now with my teaching. I find myself using the skills that we learnt about theatre and children every day. Being able to go into a school during our studies was one of the reasons I was sure that I wanted to become a teacher. (Cochrane)

Devising taught me a lot about how to react to pressure and that sometimes I take things too seriously! (May “Re: Hello (AGAIN) THEA 311 of 2017”)

THEA 311 absolutely influenced how I make art. Empathy, communication, and good creative boundaries are the backbones of my work. (McGuire).

I loved the whole entire show! (Tawa School Feedback)

\subsection{The Contribution to New Knowledge}

Candy's definition of Practice-Based Research asserts that claims of originality and contribution to knowledge can be demonstrated in the form of performance, and that while "the significance and context of the claims are described in words, a full understanding can only be obtained with direct reference to the outcomes" (1). This practice- based element of my research has resulted in the creation of two original plays for children: Moonlight - devised by Paper Bag Productions, and In The Attic- devised by Illuminations. 


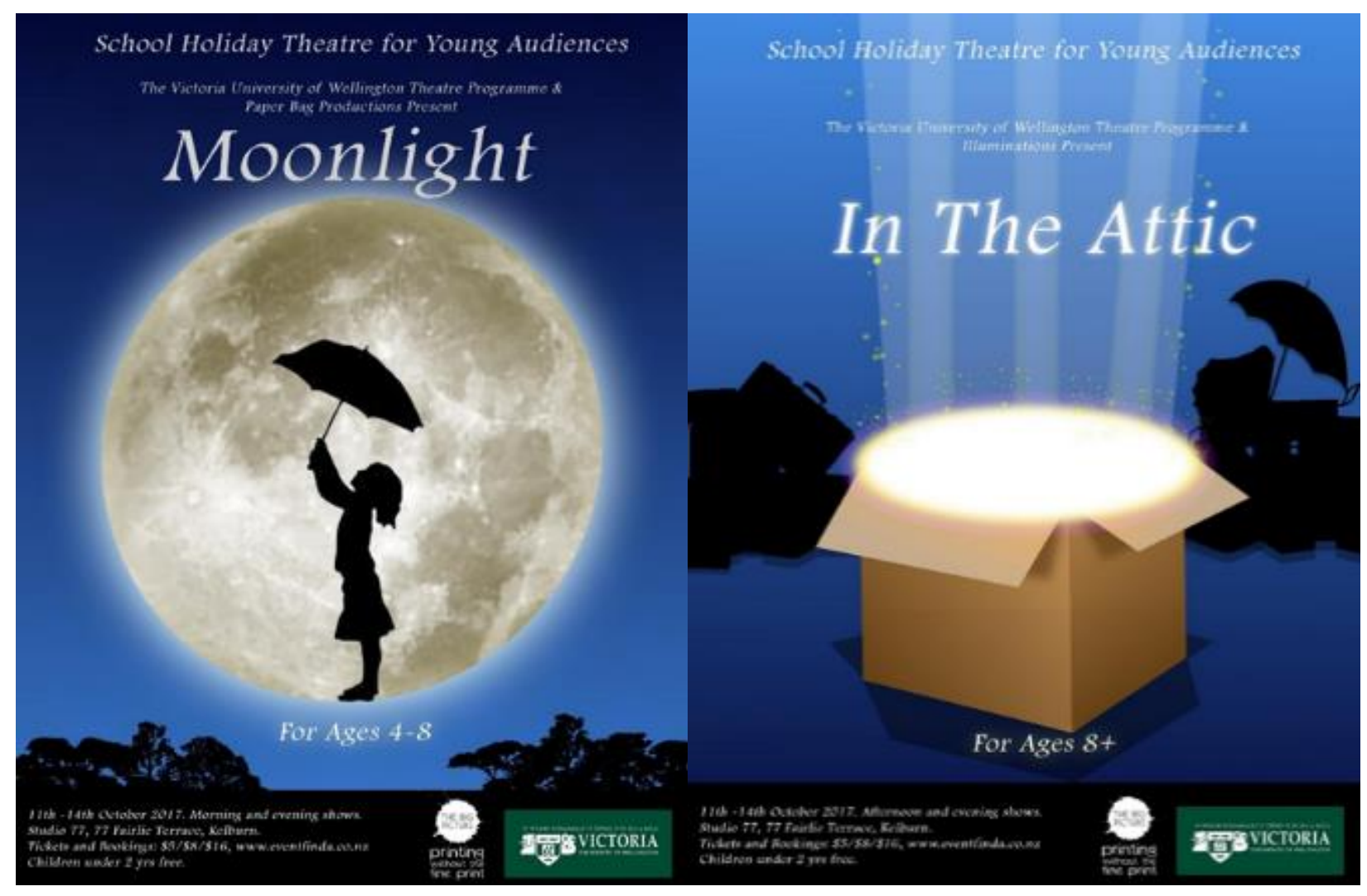

Figure 87: Posters for Moonlight and In The Attic, THEA 311 Production

The claim to originality comes in the form of these two new productions as presented in October 2017, as well as both works being available as stand-alone scripts. Although ideally the scripts should have another workshop or season before being made available for production, they are obtainable in their current state and production rights are available.

Mīharo (Working title) is a new play for children aged 3-7 that I am devising and directing with a group of established and youth practitioners. Following the creative principles of The PaperBoats project, it is a work that has evolved from the making of Moonlight and In the Attic. Two young performers (aged 22), are the key devisors and we will practice trailing the work with children for feedback. Currently, a 20-minute 
piece has been created and it will be workshopped in November 2020 into full production with the intent to tour in 2021.

Alongside the creation of original theatre works, the contribution of new knowledge within this research can be best described as:

- The synthesising and application of academic rigour to the data and findings of the status of TYA in New Zealand. Until this point, the position and state of TYA has been predominantly empirical. For the industry to move forward in its quest to become more valued and betterfunded, research on the historical and current status of TYA in New Zealand was needed, and recommendations made for how to achieve validation and greater status.

- Practical Strategies to engage a young audience, have been identified and actively tested.

- A model of an intergenerational collaborative devised theatre was created, one that outlines how to create a safe and yet artistically rigorous ensemble of young people, who have agency and feel empowered by the process and the product.

\subsection{Recommendations}

The press release for the public performances of Moonlight and In the Attic stated:

There seems to still be an attitude in New Zealand that Theatre for Young Audiences (TYA) is merely a 'filler' for a theatre company, a money-spinner, or something actors may dabble in before they get a 'real' job," says Palmer. "My aspiration with this research is to highlight ethical and effective practices, not only so that New Zealand children can experience consistently high-quality 
theatre encounters, but so that the field of TYA can take its rightful place as a fully respected, funded, integral part of the theatre ecology. (Revell)

Through this PhD journey, I have kept this aspiration at the heart of my research enquiries. Moreover, I have aimed to make this research purposeful and intend it to be used as a motivation to activate change. This research has highlighted best practice for working in TYA. It has identified methods to engage and respect a young audience and an ensemble of young people. It has articulated the importance of a pathway forward, to increase the perception and value of TYA in the wider industry.

To effectively champion and make change, the TYA industry needs advocacy. During the course of this research, the PAPYA board has been advancing to formalise their procedures and policies. One recommendation is that once PAPYA is formalised, it should invest resources into strategic planning for strengthening the TYA sector. The most important areas this research has identified that may serve to help strengthen the sector are:

1. More resourcing/funding for TYA. This includes better remuneration for creatives that aligns more strongly with New Zealand's living wage;

2. Ensuring that funding covers the entire cost of producing a show;

3.Making the funding system more transparent and fairer to both independent companies and larger theatre companies that are annually funded; 
4. Looking at ways to create a more sustainable TYA sector so that it is a genuine career choice for artists and that New Zealand children have access to a variety of theatre regardless of where they live;

5. A study into the creation of a centralised TYA booking system, touring agency or arts market (such as Denmark's April fest or as a branch of the PAANZ network that deals with predominantly adult theatre work.) This could include a set of quality control measures (such as 'Quality Principles') that assist educators, parents and young people to recognize high-quality TYA work;

6. Promotion of the value of theatre for/by and with young people. Including education around the value of viewing and participating in theatre;

7. Challenging the marginalisation of TYA work within the theatre sector and the assumptions, tropes and stereotypes made in the programming and presentation of the work. Methods to achieve this promotion could include, discussions how venues can best support TYA work, encouraging more robust viewing and critiquing of TYA work- including by young people; as well as greater support, discussion and funding of scenographic elements in TYA work;

8. Greater academic discourse, promotion of TYA and inclusion at awards events. As well as challenging funding bodies and government agencies to see that the value of TYA lies not just in monetary value, but in the way being involved in performing arts can improve confidence, make young people feel good about their lives and help them to make new friends (Creative New Zealand 6);

9. Encouraging Tertiary institutions, especially actor training programmes, to take TYA seriously and to consider methods of training and educating students about the value and the scope of TYA work in New Zealand; 
10. Inspiring TYA companies to investigate ways that they can- or continue toput children at the centre of their work, specifically by encouraging testing and interacting with children in the making of the work;

11. Facilitating an annual meeting- on line or person- for the TYA sector to share stories and strategies, feel a sense of connectedness, and discover mutually-beneficial ways to engage with more Maori and Pasifika TYA companies;

12. To examine the best practice in improving the pastoral care and wellness of TYA audiences and practitioners. In particular, young practitioners that tour TYA work.

\subsection{Conclusion}

This research has been the ultimate devising process. And like all devising processes, it has had ups and downs, frustrations, and moments of joy. It has made me cry and explode with happiness simultaneously. I have regularly been reminded of a devising philosophy that I often share with students and that is useful for summarising the process of my PhD journey:

This is awesome

I am awesome

This is tricky

This is shit

I am shit

This might be ok

This is awesome

I am awesome

(Originally Zuppa Theatre Co. Adapted by author) 
The research has reinforced my love and admiration for young people, for theatre and for dedicated theatre practitioners who against many odds, continue to create beautiful and meaningful work for young people. It has re-energised me to strengthen my advocacy and creative work in the sector, in the pursuit of New Zealand's recognition as a world leader of quality and sustainable theatre for/by/ with young people. 


\section{Works Cited}

“A Profile of Creative Professionals 2019." Creative New Zealand, 2019, www.creativenz.govt.nz/development-and-resources/research-and-reports/a-profile-ofcreative-professionals-2019.

Adolph, Kate. Feedback Arts Grants 2018. 3 June 2018.

Amey, Sunny and Rees, Nonnita. "New Zealand." International Guide to Children's

Theatre and Educational Theatre: A Historical and Geographical Source Book, edited by Lowell Swortzell, Greenwood Press Inc, 1990, pp. 243-247.

Amey, Sunny. Personal Interview. Conducted by Kerryn Palmer. 12 Feb. 2019. Andersen, Jennifer. “Not-so-Fringe-Interactive-Childrens-Theatre-Takes-Centre-Stage." The Conversation, The Conversation Media Group, 15 Sept. 2015, theconversation.com/not-so-fringe-interactive-childrens-theatre-takes-centre-stage47362. Accessed [date].

Arlander, Annette, et al., Performance as Research: Knowledge, Methods, Impact. 1st ed., Routledge, 2017.

“ASSITEJ - International Association of Theatre for Children and Young People." ASSITEJ - https://www.assitej-international.org/en/. Accessed 10 Nov 2018. Atkinson, Laurie. "Actors and acting - The rise of professional theatre, 1960 to 1980." Te Ara - the Encyclopaedia of New Zealand, www.TeAra.govt.nz/en/actors-andacting/page-3. Accessed 3 March 2020.

“Auckland's Leading Theatre for Children." Tim Bray Productions, 2019, timbrayproductions.org.nz/. 
Bailin, Sharon. "Theatre, Drama Education and the Role of the Aesthetic." Journal of Curriculum Studies, vol. 25, no. 5, Sept. 1993, pp. 423-32. DOI.org (Crossref), doi:10.1080/0022027930250502.

Banks, Hannah. A Stage of Our Own: Women Devising Theatre in Aotearoa New Zealand. 2019. Victoria University of Wellington, PhD dissertation.

Barton, Bruce, editor. Collective Creation, Collaboration and Devising. 1st ed, Playwrights Canada Press, 2008.

Barton, Bruce "Wherefore PAR? Discussions on a line of flight." Performance as Research: Knowledge, Methods, Impact, edited by Annette Arlander et al. Routledge, 2017. (1-19)

Barrett, Estelle, and Barbara Bolt. Practice as Research: Approaches to Creative Arts Enquiry. 2019. Open WorldCat, doi.org/10.5040/9780755604104?locatt=label: secondarybloomsburyCollections.

Baskerville, Delia. Personal Interview. Conducted by Kerryn Palmer. 21 Mar. 2020. Beck, Jamie et al., Delineating a Spectrum of Research-Based Theatre. Qualitative Inquiry Vol 17, Issue 8, [publisher], pp. 687-700

Bennett, Stuart. Theatre for Children and Young People: 50 Years of Professional Theatre in the UK. Aurora Metro, 2005.

Bennett, Susan. Theatre Audiences: A Theory of Production and Reception. Psychology Press, 1997.

Bishop, Gavin. Kiwi Moon. Penguin New Zealand, 2008.

Blackburn, Stephen. "Respect the Work" Playmarket Annual New Zealand Theatre.

Playmarket. 2016

Boal, Augusto. Games for Actors and Non-Actors. 2nd ed, Routledge, 2002.

Bogart, Anne, and Tina Landau. The Viewpoints Book: A Practical Guide to Viewpoints and Composition. 1st ed, Theatre Communications Group; Distributed by Consortium Book Sales and Distribution, 2005. 
Bourke, Lennie, and Mary- Ann Hunter. Not Just an Audience: Young People

Transforming Our Theatre. Platform Papers, Currency House Inc, 2011.

Bray, Tim. "Re: Research on Theatre for Young People in New Zealand." Email received by Kerryn Palmer, 19 Feb. 2018.

Broster, David. “Being There" Theatre for Young Audiences: A Critical Handbook, edited by Tom Maguire and Karian Schuitema. Institute of Education Press, 2012, pp. 117- 128. Brown, Dave. Personal Interview. Conducted by Kerryn Palmer. 18 March 2016. --- “Principles." The Paperboats, 22 Feb. 2015, www.thepaperboats.com/principles/. Accessed 15 Oct. 2019.

--- "4. Provocations and Insights." The Paperboats, us10.campaignarchive.com/?u=2ba79bb2f9fc8ef13f5d05661\&id=bf44f67f97. Accessed 16 Oct. 2019.

--- “7. Provocations and Insights.” The Paperboats, https://us10.campaignarchive.com/?u=2ba79bb2f9fc8ef13f5d05661\&id=963e0138a1. Accessed 18 Oct. 2019.

--- "8. Provocations and Insights." The Paperboats, us10.campaignarchive.com/?u=2ba79bb2f9fc8ef13f5d05661\&id=5d110d6eff. Accessed 20 Oct. 2019.

--- “16. Provocations and Insights." The Paperboats, mailchi.mp/46ed5adcce47/slowbrewing. Accessed 25 Oct. 2019.

---“The Paperboats.” The Paperboats, www.thepaperboats.com/. Accessed 15 Oct. 2019.

---“Re: Hi.” Email received by Kerryn Palmer, 18 Oct. 2019.

--- “Re: Questions Thoughts and Musings from Cold NZ" Email received by Kerryn Palmer, 31 July 2019.

---"Re: Questions around Value in Australian TYA." Email received by Kerryn Palmer, 22 June 2020.

Burnett, Kathryn. “Art Smarts: That Totally Sux!” The Big Idea, 22 Apr. 2019, www.thebigidea.nz/stories/arts-smarts-that-totally-sucks.

Calder, Amalia. "Re: Question For You." Email received by Kerryn Palmer, 4 Mar. 2019. 
Capital E National Theatre for Children. Capital E. www.capitale.org.nz. Accessed Mar. 2018

Candy, Linda. Practice Based Research: A Guide Creativity \& Cognition Studios, www.creativityandcognition.com, Accessed August 2020.

Cardy, Lynn. Phone interview. Conducted by Kerryn Palmer, 26 June. 2020.

Cauers, Constance. “A New Fragile Language Directing Young

Actors." IXYPSILONZETT - Magazine for Children and Young People's Theatre, no. 01 2020, May 2020, p. 25.

“Changes to Creative New Zealand's Grants Programme." Creative New Zealand, 8 Mar. 2019, https://www.creativenz.govt.nz/news/grants-programme-changes-2019.

Christophersen, Catharina, et al. The Cultural Rucksack A National Programme for Arts and Culture in Norwegian Schools. Published by Fagbokforlaget for Kulturråd Arts Council Norway, 2015, p. 67,

https://www.kulturradet.no/documents/10157/a7464045-2cb6-4988-9948-ffd834508a5d.

Colbert, Shannon. Phone interview. Conducted by Kerryn Palmer, 31 Jan. 2018.

Common Sense Media, “Why-Is-My-Kid-Obsessed-with-YouTube-Stars.”,

commonsensemedia.org/youtube/why-is-my-kid-obsessed-with-youtube-stars. Accessed 24 Sept. 2019.

Corsaro, William A. The Sociology of Childhood. SAGE Publications, 2014.

“Creatives In Schools.” Education.Govt. NZ, New Zealand Government, 27 May 2020, https://www.education.govt.nz/our-work/publications/budget-2019/creatives-inschools/.

Creative New Zealand, New Zealanders and the Arts. Summary Report, 2017, pp. 1-26.

---“ Report on the Priority By, With and For Young People”, November 2017

Cruz, Cassidy. "Final Workbook." Transcript. June 2017.

“Cubbin Theatre." Theatre for the Very Young." cubbin.co.nz/. Accessed May 2019.

Culture Counts - We Value Culture. https://culturecounts.cc. Accessed 1 June 2019. 
Davidson, Carl, and Martin Tolich, editors. Social Science Research in New Zealand: Many Paths to Understanding. 2d edition, Pearson Prentice Hall, 2003

Davis, Lindsay, et al. "Intergenerational learning through play". International Journal of Early Childhood, vol. 34, no. 2, pp.42-49.

Davis, Jed H \& Mary-Jane Evans. Theatre, Children and Youth. Anchorage Press, 1987.

Davis, Jed \& Tom Behm. “Terminology of Drama/Theatre with and for Children: A Redefinition." Children's Theatre Review, vol. XXV11, no. 1, 1978.

Davis, John. "Re: Actor Training at UNITEC in Auckland." Email Interview. Conducted by Kerryn Palmer, 24 Sept. 2019.

“Decile Ratings." Education Govt NZ, education.govt.nz/school/funding-andfinancials/resourcing/operational-funding/school-decile-ratings/. Accessed 10 Oct. 2019.

DeMarinis, Marco. The Semiotics of Performance. Indiana University Press, 1993 Department of Education, Employment and Workplace Relations (DEEWR). “Belonging, Being \& Becoming: The Early Years Learning Framework for Australia." Australian Government Department of Education, Skills and Employment, Department of Education, 2009, docs.education.gov.au/documents/belonging-beingbecoming-early-years-learning-framework-australia.

Derby Mark. 'Theatre companies and producers - Early theatre companies', Te Ara - the Encyclopaedia of New Zealand, TeAra.govt.nz/en/theatre-companies-and-producers/page1. Accessed 3 Mar. 2020.

Douglas, Kitrina \& Carless, David. "An Invitation to Performative Research". Methodological Innovations Online. Vol. 8, pp. 53 - 64. 10.4256/mio.2013.0004.

Drydyk, Jay. "Empowerment, agency, and power", Journal of Global Ethics, vol. 9, no. 3, pp. 249 - 262, DOI: $\underline{10.1080 / 17449626.2013 .818374}$. Accessed 30 June Dubatti, Jorge, and Nora Lia Sormani. "The taboos in theater for children and young people." Iberoamerican Theater Bulletin for Children and Youth, vol. no.9, Nov. 2011, pp. 377-94. 
Dufault, Monica. "Re: The Valuing of TYA in Canada." Message to Kerryn Palmer. 24 June 2020. Email

Duffy and the Book Bus Adventure. By Cathryn Monro. Directed by Kerryn Palmer. 2011. Duffy Theatre. National tour.

Edmond, Murray. "'Plays and Playwrights - Plays of the Mid- and Later 20th Century'," Te Ara - the Encyclopedia of New Zealand, 22 Oct. 2014, teara.govt.nz/en/playsand-playwrights.

Elam, Keir. The Semiotics of Theatre and Drama. Psychology Press, 2002.

Ellis, Carolyn, et al. "Autoethnography: An Overview." Forum: Qualitative Social Research, vol. 12, no. 1, Jan. 2011, qualitativeresearch.net/index.php/fqs/article/view/1589/3095.

Eluyefa, Dennis. "Children's Theatre: A Brief Pedagogical Approach." Arts Praxis, vol. 4, no. 1, Feb. 2019, pp. 79-93.

"Empowerment." Oxford Learner's Dictionary, Oxford University Press, 2020, https://www.oxfordlearnersdictionaries.com/definition/english/empowerment Accessed 20 June 2020

England, Alan. Theatre for the Young. Macmillan, 1990.

Esslin, Martin. An Anatomy of Drama. T. Smith, 1976.

Etchells, Tim. Certain Fragments: Contemporary Performance and Forced Entertainment. Routledge, 1999.

Felseghi, Alexandra. "Devised Theatre - a Short Introduction", Studia Ubb Dramatica, LXII, 1, 2017, p. 61 - 68. Accessed Aug.2018

“Find Funding." Creative New Zealand, 10 Oct. 2019, creativenz.govt.nz/findfunding/funds.

Flanagan, Victoria. “Children's Fantasy Literature: Why Escaping Reality Is Good for Kids." The Conversation, 3 Mar. 2014, theconversation.com/childrens-fantasy-literaturewhy-escaping-reality-is-good-for-kids-22307. 
Freire, Paulo. Pedagogy of the Oppressed. 30th anniversary ed, Continuum, 2000.

Friedman, Susan. “Theater, Live Music, and Dance: Conversations about Young Audiences." YC Young Children, vol. 65, no. 2, Mar. 2010, pp. 36-41.

Forbes, Annie. "From Animism to Digital Animation: Puppetry in New

Zealand/Aotearoa." Australasian Drama Studies; Melbourne, Vic., Oct. 2007, pp. 10-17.

Fortier, Mark. Theory/Theatre an introduction. Routledge, 1997.

Frost, Robert. “The Road Not Taken." Poetry Foundation, 2019,

poetryfoundation.org/poems/44272/the-road-not-taken.

"Funding Boost for Arts in Schools Helps Keep Creatives in Work." New Zealand Government, 12 June 2020, beehive.govt.nz/release/funding-boost-arts-schools-helpskeep-creatives-work. Accessed 25 June 2020.

Gagau, Daniel. 9 May 2017, finalworkbook311.tumblr.com/.

Gardner, Lynn. “Why Children's Theatre Matters.” The Guardian, 23 Oct. 2013, theguardian.com/stage/theatreblog/2013/oct/23/why-childrens-theatre-matters.

---“Theatre Assessment 2009.” Arts Council England, artscouncil.org.uk/sites/default/files/download file/

Theatre_Assessement_2009.pdf. Accessed Feb. 2019.

“Glossary." Creative New Zealand- Arts Council of New Zealand Toi Aotearoa, 2019, creativenz.govt.nz/find-funding/glossary.

Gluzman, Yelena. "Research as theatre (RaT)Positioning theatre at the centre of PAR, and PAR at the centre of the academy.". Performance as Research: Knowledge, Methods, Impact, edited by Annette Arlander, et al. Routledge, 2017, pp. 105-132

Graham, Bob. How to Heal a Broken Wing. 1st U.S. ed, Candlewick Press, 2008.

Graham, Scott. "The Frantic Method." Frantic Assembly, Frantic Theatre Company Limited, 2020, franticassembly.co.uk/the-frantic-method

Graham, Scott, and Steven Hoggett. The Frantic Assembly Book of Devising Theatre. Routledge, 2009. 
Graham, Tony." Building-Based Theatre. Theatre for Children and Young People: 50 Years of Professional Theatre in the UK, edited by Stuart Bennett. Aurora Metro, 2005, pp. 76-89 Gray, Carole. “Inquiry Through Practice: Developing Appropriate research strategies.” No Guru, No Method? Discussions on art and Design research, University of Art and Design, UIAH, Helsinki, Finland._carolegray.net/researchpapers.html 1996 Goldberg, Moses. Children's Theatre: A Philosophy and a Method. Pearson Education Canada, 1974.

Golding, Yasmin. “Final Report.” Transcript. June 2017.

Gopnik, Alison. “The Real Reason Children Love Fantasy.” Slate, 20 Dec. 2005, slate.com/culture/2005/12/children-s-love-of-fantasy.html.

Halprin, Lawrence. RSVP Cycles: Creative Processes in the Human Environment. George Braziller, 1970.

Harcourt, Peter. A Dramatic Appearance: New Zealand Theatre 1920-1970. Methuen, 1978. Hardie, Yvette. Vision with Action Can Change the World I ASSITEJ International. https://www.assitej-international.org/en/2019/02/vision-with-action-can-change-theworld/. Accessed 28 July 2020.

Harvey-Zahra, Lou. Growing Children Thriving Children. Floris Books, 2019. Haseman, Brad. A Manifesto for Performative Research. Media International Australia incorporating Culture and Policy, theme issue "Practice-led Research" (no. 118) pp.98-106. 2006

---"Rupture And Recognition:" Identifying The Performative Research Paradigm. Practice as Research: Approaches to Creative Arts Enquiry. edited by Estelle, Barrett and Barbara Bolt. Open WorldCat, pp 147-

1572019. https://doi.org/10.5040/9780755604104?locatt=label:secondary_bloomsburyColl ections

Head, Nicole. “Re: Urgent Reply” Received by Kerryn Palmer, 25 Sept. 2017. Email. 
Heddon, Deirdre, and Jane Milling. Devising Performance: A Critical History. Palgrave Macmillan, 2006.

Henderson, Gary “Re: Hello" Email Interview. Conducted by Kerryn Palmer, 7 Mar. 2019.

Heße, Julia Dina. “Perform Direct(Ing) Responsibility: How Directors Can Make the TreatyWorld a Better Place." IXYPSILONZETT, no. 01/2020, May 2020, pp. 14-16.

Himmelmoe, Pelle. 'Te Aro School Reflection.' Transcript, 24 July 2017.

Hine, Michelle. "Re: Questions around Actor Training." Email Interview. Conducted by Kerryn Palmer, 18 Aug. 2019.

Hodgson, Jo. "Spellbinding Wonder and Heart." Theatreview, 13 Oct. 2017, theatreview.org.nz/reviews/review.php?id=10638.

Hooks, Ed. "The Willing Suspension of Disbelief." In Acting, Education and Training I Blogs: Ed Hooks - Acting for Animators, 10 June 2011, awn.com/blog/willingsuspension-disbelief.

Hope, Emilie. "THEA311: Collaborative Production Presents In the Attic and Moonlight." Salient, 16 Oct. 2017, salient.org.nz/2017/10/thea311-collaborativeproduction-presents-in-the-attic-and-moonlight/. Accessed Nov. 2017 Houlahan, Mike. “Changing Perceptions of Children's Theatre.” The Evening Post, 1994.

Howard, Pamela. What Is Scenography? Second edition, Routledge, 2009.

Howells, Abby. "Reasons To Be Cheerful." Playmarket Annual New Zealand Theatre Hyland, Nicola. "Re: Theatre Programme's Treaty Commitments." Received by Kerryn Palmer, 19 July 2020. Email.

“Imaginate- What We Do.” Imaginate, Imaginate.org.uk/about/what-we-do/. Accessed Jan. 2020 
Ireland, Vicky. "Working with a Children's Writer- a Directors Journey." Theatre for Children and Young People: 50 Years of Professional Theatre in the UK, edited by Stuart Bennett. Aurora Metro, 2005, 148-153

"ITYARN." ITYARN, the International Theatre for Young Audience Research Network, http://www.ityarn.org/. Accessed Jan. 2021.

Jackson, Anthony, and Chris Vine, editors. Learning through Theatre: The Changing Face of Theatre in Education. Third edition, Routledge, Taylor \& Francis Group, 2013. JasonSmith, Kate. "Re: Questions Around CAT." Email Interview. Conducted by Kerryn Palmer, 19 Mar. 2020.

Jeffers, Oliver. How to Catch a Star. Harper Collins London, 2015.

Johnston, Chris. House of Games: Making Theatre from Everyday Life. Routledge; Nick Hern Books, 1998.

Keane, K \& Ombler, F." He Waka Eke Noa" kupu.maori.nz/kupu/He-waka-eke-noa. Accessed 10 Oct. 2015

Kelsey- Sugg, Anna. “Children's Books Are Tackling Dark and Taboo Topics. Morris Gleitzman Says That's Nothing to Be Afraid Of." ABC News, abc.net.au/news/2019-0921/tackling-taboo-topics-in-childrens-books-morris-gleitzman/11497552. Accessed 21 Sept. 2019.

Kerrigan, Sheila. The Performer's Guide to the Collaborative Process. Heinemann, 2001. “Kids Shows 2018/2019." The Court Theatre, 2019 2018, courttheatre.org.nz/about-thecourt/past-seasons/kids-shows-20182019/.

"Kidzstuff" https://www.kidzstufftheatre.co.nz/. Accessed 3 June 2019.

Kiwi Moon. By Rachel Callinan, directed by Kerryn Palmer. Capital E National Theatre for Children. March 2015, The Hannah Playhouse, Wellington

Landy, Robert J, and David Montgomery. Theatre for Change: Education, Social Action and Therapy. Palgrave Macmillan, 2012. 
Lorenz, Carol. "The Rhetoric of Theatre for Young Audiences and Its Construction of the Idea of The Child.' Youth Theatre Journal, 16:1, 96-111. 2002.

Lowe, Susan. “The Bookbinder Review." All Edinburgh Theatre.Com, 7 Aug. 2015, alledinburghtheatre.com/the-bookbinder-review-edfringe-five-stars/. Accessed March 2020.

Luckman, Melanie. “Re: Question Around Age Groups.” Received by Kerryn Palmer, 10 Apr. 2019. Email.

Lynch, M. “Re: Playmarket." Received by Kerryn Palmer, 4 December 2017. Email.

Maclaurin, Ali. "A Collective Approach to Designing for Devised Theatre." Studies in Theatre and Performance, vol. 20, no. 2, Jan. 2000, pp. 97-104. DOI.org (Crossref), doi:10.1080/14682761.2000.10807028.

Maguire, Emma. “Re: Hello (AGAIN) THEA 311 of 2017". Received by Kerryn Palmer, 13 May 2020. Email

Maguire, Tom, and Karian Schuitema. Theatre for Young Audiences: A Critical Handbook. Institute of Education Press, 2012.

Maori Proverbs Whakatauki. maori.cl/Proverbs.htm. Accessed 15 October 2019 Markham, Sally. Report on Young People and The Arts- For Creative New Zealand. Markham Arts, 2012

Matthews, Steve. Getting into The Act- Communication Through Drama. G P Books, 1988.

May, Georgia. “Final Journal Entry” Transcript, 24 October 2017.

... “Final Report” Transcript, 24 October 2017

... “Re: Hello (AGAIN) THEA 311 of 2017". Received by Kerryn Palmer, 13 May 2020. Email

McMaster, Brian. "Supporting Excellence in the Arts from Measurement to Judgement". Department for Culture, Media and Sport, Jan. 2008, 
webarchive.nationalarchives.gov.uk/+/http:/www.culture.gov.uk/images/publications/s upportingexcellenceinthearts.pdf.

Mermikides, Alex, and Jackie Smart, editors. Devising in Process. Palgrave Macmillan, 2010.

Milne, Geoffrey and Hunter, Mary Ann. Young people and performance in Australia and New Zealand [Paper in: Young People and Performance in Australia and New Zealand. Hunter, Mary Anne and Milne, Geoffrey (eds).] [online]. Australasian Drama Studies, No. 47, Oct 2005: 3-13.

"Mind The Gap Intermediate vs Middle Schools." Education Central, educationcentral.co.nz/mind-the-gap-intermediates-versus-middle-schools/. Accessed Sept. 2019.

Minifie, Paul. “Re: Questions Around CAT.” Received by Kerryn Palmer, 21 Mar. 2020. Email.

Ministry for Culture and Heritage. 'The Treaty in brief', URL:

https://nzhistory.govt.nz/politics/treaty/the-treaty-in-brief, updated 17-May-2017, Accessed 7 Jan. 2020

---'Treaty FAQs', URL: https://nzhistory.govt.nz/politics/treaty/treaty-faqs, updated 23 May 2017, Accessed 7 Jan. 2020.

Ministry of Education. Te Whāriki He Whāriki Mātauranga Mō Ngā Mokopuna o Aotearoa Early Childhood Curriculum. New Zealand Government, 2017, education.govt.nz/assets/Documents/Early-Childhood/ELS-Te-Whariki-EarlyChildhood-Curriculum-ENG-Web.pdf.

Monro, Briar. “Re: Hi and Quick Question.” Received by Kerryn Palmer, 21 May. 2019. Email

---"Re: “Funding Update.” Received by Kerryn Palmer, 13 July. 2020.

Moore, James W. "What Is the Sense of Agency and Why Does It Matter?" Frontiers in Psychology, vol. 7, no. 1272, Aug. 2016, doi:10.3389/fpsyg.2016.01272. 
Moston, Doug. Coming to Terms with Acting: An Instructive Glossary. 1st ed, Drama Book Publishers, 1993.

Murray, Simon and John Keefe. Physical Theatres: A Critical Introduction.

Routledge,2016

Nacey, Finnian. "Re: THEA 311". Received by Kerryn Palmer, 13 November 2017.

Email.

Nelson, Robin. Practice As Research In The Arts. Palgrave, 2013

“New Fund Focusing on Arts in the Regions to Open in 2020." CNZ, NZ Govt, Nov. 2019, https://www.creativenz.govt.nz/news/new-fund-focusing-on-arts-in-the-regionsto-open-in-2020.

"Ngā Toi ā Rohe". Creative New Zealand- Arts Council of New Zealand Toi Aotearoa, 2020 https://www.creativenz.govt.nz/find-funding/funds/nga-toi-a-rohe-arts-in-theregions-fund-2020

Nicholson, Helen. Applied Drama -the Gift of Theatre. Palgrave Macmillan, 2005. Nolan, Andrea, and Bridie Raban-Bisby. Theories into Practice: Understanding and Rethinking Our Work with Young Children and the EYLF. Teaching Solutions, 2015.

Norris, Hilary. Personal Interview. Conducted by Kerryn Palmer, 25 Feb 2020 O'Connor, Peter. "Teachers Hope to End 'near Death' of Arts in School." News Room, January 21 2020, newsroom.co.nz/2020/01/21/994613/arts-leaders-hope-to-end-neardeath-of-arts-in-school. Accessed [date].

O'Connor, Peter, and Michael Anderson. Applied Theatre: Research: Radical Departures. Bloomsbury, 2015.

Oddey, Alison. Devising Theatre: A Practical and Theoretical Handbook. Routledge, 1994.

--- "Devising (women's) theatre as meeting the needs of changing times." The Routledge Reading in Gender and Performance. Lizbeth Goodman with Jane de Gay. Eds. New York: Routledge, 1998. Pp. 118-124.

O'Donnell, David. Congratulations. 13 Oct. 2017. 
Oxford English Dictionary.

https://www.oed.com/start;jsessionid=79F55F027C8FED7FCEE859D2BACECE9E?authR

ejection=true\&url=\%2Fview\%2FEntry\%2F155878\%3Frskey\%3Dl5h30f\%26result\%3D1.

Accessed 22 Dec. 2020.

Oxenbridge, Faith. “Look Out for the Iceberg." The Listener, July 2005,

noted.co.nz/archive/archive-listener-nz-2005/look-out-for-the-iceberg.

Palmer, Kerryn. “Theatre for Young People (TYA) in Aotearoa/New Zealand 2019".

Survey. 8 Feb.2019.

--- "Preconceptions In Children's Theatre." “Victoria University, Wellington. 17 July 2017.Workshop.

--- “Course Outline THEA 311". Wellington, New Zealand. School of English, Film, Theatre, Media Studies. Victoria University, 2017.

--- “The Humanities Are Dead- Long Live The Humanities." The Humanities Are DeadLong Live The Humanities, 2017.

--- “THEA 311 Course Materials”. Wellington, New Zealand. School of English, Film, Theatre, Media Studies. Victoria University, 2017.

--- “THEA 311.31 Group A's Initial Concept Brainstorm (Age 10-12)." Thea 311, 25

Aug. 2015, evernote.com/client/web\#?n=2850cd98-8340-4ff7-bad6a4f73ea9e537\&query=311.31\&s=s744\&. Blog Post.

--- “THEA 311.1 Day One Blog." Thea 311, 17 July 2017.

evernote.com/client/web\#?anb=true\&b=6556de0a-0ab6-42ee-82a6af8f57e58d13\&n=ae9320dd-1a68-4069-9e4e-274809c05275\&s=s744\&. Blog post.

--- “THEA 311.9 Dave's Responses to Kerryn” Thea 311, 26 July 2017.

evernote.com/client/web\#?n=80b94ad5-f18b-413a-be8b-

$\underline{544649 \mathrm{fb} 1413 \& q u e r y=311.9 \& \mathrm{~s}=\mathrm{s} 744 \&}$. Blog post. 
---“THEA 311 Auxillary Note 21 August By James McKinnon” Thea 311, 25 Aug. 2017. evernote.com/client/web\#?n=c17d4c9a-08e5-4306-9dc25fbe73bb5284\&query=James\&s=s744\&. Blog Post

--- “THEA 311.11 Day 5 Blog” Thea 311, 25 July 2017.

evernote.com/client/web\#?n=f6a47dff-0a92-418c-a21ea16ab0bf57fd\&query=we\%20begin $\% 20$ to $\% 20$ devise\&s=s744\&. Blog post.

--- “THEA 311.13 Day Six Blog” Thea 311, 2 Aug. 2017

evernote.com/client/web\#?n=fb9eede9-5bce-4f6f-9bfe505a63f62efc\&query $=311.13 \& s=s 744 \&$. Blog Post

---“THEA 311.14 Some Thoughts from Dave.” Thea 311, 3 Aug. 2017

evernote.com/client/web\#?anb=true\&b=6556de0a-0ab6-42ee-82a6af8f57e58d13\&n=6648282a-b865-4269-a96d-ae6008b9a755\&s=s744\&. Blog Post.

--- “THEA 311.15 Day Seven Blog.” Thea 311, 4 Aug. 2017

evernote.com/client/web\#?n=d5cc9bfd-485d-4622-a010-

22d5c39d8d8c\&query=311.15\&s=s744\&. Blog Post

--- “THEA 311.15 Pushing Down The Panic.” Thea 311, 7 Aug.2017

evernote.com/client/web\#?n=e01e99bc-5485-4f19-a507-

a29b634e6d7a\&query=pushing\%20Down\%20the \%20panic\&s=s744\& Blog Post

---“THEA 311.16 Provocations.” Thea 311, 7 Aug.

2017 evernote.com/client/web\#?n=49cba8fc-0c46-4258-9481-

833c3ae6669a\&query=gold\&s=s744\&. Blog Post.

--- “THEA 311.25 Day 12 Blog.” Thea 311, 14 Aug. 2017.

evernote.com/client/web\#?anb=true\&b=6556de0a-0ab6-42ee-82a6af8f57e58d13\&n=ae9320dd-1a68-4069-9e4e-274809c05275\&s=s744\&. Blog post

--- “THEA 311.25, Paper Paper Everywhere.” Thea 311, 14 Aug. 2017

evernote.com/client/web\#?n=7465fb23-c0d5-42cb-a238-

$\underline{47 c e 90 f f 572 e \& q u e r y=311.25 \& s=s 744 \& .}$. Blog Post. 
---“THEA 311.25a Dave's Take On It.” Thea 311, 14 Aug. 2017, evernote.com/client/web\#?n=7465fb23-c0d5-42cb-a23847ce90ff572e\&query=Thea\%20311.25a\%20Dave's\%20Take\%20On\%20It.\&s=s744\&.

--- “THEA 311.29, Potholes in the Road.” Thea 311, 17 Aug. 2017

evernote.com/client/web\#?n=89b2efb5-d4b8-49ba-bb84-

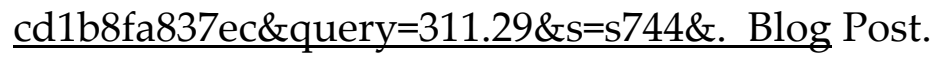

--- “THEA 311.34 Day 16 Blog.” Thea 311, 21 Aug. 2017. https://www.evernote.com/client/web\#?b=6556de0a-0ab6-42ee-82a6af8f57e58d13\&n=07918810-4c39-4cf1-85ae-4511998b9fc8\&. Blog Post. --- “THEA 311.37 Day 19 Blog.” Thea 311, 27 Aug. 2017. https://www.evernote.com/client/web\#?b=6556de0a-0ab6-42ee-82a6af8f57e58d13\&n=ca2afeb7-a22d-4360-ad95-ccd866c6ec95\&. Blog Post. --- “THEA 311.40 Day 21 Brain-Fry.” Thea 311, 1 Sept. 2017.

https://www.evernote.com/client/web\#?b=6556de0a-0ab6-42ee-82a6af8f57e58d13\&n=9f6592ce-c823-4b99-9b4e-d4ab58819a27\&. Blog Post.

---" THEA 311.49 Day 25 Blog. Casting and all them dramas. Thea311, 6 Sept.2017 https://www.evernote.com/client/web\#?n=6b458358-8796-41c2-9e86-db01ef8a8501\&. Blog Post

--- “THEA 311.76 DAY 40 Something _ Note from Dave." Thea 311, 9 Oct. 2017.https://www.evernote.com/client/web\#?b=6556de0a-0ab6-42ee-82a6af8f57e58d13\&n=ef96a2b7-55a4-45a7-bea7-ef9ee163fe48\&.Blog Post.

Palmer, Kerryn, and Class of Thea 311. "Final Drafts Of Scripts." Thea, evernote.com/client/web\#?n=d05694d1-3178-4638-840b0ceb8b6ca7df\&query=script\&s=s744\&.

Patrick, Jenny \& Laughton Around The World and Buck Again, Capital E National Theatre for Children, 2012 
The Eel and Sina. By Jono Soo-Choon, Directed by Gaby Solomona, 20 Mar.2019. Te Papa Marae, Wellington, Performance

PAYPA. PAYPA-Charitable Trust Deed. Transcript. May 2020.

"PAYPA" PAYPA - Performing Arts and Young People in Aotearoa, 2019, assitejnz.wordpress.com/.

Pantaloons, The. "We Can't Wait to Be Back with You Bringing Fairy Tale Magic to All!" The Pantaloons, 30 Apr. 2020,facebook.com/ThePantoloons/.

Pearson, Mike. - Site Specific Performance. Macmillan International Higher macmillanihe.com/page/detail/SiteSpecific-Performance Accessed Feb. 2018 Playmarket, playmarket.org.nz. Accessed Feb 2018

'Policy-and-Research/Policy-Document'. Ministry of Youth Development, 2020 myd.govt.nz/documents/policy-and-research/policy-document-final.pdf. Pollock, Kerryn, 'Young people and the arts - Arts participation', Te Ara - the Encyclopedia of New Zealand, 2014, TeAra.govt.nz/en/young-people-and-the-arts/page-1. Accessed 3 Mar. 2020.

Pope, Brant. Theatre For Early Childhood: The Work Of Dave Brown. 2019. (Unpublished article)

“Preadolescence.” Merriam Webster. Accessed 18 Oct. 2019.

Prior, Kate. “The Play In The Playground" Playmarket Annual New Zealand Theatre. Playmarket. 2016

"Proposed Changes to Toi Tōtara Haemata and Toi Uru Kahikatea." Creative New Zealand, 17 Sept. 2018, creativenz.govt.nz/news/proposed-changes-to-toi-totarahaemata-and-toi-uru-kahikatea Pullman, Phillip. “'Theatre - the True Key Stage.'” The Guardian, 30 Mar. 2004, theguardian.com/books/2004/mar/30/booksforchildrenandteenagers.schools. Quality Principles I Arts Council England. https://www.artscouncil.org.uk/qualitymetrics/quality-principles. Accessed 22 May 2019. 
Qvortrup, Jens, et al., editors. The Palgrave Handbook of Childhood Studies. Palgrave Macmillan, 2009

Rahman, Fathu. "The Revival Of Local Fairy Tales." Theory and Practice in Language Studies, vol. 7, May 2017,

pdfs.semanticscholar.org/352e/0c0651982372f8799b6e795086a4a9f0019b.pdf?_ga=2.25229 4025.1873176661.1571211233-1514441032.1571211233

Reason, Matthew. The Young Audience: Exploring and Enhancing Children's Experiences of Theatre. Trentham Books, 2010.

---“'Did You Watch the Man or Did You Watch the Goose?' Children's Responses to Puppets in Live Theatre." New Theatre Quarterly, vol. 24, no. 4, Nov. 2008, pp. 337-54. --- "Young Audiences." Matthew Reason, matthewreason.com/young-audiences/. Accessed Jan. 2020.

--- "The Possibility of Theatre for Children". Theatre for Young Audiences: A Critical Handbook, edited by Tom, Maguire, and Karian Schuitema, Institute of Education Press, 2012, pp. 23-34

Rees, Nonnita. "Report on the Priority By, With and For Young People". 1, CNZ, Nov. 2017, pp. 1-11.

--- "Personal Interview” by Kerryn Palmer. 7 Feb.2018

Revell, Gemma," Theatre Students Strive to Break Stereotypes of Children's Theatre". Victoria University, Wellington. Oct. 2017. Press Release-Transcript.

“Room On The Broom.” Eventfinder, eventfinda.co.nz/2019/room-on-thebroom/wellington . Accessed 3 June 2019.

Royal, Charles Te Ahukaram̄̄, "Orotakare: Towards a New Model for Indigenous Theatre". Performing Aotearoa: New Zealand Theatre and Drama in an Age of Transition. edited by Marc Maufort and David O'Donnell. P. I. E. Peter Lang, 2007, pp 193-208. Rudolph, Joel. “Re: Music Score.” Received by Kerryn Palmer,11 July. 2020. Email. Schechner, Richard. Performance Studies: An Introduction. 2nd ed, Routledge, 2006. 
Schirle, Joan. "Potholes in the Road to Devising". Theatre Topics, vol. 15, no. 1, 2005, pp. 91-102.

Schneider, Wolfgang. "TYA as Cultural Policy." Youth Theatre Journal, vol. 27, no. 2, July 2013, pp. 96-99. DOI.org (Crossref), doi:10.1080/08929092.2013.837686.

--- Enabling Cultural Participation." IXYPSILONZETT Magazine for Children and Young Peoples Theatre, no. 01 2014, 2014, pp. 4-7.

Schonmann, Shifra. Theatre as a Medium for Children and Young People: Images and Observations. Springer Science \& Business Media, 2006.

Scott, Samantha. "Re: Questions." Message to Kerryn Palmer. 23 Jan.2020. Email --- "Our Story". Massive Company, massivecompany.co.nz/\#our-story-section. Accessed 15 Oct. 2019

Sharma, Charru. (ed). Drama and Theatre with Children International Perspectives. Routledge, 2016

Sharp, Caroline and Lee, Ben. Using Quality Principles in Work for, by, and with Children and Young People: Results of a Pilot Study (Draft Final Report). Slough: NFER, 2015. Signore, Valentina. “A New Rhetoric Notes On Performance As Research In Academia" Performance as Research: Knowledge, Methods, Impact, edited by Annette Arlander, et al. Routledge, 2017, pp. 84 - 104

Slade, Peter. Child Drama. London, University of London Press, 1954

Smart, Jackie. "The Feeling of Devising: emotion and mind in the devising process." Trencsényi, Katalin, and Bernadette Cochrane, editors. New Dramaturgy: International Perspectives on Theory and Practice. Bloomsbury, 2014.pp101-114 Smith, Anne. "A Theoretical Framework for Childhood. "Higgins, Nancy \& Freeman Claire, editors. Childhoods: Growing up in Aotearoa New Zealand, Otago University Press, University of Otago, New Zealand. 2013. 
Smith, Anne. "Children and Young People's Participation Rights in Education." The International Journal of Children's Rights, vol. 15, no. 1, 2007, pp. 147-64. DOI.org (Crossref), doi:10.1163/092755607X181739.

Smith, Hannah. “Re: Questions Around Funding.” Received by Kerryn Palmer,13 Mar. 2019. Email Interview.

--- “Gorgeous Puppets Bedazzle and Mesmerise." Theatreview, Press Patron, 17 Apr. 2011, theatreview.org.nz/reviews/review.php?id=3910.

Smythe, John. "But What Does It Mean?" Theatreview, Presspatron, 10 2017, theatreview.org.nz/reviews/review.php?id=10637.

Songs of the Sea. By Peter Wilson, directed by Kerryn Palmer. Capital E National Theatre for Children. March 2011. The Hannah Playhouse, Wellington Shalakazap. Written and Directed by Jenny Wake. Calico Young People's Theatre. 19931994. Various Locations.

Spence, Corey. "Moonlight and In The Attic: Two Theatre Shows for Young Audiences." Art Murmurs, 21 Oct. 2017, artmurmurs.nz/theatre/moonlight-and-in-theattic-two-theatre-shows-for-young-audiences.

Stevens, Aundraea. "Putting the EI into drama: it's not as tricky as you might think." Drama and Theatre with Children International Perspectives, edited by, Charu Sharma. Routledge, 2016, pp. 13-22

Swale, Jessica. Drama Games for Devising. London: Nick Hern Books, 2012.

Swallow, Catherine. "Faces of the Captives": Aesthetic Distance and Emotional Absorption in Young Children's Engagement with Theatre. 2012. Victoria University of Wellington, MA thesis.

Swortzell, Lowell (ed). International Guide to Children's Theatre and Educational Theatre: A Historical and Geographical Source Book. Connecticut: Greenwood Press Inc, 1990 Tukiwaho, Tainui. "Fight Against Systemic Racism Not Over." The Big Idea, 25 Aug. 2020, https://www.thebigidea.nz/stories/fight-against-systemic-racism-not-over. 
“Tall Stories", 2018, tallstories.org.uk/Accessed March 2019.

Taube, Gerd. "“Facing Reality.” Facing Reality Contemporary and Realism in the Theater for Young Audiences." IXYPSILONZETT Magazine for Children and Young People's Theatre, no. 2013, pp. 9.

---“Editorial." IXYPSILONZETT Magazine for Children and Young Peoples Theatre, no. 01 2014, 2014, p. 2.

“Tawa School” tawa.school.nz. Accessed 10 May 2019.

“Tawa School Feedback”. 24 July 2017

“Tawa School Feedback”. 20 Sept. 2017.

“Te Aro School” tearo.school.nz. Accessed 9 May 2019

“Te Reo Maori Season.” Taki Rua Theatre, Taki Rua Productions, takirua.co.nz/. Accessed Jan. 2019.

“Teacher Education.” Victoria University of Wellington, Victoria University of Wellington - Te Whare Wānanga o te Ūpoko o te Ika a Māui, 2020, wgtn.ac.nz/education/study/graduate-programmes.

Teipel, K. Developmental Tasks and Attributes of Late Adolescence/Young Adulthood (Ages 18-24 Years). State Adolescent Health Resource Center, Konopka Institute, University of Minnesota, pp. 1-2, mchp.org/programsandtopics/AdolescentHealth/projects/Documents/SAHRC\%20AYA Development\%20LateAdolescentYoungAdulthood.pdf. Accessed July 2020.

Tempest, Sue. “Intergenerational Learning: A Reciprocal Knowledge Development Process That Challenges the Language of Learning." Management Learning, vol. 34, no. 2, June 2003, pp. 181-200, doi:10.1177/1350507603034002002.

The Eel and Sina. By Jono Soo-Choon, directed by Gaby Solmona. Mythmakers Theatre Company, 20 March 2019, Te Papa Te Marae, Wellington

“The Hero's Journey." Mythology Teacher, http://mythologyteacher.com/documents/TheHeroJourney.pdf. Accessed July 2019. 
The Opera House In Wellington." The Opera House In Wellington,"

The Road That Wasn't There. By Ralph McCubbin-Howell. Directed by Hannah Smith. Trick of the Light Theatre Company. (Ongoing touring production)

The Tortoise and the Hare. By Gregory Cooper. New Zealand Playhouse, 24 July 2019, Porirua East School, Wellington

venueswellington.com/venues/the-opera-house/. Accessed 3 June 2019.

The Whole Hearted. Written by Massive Theatre Company. Directed by Sam Scott. 2017. National Tour.

THEA 311. “FEEDBACK: Class of 2017- Thank You to Kerryn.” Transcript. June 2017.

Theatre Achieves New Zealand. theatrearchives.nz. Accessed Mar. 2019

Theatre Funding Guidelines. https://www.guidelines.creativenz.govt.nz/help/theatre. Accessed 29 Jan. 2021.

“Theatre of the Oppressed." The Mandala Center for Change, http://www.mandalaforchange.com/site/applied-theatre/theatre-of-the-oppressed/. Accessed 30 July 2020.

THETA. theta.org.nz/. Accessed 20 Mar. 2018.

Thomas, Mitch. "Re: Questions around Actor Training." Received by Kerryn Palmer. 18 Aug. 2019. Email Interview.

Throwback Thursday: The School Journal in 1942,

Ti, Room. “Room Ti Children's Feedback Te Aro School.” Transcript, 28 Sept. 2017. lifteducation.com/schooljournal1942/. Accessed 15 October 2019

Toi Whakaari: New Zealand Drama School. https://www.toiwhakaari.ac.nz/. Accessed 26 March. 2020.

Tosconi, Nora, Manuela Runge, et al. "Then We Can Stir Things Up." IXYPSILONZETT - Magazine for Children and Young People's Theatre, no. 01 2020, May 2020, pp. 23.

“Trick Of The Light Theatre”. trickofthelight.co.nz/aboutus. Accessed 16 Oct. 2019. 
Troughton, Saffron. “Final Journal Entry" Transcript, 24 October 2017.

United Nations Charter: Human Rights Officer of The High Commissioner. Convention on the Rights of the Child. ohchr.org. Accessed February 2018 United Nations Educational, Scientific, and Cultural Organization (UNESCO). 2005. Convention on the Protection and Promotion of the Diversity of Cultural Expressions 2005. Paris.

Upton, Meg. “Supporting Young Theatre Audiences to Engage with Challenging Subject Matter- a Partnership Approach." Mask. Spring/Summer 2012 Upjohn-Beatson, Tane. Composer- Sound Designer. 23 Sept. 2019, taneub.com/. Valente, Louis. Interview with Secretary General of ASSITEJ International and Executive Director of ASSITEJ Denmark. 12 June 2019.

---“Re: Culture Crews” Received by Kerryn Palmer, 18 June 2020. van Dijk, Bert. Devised Theatre: A Practical Guide to the Devising Process. Bert van Dijk, 2011.

van de Water, Manon (ed). TYA, Culture, Society. International Essays on Theatre for Young Audiences: A Publication of ASSITEJ and ITYARN. Peter Lang, 2012 ---“Constructed Narratives: Situating Theatre for Young Audiences in the United States." Youth Theatre Journal, vol. 14, no. 1, May 2000, pp. 101-13. DOI.org (Crossref), doi:10.1080/08929092.2000.10012521. ---(. ed). Teatro Para Públicos Jóvenes. Perspectivas Internacionales. Spanish Edition. Ediciones El Milagro, Instituto Nacional de Bellas Artes., 2012.

--- (ed) Diversity, Representation and Culture in TYA. ASSITEJ South Africa, 2020 vom Orde, Heike. “Children Need Fairy Tales - Bruno Bettleheim’s The Use of Enchantment." TELEVIZION, vol. 26, no. E, 2013, ucy.ac.cy/nursery/documents/children_need_fairytales.pdf. 
Wadham, Tim. “Full of Adventures, Full of Wisdom: Children's Literature as a Homeward Voyage." Children's Book and Media Review, vol. 21, no. 5, Article 2, 2000, scholarsarchive.byu.edu/cbmr/vol21/iss5/2.

Wake, Jenny. "Theatre to Schools or Schools to Theatres? Playmarket Annual New Zealand Theatre. Playmarket. 2016

--- Text message to author. 18 June 2020

Watkins, Beth. "Working from Scratch: The Pedagogic Value of Undergraduate

Devising." Theatre Topics, vol. 26 no. 2, 2016, pp. 169-180. Project

MUSE, doi:10.1353/tt.2016.0029.

Warrington, Lisa: “Shalakazap! -empowerment in young people's theatre.

Aotearoa/New Zealand: an interview with Jenny Wake of Calico Theatre." Australasian

Drama Studies 47. October 2005, pp. 89-104

Wartemann, Geesche, et al., editors. Youth and Performance: Perceptions of the

Contemporary Child; [a Selection of the Papers Presented at the Third ITYARN

Conference "Theatre for Young Audiences and Perceptions of the Contemporary Child" in Warzaw, 2014]. Olms, 2015.

Weyrauch, Romy, et al. "Shared Playgrounds. Four Directors Share Their Enthusiasm for Theatrical Teamwork by Romy Weyrauch, Hannah Biedermann, Franziska Henschel, Ariel Doron." IXYPSILONZETT - Magazine For Children and Young People's Theatre, no. 01 2020, May 2020, pp. 32-34.

“What You'll Need.” Capital E, 2019, capitale.org.nz/what-youll-need/.

Wilkie, F. "Mapping The Terrain: a Survey of Site-specific Performance in Britain", New Theatre Quarterly, 18,2, 140-60

Wills, Corey. “Re: Hello Thea 311 of 2017.” Received by Kerryn Palmer, 26 May 2019. Email.

Wilson, Linda." Re: Questions About Pantomimes." Received by Kerryn Palmer. 22 May 2019. Email Interview. 
Wilson, Peter. Interview by Kerryn Palmer. 8 June 2019.

---Re: “Question Around Age Groups.” Received by Kerryn Palmer, 10 Mar. 2019. Email.

---Songs of The Sea, Capital E National Theatre for Children. 2017

---Seasons. Capital E National Theatre for Children. 2009.

Wiseman, Theresa. "A Concept Analysis of Empathy." Journal of Advanced Nursing, vol. 23, no. 6, June 1996, pp. 1162-67.

White, Gareth. Audience Participation in Theatre. Palgrave Macmillan. (2013)

“Who Got Funded." Creative New Zealand, NZ Government, 2019,

creativenz.govt.nz/results-of-our-work/who-got-funded/funding-rounds/arts-grants-10000-75-000-2019-round-2.

Woolland, Brian. " What Did You Make of That? More Than Just a Figure of Speech." Drama and Theatre with Children International Perspectives edited by, Charru Sharma. Routledge, 2016, pp. 23-30

Wood, David, "Foreword". Theatre for Young Audiences: A Critical Handbook, edited by Tom, Maguire, and Karian Schuitema, Institute of Education Press, 2012, pp. vii-ix.

Wood, D. and Grant, J. Theatre for Children: Guide to Writing, Adapting, Directing, and Acting. London: Faber and Faber. (1997)

Young New Zealanders I Funding Guidelines.

https://www.guidelines.creativenz.govt.nz/help/young-new-zealanders. Accessed 29 Jan. 2021.

“Young New Zealanders to Get More Opportunities for Arts Experiences." Creative New Zealand, 2018, creativenz.govt.nz/news/young-new-zealanders-to-get-moreopportunities-for-arts-experiences. 


\section{Appendix A}

Ethics Approval

1 June 2017

Ethics Approval: 24473 Child's Play-Theatre For Young

Audiences in Aotearoa/New Zealand

Averil Coxhead, Acting Convener, Victoria University Human

Ethics Committee 


\section{Appendix B}

\section{Survey Questions for Theatre Practitioners.}

\section{Survey Questions: Theatre For Young People/Audiences (TYA) In Aotearoa/New}

Zealand 2019

Name your company and briefly describe the TYA work you or your company makes

Would you describe the majority of your work as being BY/WITH/FOR / Young people or a COMBINATION of?

What age group is your work aimed at?

What do you think the current environment is like for practitioners of TYA in Aotearoa/New Zealand? (in particular in terms of box office numbers, funding, industry recognition of TYA work.)

What do we do well in the field of TYA in New Zealand?

What (if any) factors limit your work as a TYA practitioner/company

Have you ever used young people to contribute to the development of your work? And if so, how have you done this?

How can we improve the TYA sector in New Zealand? 
When making your work, do you consider other stakeholders (such as parents and teachers) in the way you make the work and what you make it about? If so, how do you do this

What has influenced your work and why do you make TYA? 


\section{Appendix C \\ Questions For Tawa School Children}

IN THE ATTIC: Thanks for coming to our rehearsal. We really value your feedback and would love some more:

What do you think the story was about?

What were the moments for you that were the strongest/most interesting/exciting?

What were the least interesting/exciting moments- was there anywhere you felt bored?

What do you think could have been done differently by the director?

Did the performance make you feel anything or think about anything about your own life?

If you could be one of the characters who would you be and why?

What would you change about the play and why?

Any final comments?

Based on Matthew Reason's “Talking About Theatre” questions (The Young Audience 154-166) 


\section{Appendix D}

\section{Drama Games used at Tawa and Te Aro Schools}

\section{Bus Stop}

The objective of the game is to improvise a role and play that role out in a makeshift bus stop. The bus stop is made up of three chairs, and as the game starts all three are filled. Each person must act as if they are at the bus stop, and each one acts as if they have a quirk, whether it be physical, psychological, or otherwise. The quirk could be blindness or hysteria, or it could be more concrete, such as the person acting as if he is hiding a bomb or have a suitcase full of money. He must interact with each other person and improvise. After a while (this can be gauged by an observer or just determined by the person), the person on the last seat leaves, the next person moves up, and a new person enters. This repeats until there are no more people left or until everyone gets sufficiently bored (Olivas)

\section{Grandma's Keys,}

One person is Grandma - he/she faces a wall. The others in the group start at the other end of the room, then try to creep up to Grandma and tap her on the shoulder. [or steal her keys which have been placed at her feet.] However, at any moment, Grandma can turn around suddenly. If she sees anyone moving, she points at them and that person must return to the start. No-one is allowed to move while she is watching them. Whoever manages to tap her on the shoulder becomes Grandma (male or female) and the game starts again. (Farmer) 


\section{What are you doing?}

Stand in a circle. The first person (A) starts miming an activity, such as eating an apple. The person to their left (B) says "What are you doing?". A keeps miming and at the same time says the name of a different activity. For example, if A was miming eating an apple, they could say "playing the piano". B then starts playing a piano. A stops their mime. Now the third person (C) asks B, "What are you doing?". B keeps playing the piano and names a different activity, which $\mathrm{C}$ must mime. And so it goes on. (Farmer, “What Are You Doing?")

\section{Clumps.}

Have the group walking around and then call out numbers that they clump into. Repeat with different numbers. Whatever number you want in each group call out that number for the group. ("60 Games and Icebreakers")

\section{Fruit Salad}

Students are on chairs in a Drama circle. The teacher explains the game and labels everyone around the circle a type of fruit (apple, peach, banana, orange, etc). Then the teacher takes away one chair and one of the students is in the centre of the circle as the caller. The student in the middle calls the name of a fruit, and everyone in the circle with that name must swap places and find another chair to sit on. At the same time the person in the middle must try to find a chair. The person left standing is the new caller.

Calling out "fruit bowl" means everyone must change places. (Drama Toolkit - Fruit Salad) 


\section{Appendix E}

\section{THEA 311 Child Observation}

Name of child:

Date:

Time:

Observation completed by:

Child Initiated Activity:

Adult Led Activity:

Solitary Play

Small group Play

Large Group Play

Context: (where is the child? Who else is present?)

What is happening? (What is the child saying and/or doing?) 


\section{Appendix F}

\section{Dave Brown's Critical Response Protocol}

"Notice and Remind me to Feel Wonder and Enlightenment to this piece" Critical Response Protocol

1: What do you notice?

- describe what you see/hear without judgment.

- answer using descriptive terms, without making judgments or offering personal preferences.

- $\quad$ I notice that ...

2: What does it remind you of?

- consider how you can connect the experience of the segment to the experience of your own life.

- respond with any memory, experience, story, music, or other work that this example triggers.

3: How does it make you feel?

- what feelings does the work evokes in you?

- describe your feelings in one or two words.

4: What questions does it raise? 
- what questions does the work trigger?

- respond with: "I wonder ..."

5: Speculate

- speculate about what the work helps you understand.

- what could be the segment's artistic intention?

- what is its essence?

Our mnemonic for remembering the Critical Response Protocol is ...

Notice and Remind me to Feel Wonder and Enlightenment.

(Brown "THEA 311.29, Potholes in the Road") 
Appendix G

Links to Plays -USB also included

Moonlight

https://drive.google.com/file/d/1KyfXFkfOKeme2Sn

oPQt3GMjgijhrtzd/view?usp=sharing

In the Attic

https://drive.google.com/file/d/1wnF0kGcaWKxEeK zAg3ybMP1oPJBh7juF/view?usp=sharing 